\title{
DO CHILDHOOD EXCESS WEIGHT AND FAMILY FOOD INSECURITY SHARE COMMON RISK FACTORS IN THE LOCAL ENVIRONMENT? AN EXAMINATION USING A QUEBEC BIRTH COHORT
}

\section{BY:}

\section{Megan Ann Carter}

Thesis submitted to the Faculty of Graduate and Postdoctoral Studies in partial fulfillment of the requirements for the $\mathrm{PhD}$ degree in Population Health

\author{
University of Ottawa
}

(C) Megan Ann Carter, Ottawa, Canada, 2013 


\begin{abstract}
Background: Childhood excess weight and family food insecurity are food-system related public health problems that exist in Canada. Since both relate to issues of food accessibility and availability, which have elements of "place", they may share common risk factors in the local environment that are amenable to intervention. In this area of research, the literature derives mostly from a US context, and there is a dearth of high quality evidence, specifically from longitudinal studies.
\end{abstract}

Objectives: The main objectives of this thesis were to examine the adjusted associations between the place factors: material deprivation, social deprivation, social cohesion, disorder, and living location, with change in child BMI Z-score and with change in family food insecurity status in a Canadian cohort of children.

Methods: The Québec Longitudinal Study of Child Development was used to meet the main objectives of this thesis. Response data from six collection cycles ( $4-10$ years of age) were used in three main analyses. The first analysis examined change in child BMI Z-score as a function of the place factors using mixed models regression. The second analysis examined change in child BMI Z-score as a function of place factors using group-based trajectory modeling. The third and final analysis examined change in family food insecurity status as a function of the place factors using generalized estimating equations.

Results: Social deprivation, social cohesion and disorder were strongly and positively associated with family food insecurity, increasing the odds by $45-76 \%$. These place factors, on the other hand, were not consistently associated with child weight status. Material deprivation was not important for either outcome, except for a slight positive association in 
the mixed models analysis of child weight status. Living location was not important in explaining family food insecurity. On the other hand, it was associated with child weight status in both analyses, but the nature of the relationship is still unclear.

Conclusions: Results do not suggest that addressing similar place factors may alleviate both child excess weight and family food insecurity. More high quality longitudinal and experimental studies are needed to clarify relationships between the local environment and child weight status and family food insecurity. 


\section{CO-AUTHORSHIP STATEMENT}

This thesis presents the research of Megan Ann Carter in collaboration with her thesis supervisors Drs. Lise Dubois and Mark Tremblay and manuscript co-authors Drs. Monica Taljaard and Bobby L. Jones. This thesis has five manuscripts:

Manuscript 1 - Neighbourhoods and child adiposity: a critical appraisal of the literature. M.A. Carter conceived the study topic and design, collected article data, and wrote and edited the review. L. Dubois provided advice and content expertise, read, edited, and approved the final manuscript draft.

Manuscript 2 - Place and food insecurity: a critical review and synthesis of the literature. M.A. Carter conceived the study topic and design, collected article data, and wrote and edited the review. L. Dubois and M.S. Tremblay provided advice and content expertise, and read, edited, and approved the final manuscript draft.

Manuscript 3 - The influence of place on weight gain during early childhood: a populationbased, longitudinal study. M.A. Carter conceived the study topic and design, carried out the analysis, and wrote and edited the article. L. Dubois and M.S. Tremblay provided advice and content expertise, and read, edited, and approved the final manuscript draft. M. Taljaard provided statistical guidance and read, edited, and approved the final manuscript draft.

Manuscript 4 - Trajectories of childhood weight gain: the relative importance of local environment versus individual social and early life factors. M.A. Carter conceived the study topic and design, carried out the analysis, and wrote and edited the article. L. Dubois played a role in study conception (method of statistical analysis), provided advice and content expertise, and read, edited, and approved the final manuscript draft. M.S. Tremblay provided advice and content expertise, and read, edited, and approved the final manuscript 
draft. M. Taljaard provided general statistical guidance and read, edited, and approved the final manuscript draft. B.L. Jones provided guidance specific to group-based trajectory modeling and read, edited, and approved the final manuscript draft.

Manuscript 5 - Local social environmental factors are associated with household food insecurity in a longitudinal study of children. M.A. Carter conceived the study topic and design, carried out the analysis, and wrote and edited the article. L. Dubois played a role in study conception (analyzing family food insecurity) provided advice and content expertise, and read, edited, and approved the final manuscript draft. M.S. Tremblay provided advice and content expertise, and read, edited, and approved the final manuscript draft. M. Taljaard provided statistical guidance and read, edited, and approved the final manuscript draft. The other components of this thesis (Chapters 1- 4 and 6, and the Appendices) are all original works of M.A. Carter with editorial changes provided throughout by L. Dubois and M.S. Tremblay; M. Taljaard provided editorial changes for Chapters 1, 2 and 4. 


\section{ACKNOWLEDGEMENTS}

To my better half, Etienne: You have been there since the beginning, providing support in good and bad times, even while you dealt with similar challenges. No matter how hard it might be in the end, I'm glad that we were able to share this experience together. Just knowing that you understood what I was feeling because you had experienced it yourself helped me get through so much. I could not have done it without you. You deserve this degree as much as I do.

To my parents Jeannie and Michael, and my sisters Lindsay and Sarah: You have been solid pillars of support and my cheering squad, not only through these four years, but throughout my life. You always know what to say to cheer me up, to get me motivated, and to make me laugh. This thesis is also for you.

This thesis, of course, would not have been possible without the collaboration of a few thoughtful, intelligent, and supportive people. Thank-you, Lise for your guidance and support, not only in this thesis, but with my career in general. I have also appreciated your drive to motivate me to finish this thesis in a timely fashion - especially towards the end! I immensely enjoyed my time as member of the Nutrition Team. Mark, you have provided incredibly detailed and prompt feedback that I highly value, and have connected me with important career development opportunities (e.g. Obesity Boot Camp). I am truly thankful for this. Finally, Monica, you have gone above and beyond the statistical expert I was seeking. Thanks so much for all of your guidance and feedback. You helped to make my thesis that much better.

Throughout this degree I have also connected with some great people that have either supported me and/or influenced the way that I think about things. In this vein I would like to 
thank my colleagues in the IPH Nutrition Team and the HALO student group, participants of Obesity Boot Camp 2010, and the Population Health students of 2008. There are others who have helped me along the way. Whether it was listening to me vent, sympathizing with me, providing advice, discussing issues with me, or helping me to empty my mind of schoolrelated things, you know who you are and I thank all of you! 


\section{TABLE OF CONTENTS}

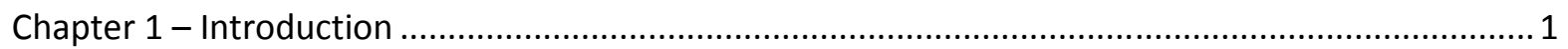

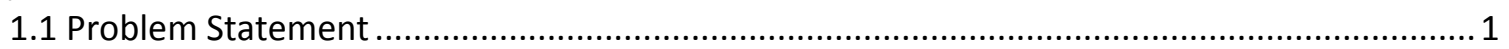

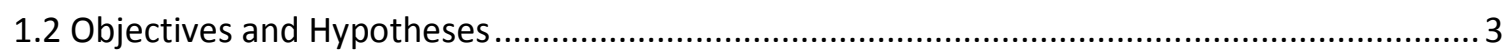

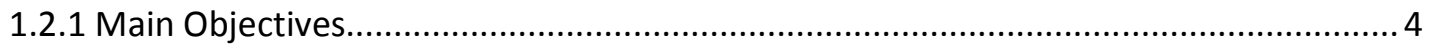

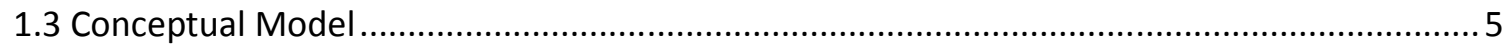

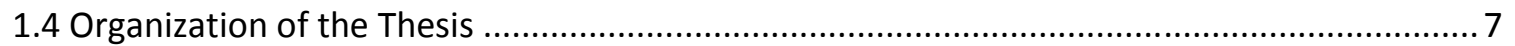

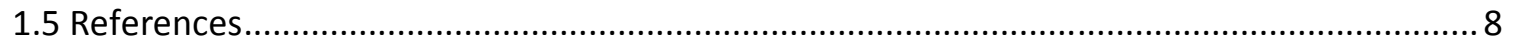

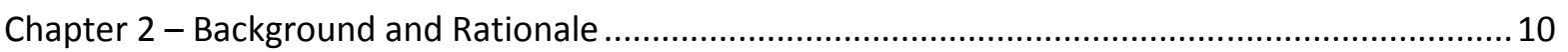

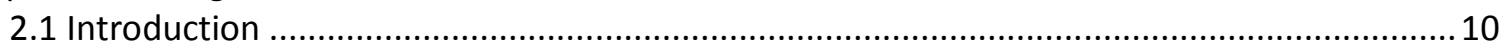

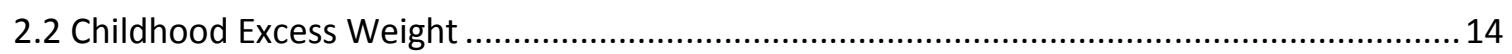

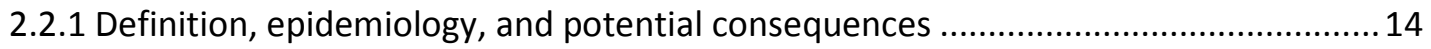

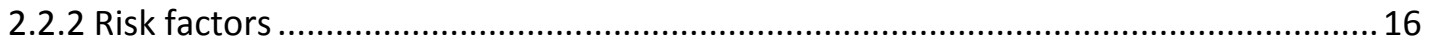

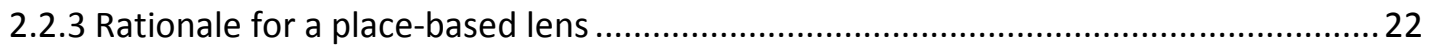

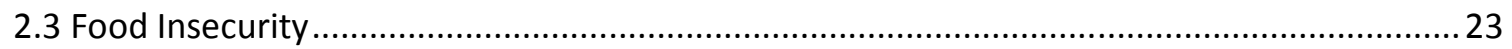

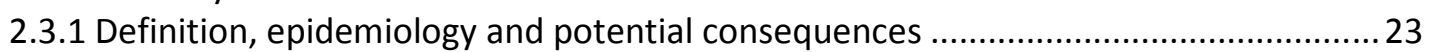

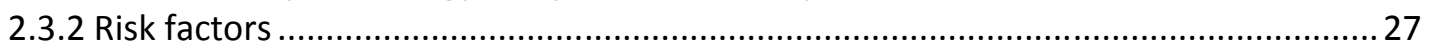

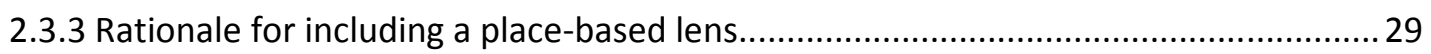

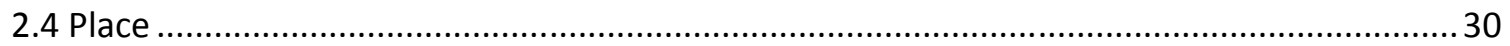

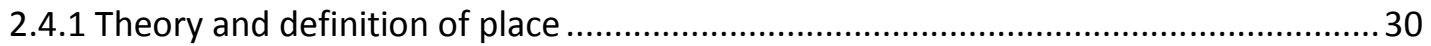

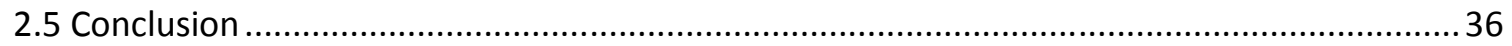

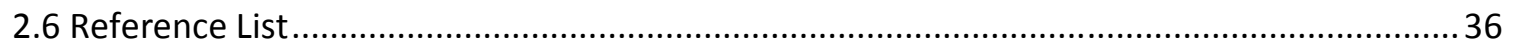

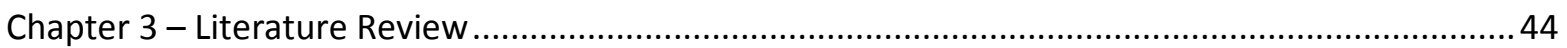

3.1 Neighbourhoods \& child adiposity: a critical appraisal of the literature - Manuscript $1 \ldots \ldots . . .45$

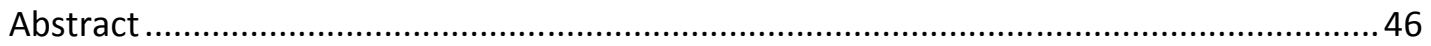

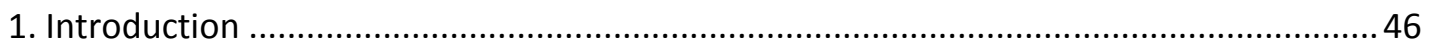

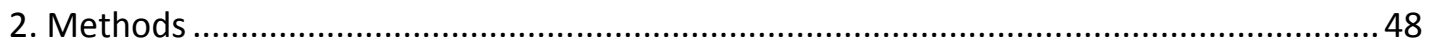

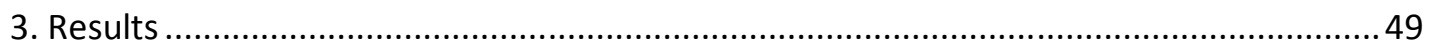

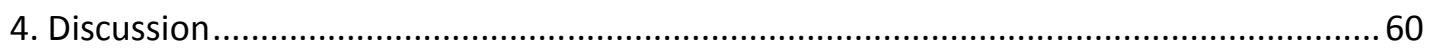

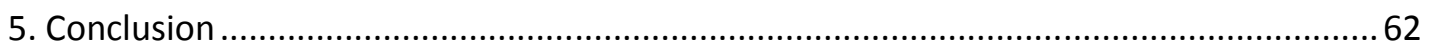

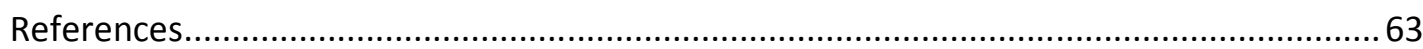

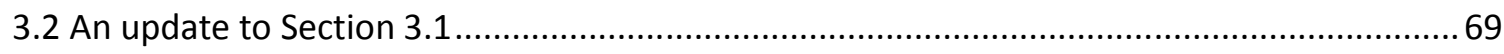

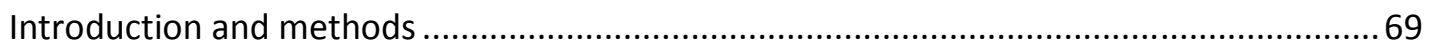

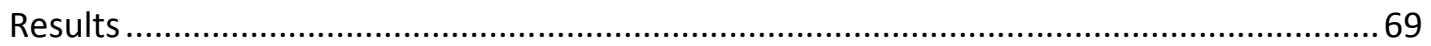

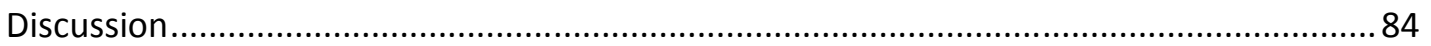

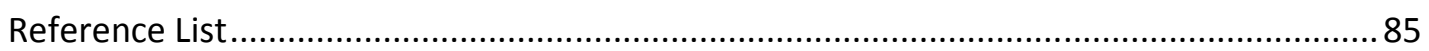

3.3 Place and food insecurity: a critical review and synthesis of the literature - Manuscript $2 . .88$

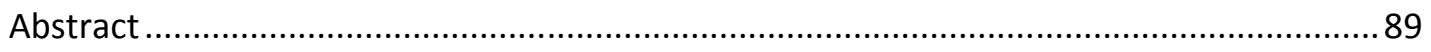

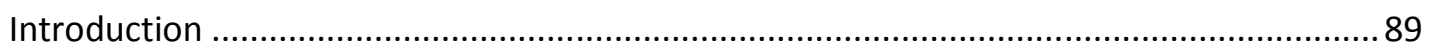

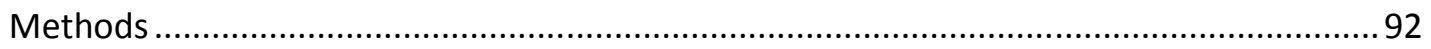

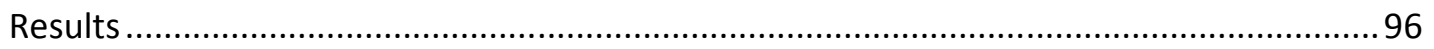

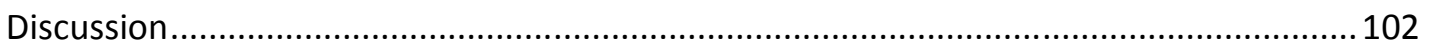

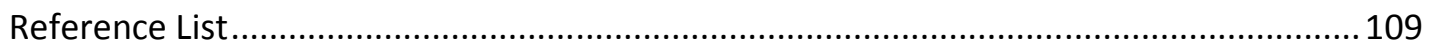

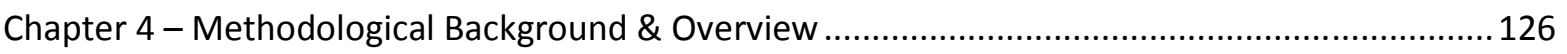

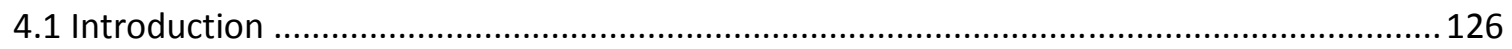

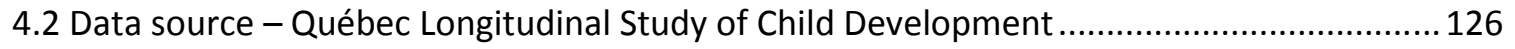

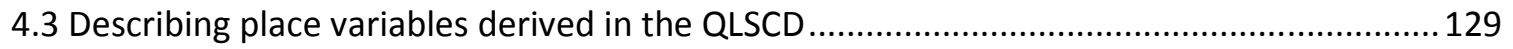




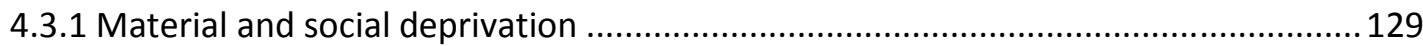

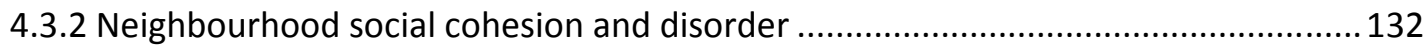

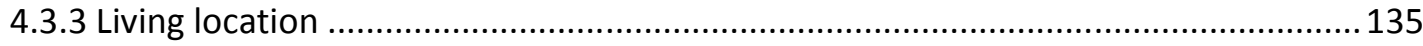

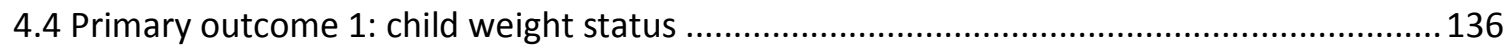

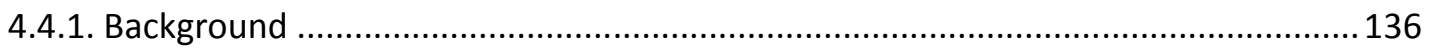

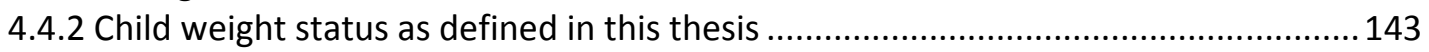

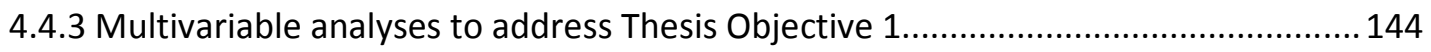

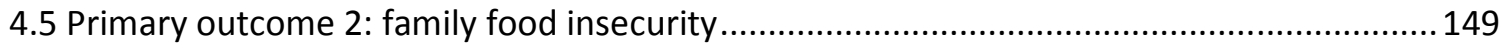

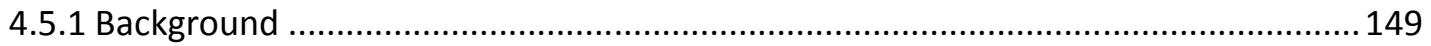

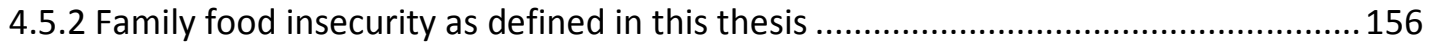

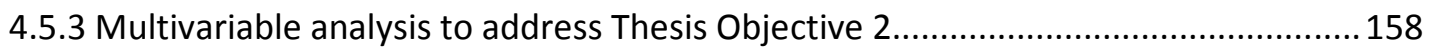

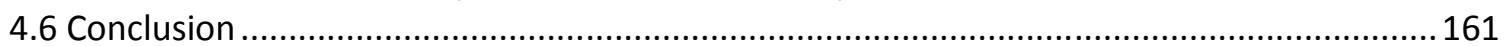

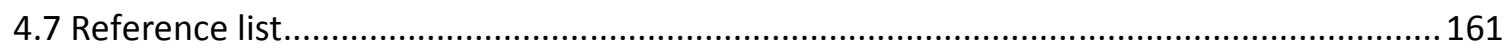

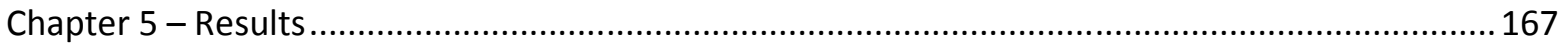

5.1 The influence of place on weight gain during early childhood: A population-based

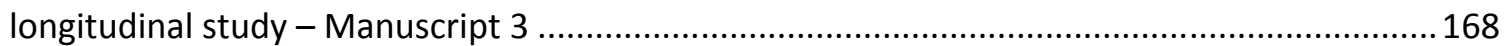

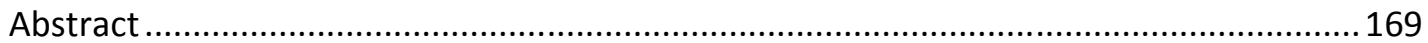

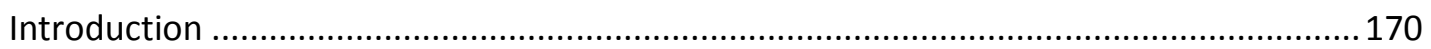

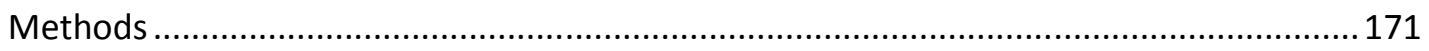

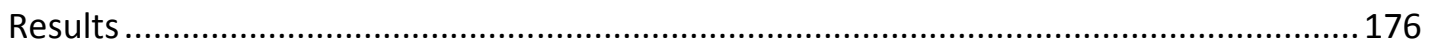

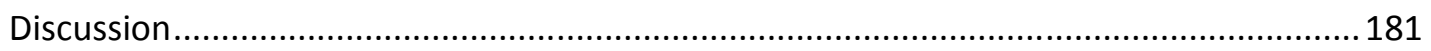

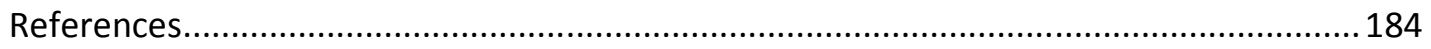

5.2 Trajectories of childhood weight gain: the relative importance of local environment versus

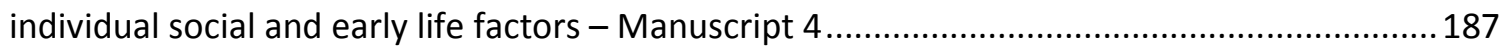

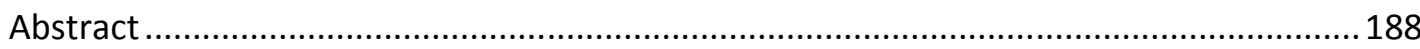

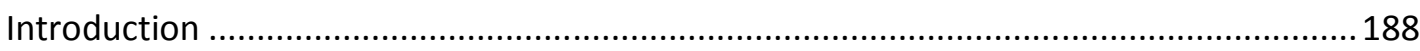

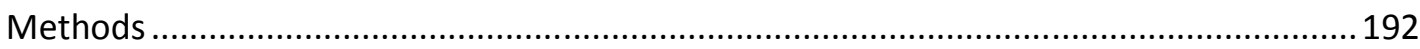

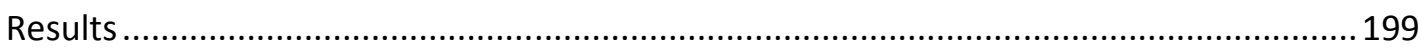

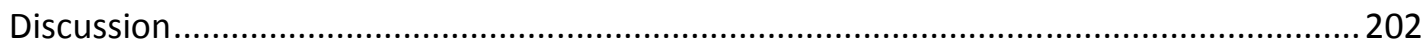

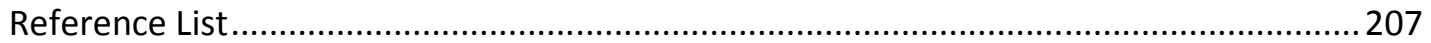

5.3 Local social environmental factors are associated with household food insecurity in a

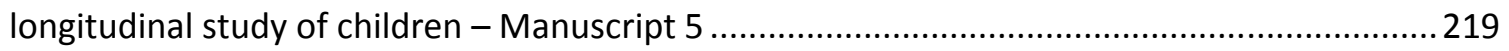

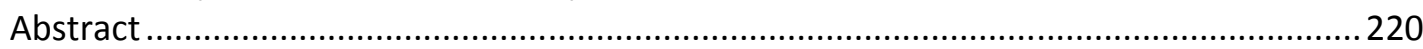

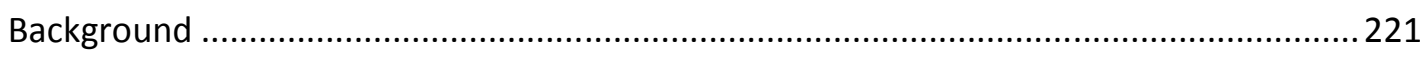

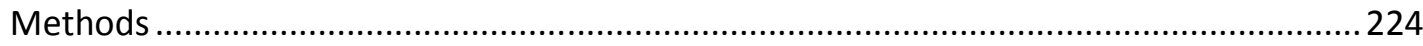

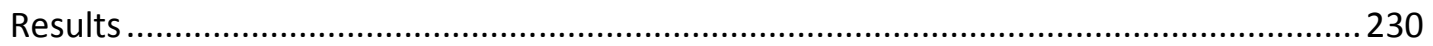

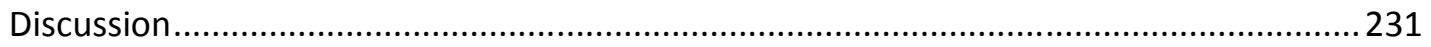

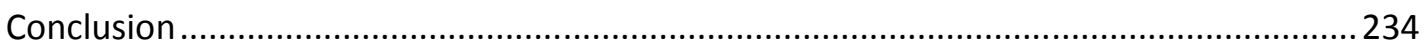

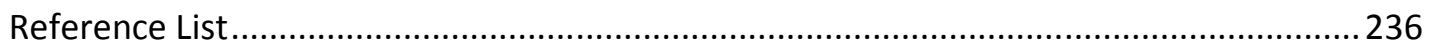

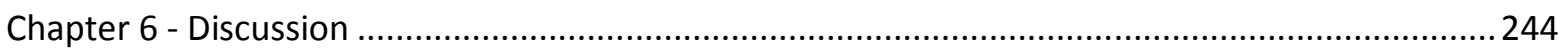

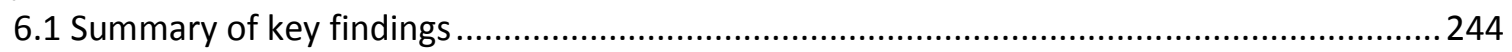

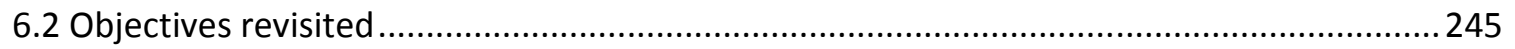

6.2.1 Place and weight gain - a comparison of two approaches .......................................245

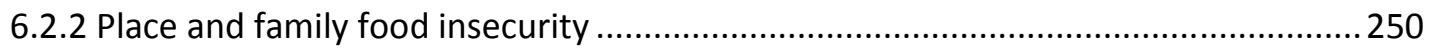

6.2.3 The importance of place for different population health outcomes..........................252

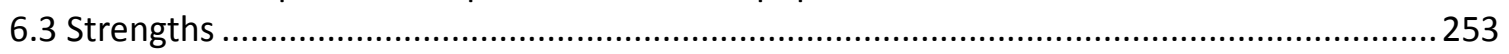

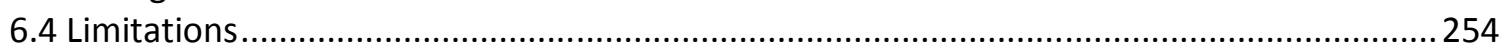

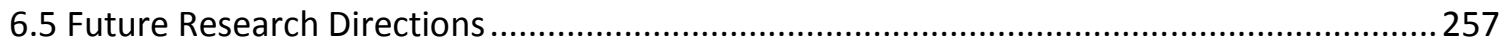




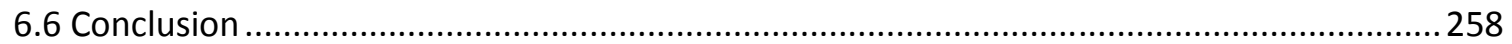

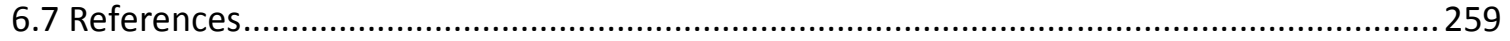

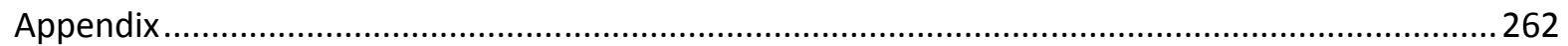




\section{LIST OF TABLES}

\section{Chapter 3}

Section 3.1

Table 1 Characteristics of studies that examined the relationship between the neighbourhood physical environment and child adiposity....

Table 2 Characteristics of studies that examined the relationship between the neighbourhood social environment and child adiposity.....

Table 3 Characteristics of a study that examined the relationship between a combined measure of the neighbourhood physical and social environment with child adiposity

Section 3.2

Table 1 Characteristics of reviewed studies that examined the relationship between area deprivation and child excess weight

Table 2 Characteristics of reviewed studies that examined the relationship between social capital and/or disorder with child excess weight.

Table 3 Characteristics of reviewed studies that examined the relationship between living location and child excess weight.

Table 4 Characteristics of reviewed studies that examined the relationship Section 3.3

between exposures related to living location and child excess weight........

Table 1 Characteristics of included studies.

\section{Chapter 4}

Table 4.1 Census indictors making up the material and social deprivation dimensions of area deprivation.

Table 4.2

Neighbourhood Social Scale Items.

Table 4.3 Percentage overweight (including obesity) and obese by sex and age group using WHO, IOTF, and CDC cut-points and data from the 2004 CCHS - adapted from Shields \& Tremblay, 2010.

Table 4.4 Longitudinal studies statistically estimating multiple weight status trajectory or transition groups in children.

Table 4.5 Number of BMI Z-score repeated measures and frequency of children in the QLSCD.

Table 4.6 Definitions of explanatory variables included in analyses to address Objectives $1 \mathrm{a}$ and $1 \mathrm{~b}$.

Table 4.7 Household Food Security Survey Module (HFSSM) Adult and Child Scales.

Table 4.8

Thresholds of food security status using the HFSSM (Canada).

Number of repeated food insecurity measures and frequency of children in the QLSCD.

Table 4.11

Definitions of explanatory variables included in the analysis to address Objective 2

\section{Chapter 5}

Section 5.1

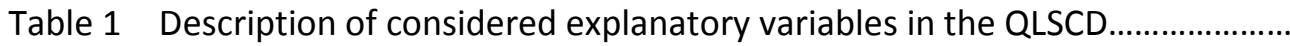

Table 2 Baseline descriptive data (4 years) of included children $(n=1,580)$ 
Table 3 Directly measured mean BMI and BMI Z-score by mean age for included children $(n=1,580)$

Table 4 Unadjusted and adjusted BMI Z-score trend models: significant fixed effect parameters and their $95 \%$ confidence limits $(n=1,580)$.

Section 5.2

Table 1 Definitions of explanatory variables.

212

Table 2 Mean BMI and BMI Z-score by age and weight trajectory group $(\mathrm{N}=1566)$.

Table 3 Characteristics of QLSCD children by weight trajectory group (Total N = 1566)

Table 4 Results of unadjusted and multivariable group-based trajectory models estimating the relationship between time-stable explanatory variables and probability of group membership, and change in average group BMI Z-score as a function of time-dependent explanatory variables (QLSCD children from $4-10$ y of age)

Section 5.3

Table 1 Characteristics of households with children participating in the QLSCD and included in the analysis at age $4 \mathrm{y}$, by food insecurity

status

Table 2 GEE multivariable logistic regression model to measure the adjusted association between place and food insecurity among households with children participating in the QLSCD. 


\section{LIST OF FIGURES}

\section{Chapter 1}

Figure 1.1 Conceptual model of relationship between local environmental factors of interest and child weight status and family food security status................... 6

\section{Chapter 2}

Figure 2.1 The Total Environment Assessment Model of Early Child Development...... 11

Figure 2.2 Reduced Foresight map.............................................................................. 19

Figure 2.3 Concept model: food systems and health disparities.................................... 28

Figure 2.4 Neighbourhood environments and rules of access....................................... 32

Chapter 3

Section 3.1

Figure 1

Section 3.3

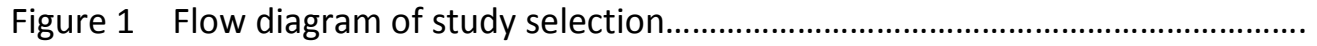

Figure 4.1 Conceptual model of relationship between local environmental factors of interest and child weight status.

Figure 4.2 The group-based trajectory model with time-stable $\left(x_{m}\right)$ and timedependent explanatory variables $\left(z_{k t}\right)$

Figure 4.3 Conceptual model of relationship between local environmental factors of interest and family food security status.

Chapter 5

Section 5.1

Figure 1 Sampling of children in the Québec Longitudinal Study of Child

Development

Figure 2 Predicted BMI Z-score smoothed individual trends by significant place factors in the QLSCD, adjusted for other model covariates

Figure 3 Predicted BMI Z-score smoothed individual trends by significant social and early life factors, adjusted for other model covariates...

Section 5.2

Figure 1 Estimated weight change trajectories and 95\% confidence intervals in the QLSCD from 4-10 y of age ( $n=1566)$

Figure 2 Example of time-varying local environment associations: effect of change in living location between 6-7 years of age on trajectory group shape (unadjusted)..... 


\section{LIST OF ABBREVIATIONS}

BIC - Bayesian Information Criteria

$\mathrm{BMI}$ - body mass index

$\mathrm{CA}$ - census agglomeration

CCHIP - Community Childhood Hunger Identification Project

CCHS - Canadian Community Health Survey

CMA - census metropolitan area

CDC - Centers for Disease Control and Prevention

EM - expectation-maximization algorithm method

FSSM - Food Security Survey Module (US)

GEE - generalized estimating equations

HFSSM - Household Food Security Survey Module (Canada)

IOTF - International Obesity Task Force

ISQ - I'Institut de la statistique du Québec

MIZ - metropolitan influenced zones

NEAT - non-exercise activity thermogenesis

NHANES - National Health and Nutrition Examination Survey

NHES - National Health Examination Survey

NLSCY - National Longitudinal Survey of Children and Youth

PA - physical activity

PSU - primary sampling unit

QLSCD - Québec Longitudinal Study of Child Development

QIC - quasilikelihood model information criterion

SAS - Statistical Analysis System (SAS Institute Inc.)

SD - standard deviation

SES - socioeconomic status

SSU - secondary sampling unit

UK - United Kingdom

USDA - United States Department of Agriculture

US - United States of America

WHO - World Health Organization 


\section{Chapter 1 - Introduction}

This first chapter presents the problem statement for the thesis, providing a summary of the background, rationale and overall purpose. The main objectives are next described, along with associated hypotheses. A conceptual model then visually highlights the hypothesized relationships. The problem statement, objectives, hypotheses and conceptual model have all been informed by a comprehensive literature review that is discussed in Chapters 2 and 3 of this thesis. Finally, to help the reader orient him/herself, a layout of the thesis is presented.

\subsection{Problem Statement}

Humans do not live in isolation. We live in and continuously interact with our surrounding environments. It is therefore likely that many different aspects of our respective social and physical environments (e.g. social capital, physical layout of spaces) influence our health, above and beyond factors at the individual level (e.g. lifestyle behaviours). Moving beyond these traditional individual factors, to also consider the environments in which we live and interact, is needed to understand how people become and remain healthy, and therefore, to develop interventions that will be effective, sustainable and equitable. Creation of supportive environments for health is a key pillar of the Ottawa Charter for Health Promotion (1).

Childhood excess weight and family food insecurity are food-system related public health problems that exist in Canada. In a simplistic sense, obesity is a condition of excessive adipose tissue caused by a positive energy balance (2); which includes excess energy intake, low energy expenditure, or both. In 2004, $8 \%$ of children 2-17 years of age were obese (3). Not only does this have potential short term impacts on health and well- 
being, but obese children often become obese adults (4), which could lead to substantial individual and societal costs in the future (5). Family food insecurity, on the other hand, describes the economic uncertainty of being able to access and consume nutritionally adequate foods, with differing degrees of severity. In 2007/2008 it was estimated that 7.7\% of Canadian households, and 9.7\% of those with children, were food insecure (6). Food insecurity is not only morally unjust, especially in rich, democratic countries such as Canada, but is also associated with a number of physical and psychosocial problems in children $(7 ; 8)$ and adults $(8 ; 9)$. It is especially worrisome for young children as they are most likely to be affected, and may bare its negative consequences throughout the lifecourse (8). Like obesity, food insecurity may have social and economic consequences down the road.

Both childhood obesity and family food insecurity involve food accessibility, availability, and utilization; with accessibility and availability having obvious environmental elements. Including a place-based lens for determining why certain children develop and remain at excess weight, and why families with children become food insecure may lead to the identification of common environmental risk factors amenable to change that could ameliorate both conditions. As such, there have been recent calls in both areas of study, to further our understanding of potential environmental influences $(9 ; 10)$. Local environments surrounding places of residence, such as neighbourhoods, are a natural way to conceptualize 'place' in terms of child and family health and acquiring health resources; and studies are finding significant relationships between certain local environmental features and both weight status and food insecurity (see Chapter 3). However, this literature is heterogeneous, mostly cross-sectional, and often has other methodological flaws, such as failing to consider 
important determinants like family socioeconomic status (SES). There is also a dearth of evidence from Canadian populations; in both areas of study, the majority of studies have been conducted in the United States (US).

This thesis, therefore, takes a population health approach and an overarching socialecological perspective in examining the determinants of childhood excess weight and family food insecurity, with a particular focus on indicators of the local environment. Shortcomings in the literature are addressed through the use of theory, following children and their families over time, and using longitudinal statistical methods appropriate to each study's purpose. A theory of place's potential effect on child weight status and family food security status is primarily based on Bernard et al's (2007) social-ecological theory of neighbourhoods (11). All analyses are based on participants of the Québec Longitudinal Study of Child Development (QLSCD): a birth cohort study, conducted by the Institut de la statistique du Québec (ISQ) (12).

The purpose of this thesis is to determine if and how particular characteristics of the local environment are related to child excess weight and family food insecurity. This research is important as it not only can help point to potential areas of research and intervention that may alleviate both child excess weight and family food insecurity, but also to identify avenues that may not be as fruitful for exploration, thus allowing for more effective use of future resources.

\subsection{Objectives and Hypotheses}

This thesis has three main objectives based on secondary analyses of a Canadian cohort of young children. These are discussed below along with their associated hypotheses. 


\subsubsection{Main Objectives}

Objective 1: To determine the longitudinal association of local environmental factors (living location, social cohesion, disorder, and material and social deprivation) with child weight status, after consideration for important social and early life factors; achieved through comparison of results using two different statistical methods: a) mixed models regression and b) group-based trajectory modeling. These are two different ways of modeling growth and thus offer differing perspectives on how local environmental factors may be related to weight status.

Hypothesis 1a: Children living in areas characterized as rural, or having high disorder or high material/social deprivation would have higher weights on average and have faster rates of weight increase than children not living in these areas; children living in areas characterized as having high social cohesion would have lower weights on average and slower rates of weight increase than children not living in these areas.

Hypothesis 1b: Children in materially and socially deprived areas would be more likely to belong to a weight group exhibiting a stable excess weight trajectory, or to a group with a trajectory that increased from normal to excess weight, compared to a stable "normal" group. In each trajectory group, living in areas characterized as rural, having high disorder, or low social cohesion would be associated with an increase in weight over time. 
Objective 2: To determine the longitudinal association of local environmental factors (living location, social cohesion, disorder, and material and social deprivation) with family food insecurity, after consideration for other important social factors.

Hypothesis 2: Families living in areas characterized as rural, having high disorder or high material/social deprivation, or low social cohesion would have higher odds of food insecurity on average, and the odds of food insecurity would increase over time for these families.

Objective 3: To compare the results from Objectives 1 and 2.

Hypothesis 3: High material/social deprivation, high disorder, low social cohesion and rural living would be important in explaining both child weight status and family food insecurity, and thus represent potential leverage points for intervention in both public health problems.

\subsection{Conceptual Model}

Taking a social-ecological perspective (Figure 1.1), children are nested within families/households, and families/households are nested within local environments such as neighbourhoods. Local environments are nested within the broader socio-political environment (although this is beyond the scope of this thesis). This nested structure can change over time, as depicted by the arrow. Features of the social and physical environments of local places may influence family food security as well as child weight status through many different factors; however, only the ones of interest in this thesis are presented in the figure. Factors operating at the family level are hypothesized to influence both outcomes, whereas those at the individual level are hypothesized to influence child weight status only. 
Examining these explanatory variables along with the place factors of interest is necessary to eliminate potential confounding and present a more holistic picture of both public health problems. This conceptual model originated from the background theory provided in Chapter 2, and the results of two critical appraisals, which can be found in Chapter 3.
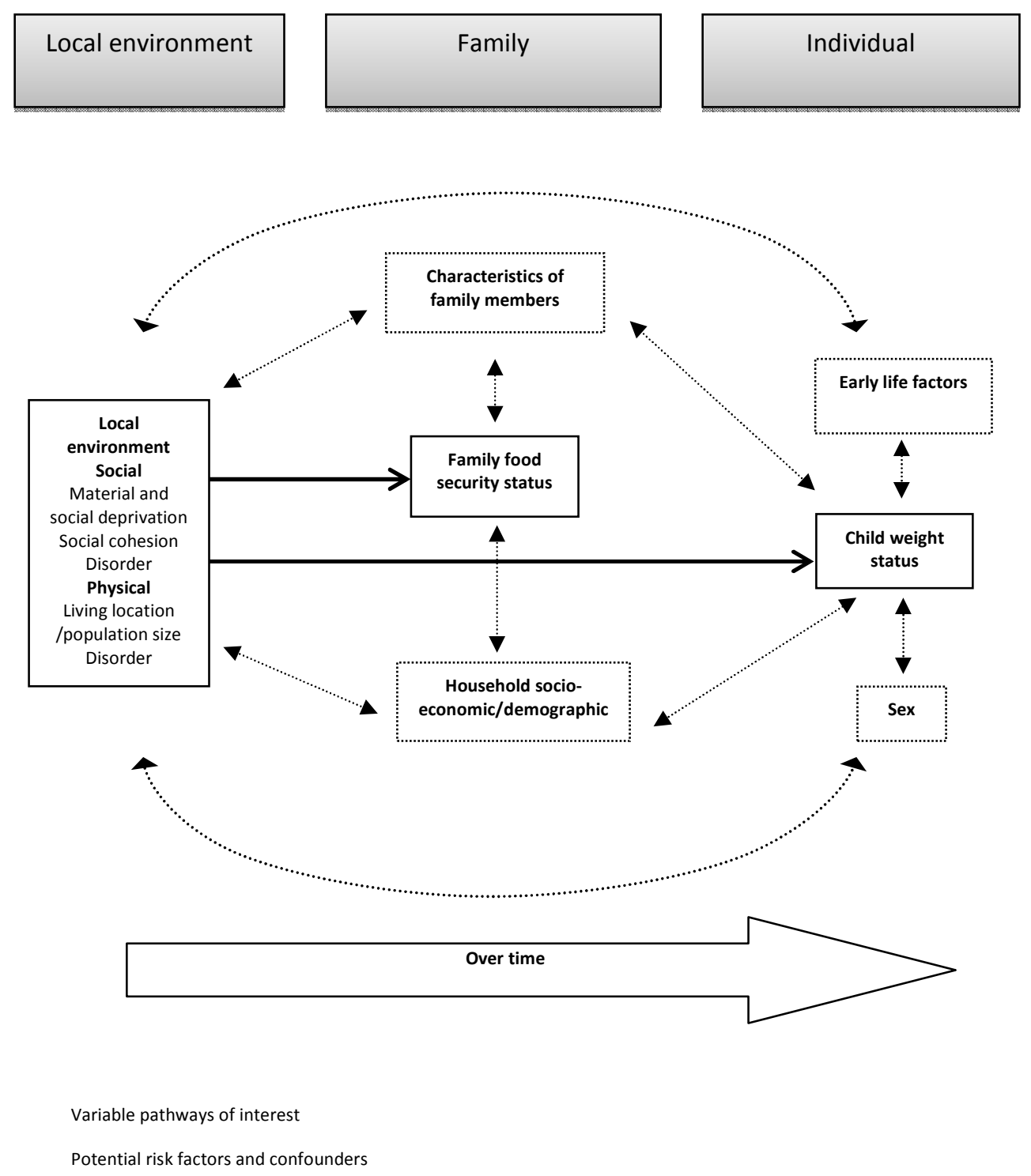

Figure 1.1: Conceptual model of the relationship between local environmental factors of interest and child weight status and family food security status 


\subsection{Organization of the Thesis}

This thesis is organized into six chapters. Chapter 2 provides an overview of child excess weight and family food insecurity, including a detailed account of health correlates, extent of both problems in Canada, a description of their determinants, and an in-depth discussion of the local environment as considered in this thesis. Chapter 3 provides a thorough review of the literature examining local environmental correlates of child excess weight and food insecurity. Manuscript 1 begins Chapter 3 . This manuscript is a critical appraisal of published studies examining the association between broad neighbourhood factors and child excess weight. It was published in the journal Health \& Place (13). Since it was published in 2010, an update and slight expansion of the review was conducted; this follows the presentation of Manuscript 1. Manuscript 2 is a critical appraisal of published studies examining the association between broad local environmental factors and food insecurity. This has been revised and resubmitted to the journal Public Health Nutrition. Following Chapter 3, an overview of methodological issues and methods used to conduct the three studies that comprise this thesis is presented in Chapter 4. Chapter 5 presents the results of these three studies, which collectively address Objectives $1 \mathrm{a}, 1 \mathrm{~b}$, and 2 of this thesis. The first section of Chapter 5 presents Study 1, which addresses Objective 1a, the relationship between place and child excess weight using a mixed models approach. This has been published in the Journal of Urban Health (14). Section 2 of Chapter 5 addresses Objective $1 \mathrm{~b}$, the relationship between place and child excess weight using group-based trajectory modeling. This manuscript (Manuscript 4) has been accepted by the open access journal, PLoS ONE. The fifth manuscript and third study, which addresses Objective 2 of this thesis, to explore the relationship between place and family food insecurity, is presented in the third and final section of Chapter 5. This has been resubmitted with revisions to the 
journal BMC Public Health. Finally, Chapter 6 integrates and discusses the results of the thesis, highlights implications, and outlines recommendations for future research. It also specifically addresses the third objective of this thesis, which is to compare the results of Objectives $1 \mathrm{a}, 1 \mathrm{~b}$ and 2 .

\subsection{References}

(1) The Ottawa Charter of Health Promotion. World Health Organization 1986 [cited 2012 June 14] Available from URL: http://www.who.int/hpr/NPH/docs/ottawa_charter_hp.pdf

(2) Gidding SS, Leibel RL, Daniels S, Rosenbaum M, Van HL, Marx GR. Understanding obesity in youth. A statement for healthcare professionals from the Committee on Atherosclerosis and Hypertension in the Young of the Council on Cardiovascular Disease in the Young and the Nutrition Committee, American Heart Association. Writing Group. Circulation 1996; 94(12):3383-7.

(3) Shields M. Overweight and obesity among children and youth. Health Rep 2006;17(3):27-42.

(4) Singh AS, Mulder C, Twisk JW, van MW, Chinapaw MJ. Tracking of childhood overweight into adulthood: a systematic review of the literature. Obes Rev 2008; 9(5):474-88.

(5) Wang YC, McPherson K, Marsh T, Gortmaker SL, Brown M. Health and economic burden of the projected obesity trends in the USA and the UK. Lancet 2011; 378(9793):815-25.

(6) Health Canada. Household Food Insecurity In Canada in 2007-2008: Key Statistics and Graphics. Health Canada 2011 [cited 2011 Oct 12]; Available from URL: http://www.hcsc.gc.ca/fn-an/surveill/nutrition/commun/insecurit/key-stats-cles-2007-2008-eng.php

(7) Nord M, Parker L. How adequately are food needs of children in low-income households being met? Children and Youth Services Review 2010; (9):1175-85.

(8) Cook JT, Frank DA. Food security, poverty, and human development in the United States. Ann N Y Acad Sci 2008; 1136:193-209.

(9) Gundersen C, Kreider B, Pepper J. The Economics of Food Insecurity in the United States. Applied Economic Perspectives and Policy 2011; 33(3):281-303.

(10) Law C, Power C, Graham H, Merrick D. Obesity and health inequalities. Obes Rev 2007; 8 Suppl 1:19-22.

(11) Bernard P, Charafeddine R, Frohlich KL, Daniel M, Kestens Y, Potvin L. Health inequalities and place: a theoretical conception of neighbourhood. Soc Sci Med 2007; 65(9):1839-52.

(12) Jetté M, Des Groseilliers L. Longitudinal Study of Child Development in Québec (ELDEQ 1998-2002) 5 month old infants: Survey Description and Methodology. Montreal: Institut de la statistique du Québec, Government du Québec; 2000. Report No.: 1. 
(13) Carter MA, Dubois L. Neighbourhoods and child adiposity: a critical appraisal of the literature. Health Place 2010; 16(3):616-28.

(14) Carter MA, Dubois L, Tremblay MS, Taljaard M. The Influence of Place on Weight Gain during Early Childhood: A Population-Based, Longitudinal Study. J Urban Health 2012 Early Online Jul 18. 


\section{Chapter 2 - Background and Rationale}

In this chapter, the population health approach and overarching social-ecological theory are first discussed, in order to provide the perspective through which the problems of child excess weight and family food insecurity are viewed in this thesis. Next, background information is presented to highlight the nature of both public health problems, including consequences and hypothesized causes, and the added understanding that could come if a place perspective was also included in research. Finally, the definition and theoretical underpinnings of place, as understood in this thesis, are discussed.

\subsection{Introduction}

Population health is defined as "the health outcomes of a group of individuals, including the distribution of such outcomes within the group" (1). A population health approach acknowledges that health arises from multiple interrelated determinants, and is not simply a result of the healthcare system. The Public Health Agency of Canada considers income and social status, social support networks, education, employment/working conditions, social environments, physical environments, personal health practices and coping skills, healthy child development, biologic and genetic endowment, health services, gender, and culture to be the determinants of health (2). These more or less correspond to those highlighted by Kindig \& Stoddart (2003), who also emphasize that population health is concerned with how these determinants interact ("patterns of determinants"), not just in how they operate on their own (1).

The primary goal of the population health approach is, not only to improve the health of a population, but also to decrease health disparities between population subgroups through policy and program development (1). In order to achieve this, the population health 
approach emphasizes a focus on upstream factors (e.g. the 'causes of the causes'), such as economic, political, and environmental determinants, in addition to those operating further down-stream at the individual-level, such as biological and behavioural factors.

A social-ecological perspective can provide an organizing framework to better understand these determinants as they relate to children and families. The overarching framework used in this thesis was that developed by Irwin et al (2008), which originated from their knowledge synthesis for the World Health Organization (Figure 2.1) on child development (3).

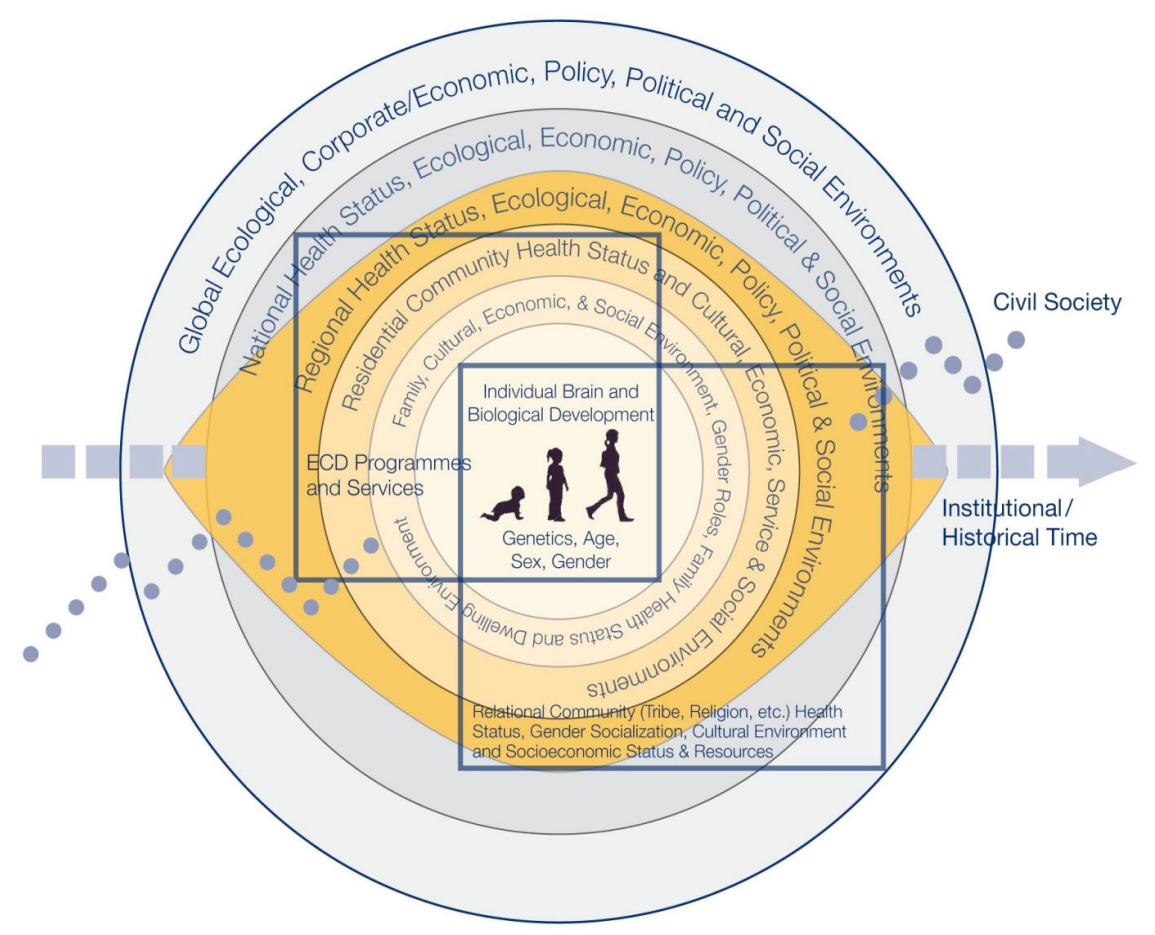

Figure 2.1: The Total Environment Assessment Model of Early Child Development from total environment assessment model for early child development. Evidence report for the Commission on the Social Determinants of Health (p.15). by A. Siddiqi, L.G. Irwin, and C. Hertzman, 2007, Geneva, Switzerland: World Health Organization, Commission on the Social Determinants of Health [Reprinted with permission of the World Health Organization]

The framework puts children at the centre, nested within families, families within neighbourhoods and relational communities (such as religious, language/cultural groups), situated in a broader socioeconomic context derived from regional, national, and global level 
factors. These environments are not necessarily hierarchical, but rather overlap, interact, and blend together (3). Social capital, or the actions of civil societal groups, is seen to affect all levels of social organization, advocating on behalf of children (3). The framework also explicitly takes a lifecourse perspective, where past social experiences become embodied in the child in the early years, predisposing them to future advantage/disadvantage. This perspective also considers the history of different societal structures and their effects on health and well-being. Growth is also seen as transactional, whereby children are social actors shaping, and in turn being shaped, by their environment (3).

Child-level determinants of healthy growth include age, sex/gender, behaviours (e.g. play, dietary intake), genetics and unique developmental patterns. While these are important, the principal driving forces are nurturing relationships and supportive environments (3). Families (and other primary care providers) provide children with the largest share of human contact and mediate access to the broader environment, and are thus the primary source of experience for young children. Presence of social and economic resources in the family environment (e.g. income, parenting skills) increases the likelihood that a nurturing, stimulating, and healthy environment is provided to children (3). Resources in neighbourhoods and relational communities such as local institutional funding, policymaking and program implementation, social networks and collective efficacy, quality accessible programs and services, and other amenities in the built environment, can further support families, while the presence of other factors, such as crime, violence, gangs (negative social cohesion), discrimination, social exclusion, and material and social deprivation, can hinder healthy growth (3). Regional environmental influences derive mainly from policy-making and funding that are translated to a large degree at the local 
level, and affect the social, built and economic environments (3). The national environment has the capacity to influence regional policy-making as well as determinants at the community and family level, particularly through creation of wealth, public spending, implementing child and family-friendly policies, and protection of basic human rights (3). The global environment can influence national policies and can directly affect determinants at the family and community level through the actions of multilateral economic organizations, and multilateral and nongovernmental development (3).

Childhood excess weight ${ }^{1}$ and food insecurity are considered "wicked" health problems (4). They are complex, not easily defined, and do not have "true" solutions (4). Wicked problems are often thought to be policy resistant; however, by acknowledging that these problems are wicked, we can move away from our fixation on trying to find simple solutions (4). The population health approach and social-ecological perspective provide a means for us to consider complexity, while also acknowledging that health is socially structured.

Both the existence of excess weight and food insecurity signal a food system that is failing to deliver healthful food to all (5). Recently, a committee of experts was brought together by the Institute of Medicine in the US to discuss the coexistence of excess weight and food insecurity in the same families, communities and even the same individuals in developed countries. While it was acknowledged that research seeking to determine a causal link between the two is not necessarily needed, determining ways in which the environment, particularly common local residential factors, are related to excess weight and food insecurity could be one very important facet for policy development (5). In other words,

\footnotetext{
${ }^{1}$ The term 'excess weight' used in this thesis represents overweight and obesity. 'Weight status' will also be used throughout this document and refers to a child's body mass index (BMI) measure along the continuum of underweight, normal weight, overweight, to obesity. The use of the word 'weight' in this document always refers to weight relative to height.
} 
common disparities in the characteristics of the places in which we live may lead to disparities in childhood excess weight and family food insecurity. Interventions targeted to place, while considering other important individual and family-level factors, may then help to improve both public health problems, and therefore the sustainability of our food system.

Sections 2.2 and 2.3 in this chapter go on to describe childhood excess weight and family food insecurity in more detail (the most common methods of measurement are outlined in Chapter 4). The last section of this chapter provides an in-depth discussion of how place (i.e. the local environment) is defined and how it could theoretically influence both childhood weight status and family food security status. These sections are meant to provide general overviews. Critical examinations of how place factors may be related to child weight status and family food insecurity are presented in Chapter 3.

\subsection{Childhood Excess Weight}

\subsubsection{Definition, epidemiology, and potential consequences}

As in adults, childhood obesity is defined as a condition of excessive adipose tissue (6).

Over the last few decades, the prevalence of childhood overweight - the state of being at risk for obesity (7) - and obesity have risen dramatically in Canada (8;9) and in many other countries (10), becoming a major public health concern. In 2004, 26\% of Canadian children aged 2-17 years were overweight or obese, and 8\% were obese (9). From 1978/79 to 2004, the prevalence of overweight (including obesity) and obesity remained the same for 2-5 year olds, but increased two-fold among 6-11 year olds (13\% to 26\%) and $12-17$ year olds (14\% to $29 \%)$. 
In children, obesity is associated with short-term problems such as an increased risk of gallbladder disease, asthma, obstructive sleep apnoea, physical functional limitations, type II diabetes, and cardiovascular disease risk factors such as hypertension, dyslipidemia, and the metabolic syndrome (11-13). Type II diabetes may be the most concerning given the steep global rise in incidence (14) and because it was previously only a disease of adulthood. Psychosocial problems such as depression, low self-esteem, and anxiety disorders are more likely to occur in obese children compared to their non-obese peers $(12 ; 15)$, although these may precede obesity (13). In addition, quality of life has been found to be lower among obese children (16).

Also concerning is that childhood obesity is associated with longer term consequences such as adult obesity $(17 ; 18)$, and increased adult mortality and cardio-metabolic morbidity (19). For example, seven out of eight studies in a review by Reilly \& Kelly (2011) found that childhood/adolescent excess weight was associated with a $1.4-2.9$ times increased risk of adult premature mortality (19).

A recent Lancet report highlighted the potential economic perils of the obesity epidemic (20). They used two modeling strategies ${ }^{2}$ to estimate trends and projections for obesity and related chronic diseases ${ }^{3}$, and cost of treatment for these diseases in the US and UK from the early 1990 's to 2030 . They estimated that compared to 2010 , there will be 65 million more obese US adults in 2030, and 11 million more obese Britons. This will translate into added healthcare costs of \$48-66 billion per year in the US, and $£ 1.9-2$ billion per year in the UK. Estimates of indirect costs (lost workdays, lost productivity and absenteeism) were also

\footnotetext{
${ }^{2}$ The two modeling strategies were 1 ) historical trends with regression analysis, and 2) recent trends with micro simulation to derive two estimates for all morbidity and cost of treatment outcomes for each country. The second strategy was considered more optimistic.

${ }^{3}$ These were diabetes, heart disease, stroke, obesity-related cancer, and arthritis.
} 
calculated. ${ }^{4}$ Obesity is estimated to lead to a loss of $1.7-3$ million productive person-years among working US adults, which translates into an indirect economic cost of $\$ 390-580$ billion.

Because obesity in childhood is related to numerous comorbidities that present during childhood, childhood obesity has potential healthcare costs not only in the long term, but the short term as well. A recent Canadian prospective cohort study (21) conducted in the province of Nova Scotia found that healthcare costs (physician and hospital) in the three years following the initial survey were significantly higher [21\% (95\%CI: $2-43)]$ among obese children compared to normal weight children. For lifetime costs (up to 14 years of age), significant differences appeared as early as three years (21). Therefore, in addition to population health goals, halting and reversing the childhood obesity epidemic also makes economic sense.

\subsubsection{Risk factors}

In a simplistic sense, obesity is always a result of positive energy balance. The heritability of weight status is high (22); however, due to its comparatively swift onset, the childhood obesity epidemic cannot solely be explained by an increase in genetic predisposition $(23 ; 24)$. Unhealthy diets, physical inactivity and sedentary behaviours have been implicated, as they are directly related to energy intake and expenditure, but considerable debate remains about which components are most important $(25 ; 26)$.

The results of a recent systematic review of systematic reviews that attempted to synthesize the existing literature on risk factors of childhood obesity did find evidence for

\footnotetext{
${ }^{4}$ Adequate population-level data to derive estimates were lacking for the UK.
} 
the influence of poor diet and physical inactivity-related factors, namely obtaining less than 30 minutes of daily physical activity (PA), television viewing, and consumption of sugarsweetened beverages (27). However, they also found convincing evidence for other, perhaps more important factors, with many operating even before children are born. Exposures in utero as well as in early life may lead to physiological adaptations that can result in changes to the metabolic and endocrine systems of young children. This is termed the developmental origins hypothesis (28). Thus, through mechanisms operating in early life, obesity may be transmitted across generations. Indicators of these early life exposures found to relate significantly to child obesity in this review included maternal smoking, no or short breastfeeding duration, rapid infant growth, maternal diabetes, small or large size at birth, and restricted intrauterine growth (27). Other important factors uncovered in the review included short sleep duration, parental obesity, and low SES. These same factors have also been uncovered in studies using the QLSCD $(29 ; 30)$.

This review provides some insight into the complexity of obesity, but is largely linear in its discussion of variable relationships, and only goes insofar as the published literature can allow, with respect to risk factors examined. A population health perspective is needed to fully appreciate obesity's complexity. Recently, the UK government commissioned The Foresight Group to assemble transdisciplinary evidence and expertise on contributors to the obesity epidemic among both adults and children. This large project engaged a broad range of stakeholders emanating from many different scientific disciplines and societal sectors (e.g. scientists, private sector and government departments). A complex causal map of obesity was one of the main outcomes of this project, developed using a systems mapping approach (31). Although not 100\% comprehensive, its main function serves as a heuristic, 
and its development has "helped to forge multi-sector, multi-disciplinary relationships that support future government decision-making based on evidence" (4). Given that this project represents the most comprehensive evidence synthesis to date on the posited "whole system" causes of obesity, a brief summary of the project's results is provided in the next few pages. The reader is cautioned that these are hypothesized causes based on transdisciplinary evidence and expertise, where the goal of describing this framework is to illustrate the sheer complexity of obesity.

Overall project results show that the development of obesity is extremely complex and multifactorial with interacting behavioural and biological factors operating within a social, cultural and environmental landscape (31). The development of obesity is not simply a result of lack of willpower in terms of eating too much and moving too little, it is seen as a relatively passive occurrence (31). The actual map is extremely detailed and complex, with 108 variables and greater than 300 positive or negative links between variables (4). The map also contains feedback loops, indicating that changes in one variable may have unintended or undesirable consequences elsewhere in the model. Since the original map is too large to incorporate here, a simplified map is presented in Figure 2.2.

Hypothesized causes are grouped into seven clusters: physiology, food production, food consumption, social psychology, individual psychology, individual PA, and PA environment that act on four key determinants: primary appetite control in the brain (located in the physiology cluster), the force of dietary habits (located in the food consumption cluster), the level of PA (located in the individual PA cluster), and psychological ambivalence in making lifestyle choices (located in the individual psychology cluster). These all centre on the "engine" of energy balance (31). By comparison, the physiology, food consumption, 
individual psychology and individual PA clusters operate further downstream, whereas the food production, social psychology, and the PA environment clusters operate upstream.

These clusters are discussed in more detail below.

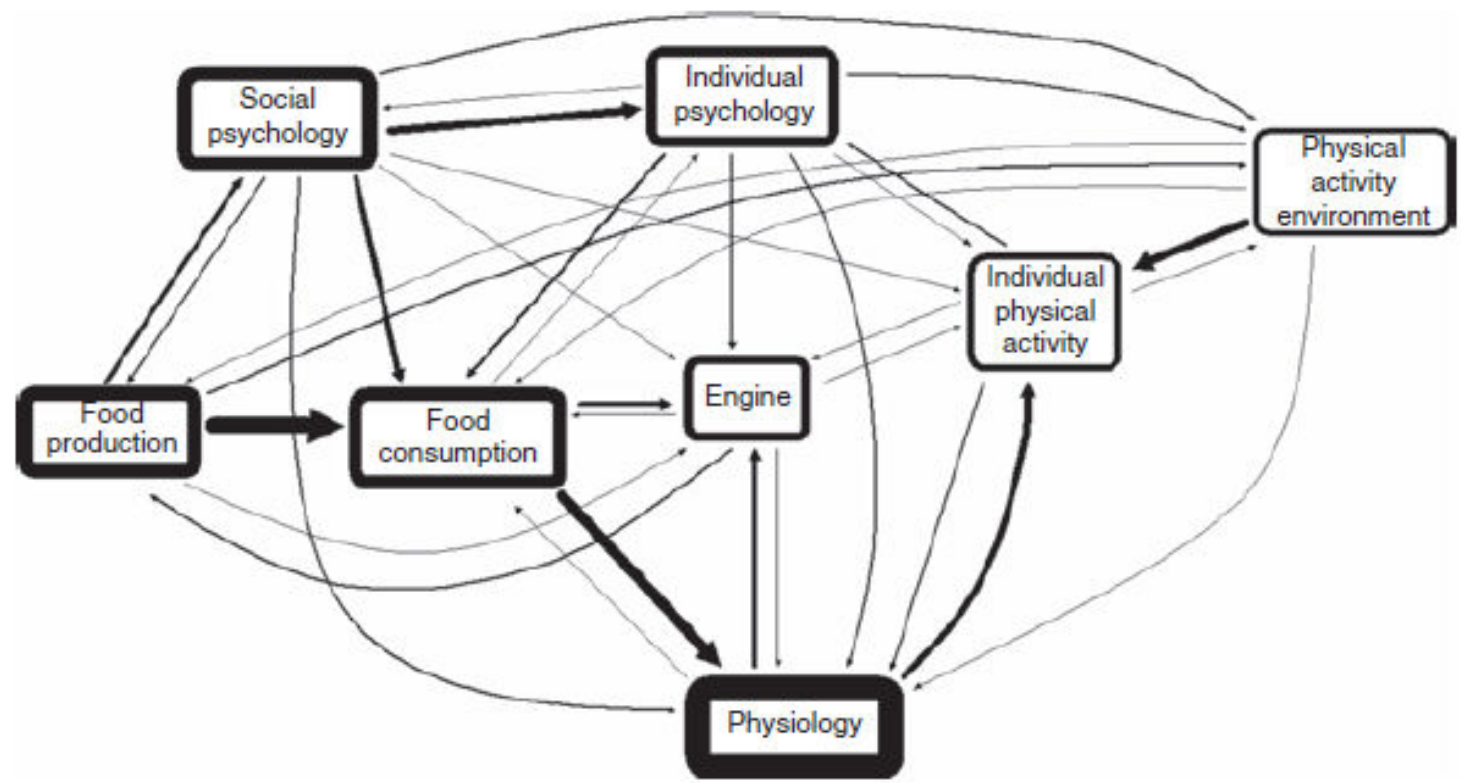

Figure 2.2: Reduced Foresight map. The number of individual connections between variables in each cluster is represented in the thickness of connecting lines, whereas the number of connections within a cluster is shown as the cluster's border thickness [Reprinted by permission from Macmillan Publishers Ltd: Obesity. Finegood DT, Merth TD, Rutter H. Implications of the foresight obesity system map for solutions to childhood obesity 18 Suppl 1:S13-S16. (02010

The physiology cluster includes genetic predisposition, level of satiety and resting metabolic rate, and the pattern of growth in early life - such as low or high birth weight and rapid growth in infancy (31). Factors in the physiology cluster, for the most part, are hypothesized to affect primary appetite control, and energy balance directly (31).

Food production includes the many drivers of the food industry, in relation to the wider socioeconomic environment. The strong drive for profitability among industry players influences desires to minimize cost, improve efficiency, increase volume produced, and 
standardize, and differentiate food products (31). These along with other market demands influence the price of food. Purchasing power of the individual (income level), employment status, pressures to consume, and two-parent-working family also contribute to this cluster.

In turn, food production influences the consumer's food environment - termed here the food consumption cluster. Factors implicated in food production include the portion size and energy density/nutritional quality of foods, the degree of exposure to the amount and variety of foods, palatability of foods, the demand for convenience and actual convenience of foods coupled with the loss of cooking skills of consumers (31). For children, this also includes the degree to which they have control over their own diets. Factors in the food consumption cluster feed mainly into the physiology cluster, and the main determinant: force of dietary habits - a culmination of these variables that keep individuals from adopting healthy behaviours.

The social psychology cluster describes the socio-cultural environment in which consumers live. Factors include education, peer pressure, exposure to media and food advertising, social norms and values in relation to body size, food, acceptability of fatness, and availability of passive entertainment options (31). These are seen to feed largely into the food production and consumption clusters, the individual psychology cluster, as well as the PA environment and individual PA clusters. Parental control over children's diets exists in the social psychology cluster; it is negatively influenced by perceived lack of time, which in turn is seen to influence children's control over their own diets.

Individual psychology is largely seen to be influenced by factors operating in the social psychology cluster. These individual factors include food literacy, stress, and face to face 
social interaction versus use of technology (31). Factors in this cluster are hypothesized to play a part in the 'psychological ambivalence' of individuals in making lifestyle choices; a key obesity determinant. Stress is seen to have multiple influences reaching into the individual PA, food consumption, social psychology, and physiology clusters.

Factors in the PA environment cluster describe opportunities and barriers for being physically active. Examples include perceived danger of the environment itself, danger of non-motorized travel, dominance of sedentary employment and motorized travel, access to opportunities for PA (physical and economic factors), and walkability of the living environment (31). This cluster is mainly influenced by factors in the social psychology cluster and purchasing power (or income level) in the food production cluster. Factors making up this cluster, in turn, feed into individual PA.

Finally, the individual PA component is defined by levels of occupational, transport (e.g. walking or biking), and recreational PA, parental modeling and learned PA patterns in childhood, NEAT (non-exercise activity thermogenesis), and functional fitness (31). These in turn comprise the PA factor, one of the main determinants of obesity. Factors in this cluster are largely influenced by factors in the PA environment cluster; although, some aspects of the social psychology and physiology clusters also play a role. Physiological factors: resting metabolic rate and NEAT can also influence functional fitness.

Much of the research included in the Foresight model was conducted on adults. A preliminary model was developed focusing on children; however much evidence remains to be developed to substantiate many of the proposed pathways. The map also does not specifically take a lifecourse perspective, is difficult to understand in terms of levels of 
social aggregation (e.g. individual, family, community/neighbourhood, country-wide, etc.), and does not adequately consider the potential influence of social capital or broader social issues.

\subsubsection{Rationale for a place-based lens}

Unhealthy diets and physical inactivity behaviours have been traditional targets of childhood obesity prevention and treatment efforts - an individual-level focus that puts the onus on individuals to rectify behaviours in sometimes unsupportive environments (32). Indeed, the Foresight Obesity Map adequately illustrates the complex environment that individuals and families live and interact in.

The prevalence of childhood obesity varies geographically, both within and between high income countries $(9 ; 33)$; trends appear to be plateauing in some countries but have not reversed (34). This suggests that childhood obesity varies with types of environment and that individual behaviour-targeted interventions may not be successfully combating childhood obesity at a population-level, without also simultaneously considering elements of the environments in which people live.

The Collaborative Obesity Modeling Network, which coordinates childhood obesity research across the National Institutes of Health, Centers for Disease Control and Prevention (CDC), Department of Agriculture, and the Robert Wood Johnson Foundation, recently

published a report in the Lancet outlining their work on drivers of the obesity epidemic (32). Their work identified ubiquitous access to affordable, energy-dense, highly palatable, and effectively marketed food as key global drivers of obesity (32). A potential leverage point for obesity prevention may be local social and physical environments, as these may mediate 
and/or moderate these broad societal causes (32). These environments may also interact with individual level factors to further produce variation in obesity prevalence. Thus, it is now believed that a focus on the 'causes of the causes' is necessary to combat this complex public health problem.

In addition to this work, others in the obesity research community have increasingly called for a better understanding of these environmental mechanisms (24;35). More information is needed on if and how specific local environmental factors influence childhood obesity. As a starting point for this thesis, a critical examination of the existing literature is presented in the next chapter.

\subsection{Food Insecurity}

\subsubsection{Definition, epidemiology and potential consequences}

The United Nations Universal Declaration of Human Rights decrees that "Everyone has the right to a standard of living adequate for the health and well-being of himself and of his family, including food" (36). Yet, poor and developing countries deal with famine and undernutrition regularly, even though the world produces enough food to feed all of its inhabitants (37). Even in rich democratic countries like Canada, where problems of overconsumption are evident, financial difficulties constrain households to the quantity and quality of foods eaten. The Canadian government prioritized the right to food in 1998 in response to the 1996 World Food Summit (38). Yet in 2007-2008, 9.7\% of Canadian households with children were food insecure (39); a concerning public health problem that is echoed in other Western countries such as the US (40), Australia (41), and the UK (42). Changes in food insecurity over the last few years in Canada are difficult to assess due to 
changes in survey methodology (43;44); however, in the US, food insecurity has been rigorously monitored since 1995 (40). From 1998-2007 the prevalence of food insecurity among US households with children remained fairly stable, at around $16 \%$. Then, in 2008 , it increased to $21 \%$ and has since remained relatively stable (40).

The prevailing definition of food security is "a situation that exists when all people, at all times, have physical, social, and economic access to sufficient, safe and nutritious food that meets their dietary needs and food preferences for an active and healthy life" (38). The concept of community food security generally follows the same definition but emphasizes sustainability of food systems, self-reliance, and social justice for community members (45). Food insecurity on the other hand, has been defined as the limited or uncertain availability of nutritionally adequate and safe foods or limited or uncertain ability to acquire acceptable foods in socially acceptable ways (46). In other words, food security is one of several prerequisites for a healthy and vibrant population.

Food security and insecurity are on opposite ends of a continuum. Being food secure entails having food readily available, as well as the ability to access and utilize enough of it to lead a healthy life (47). Food insecurity, on the other hand, has different stages of severity, starting with not being able to buy and eat what one would like, due to incomerelated resource constraints (48). This incorporates issues of food quality including variety, safety, nutrient content, and attempts to make food last until there is money to buy more. Decreases in food quantity may then lead to the physical sensation of hunger. Finally, the most severe stage is the complete absence of food intake (48). In addition to the quality and quantity elements of food insecurity, psychological distress (e.g. worry or concern about not 
having enough to eat) and social-familial perturbations (e.g. resorting to socially unacceptable ways of getting food such as stealing) are also important dimensions $(49 ; 50)$.

Food insecurity is experienced at the household and individual level in different ways; at the household level, this relates to access and food supply management, while for the individual, this relates to issues of food consumption and allocation (48). It is also a managed process whereby adults first compromise their food intake to lessen the impact on children $(51 ; 52)$. However, households with children are more likely to be food insecure than households without children (39;40). In 2007-2008, almost $10 \%$ of Canadian households with children were food insecure, versus approximately $8 \%$ in households without children (39). A Canadian study also found that children aged 0-17 years had five times the odds of living in a food insecure household than individuals 65 years of age or older, where the odds decreased in a dose-response-like fashion as one moved up the age category ladder (53). Results were not attenuated after adjustment for other explanatory factors such as income, signalling that children are a major vulnerable group.

There are a number of health correlates of food insecurity that do not always relate to the obvious quality and quantity aspects of food intake. For instance, food insecurity has been found to significantly relate to a number of developmental problems among children, including emotional and behavior problems (54), suicidal ideation (55), poor school performance (56), lower cognition (57), and poorer psychosocial well-being (58). Depression has often been found to relate to adult food insecurity $(59 ; 60)$. This in turn is hypothesized to negatively affect parenting practices, which could contribute to developmental and physical health problems among children (60). 
The nutritional effects of food insecurity are less clear. This is in large part attributed to the cyclical nature of food insecurity and food environment that exists in more wealthy nations, versus the absolute malnourishment of people in poorer nations. A Canadian population-based study found that adults, and to some extent adolescents, who were food insecure were more likely to have inadequate intakes of some nutrients, compared to those who were not food insecure; although no important differences were found between food insecure and food secure children (61). This suggests the potential protective behaviour of adults to avoid substantially reducing children's food intakes in times of hardship. Other studies, on the other hand, have found an association between food insecurity and iron deficiency anemia in young children (62) and adolescents (63). Restricting food intake then resuming normal intake (64), avoiding food waste through overconsumption (65), and attitudes toward food (66) may contribute to the finding that food insecure women are more likely to be overweight or obese than food secure women (67). For children (68) and men (67), the findings have been more mixed.

Finally, evidence derived largely from the US, suggests that food insecurity may have a negative impact on the physical health status of both adults and children, and may even be detrimental to fetal development. For instance, among adults, diabetes, hypertension, and heart disease may be more likely to occur in food insecure versus food secure individuals $(69 ; 70)$. Among children, food insecurity may compromise general health status (71), as well as physical functioning (58). And in older children, hunger (severe food insecurity) has been found to significantly increase the odds of asthma and other chronic conditions (71). During pregnancy, food insecurity has been linked to higher gestational weight gain and gestational diabetes (72). Particularly for US residents, those dealing with food insecurity 
may also be more likely to postpone needed medications and medical care in order to make sure that basic needs are addressed first (73).

\subsubsection{Risk factors}

The major determinant of food insecurity is well understood to be a lack of financial resources $(47 ; 53 ; 74 ; 75)$. Yet, living above the poverty line does not guarantee food security, and food insecurity is not inevitable for those living in poverty (75). A focus on poverty, therefore, may mask the contribution of other factors. Food insecurity is not necessarily a fixed characteristic. Income shocks such as job loss, utility fee changes, sudden increase in household size, and loss of eligibility for a food supplemental program (in the US) are all associated with the occurrence of food insecurity (75). Timing of income supplements can play a role, such that food insecurity often arises at the end of the month when money has run out $(48 ; 50)$. In the US, households that indicated they had been food insecure during the previous year were not food insecure for the entire year. And, on average, they were food insecure at least one point in seven out of the 12 months of the year (40).

Low income is one of the key drivers of food insecurity. However, other social inequities can play a role. A recent review of the literature suggests that single-parent families headed by a female, but not those headed by a male, and those that rent, instead of own, are more likely to be food insecure (76). Other significant associations found in multivariate analysis include smoking $(77 ; 78)$, lack of private transportation $(79)$, and aboriginal status (53). Low education and lack of employment have also been described as correlates (US and Canadian surveys), but are likely to operate in large part through income (74). 
Individual-level attributes are a far too simplistic way to examine this complex public health problem. Neff et al (2009) have developed a conceptual model based on a systems framework and human rights approach to adequate food and food security (80). This model illustrates how disparities in food systems may lead to disparities in health (Figure 2.3). The model may also be relevant for certain aspects of obesity, since as previously discussed, diet and energy intake are major determinants of obesity, and thus, dependent on food systems.

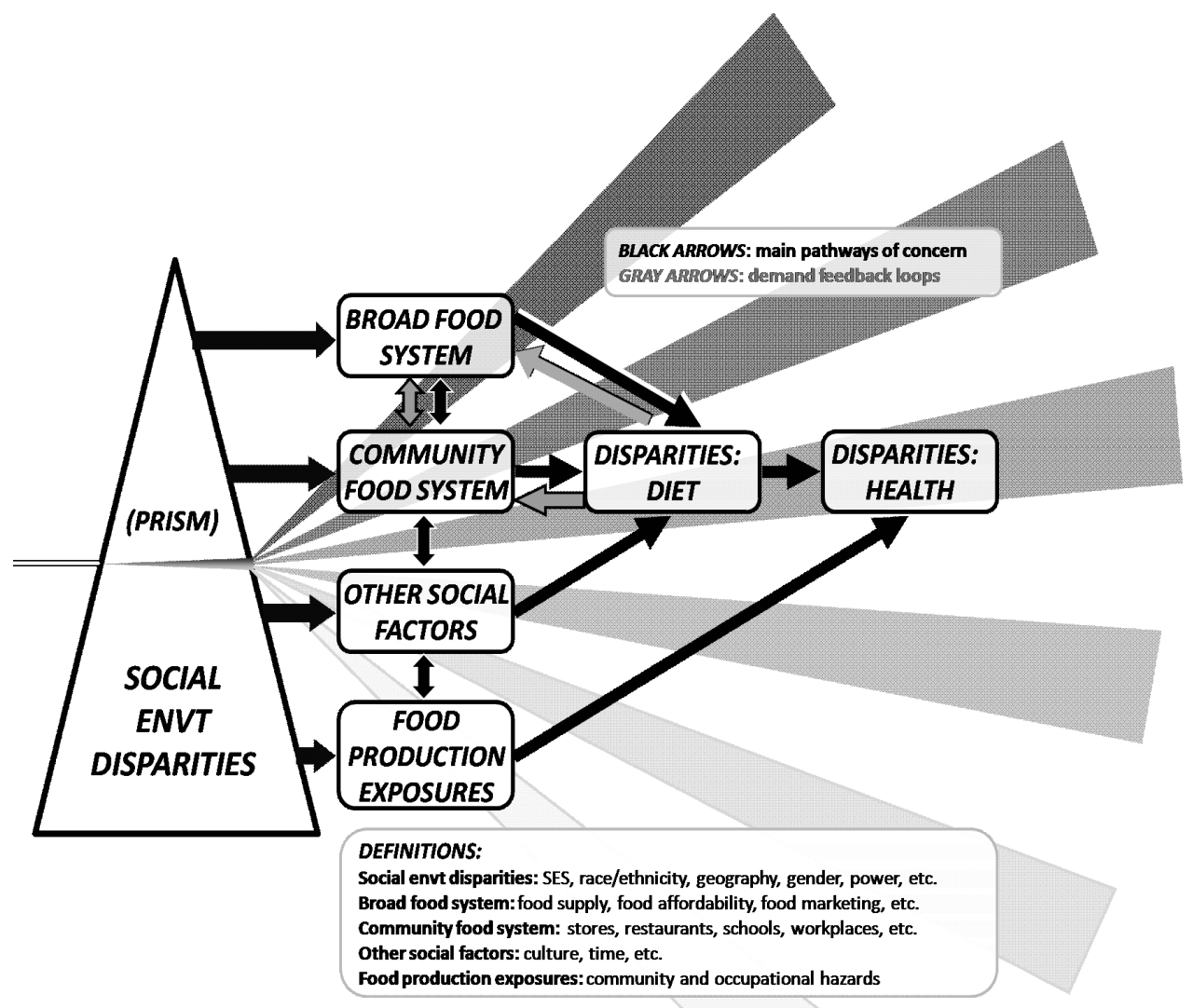

Figure 2.3: Concept model: food systems and health disparities from Neff RA,

Palmer AM, McKenzie SE, Lawrence RS. Food Systems and Public Health

Disparities. Journal of Hunger and Environmental Nutrition 2009;4(3-4):282-

314. Reprinted with permission from Taylor \& Francis

(http://www.tandfonline.com).

Similar to the Foresight model, this model describes broad food system conditions,

which include food production, affordability, and marketing. These attributes are driven by 
food policy, access to sustainably produced food, and national and global macroeconomic factors. This broad system interacts (e.g. supply/demand) with the community food system, which includes food stores, the food environment within schools and workplaces, and local policies that can impact food availability, accessibility, and utilization (80). The community food system reciprocally interacts with other social factors such as culture and time, to affect the extent to which individuals will eat a healthy, sustainable diet (80). The use of a prism illustrates how disparities in social conditions such as SES, race, power, geography, gender, may 'refract,' affecting all levels of the model, which in turn lead to diet and health disparities (80).

Although this conceptual model is much simpler to understand than the Foresight model, it also lacks a description of how social capital, especially at the community level, may promote or protect against food insecurity and health disparities. It is also based primarily on the US context; thus some aspects may not be relevant in other contexts (e.g. discussions of the Special Supplemental Nutrition Program for Women, Infants, and Children, and the food stamp program). Finally, there is no incorporation of a lifecourse perspective.

\subsubsection{Rationale for including a place-based lens}

The review and conceptual model developed by Neff et al (2009) and the fact that food insecurity varies geographically, within (39) and between high income countries (81), show that individual or family factors do not provide the whole picture of food insecurity development. Similar to combating childhood obesity, addressing characteristics within the community food system may serve as a leverage point for intervening in food insecurity. That is, increasing the availability and accessibility of healthy food at the local level may provide a way to bridge the gap between macro socio-political factors and individual income 
level. As such, there have been recent calls by researchers in the field to improve our understanding of potential environmental influences on food insecurity $(5 ; 82)$. A critical examination of the existing literature on how place characteristics relate to food insecurity is presented in Chapter 3.

\subsection{Place}

\subsubsection{Theory and definition of place}

Local residential environments in relation to child excess weight and family food insecurity may be highly relevant for young families with children, due in large part to childrearing duties. Women spend more time on these duties than do men, and on average, they spend almost 68 hours per week caring for young children (0-4 years) in the household (83). That is at least 10 hours per day spent within the local area. As children get older (514 years), time decreases to about 38 hours per week (5.5 hours per day) (83). This highlights how young families are tied to their local residential environments.

Following the social-ecological perspective, and as the discussion on hypothesized causal factors for both childhood obesity and food insecurity highlighted, factors operating at broader societal levels could be significant drivers of both conditions. It is assumed here that local environments provide one of many social-ecological leverage points for research and intervention. Therefore, in addition to the local environment's relevance to young families, it also may be an important area of research focus, as the effects of broader causal factors are likely to be translated by more micro or local-level circumstances (3), such as those described in the following section. 
Considering place to represent the local environment relative to one's place of residence is meant to be broad, in order to capture the range of area boundaries examined in this thesis -boundaries cover the mother's 'perceived' neighbourhood, the Canadian Census enumeration area (equivalent to one or more city blocks), and large areas defined at the municipality level. These place variables are discussed more generally, in line with the proposed theory outlined below. A more detailed discussion of how they were defined and analyzed in this thesis is presented in Chapter 4.

A theoretical understanding of how the local environment might influence child excess weight and family food insecurity follows from the conceptual description of neighbourhood and health inequities provided by Bernard et al (2007) (84). Even though the focus is on neighbourhood, a geographically defined entity, the theory is relevant for explaining potential relationships at perceived and broader geographical levels.

What links childhood obesity and food insecurity is their dependence on food and energy intake. Obesity has an energy expenditure component that must also be taken into account when discussing risk factors. As such, certain aspects of the environment may also influence PA or sedentary behaviour - these are also discussed in this section to give the reader an overall picture of how obesity is hypothesized to develop using a place-based lens.

Bernard et al (2007) see neighbourhoods as opportunity structures that involve the availability of, and access to health-relevant resources in a geographically defined area (Figure 2.4) (84). Availability and access to health-relevant resources, such as healthy food and opportunities for PA, are seen to be regulated by four sets of interacting rules (proximity, prices, rights, and informal reciprocity) that govern five specific domains 
(physical, economic, community organizations, local sociability, and institutional) of the physical and social environments of neighbourhoods. The decisions of residents arise from the interplay between these opportunity structures and compositional factors such as individual income and lifestyle preferences, as well as through social interactions between neighbourhood users (residents) and producers (other influencers) (84), which is in line with social-ecological theories of health.

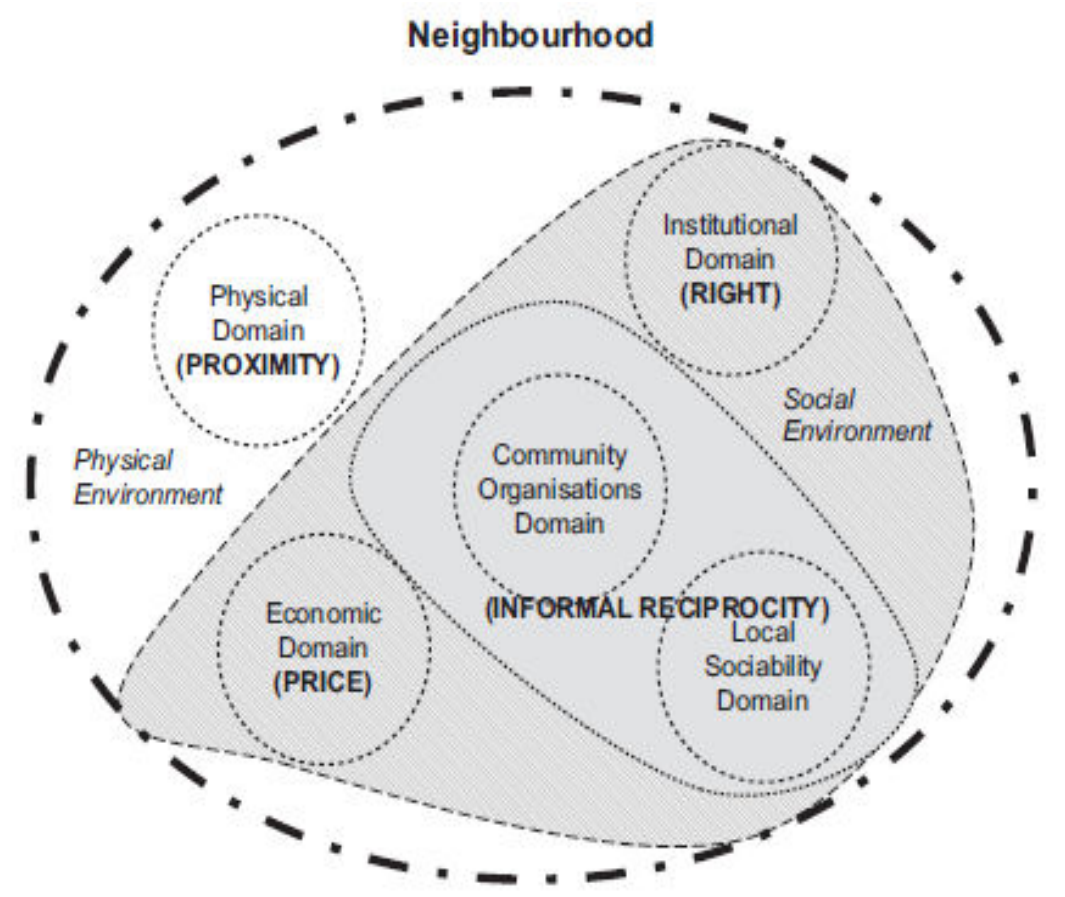

Figure 2.4: Neighbourhood environments and rules of access. Note: Four sets of rules (indicated in bold capital letters) determine access to neighbourhood resources coming from the physical environment as well as from the social environment. The neighbourhood social environment (indicated by the [textured] shade of grey) comprises four domains. Two of these domains (indicated by the [smooth] shade of grey) both obey the rule of informal reciprocity. All these environments and domains are in mutual interaction [Reprinted from Social Science \& Medicine 65(9):1839-52 Bernard P, Charafeddine R, Frohlich KL, Daniel M, Kestens Y, Potvin L. Health inequalities and place: a theoretical conception of neighbourhood (C2007 with permission from Elsevier]

\subsubsection{The physical environment}

The physical domain or 'physical environment' includes natural and man-made components that can affect excess weight development and food insecurity through three 
main pathways. These pathways include: 1) environmental and social stressors on the quality of natural and built components such as neighbourhood disorder (i.e. graffiti, vandalism, and abandoned buildings); 2) health behaviours arising from available options for PA and healthy eating; and 3) opportunities to become socially integrated such as having places for social interaction, interesting places to walk to, and feeling safe (84). These pathways are in turn governed by proximity - children and families living in the same areas are exposed to the same positive or negative resources.

In this thesis, living location is considered to be an aspect of the physical environment. How developed an area is with respect to urban/rural status may have ramifications for both child excess weight and food insecurity. Fewer services and resources are available in rural areas $(85 ; 86)$, and the quality of foods may vary depending on the location of stores $(87)$. Growth in supermarket size and food system innovations have enabled prices to decrease and quality to increase (88). Because large tracts of land are needed, these stores are increasingly relocating from urban to suburban areas (88). This may have consequences for those who are unable to afford personal transportation. Additionally, as distance from the city centre increases, time spent in the car increases (89), which increases sedentary time, and may have implications for child excess weight.

Disorder, another variable examined in this thesis, also captures aspects of the physical environment. Areas of increasing social disorganization, characterized by increasing disorder, may promote stress, discourage healthy behaviours among residents, such as being physically active outside, and itself may negatively impact the social environment (for example, dissuade businesses and services from operating in the area) (90). It could be considered a measure of overall neighbourhood quality. 


\subsubsection{The social environment}

Proximity is largely shaped by social forces (the "social environment") operating at or above the neighbourhood level. These include economic forces, institutional arrangements and relations of informal reciprocity, which are the other important components in the neighbourhood framework (84).

Over and above its influence on proximity, economic forces determine whether resources will be available in the neighbourhood or not, at what cost, and to whom those resources will be accessible, depending to a large extent on SES of residents (84). On the other hand, it may not be a question of availability/access, but quality; instead, disadvantaged people may be more likely to be exposed to poorer quality amenities and infrastructure (91), which therefore could negatively impact both child weight status and food security. In this thesis, economic forces are captured through the variable material deprivation.

In the institutional domain, institutions (either government or government-funded) are seen to provide public services to citizens - each citizen has a right to receive these services (84). In an equal society, these services are distributed evenly and fairly, and are therefore accessible to all, to the same degree. However, through contextual and compositional interactions giving rise to power imbalances, this is generally not the case (84). For example, a study of Toronto, Ontario neighbourhoods determined that low-income, high immigration areas were underserved by public transit services, with a lower density of stops (92). This may limit residents, depending on other compositional and contextual factors, in their near-by options to buy foods (proximity), which may give rise to the development of excess weight in children if convenience stores are relied upon, or food insecurity if food 
cannot be accessed at all. In Québec, wide-spread government and non-governmental support for community housing and alternative food distribution systems (e.g. food banks, community supported agriculture and community kitchens) (93) may be one reason why it has one of the lowest rates of food insecurity in Canada (39).

Finally, informal reciprocity (gift giving with the expectation of receiving) gives rise to two domains: community organizations and local sociability (84). These are considered to be two types of social networks - the former to pursue collective goals that can change the other neighbourhood domains (physical, economic and institutional), and the latter to fulfill the individual need for material and non-material support. Informal reciprocity is similar to the concept of social capital - the social connectedness, mutual trust and cooperation among members of a particular group (94). This thesis was able to measure two different aspects of social capital. Social cohesion is a group-level attribute that refers to the resources - such as trust, norms, and the exercise of sanctions - available to the members of social groups (95). Broadly speaking, posited ways that high social cohesion may prevent childhood excess weight and food insecurity include increased ability to link with health relevant resources, ability to borrow from neighbours in time of need, collective action to bring needed resources into the community, and the existence of social norms that enforce healthy behaviours, and prevent deviant behaviors that may lead to degradation or disorder of the physical (e.g., garbage, graffiti) and social environments (e.g. fear, crime, bad reputation). The second measure, social deprivation is similar to the network aspect of social capital, and also relates to the concepts of social fragmentation, and social isolation (96). Areas with high social deprivation (fewer social ties, less dense network) may decrease resident's access 
to material and non-material resources conducive to healthy living, increase stress, and decrease well-being, all of which may contribute to child excess weight and food insecurity.

\subsection{Conclusion}

Child excess weight and family food insecurity are two different but food system-related public health problems. Understanding potential influences of the local environment could lead to the development of more effective, equitable, and sustainable interventions at the population-level.

Critical research syntheses are necessary to develop a comprehensive understanding of what has been published in both fields, and to make recommendations for future research. These syntheses are presented in Chapter 3. Primary studies, based on theory, a populationbased cohort of young children with family and local environmental contextual data, and longitudinal regression methods could contribute to the knowledge base in both fields.

Primary studies addressing these issues can be found in Chapter 5.

\subsection{Reference List}

(1) Kindig D, Stoddart G. What is population health? Am J Public Health 2003; 93(3):380-3.

(2) Public Health Agency of Canada. The Population Health Template: Key Elements and Actions That Define A Population Health Approach. PHAC 2001 [cited 2012 May 15]; Available from: URL: http://www.phac-aspc.gc.ca/ph-sp/pdf/discussion-eng.pdf

(3) Irwin LG, Siddiqi A, Hertzman C. The Equalizing Power of Early Child Development: From the Commission on Social Determinants of Health to Action. Child Health \& Education 2010; 1(3):146-61.

(4) Finegood DT, Merth TD, Rutter H. Implications of the foresight obesity system map for solutions to childhood obesity. Obesity 2010; 18 Suppl 1:S13-S16.

(5) Troy LM, Miller EA, Olson S. Hunger and Obesity: Understanding a Food Insecurity Paradigm: Workshop Summary. Institute of Medicine 2011 [cited 2012 Dec 4]; Available from URL: http://www.iom.edu/Reports/2011/Hunger-and-Obesity-Understanding-aFood-Insecurity-Paradigm.aspx 
(6) Gidding SS, Leibel RL, Daniels S, Rosenbaum M, Van HL, Marx GR. Understanding obesity in youth. A statement for healthcare professionals from the Committee on Atherosclerosis and Hypertension in the Young of the Council on Cardiovascular Disease in the Young and the Nutrition Committee, American Heart Association. Writing Group. Circulation 1996; 94(12):3383-7.

(7) Barlow SE, Dietz WH. Obesity evaluation and treatment: Expert Committee recommendations. The Maternal and Child Health Bureau, Health Resources and Services Administration and the Department of Health and Human Services. Pediatrics 1998; 102(3):E29.

(8) Tremblay MS, Katzmarzyk PT, Willms JD. Temporal trends in overweight and obesity in Canada, 1981-1996. Int J Obes Relat Metab Disord 2002; 26(4):538-43.

(9) Shields M. Overweight and obesity among children and youth. Health Rep 2006; 17(3):2742 .

(10) Wang Y, Lobstein T. Worldwide trends in childhood overweight and obesity. Int J Pediatr Obes 2006; 1(1):11-25.

(11) Ball GDC, McCargar LJ. Childhood obesity in Canada: a review of prevalence estimates and risk factors for cardiovascular diseases and type 2 diabetes. Can J Appl Physiol 2003; 28:117-40.

(12) Reilly JJ, Methven E, McDowell ZC, Hacking B, Alexander D, Stewart L, et al. Health consequences of obesity. Arch Dis Child 2003; 88:748-52.

(13) Daniels SR. Complications of obesity in children and adolescents. Int J Obes 2009; 33(Suppl 1):S60-S65.

(14) Pinhas-Hamiel O, Zeitler P. The global spread of type 2 diabetes mellitus in children and adolescents. J Pediatr 2005; 146(5):693-700.

(15) Mustillo S, Worthman C, Erkanli A, Keeler G, Angold A, Costello EJ. Obesity and psychiatric disorder: developmental trajectories. Pediatrics 2003; 111(4 Pt 1):851-9.

(16) Friedlander SL, Larkin EK, Rosen CL, Palermo TM, Redline S. Decreased quality of life associated with obesity in school-aged children. Arch Pediatr Adolesc Med 2003; 157:1206-11.

(17) Guo SS, Wu W, Chumlea WC, Roche AF. Predicting overweight and obesity in adulthood from body mass index in childhood and adolescence. Am J Clin Nutr 2002; 76:653-8.

(18) Singh AS, Mulder C, Twisk JW, van MW, Chinapaw MJ. Tracking of childhood overweight into adulthood: a systematic review of the literature. Obes Rev 2008; 9(5):47488.

(19) Reilly JJ, Kelly J. Long-term impact of overweight and obesity in childhood and adolescence on morbidity and premature mortality in adulthood: systematic review. Int $\mathbf{J}$ Obes 2011; 35(7):891-8. 
(20) Wang YC, McPherson K, Marsh T, Gortmaker SL, Brown M. Health and economic burden of the projected obesity trends in the USA and the UK. Lancet 201; 378(9793):815-25.

(21) Kuhle S, Kirk S, Ohinmaa A, Yasui Y, Allen AC, Veugelers PJ. Use and cost of health services among overweight and obese Canadian children. Int J Pediatr Obes 2011; 6(2):142-8.

(22) Dubois L, Ohm KK, Girard M, Tatone-Tokuda F, Perusse D, Hjelmborg J, et al. Genetic and environmental contributions to weight, height, and BMI from birth to 19 years of age: an international study of over 12,000 twin pairs. PLoS One 2012; 7(2):e30153.

(23) World Health Organization. Obesity: preventing and managing the global epidemic: report of a WHO consultation. Geneva: World Health Organization; 2000.

(24) Law C, Power C, Graham H, Merrick D. Obesity and health inequalities. Obes Rev 2007;8 Suppl 1:19-22.

(25) Newby PK. Are dietary intake and eating behaviors related to childhood obesity? A comprehensive review of the evidence. The Journal of Law, Medicine, \& Ethics 2007; 35(1):35-60.

(26) Wilks DC, Besson H, Lindroos AK, Ekelund U. Objectively measured physical activity and obesity prevention in children, adolescents and adults: a systematic review of prospective studies. Obes Rev 2011; 12(5):e119-e129.

(27) Monasta L, Batty GD, Cattaneo A, Lutje V, Ronfani L, van Lenthe FJ, et al. Early-life determinants of overweight and obesity: a review of systematic reviews. Obes Rev 2010;11(10):695-708.

(28) Barker DJ. The developmental origins of chronic adult disease. Acta Paediatr Suppl 2004; 93(446):26-33.

(29) Tatone-Tokuda F, Dubois L, Ramsay T, Girard M, Touchette E, Petit D, et al. Sex differences in the association between sleep duration, diet and body mass index: a birth cohort study. J Sleep Res 2012; 21(4):448-60.

(30) Dubois L, Girard M. Early determinants of overweight at 4.5 years in a population-based longitudinal study. Int J Obes 2006 ; 30(4):610-7.

(31) Butland B, Jebb S, Kopelman P, McPherson K, Thomas S, Mardell J, et al. Tackling Obesities: Future Choices - Project report. Foresight 2007 Available from URL: http://www.bis.gov.uk/assets/foresight/docs/obesity/17.pdf

(32) Swinburn BA, Sacks G, Hall KD, McPherson K, Finegood DT, Moodie ML, et al. The global obesity pandemic: shaped by global drivers and local environments. Lancet 2011; 378(9793):804-14.

(33) OECD. Health at a Glance 2011: OECD Indicators. OECD Publishing 2011 [cited 2012 May 5]; Available from URL: http://www.oecd-ilibrary.org/social-issues-migrationhealth/health-at-a-glance-2011_health_glance-2011-en 
(34) Olds T, Maher C, Zumin S, Peneau S, Lioret S, Castetbon K, et al. Evidence that the prevalence of childhood overweight is plateauing: data from nine countries. Int J Pediatr Obes 2011; 6: 342-60

(35) Kumanyika SK. Environmental influences on childhood obesity: ethnic and cultural influences in context. Physiol Behav 2008; 94(1):61-70.

(36) UN. The Universal Declaration of Human Rights. United Nations 2012 [cited 2012 May 4]; Available from URL: http://www.un.org/en/documents/udhr/

(37) Dewbre J. Food security. OECD Observer 2010 March [cited 2012 May 4]; Available from URL: http://www.oecdobserver.org/news/fullstory.php/aid/3212/Food security.html

(38) Government of Canada. Canada's Action Plan for Food Security: In response to the World Food Summit Plan of Action. Government of Canada 1998 [cited 2011 Jan 10]; Available from URL: http://www.agr.gc.ca/misb/fsec-seca/pdf/action_e.pdf

(39) Health Canada. Household Food Insecurity In Canada in 2007-2008: Key Statistics and Graphics. Health Canada 2011 [cited 2011 Oct 12]; Available from URL: http://www.hcsc.gc.ca/fn-an/surveill/nutrition/commun/insecurit/key-stats-cles-2007-2008-eng.php

(40) Coleman-Jensen A, Nord M, Andrews M, Carlson S. Household Food Security in the United States in 2010. USDA, Economic Research Service 2011 [cited 2012 Feb 2]; Available from URL: http://www.ers.usda.gov/Publications/ERR125/ERR125.pdf

(41) Foley W, Ward P, Carter P, Coveney J, Tsourtos G, Taylor A. An ecological analysis of factors associated with food insecurity in South Australia, 2002-7. Public Health Nutr 2010; 13(2):215-21.

(42) Pilgrim A, Barker M, Jackson A, Ntani G, Crozier S, Inskip H, et al. Does living in a food insecure household impact on the diets and body composition of young children? Findings from the Southampton Women's Survey. J Epidemiology \& Community Health 2011 June 7 Early Online.

(43) Kirkpatrick SI, Tarasuk V. Food insecurity in Canada: considerations for monitoring. Can J Public Health 2008;99(4):324-7.

(44) Health Canada. Food and Nutrition: Determining Food Security Status. Government of Canada 2010 [cited 2012 Feb 2]; Available from URL: http://www.hc-sc.gc.ca/fnan/surveill/nutrition/commun/insecurit/status-situation-eng.php

(45) Hamm MW, Bellows AC. Community food security and nutrition educators. Journal of Nutrition Education \& Behavior 2003; 35(1):37-43.

(46) Andersen SA (Ed). Life Sciences Research Office Report: Core Indicators of Nutritional State for Difficult-to-Sample Populations. J Nutr 1990;120 (11 Suppl):1555-600.

(47) Barrett CB. Measuring food insecurity. Science 2010; 327(5967):825-8. 
(48) Tarasuk V. Discussion Paper on Household and Individual Food Insecurity. Health Canada 2001 [cited 2012 May 3]; Available from URL: http://www.hc-sc.gc.ca/fnan/alt_formats/hpfb-dgpsa/pdf/nutrition/food_sec_entire-sec_aliments_entier-eng.pdf

(49) Radimer KL, Olson CM, Campbell CC. Development of indicators to assess hunger. J Nutr 1990; 120(Suppl 11):1544-8.

(50) Hamelin AM, Beaudry M, Habicht JP. Characterization of household food insecurity in Quebec: food and feelings. Soc Sci Med 2002; 54(1):119-32.

(51) McIntyre L, Connor SK, Warren J. Child hunger in Canada: results of the 1994 National Longitudinal Survey of Children and Youth. CMAJ 2000;163(8):961-5.

(52) McIntyre L, Glanville NT, Raine KD, Dayle JB, Anderson B, Battaglia N. Do low-income lone mothers compromise their nutrition to feed their children? CMAJ 2003 18;168(6):686-91.

(53) Che J, Chen J. Food security in Canadian households. Health Rep 2001;12(4):11-22.

(54) Slopen N, Fitzmaurice G, Williams DR, Gilman SE. Poverty, food insecurity, and the behavior for childhood internalizing and externalizing disorders. J Am Acad Child Adolesc Psychiatry 2010; 49(5):444-52.

(55) Alaimo K, Olson CM, Frongillo EA. Family food insufficiency, but not low family income, is positively associated with dysthymia and suicide symptoms in adolescents. $\mathrm{J}$ Nutr 2002; 132(4):719-25.

(56) Jyoti DF, Frongillo EA, Jones SJ. Food insecurity affects school children's academic performance, weight gain, and social skills. J Nutr 2005;135(12):2831-9.

(57) Alaimo K, Olson CM, Frongillo EA, Jr. Food insufficiency and American school-aged children's cognitive, academic, and psychosocial development. Pediatrics 2001; 108(1):4453.

(58) Casey PH, Szeto KL, Robbins JM, Stuff JE, Connell C, Gossett JM, et al. Child healthrelated quality of life and household food security. Arch Pediatr Adolesc Med 2005; 159(1):51-6.

(59) Heflin CM, Siefert K, Williams DR. Food insufficiency and women's mental health: findings from a 3-year panel of welfare recipients. Soc Sci Med 2005; 61(9):1971-82.

(60) Zaslow M, Bronte-Tinkew J, Capps R, Horowitz A, Moore KA, Weinstein D. Food security during infancy: implications for attachment and mental proficiency in toddlerhood. Maternal \& Child Health Journal 2009;13(1):66-80.

(61) Kirkpatrick SI, Tarasuk V. Food insecurity is associated with nutrient inadequacies among Canadian adults and adolescents. J Nutr 2008;138(3):604-12.

(62) Skalicky A, Meyers AF, Adams WG, Yang Z, Cook JT, Frank DA. Child food insecurity and iron deficiency anemia in low-income infants and toddlers in the United States. Maternal \& Child Health Journal 2006; 10(2):177-85. 
(63) Eicher-Miller HA, Mason AC, Weaver CM, McCabe GP, Boushey CJ. Food insecurity is associated with iron deficiency anemia in US adolescents. Am J Clin Nutr 2009; 90(5):1358-71.

(64) Radimer KL, Allsopp R, Harvey PW, Firman DW, Watson EK. Food insufficiency in Queensland. Aust NZ J Public Health 1997; 21(3):303-10.

(65) Seligman HK, Schillinger D. Hunger and socioeconomic disparities in chronic disease. NEJM 2010; 363(1): 6-9.

(66) Olson CM, Bove CF, Miller EO. Growing up poor: long-term implications for eating patterns and body weight. Appetite 2007; 49(1):198-207.

(67) Larson NI, Story MT. Food insecurity and weight status among U.S. children and families: a review of the literature. Am J Prev Med 2011; 40(2):166-73.

(68) Eisenmann JC, Gundersen C, Lohman BJ, Garasky S, Stewart SD. Is food insecurity related to overweight and obesity in children and adolescents? A summary of studies, 1995-2009. Obes Rev 2011; 12(5):e73-e83.

(69) Seligman HK, Laraia BA, Kushel MB. Food insecurity is associated with chronic disease among low-income NHANES participants. J Nutr 2010; 140(2):304-10.

(70) Stuff JE, Casey PH, Connell CL, Champagne CM, Gossett JM, Harsha D, et al. Household food insecurity and obesity, chronic disease, and chronic disease risk factors. Journal of Hunger and Environmental Nutrition 2007 2007;1(2): 43-62

(71) Kirkpatrick SI, McIntyre L, Potestio ML. Child hunger and long-term adverse consequences for health. Arch Pediatr Adolesc Med 2010; 164(8):754-62.

(72) Laraia BA, Siega-Riz AM, Gundersen C. Household food insecurity is associated with self-reported pregravid weight status, gestational weight gain, and pregnancy complications. J Am Diet Assoc 2010; 110(5):692-701.

(73) Kushel MB, Gupta R, Gee L, Haas JS. Housing instability and food insecurity as barriers to health care among low-income Americans. J Gen Intern Med 2006; 21(1):71-7.

(74) Nord M, Parker L. How adequately are food needs of children in low-income households being met? Children and Youth Services Review 2010; (9):1175-85.

(75) Rose D. Economic determinants and dietary consequences of food insecurity in the United States. J Nutr 1999; 129(2 Suppl):517S-20S.

(76) Gorton D, Bullen CR, Mhurchu CN. Environmental influences on food security in highincome countries. Nutr Rev 2010; 68(1):1-29.

(77) Armour BS, Pitts MM, Lee CW. Cigarette smoking and food insecurity among lowincome families in the United States, 2001. Am J Health Promot 2008; 22(6):386-92. 
(78) Cutler-Triggs C, Fryer GE, Miyoshi TJ, Weitzman M. Increased rates and severity of child and adult food insecurity in households with adult smokers. Arch Ped Adolesc Med 2008;162(11):1056-62.

(79) Nolan M, Williams M, Rikard-Bell G, Mohsin M. Food insecurity in three socially disadvantaged localities in Sydney, Australia. Health Promotion Journal of Australia 2006; $17(3): 247-54$.

(80) Neff RA, Palmer AM, McKenzie SE, Lawrence RS. Food Systems and Public Health Disparities. Journal of Hunger and Environmental Nutrition 2009; 4(3-4):282-314.

(81) Nord M, Hooper MD, Hopwood H. Household-level income-related food insecurity is less prevalent in Canada than in the United States. Journal of Hunger and Environmental Nutrition 2008; 3(1):17-35.

(82) Gundersen C, Kreider B, Pepper J. The Economics of Food Insecurity in the United States. Applied Economic Perspectives and Policy 2011; 33(3):281-303.

(83) Milan A, Keown L-A, Urquijo CR. Families, Living Arrangements and Unpaid Work. Statistics Canada 2012 February 24 [cited 2012 Jun 8]; Available from URL: http://www.statcan.gc.ca/pub/89-503-x/2010001/article/11546-eng.htm\#a12

(84) Bernard P, Charafeddine R, Frohlich KL, Daniel M, Kestens Y, Potvin L. Health inequalities and place: a theoretical conception of neighbourhood. Soc Sci Med 2007; 65(9):1839-52.

(85) Drouin S, Hamelin AM, Ouellet D. Economic access to fruits and vegetables in the greater Quebec City: do disparities exist? Can J Public Health 2009;100(5):361-4.

(86) Pearce J, Witten K, Hiscock R, Blakely T. Regional and urban-rural variations in the association of neighbourhood deprivation with community resource access: a national study. Environment and Planning A 2008; 40(10):2469-89.

(87) Cummins S, Smith DM, Taylor M, Dawson J, Marshall D, Sparks L, et al. Variations in fresh fruit and vegetable quality by store type, urban-rural setting and neighbourhood deprivation in Scotland. Pub health nutr 2009; 12(11):2044-50.

(88) USDA. Access to Affordable and Nutritious Food: Measuring and Understanding Food Deserts and Their Consequences. United States Department of Agriculture 2009 June [cited 12 A.D. Feb 29]; Available from URL: http://www.ers.usda.gov/publications/ap/ap036/ap036.pdf

(89) Turcotte M. Dependence on cars in urban neighbourhoods: Life in metropolitan areas. Statistics Canada 2008 [cited 2012 Apr 4]; Available from URL: http://www.statcan.gc.ca/pub/11-008-x/2008001/article/10503-eng.htm\#7

(90) Macintyre S, Ellaway A, Cummins S. Place effects on health: How can we conceptualise, operationalise and measure them? Soc Sci Med 2002; 55(1):125-39. 
(91) Macintyre S. Deprivation amplification revisited; or, is it always true that poorer places have poorer access to resources for healthy diets and physical activity? Int J Behav Nutr Phys Act 2007; 4:32.

(92) Glazier R, Booth G. Neighbourhood environments and resources for healthy living - A focus on diabetes in Toronto. Toronto, ON: Institute for Clinical Evaluative Sciences; 2007.

(93) Rouffignat J, Dubois L, Panet-Raymond J, Lamontagne P, Cameron S, Girard M. De la Sécurité Alimentaire au Développement Social: Les effets des pratiques alternatives dans les régions du Québec 1999-2000. Québec: Département de géographie, Université Laval; 2001.

(94) Kawachi I, Kim D, Coutts A, Subramanian SV. Commentary: Reconciling the three accounts of social capital. Int J Epidemiol 2004; 33(4):682-90.

(95) Social Capital \& Health. Kawachi I., Subramanian SV., Kim D., editors. New York: Springer; 2008.

(96) Pampalon R, Hamel D, Gamache P, Raymond G. A deprivation index for health planning in Canada. Chronic Dis Can 2009; 29(4):178-91. 


\section{Chapter 3 - Literature Review}

Two critical appraisals were conducted as part of this thesis, to synthesize the literature examining the relationship between local environments and child weight status and food insecurity. Section 3.1 presents the critical appraisal of studies assessing potential links between broad neighbourhood characteristics and child excess weight, which was published in the journal Health \& Place. This is followed by an update in 3.2, as the original article was published in May, 2010. The update has not been published in a peer-reviewed journal. It considers larger geographical areas as compared to the original review, which was focused specifically on neighbourhoods, but narrows down the explanatory place variables of interest to those that are examined in this thesis, namely: material and social deprivation, social cohesion, disorder, and living location. Section 3.3 presents the critical appraisal of studies assessing potential links between broad local environmental factors and food insecurity. A revised version of this manuscript is currently under review at the journal, Public Health Nutrition. 


\subsection{Neighbourhoods \& child adiposity: a critical appraisal of the}

\section{literature - Manuscript 1}

Authors: Megan Ann Carter $^{1} \&$ Lise Dubois $^{2}$

${ }^{1}$ Population Health Program, Institute of Population Health, University of Ottawa

${ }^{2}$ Department of Epidemiology and Community Medicine, University of Ottawa

This manuscript was written and published in accordance to the specifications for submission to the peer-reviewed journal Health \& Place. It has been published as an open access article and it appears here in its online published format.

Suggested citation:

Carter MA, Dubois L. Neighbourhoods \& child adiposity: a critical appraisal of the literature. Health Place. 2010; 16(3): 616-628 


\title{
Neighbourhoods and child adiposity: A critical appraisal of the literature
} Open Access Article

\author{
Megan Ann Carter \\ Lise Duboisa, b \\ a Population Health Program, Institute of Population Health, University of Ottawa, \\ b Department of Epidemiology and Community Medicine, University of Ottawa, \\ http://dx.doi.org/10.1016/j.healthplace.2009.12.012, How to Cite or Link Using DOI \\ Permissions \& Reprints
}

\section{Abstract}

This paper critically appraised the published literature to determine the relationship between physical and social environmental features of neighbourhoods with child adiposity. MEDLINE, EMBASE, PsychINFO, and SCOPUS were searched from 1999 to July 2009 using a systematic search strategy. Twenty-seven primary studies were included based on a priori eligibility criteria. Socioeconomic disadvantage was consistently shown to increase child adiposity, while there was some evidence that high social capital protected against increased adiposity. It is unclear at this time if and how other neighbourhood environmental features play a role. Heterogeneity and methodological issues across studies limits our ability to draw overall conclusions.

Keywords: Children; Adiposity; Obesity; Neighbourhood; Social environment; Physical environment

\section{Introduction}

Canada and the United States have seen a dramatic rise in the prevalence of childhood obesity in the last three decades (Ogden et al., 2006; Shields, 2006; Tremblay et al., 2002; Wang and Beydoun, 2007). In 2004, 26\% of Canadian children aged 2-17 years were overweight or obese, and 8\% were obese (Shields, 2006). From 1978-1979 to 2004, the prevalence of overweight including obesity increased almost two-fold among 6-11- and 12-17-year-olds. Overweight and obesity rates remained relatively stable, however, among younger ages (2-5 years) (Shields, 2006). The problem appears to be more pronounced in the US where almost 34\% of children aged 2-19 in 2003-2004 were overweight or obese, and 17\% were obese (Ogden et al., 2006). Similar to Canada, obesity rates have more than tripled in the time period from 1976-1980 to 2003-2004 among 6-11 and 12-19-year-old American children, with a less dramatic increase among 2-5-year-olds (Wang and Beydoun, 2007).

Due to its comparatively swift onset, the rise of childhood obesity cannot solely be explained by genetic predisposition (Law et al., 2007; World Health Organization, 2000). Instead, it is thought that societal changes to more sedentary living and over consumption of high-fat, energy-dense diets may be potential underlying mechanisms, or the 'causes of the causes' of the obesity 'epidemic' (World Health Organization, 2000). In terms of obesity development, there has traditionally been a focus on individual behaviours while neglecting environmental influences (Law et al., 2007). Humans do not live in isolation. We live and interact with diverse elements of our surrounding environments. It is therefore likely that many different aspects of our 
respective socioeconomic and physical environments influence our health. This thus warrants researchers to consider place (contextual) factors and their interactions in addition to individual (compositional) factors in their aetiological research of childhood obesity. This is especially important among children since they have comparatively less control over their external environments.

There are many debates as to how to define place. Cummins et al. (2007) contrasts the 'conventional' and 'relational' understanding of place, underlining the need to move away from the traditional geographical preoccupation with scale and distance. They contend that defining context based on a fixed geographical area does not always provide an accurate representation of an environmental exposure. For example, their idea of an 'action space' takes into account spatial mobility (i.e., different settings such as work, school, commuting, neighbourhood, home, day-care, etc.), as well as temporal mobility (i.e., changes across the lifecourse). Using the concept of action space may be ideal for certain populations, but not always possible, depending on the research design. A focus on neighbourhood as the encompassing environment of interest may most relevant for children as it is a physical community in which children are placed beyond their control, as well as a community of relationships, both of which can influence child development (Barnes et al., 2006). Additionally, the action space of children, especially younger children, is likely much smaller than those of adults due to their relative lack of independence.

The definition of neighbourhood is not applied consistently and is often used synonymously with community. Usually it is defined on a geographical scale where residents share proximity and circumstance (Bernard et al., 2007; Chaskin, 1997). The 'perceived' neighbourhood may be most relevant as residents tend to define their neighbourhood as being much smaller than actual administrative boundaries (Barnes et al., 2006). Contextual factors measured at a more global scale, such as provincial/state policies and legislation are certainly of importance, but their effects are likely to be translated by more micro or local-level circumstances. For example, national and provincial anti-smoking policies in Canada are enforced through the application of municipal bylaws. Local ecological factors such as sociodemographics, geographical region, and smoking rates play a role in bylaw composition and strength (Nykiforuk et al., 2007).

Potential physical environmental influences on the development and maintenance of obesity are those neighbourhood infrastructure elements which are 'man-made' or modified, as well as services that are provided publicly or privately (Macintyre et al., 2002). Aspects of the social environment, such as the political, economic, ethnic and religious history of a neighbourhood, norms and values in regards to physical activity (PA), food consumption and body shape, degree of neighbourhood integration and trust, levels of crime and threats to personal safety, and networks of neighbourhood support are also potential obesogenic factors. The social environment, or 'collective social functioning' as described by Macintyre et al. (2002), can also include how the neighbourhood is perceived by different actors ('the reputation of the area'). Different perceptions can influence investments in the infrastructure of the area, impact the health and well-being of area residents, and influence the types of people who decide to move into or move out of the neighbourhood. Additionally, it is worth noting that in different socioeconomic and historical situations and in different population groups, physical and social environmental factors are likely to differ in terms of their relative explanatory importance, as well as in how they operate together, and with other compositional factors (Macintyre et al., 2002).

In the last 10 years, given the popularity of obesity as a research topic, and improvements made in the area of statistical modeling and geographical information systems (GIS) mapping, there has been an increase in the number of researchers examining place effects on childhood obesity. The objective of this paper therefore, was to conduct a critical appraisal of the published literature within the last 10 years to determine how features of the physical and social environments of children's residential neighbourhoods contribute to their adiposity. Adiposity is taken to mean all levels of excess weight in children because definitions of overweight and obesity are inconsistent between studies (Shrewsbury and Wardle, 2008). 


\section{Methods}

\subsection{Eligibility criteria}

Research studies were considered for inclusion if they examined features of the physical and social neighbourhood environments, based on the broad definitions presented in the introduction, and related them to children's adiposity. Evaluating the effect of these environments on child adiposity had to be one of the primary objectives of the study. The exposure measure, or aspect of the environment, could either be objective, such as interviewer observed number of parks, or subjective, such as the parent's perception of safety. Any type of adiposity measure was considered, such as overweight, obesity, skinfold thickness, body mass index (BMI), percentage lean body mass etc. Studies that examined large areas such as counties, municipalities (i.e., census metropolitan areas, large zip/postal code areas), cities, 'regions,' and whole countries were excluded. As areas become larger, physical and social environmental exposures become more heterogeneous, making it harder to tease out specific place features that influence adiposity. Additionally, studies that used school location as a proxy for the child's neighbourhood of residence were included. Even though, this increases the likelihood of misclassification bias when children do not live in the same neighbourhood as their school, this assumption tends to be valid for public schools in places like Québec and in many US states where the taxation system makes it more likely that children go to the schools that are located in or close to their neighbourhood of residence (Gouvernement du Québec, 2008;Rooney et al., 2006).

'Children' were defined as being between the ages of 2 and 18 years. Thus, studies assessing those younger than 2 or older than 18 years of age were excluded. Studies that aggregated adolescents with adults (i.e., 16-24 years) were also excluded.

Only primary studies and systematic reviews/meta-analyses of primary studies published in peer-reviewed scientific journals were considered for inclusion. Studies could be experimental or observational as long as they had a comparison group or groups that were either not exposed or had varying levels of exposure. Non-randomized studies, however, had to control or stratify (and report their results) for at least sex and age in order to be included. For this reason, studies were excluded if the sample sizes analyzed were less than $n=100$, as small sample sizes and including more variables in multivariate models decreases overall study power. Articles not written in French or English, and those published prior to 1999 were excluded. Finally, studies had to have been conducted in a Western country. Those conducted in other countries were excluded because the primary interest was to determine significant factors in the neighbourhoods of the wealthiest and most developed countries of the 'Western culture.' The neighbourhood-adiposity relationship is not likely to be the same in poorer countries and in those having different cultural norms and political ideologies such as Japan.

\subsection{Search strategy and identification of studies}

Three electronic databases were searched using the Ovid Interface version OvidSP 10.2: MEDLINE (1996 to July 2009), EMBASE (1980 to July 2009), and PsycINFO (1806 to July2009). The search strategy was developed in MEDLINE and refined as appropriate in each of the other two databases to compensate for changes in indexing from database to database. Basic search terms included indexed (exploded where appropriate) and free text terms such as 'obesity', 'overweight', ' thinness', 'body weight', 'body mass index', 'body fat distribution', 'body size', 'waist circumference', 'waist-hip ratio', 'skinfold thickness', 'adiposity', 'fatness', 'residence characteristics', 'neighbourhood', 'environment', 'census tract', 'child', 'adolescent', ' teenager', 'youth', and 'student.' The full strategy is available upon request. A fourth database, SCOPUS, was also searched using a modified search strategy.

Citations from each database were saved as text files and then imported to Reference Manager 11.0 using the appropriate filter. Potential studies first underwent a duplicate search to narrow the pool of relevant studies. The first screen was conducted using titles and abstracts and the eligibility criteria discussed previously. Studies for which it was difficult to determine eligibility based on information in the title and abstract were included in the next round of screening. After the first screen, eligibility of the remaining studies was assessed using information provided in the full-text articles and the criteria 
discussed previously. Handsearching the reference lists of included studies was also conducted. Eligible systematic reviews/meta-analyses were included solely for this purpose (the articles themselves were not reviewed).

Data abstraction tables were organized by the type of neighbourhood exposure being examined (physical environment, social environment, and measures incorporating both). Some studies had multiple exposure measures, either of the same or different types. Thus, some studies appear more than once in the data abstraction tables.

\section{Results}

\subsection{Literature search}

A total of 3240 unique studies were identified from the literature based on the search strategy outlined above. Of these, only 25 primary studies and 1 systematic review met the eligibility criteria. One study was added based on handsearching the reference lists of the included primary studies, and one other was added based on handsearching the reference list of the systematic review (see Fig. 1). A total of 62 exposure-adiposity associations were examined.

\subsection{General overview of included studies}

Of the 27 primarystudies, the majority $(n=16)$ were conducted in the US. From the remaining 11 , six were conducted in Canada, two in Australia, two in the UK, and one in Germany. Twenty-two were cross-sectional (81\%), while four used the prospective cohort design and one used the retrospective cohort design. Thirteen studies examined young children between the ages of two and 11, eight examined older children between the ages of 12 and 18, and six studies examined a range of ages that spanned these two categories. Two of the 27 studies were conducted on girls only, with the remainder including both sexes. Sample sizes ranged from as few as 315 , to as many as 529,367 participants. Twelve studies were based on the same or very similar samples. Three pairs of studies (Evenson et al., 2007; Scott et al., 2007), (Veugelers et al., 2008; Veugelers and Fitzgerald, 2005), and (Crawford et al., 2008; Timperio et al., 2005), were based on the same sample, consisted of at least some of the same authors, but conducted different analyses. Two pairs of studies, (Lumeng et al., 2006; O'Brien et al., 2007) and (McKay et al., 2007; Singh et al., 2008), used the same sample, conducted different analyses, but were not collaborating authors. A final pair of studies (Bell et al., 2008; Liu et al., 2007) were collaborating authors, derived their samples from the same pool of children (some children may have been the same), but had different study designs.

Of the 22 cross-sectionalstudies, only eight modeled the neighbourhood environment-adiposity relationship at multiple levels of influence (i.e., accounting for correlations between children in the same neighbourhood) (Cohen et al., 2006; Evenson et al., 2007; Janssen et al., 2006; Koller and Mielck, 2009; Oliver and Hayes, 2005; Scott et al., 2007; Veugelers et al., 2008; Veugelers and Fitzgerald, 2005). Two studies chose not to use multi-level modeling or other methods because they had small cluster sample sizes (Grafova, 2008;Spence et al., 2008). Seven used other statistical means to control for clustering (Crawford et al., 2008;Davis and Carpenter, 2009; Franzini et al., 2009; McKay et al., 2007; Nelson et al., 2006; Singh et al., 2008; Timperio et al., 2005), while five did not appear to consider clustering at the neighbourhood or other area levels ( [Burdette and Whitaker, 2004] and [Burdette and Whitaker, 2005]; Chen and Paterson, 2006; Kinra et al., 2000; Liu et al., 2007).

Only one out of the five cohortstudies used multi-level modeling to model the neighbourhood environment-adiposity relationship longitudinally (Oliver and Hayes, 2008). Intra-neighbourhood correlations were not modeled in this study due to small sample sizes. One study attempted a group-based growth curve analysis called 'latent transition analysis,' but had to collapse categories due to small sample sizes (O'Brien et al., 2007). After derivation of the groups, they interestingly used multi-level modeling, not to account for clustering within neighbourhoods, but to model the home environment and proximal child experiences (child care, PA, neighbourhood safety) as contextual effects. Two of the five cohort studies used multi-level 
modeling or a population averaged approach (Lumeng et al., 2006; Wardle et al., 2006), and one adjusted the standard errors of the model parameters to account for correlations within neighbourhoods (Bell et al., 2008).

All 27 studies used BMI either as the outcome, or to derive one or more of the outcomes. Eight studies did not have BMI data based on directly measured heights and weights. Studies that exclusively examined social environmental exposures were most likely to be based on self- or parent-reported height and weight (6/8 or 75\%). Most studies used overweight, obesity or BMI as the outcome, although one study also considered waist circumference (Wardle et al., 2006).

Neighbourhood definitions varied widely from study to study. Administrative boundaries such as census tracts were used by seven out of the 27 studies (26\%). Seven studies relied on respondents' perceptions of their neighbourhood boundaries, while one conversely relied on the interviewer to observe the face-block of the child's residence. Six studies used a buffer (or radius) of a certain distance that was calculated from the child's address. Buffer sizes ranged from 1 to $5 \mathrm{~km}$. Three studies defined the neighbourhood based on the school catchment area or school district, and three studies used multiple definitions as they examined different types of exposures.

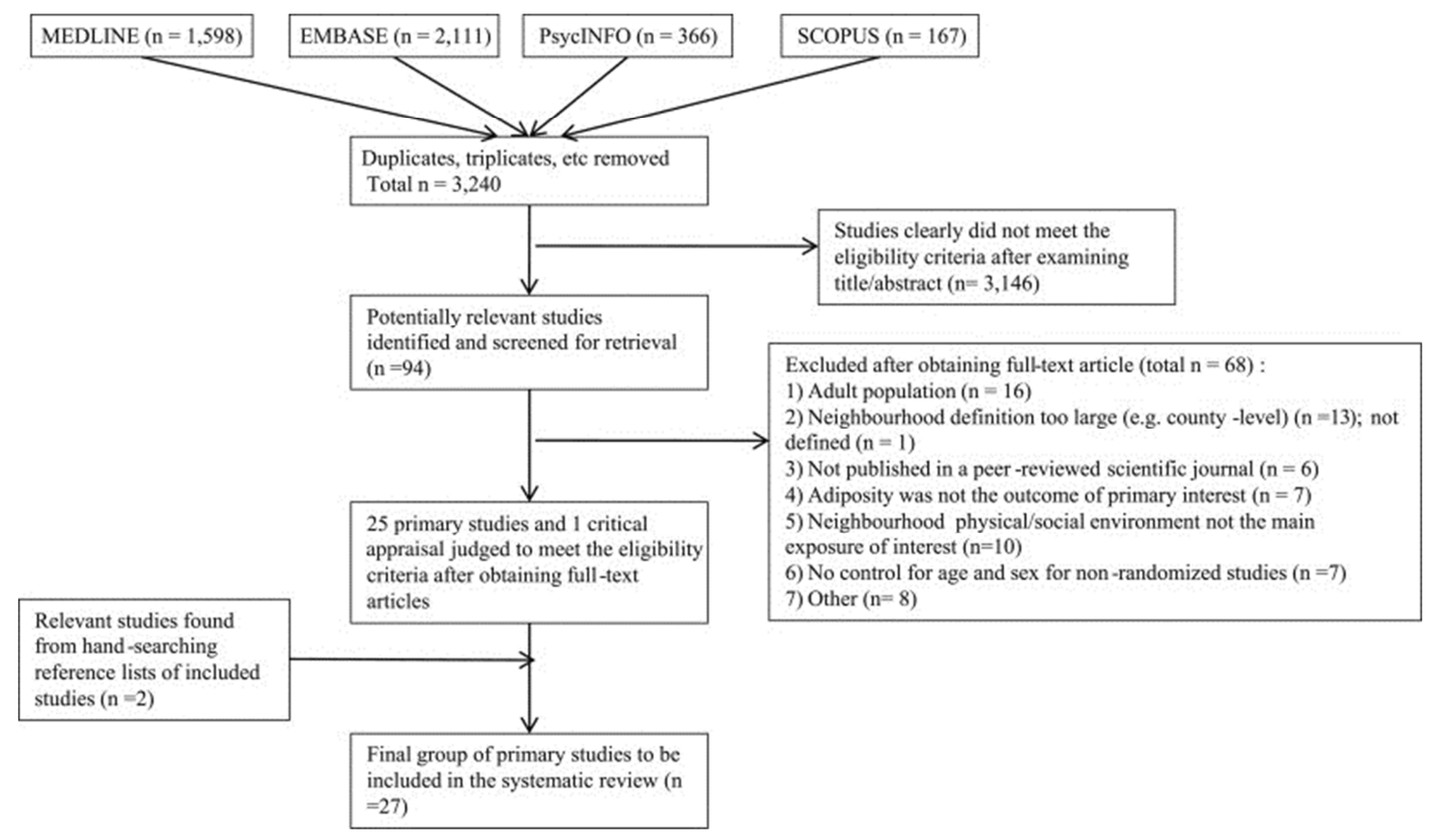

Fig. 1 Quorum flow diagram for study inclusion.

In terms of addressing duration of exposure, only $18.5 \%$ (5/27) of studies considered residential mobility in the design or analysis. For example, three studies restricted the sample to only those children living at the same address for a certain number of years (Bell et al., 2008; Crawford et al., 2008; Lumeng et al., 2006); one study conducted a sensitivity analysis comparing those who had recently moved to those who had not (Grafova, 2008); while the last incorporated changes in the level of exposure over time into the final model (O'Brien et al., 2007).

\subsection{Neighbourhood physical environment}

Eleven studies in this review examined at least one feature of the neighbourhood physical environment and its relation to child adiposity (Table 1). Thirty associations were analyzed across the 11 studies. Four studies investigated the relationship between the appearance of the neighbourhood and child adiposity. Two of these four examined the degree of neighbourhood 
greenness using the Normalized Difference Vegetation Index, a measurement based on satellite imagery of the amount of plant life in a particular area (Bell et al., 2008; Liu et al., 2007). Both found that as the NDVI increased (indicating more plant life in the neighbourhood), adiposity significantly decreased. Evenson et al. (2007) did not find that young girl's perceptions of their neighbourhood as aesthetically pleasing was significantly related to BMI, overweight or obesity. However, Grafova (2008) determined that children living in neighbourhoods with physical disorder observed by the interviewer, such as garbage, broken glass, drug-related paraphernalia, condoms, beer containers, etc. on the streets and sidewalks, were more likely to be obese than children living in neighbourhoods without this observed disorder.

Four studies examined accessibility of PA facilities, such as parks and playgrounds (Burdette and Whitaker, 2004; Evenson et al., 2007; Scott et al., 2007; Veugelers et al., 2008), with mixed results. One study did not find that distance to the nearest playground was related to obesity (Burdette and Whitaker, 2004). Another that examined girls' perceptions of their neighbourhood, found that those who reported a high number of PA facilities within walking distance of their home (highest quartile) were less likely to be overweight than those reporting few or no facilities (lowest quartile) (Evenson et al., 2007). There was no significant association with obesity. For BMI, only the middle two quartiles of PA facility accessibility were significantly different from the lowest quartile. Scott et al. (2007) did not find that the number of parks, number of unlocked schools, or having at least one school within a half mile radius of child's residence were significantly related to BMI. Despite this, they did find that as the number of locked schools in the neighbourhood increased, BMI significantly increased. The fourth and final study found that children living in rural neighbourhoods with excellent access to playgrounds/parks, as perceived by their parents, were significantly less likely to be overweight than children who had poor access (Veugelers et al., 2008). The relationship was the same for obesity but significant in both rural and urban areas. For access to other recreational facilities, those with excellent access were less likely to be overweight, regardless of urban/rural status, and less likely to be obese if they lived in a rural area.

Five studies investigated the relationship between access to food retail establishments and child adiposity levels (Burdette and Whitaker, 2004; Davis and Carpenter, 2009; Liu et al., 2007; Veugelers et al., 2008). Results again were mixed. One study did not find any significant association with adiposity (Burdette and Whitaker, 2004). Another had significant but unexpected results-the availability of fast food restaurants appeared to protect against adiposity. However, this was not consistent across adiposity measures, and was complex in that age and sex modified the relationship (Crawford et al., 2008). In contrast, another study found that two availability indicators: one or more fast food restaurants and one or more non-fast food restaurants in the neighbourhood were both positively related to BMI and overweight (Davis and Carpenter, 2009). Liu et al. (2007) found that in areas of low population density, the distance to the nearest supermarket significantly predicted obesity. Other store types were not found to be important, even when considering population density. Finally, regardless of the type of store, Veugelers et al. (2008) found that average and excellent parental perceived access significantly protected against overweight in urban areas, and obesity in both rural and urban areas.

Two studies considered the potential effect of neighbourhood street layout on child adiposity (Grafova, 2008; Spence et al., 2008). Grafova (2008) found no effect of street connectivity on obesity; however, children living in neighbourhoods built after 1969 were more likely to be obese than those living in neighbourhoods built before 1969. Spence et al. (2008) developed an index of walkability that included indicators such as dwelling and intersection densities, land-use mix, and number of PA facilities in the neighbourhood. Girls, but not boys, living in highly walkable neighbourhoods were less likely to be overweight than those living in less walkable neighbourhoods.

Only two studies investigated the potential effect of population density (Bell et al., 2008; Grafova, 2008). Neither found a significant effect at the census block-group and census tract levels. Finally, one study derived a latent construct for the neighbourhood physical environment that incorporated many of the variables that have been described in this section (see Table 1) (Franzini et al., 2009). The authors of this study used structural equation modeling to determine the relationship between the latent construct and obesity through mediation by level of PA. They found that the physical environment was not significantly associated with PA, but PA was negatively associated with obesity, after controlling for individual sociodemographic factors. 


\begin{tabular}{|c|c|c|c|c|c|c|c|c|c|c|c|}
\hline \multicolumn{3}{|c|}{ Study basics } & \multicolumn{3}{|c|}{ Physical environment } & \multicolumn{2}{|c|}{ Weight Status } & \multicolumn{2}{|l|}{ Analysis } & \multicolumn{2}{|c|}{ Results } \\
\hline Reference & $\begin{array}{l}\text { Design } \\
\text { and } \\
\text { level of } \\
\text { analysis }\end{array}$ & $\begin{array}{l}\text { Population } \\
\text { (location; age; } \\
\text { sample size) }\end{array}$ & Main & dictor(s) & $\begin{array}{l}\text { Neighbourhood } \\
\text { definition }\end{array}$ & $\begin{array}{l}\text { Measured } \\
\text { height } \\
\text { and } \\
\text { weight }\end{array}$ & $\begin{array}{l}\text { Main weight } \\
\text { status } \\
\text { measure(s) }\end{array}$ & $\begin{array}{l}\text { Confounders and } \\
\text { other statistical } \\
\text { adjustments }\end{array}$ & $\begin{array}{l}\text { Addressed } \\
\text { residential } \\
\text { mobility }\end{array}$ & & \\
\hline $\begin{array}{l}\text { Bell et al. } \\
(2008)\end{array}$ & $\mathrm{RCI}$ & $\begin{array}{l}\text { Indianapolis, US; 3- } \\
16 \text { years in 1996- } \\
2000 \text {, followed to 5- } \\
18 \text { years; } \\
n=3831 \text { Some } \\
\text { children may be the } \\
\text { same as in Liu et al. } \\
(2007)\end{array}$ & (1) & $\begin{array}{l}\text { Amount of } \\
\text { greenness- } \\
\text { Normalized } \\
\text { Difference } \\
\text { Vegetation Index } \\
\text { (NDVI) } \\
\text { Residential density }\end{array}$ & $\begin{array}{ll} & 1 \mathrm{~km} \\
\text { circular } \\
\text { buffer } \\
\text { around } \\
\text { child's } \\
\text { residence }\end{array}$ & Yes & $\begin{array}{l}\text { BMI Z-score } \\
\text { (CDC) at Time } \\
2 \text { (5-18 years) }\end{array}$ & $\begin{array}{l}\text { Sex, Time } 1 \text { age, } \\
\text { race/ethnicity, and } \\
\text { Time } 1 \text { BMM Z-score, } \\
\text { family health } \\
\text { insurance type; area } \\
\text { SES, index year; both } \\
\text { predictors incl in same } \\
\text { model; adjusted SEs } \\
\text { for clustering of } \\
\text { neighbourhoods }\end{array}$ & $\begin{array}{l}\text { Incl only } \\
\text { children who } \\
\text { lived at the } \\
\text { same } \\
\text { address for at } \\
\text { least } 24 \\
\text { months }\end{array}$ & $\begin{array}{l}\text { (1) } \\
\text { (2) }\end{array}$ & $\begin{array}{l}\text { - for NDVI } \\
\varnothing \text { for residential } \\
\text { density }\end{array}$ \\
\hline $\begin{array}{l}\text { Burdette } \\
\text { and } \\
\text { Whitaker } \\
(2004)\end{array}$ & Xs I & $\begin{array}{l}\text { Cincinnati }(\mathrm{OH}) \text {, US; } \\
\text { 3-4 years between } \\
\text { 1/1//98 and } \\
6 / 30 / 01 ; \boldsymbol{n}=7020\end{array}$ & $\begin{array}{l}\text { Dista } \\
\text { (1) pl } \\
\text { (2) F }\end{array}$ & $\begin{array}{l}\text { (miles) to nearest: } \\
\text { round, }\end{array}$ & $\begin{array}{l}\text { Based on boundaries } \\
\text { used by Cincinnati } \\
\text { Police Department } \\
\text { (total= } 46 \text { ) to report } \\
\text { crime rates }\end{array}$ & Yes & Obesity (CDC) & $\begin{array}{l}\text { Poverty ratio, race, } \\
\text { sex }\end{array}$ & No & $\varnothing$ for & oredictors \\
\hline $\begin{array}{l}\text { Crawford } \\
\text { et al. } \\
\text { (2008) }\end{array}$ & XSI & $\begin{array}{l}\text { Same population as } \\
\text { Timperio et al. } \\
\text { (2005) but } 3 \text { years } \\
\text { later in } 2004, n=137 \\
(8-9 \text { years), } n=243 \\
\text { (13-15 years) }\end{array}$ & $\begin{array}{l}\text { (1) } \\
\text { (2) } \\
\text { (3) }\end{array}$ & $\begin{array}{l}\text { At least } 1 \mathrm{FF} \text { in } \\
\text { neighbourhood } \\
\text { Density of FF in } \\
\text { neighbourhood } \\
\text { Distance (km) to the } \\
\text { nearest } \mathrm{FF}(\mathrm{using} \\
\text { road network) } \\
\text { regardless of } 2 \mathrm{~km} \\
\text { buffer }\end{array}$ & $\begin{array}{l}2 \mathrm{~km} \text { circular buffer } \\
\text { around residential } \\
\text { address }\end{array}$ & Yes & $\begin{array}{l}\text { BMI Z-score } \\
\text { (CDC) } \\
\text { Overweight } \\
\text { incl obesity } \\
\text { (IOTF) }\end{array}$ & $\begin{array}{l}\text { PA status; stratified by } \\
\text { sex and age group; } \\
\text { adjusted for clustering } \\
\text { by school }\end{array}$ & $\begin{array}{l}\text { Restricted } \\
\text { analysis to } \\
\text { children who } \\
\text { lived at the } \\
\text { same } \\
\text { address for at } \\
\text { least the } \\
\text { previous } 3 \\
\text { years }\end{array}$ & (2) & $\begin{array}{l}\text { At least } 1 \mathrm{FF} \text { in } \\
\text { neighbourhood: - } \\
\text { for } 13-15 \text { years } \\
\text { (both sexes) with } \\
\text { BMI } Z \text {-score; - for } \\
13-15 \text { years girls } \\
\text { with overweight } \\
\text { Density: } \varnothing \text { for both } \\
\text { sexes and age } \\
\text { groups with BMl } Z \text { - } \\
\text { score; - for } 13-15 \\
\text { years girls with } \\
\text { overweight } \\
\text { Distance: } \varnothing \text { for all } \\
\text { groups with all } \\
\text { outcomes }\end{array}$ \\
\hline $\begin{array}{l}\text { Davis and } \\
\text { Carpenter } \\
\text { (2009) }\end{array}$ & XS I & $\begin{array}{l}\text { California, US; } \\
\text { Grades 7-12 from } \\
2002 \text { to } \\
2005 ; n=529,367\end{array}$ & $\begin{array}{l}(1) \\
\text { (2) }\end{array}$ & $\begin{array}{l}\text { One or more FF } \\
\text { One or more 'other' } \\
\text { restaurants }\end{array}$ & $\begin{array}{l}1 / 2 \text { mile buffer around } \\
\text { school location }\end{array}$ & $\begin{array}{l}\text { Not } \\
\text { reported }\end{array}$ & $\begin{array}{l}\text { BMI, } \\
\text { Overweight } \\
\text { (incl obesity), } \\
\text { Obesity (CDC) }\end{array}$ & $\begin{array}{l}\text { School, urban/rural } \\
\text { status of school; child } \\
\text { sex, grade level, age, } \\
\text { race/ethnicity, and PA; } \\
\text { adjusted SEs for } \\
\text { clustering between } \\
\text { schools; both } \\
\text { predictors incl in same } \\
\text { model }\end{array}$ & No & (1) & $\begin{array}{l}\text { + for one or more } \\
\text { FF with all } 3 \\
\text { outcomes; } \\
\text { + for one or more } \\
\text { 'other' restaurants } \\
\text { with BMl and } \\
\text { overweight only }\end{array}$ \\
\hline $\begin{array}{l}\text { Evenson et } \\
\text { al. (2007) }\end{array}$ & XS M & $\begin{array}{l}\text { US (6 States); } \\
\text { Grade } 6 \text { females in } \\
\text { 2003; } \boldsymbol{n}=1554\end{array}$ & $\begin{array}{l}\text { Child } \\
\text { neigh } \\
\text { (1) }\end{array}$ & $\begin{array}{l}\text { erception of her } \\
\text { urhood: } \\
\text { Aesthetics (1 Likert } \\
\text { item assessing } \\
\text { agreement) } \\
\text { \# of accessible PA } \\
\text { facilities within } \\
\text { walking distance }\end{array}$ & $\begin{array}{l}\text { Perceived } \\
\text { neighbourhood }\end{array}$ & Yes & $\begin{array}{l}\text { BMI, } \\
\text { Overweight } \\
\text { (incl obesity), } \\
\text { Obesity (CDC) }\end{array}$ & $\begin{array}{l}\text { State, school, school } \\
\text { SES; child } \\
\text { racelethnicity and non- } \\
\text { school PA; } \\
\text { neighbourhood SES }\end{array}$ & No & $\begin{array}{l}\text { (1) } \\
\text { (2) }\end{array}$ & $\begin{array}{l}\varnothing \text { for aesthetics } \\
\text { with all outcomes } \\
\text { - for accessibility } \\
\text { with BMI (2nd and } \\
\text { 3rd quartiles); - for } \\
\text { accessibility with } \\
\text { overweight } \\
\text { (4thquartile only); }\end{array}$ \\
\hline
\end{tabular}




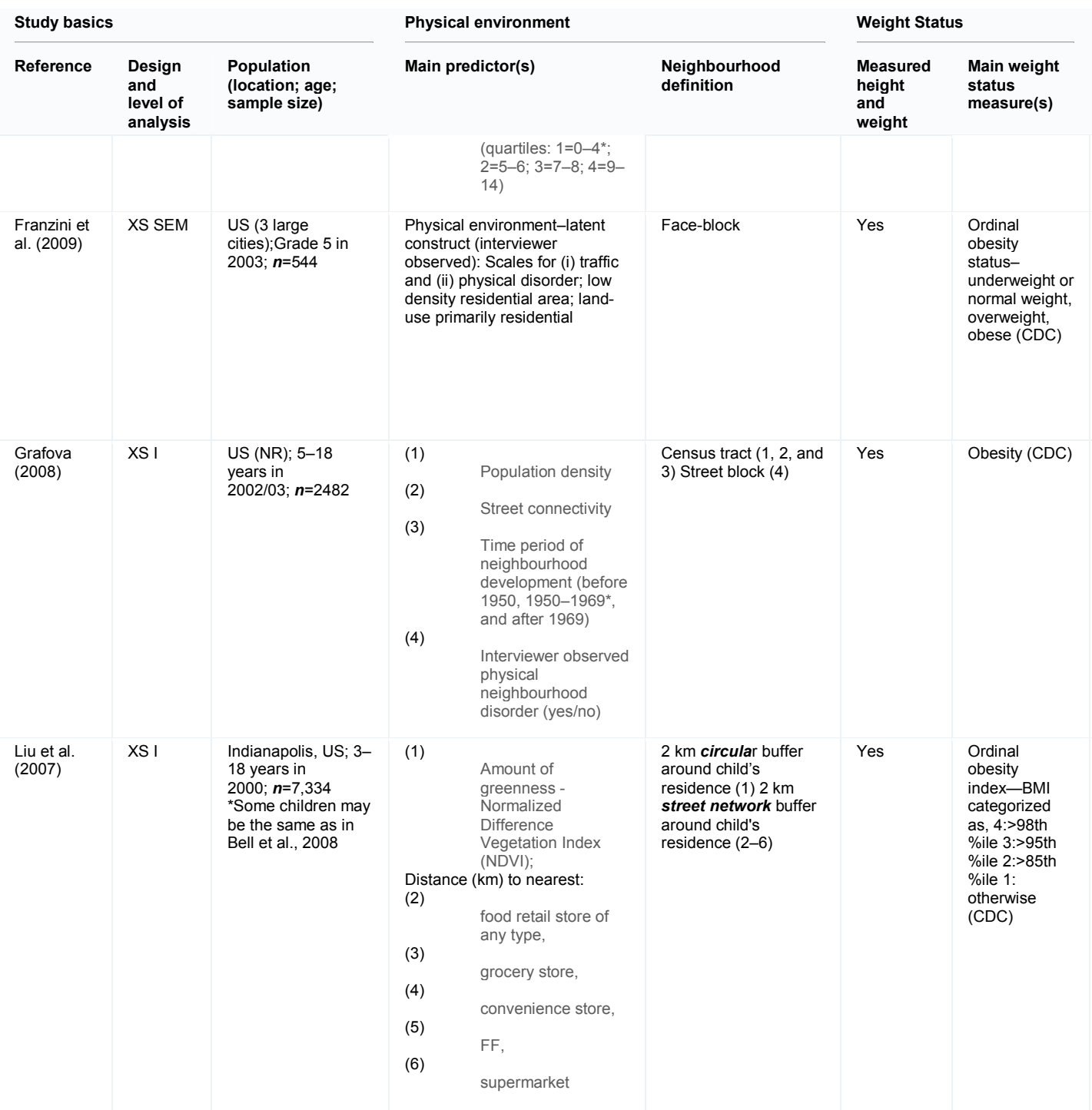

\begin{tabular}{ll} 
Analysis & \\
\hline $\begin{array}{l}\text { Confounders and } \\
\text { other statistical } \\
\text { adjustments }\end{array}$ & $\begin{array}{l}\text { Addressed } \\
\text { residential } \\
\text { mobility }\end{array}$
\end{tabular}

Results

$\varnothing$ for accessibility

Child age, $\quad$ No for PA with weight status

sex; family type,

parental income, an

education; social

construct (see Table

construct (see Table
2); mediation by PA

(composite score);

adjusted for clustering

Child age, sex, and

race/ethnicity;

household SES, \# of
children, and female-

headed household;

mother's BMI and

annual hours of work;

and education; region

of residence

Residential

mobility

paterfer

not differ by
obesity status

(1)

$\varnothing$ for population

(2) $\oslash$ for

$\varnothing$ for street
connectivity

(3) + for

+ for
neighbourhoods

(4)

- for no physical
disorder observed

Township population

child age, race, sex:

avg block-group

median family income

No

(1)

- for NDVl in high $\varnothing$ for distance to
any food retail, no

$\varnothing$ for distance to nearest grocery, no

$\varnothing$ for distance to nearest convenience, no $\varnothing$ for distance to
nearest FF, no EM

(6) +for distance to nearest

supermarket in low 


\begin{tabular}{|c|c|c|c|c|c|c|c|c|c|c|}
\hline \multicolumn{3}{|c|}{ Study basics } & \multicolumn{2}{|l|}{ Physical environment } & \multicolumn{2}{|c|}{ Weight Status } & \multicolumn{2}{|l|}{ Analysis } & \multicolumn{2}{|l|}{ Results } \\
\hline Reference & $\begin{array}{l}\text { Design } \\
\text { and } \\
\text { level of } \\
\text { analysis }\end{array}$ & $\begin{array}{l}\text { Population } \\
\text { (location; age; } \\
\text { sample size) }\end{array}$ & Main predictor(s) & $\begin{array}{l}\text { Neighbourhood } \\
\text { definition }\end{array}$ & $\begin{array}{l}\text { Measured } \\
\text { height } \\
\text { and } \\
\text { weight }\end{array}$ & $\begin{array}{l}\text { Main weight } \\
\text { status } \\
\text { measure(s) }\end{array}$ & $\begin{array}{l}\text { Confounders and } \\
\text { other statistical } \\
\text { adjustments }\end{array}$ & $\begin{array}{l}\text { Addressed } \\
\text { residential } \\
\text { mobility }\end{array}$ & & \\
\hline $\begin{array}{l}\text { Scott et al. } \\
\text { (2007) }\end{array}$ & Xs M & $\begin{array}{l}\text { Same population as } \\
\text { in Evenson et al. } \\
\text { (2007) }\end{array}$ & $\begin{array}{l}\text { \# of: (1) parks, (2) unlocked } \\
\text { schools with active amenities, } \\
\text { (3) locked schools, (4) } \\
\text { presence of at least one school }\end{array}$ & $\begin{array}{l}1 / 2 \text { mile radius around } \\
\text { girl's residential } \\
\text { address }\end{array}$ & Yes & BMI & $\begin{array}{l}\text { State, school, \% of } \\
\text { 6th-8th graders } \\
\text { receiving free or } \\
\text { reduced price lunch; } \\
\text { child race }\end{array}$ & No & $\begin{array}{l}\text { (1) } \\
(2) \\
(3) \\
\text { (4) }\end{array}$ & $\begin{array}{l}\varnothing \text { for \# of parks; } \\
\varnothing \text { for \# of unlocked } \\
\text { schools; } \\
\text { + for \# of locked } \\
\text { schools; } \\
\varnothing \text { for at least one } \\
\text { school }\end{array}$ \\
\hline $\begin{array}{l}\text { Spence et } \\
\text { al. (2008) }\end{array}$ & xs I & $\begin{array}{l}\text { Edmonton (AB), } \\
\text { Canada } 4-6 \text { years } \\
\text { in 2004; } \boldsymbol{n}=239 \\
\text { boys; } \boldsymbol{n}=262 \text { girls }\end{array}$ & $\begin{array}{l}\text { Index of walkability based on: } \\
\text { (1) dwelling density, (2) } \\
\text { intersection density, (3) land- } \\
\text { use mix, and (4) \# of PA } \\
\text { facilities }\end{array}$ & $\begin{array}{l}\text { Postal code (1-3) } \\
1.5 \mathrm{~km} \text { radius of postal } \\
\text { code centroid (4) }\end{array}$ & Yes & $\begin{array}{l}\text { Overweight } \\
\text { incl obesity } \\
\text { (CDC and } \\
\text { IOTF) }\end{array}$ & $\begin{array}{l}\text { Neighbourhood } \\
\text { education level, } \\
\text { proportion of women } \\
\text { employed; child age, } \\
\text { sex (tested EM), PA } \\
\text { status, and junk food } \\
\text { consumption }\end{array}$ & No & $\begin{array}{l}\text { - for girls u } \\
\text { definition; } ; \\
\text { either defin }\end{array}$ & $\begin{array}{l}\text { using either } \\
\varnothing \text { for boys using } \\
\text { nition }\end{array}$ \\
\hline $\begin{array}{l}\text { Veugelers } \\
\text { et al. } \\
\text { (2008) }\end{array}$ & Xs M & $\begin{array}{l}\text { Nova Scotia, } \\
\text { Canada; Grade } 5 \text { in } \\
2003 ; \boldsymbol{n}=4298\end{array}$ & $\begin{array}{l}\text { Parental perceived access to } \\
\text { (1) shops, (2) playgrounds and } \\
\text { parks, ( } 3 \text { ) recreational } \\
\text { facilities-responses to each } \\
\text { item on } 5 \text { pt scale aggregated } \\
\text { by neighbourhood and } \\
\text { categorized into tertiles: poor, } \\
\text { average, and excellent access }\end{array}$ & $\begin{array}{l}\text { School catchment } \\
\text { area based on student } \\
\text { postal codes }\end{array}$ & Yes & $\begin{array}{l}\text { Overweight } \\
\text { (incl obesity) } \\
\text { and Obesity } \\
\text { (IOTF) }\end{array}$ & $\begin{array}{l}\text { Residential area; child } \\
\text { sex; parental } \\
\text { education, household } \\
\text { income; tested for EM } \\
\text { by urban/rural status } \\
\text { of school location }\end{array}$ & No & $\begin{array}{l}\text { (1) } \\
\text { (2) } \\
\end{array}$ & $\begin{array}{l}\text { Shops: - for avg } \\
\text { and excellent } \\
\text { access with } \\
\text { overweight in } \\
\text { urban areas; - for } \\
\text { excellent access } \\
\text { with obesity (no } \\
\text { EM) } \\
\text { Parks and } \\
\text { playgrounds: - for } \\
\text { excellent access } \\
\text { with overweight in } \\
\text { rural areas; - for } \\
\text { excellent access } \\
\text { with obesity (no } \\
\text { EM) } \\
\text { Recreational } \\
\text { facilities: - for } \\
\text { excellent access } \\
\text { with overweight (no } \\
\text { EM); - for excellent } \\
\text { access with obesity } \\
\text { in rural areas }\end{array}$ \\
\hline
\end{tabular}




\begin{tabular}{|c|c|c|c|c|c|c|c|}
\hline Reference & $\begin{array}{l}\text { Design } \\
\text { and } \\
\text { level of } \\
\text { analysis }\end{array}$ & $\begin{array}{l}\text { Population } \\
\text { (location; age; } \\
\text { sample size) }\end{array}$ & \multicolumn{2}{|c|}{ Main predictor(s) } & $\begin{array}{l}\text { Neighbourhood } \\
\text { definition }\end{array}$ & $\begin{array}{l}\text { Measured } \\
\text { height } \\
\text { and } \\
\text { Weight }\end{array}$ & $\begin{array}{l}\text { Main weight status } \\
\text { measure(s) }\end{array}$ \\
\hline $\begin{array}{l}\text { Burdette } \\
\text { and } \\
\text { Whitaker } \\
\text { (2005) }\end{array}$ & Xs I & $\begin{array}{l}\text { US; } 3 \text { years in 2001- } \\
2003 ; \boldsymbol{n}=3141\end{array}$ & \multicolumn{2}{|c|}{$\begin{array}{l}\text { Parental perceived } \\
\text { neighbourhood safety } \\
\text { (neighbourhood environment } \\
\text { for Children Rating Scales) } \\
\text { Score categorized into tertiles } \\
\text { of low, med, and high safety }\end{array}$} & $\begin{array}{l}\text { Perceived } \\
\text { neighbourhood }\end{array}$ & Yes & $\begin{array}{l}\text { BMI Z-score (CDC) } \\
\text { Obesity (CDC) }\end{array}$ \\
\hline $\begin{array}{l}\text { Burdette } \\
\text { and } \\
\text { Whitaker } \\
(2004)\end{array}$ & XSI & $\begin{array}{l}\text { Cincinnati }(\mathrm{OH}), \text { US; } \\
\text { 3-4 years between } \\
\text { 1/1/198 and } \\
6 / 30 / 01 ; n=7020\end{array}$ & \multicolumn{2}{|c|}{$\begin{array}{l}\text { Quintiles of neighbourhood: } \\
\text { (1) crime rate (per } 1000 \\
\text { residents/year); (2) } 911 \text { call } \\
\text { rate (per } 1000 \text { residents/year) }\end{array}$} & $\begin{array}{l}\text { Based on } \\
\text { boundaries used } \\
\text { by Cincinnati } \\
\text { Police Dept } \\
\text { (total=46) to } \\
\text { report crime rates }\end{array}$ & Yes & Obesity (CDC) \\
\hline $\begin{array}{l}\text { Chen and } \\
\text { Paterson } \\
\text { (2006) }\end{array}$ & Xs I & $\begin{array}{l}\text { St. Louis, US; } 14-19 \\
\text { years (year?); } \boldsymbol{n}=315\end{array}$ & \multicolumn{2}{|c|}{$\begin{array}{l}\text { \% families: (1) employed, (2) } \\
\text { with high school education or } \\
\text { more; median: (3) family } \\
\text { income, (4) value of owner- } \\
\text { occupied houses }\end{array}$} & $\begin{array}{l}\text { Census block- } \\
\text { group }\end{array}$ & Yes & BMI \\
\hline $\begin{array}{l}\text { Cohen et } \\
\text { al. (2006) }\end{array}$ & XS M & $\begin{array}{l}\text { Los Angeles, US; } \\
12-17 \text { years; } \boldsymbol{n}=807\end{array}$ & (2) & $\begin{array}{l}\text { Collective efficacy } \\
\text { (based on } \\
\text { aggregated Likert } \\
\text { responses to } 9 \\
\text { items by } ~ 55 \\
\text { adults in } 65 \\
\text { census tracts) } \\
\\
\text { Tract } \\
\text { disadvantage } \\
\text { (based on } 4 \\
\text { indicators from } \\
2000 \text { census data) }\end{array}$ & $\begin{array}{l}\text { Census tract } \\
\text { (1990) }\end{array}$ & No & $\begin{array}{l}\text { BMl, overweight incl } \\
\text { obesity, and obesity } \\
\text { (CDC) }\end{array}$ \\
\hline $\begin{array}{l}\text { Evenson et } \\
\text { al. (2007) }\end{array}$ & XS M & $\begin{array}{l}\text { US ( } 6 \text { States); Grade } \\
6 \text { females in } \\
2003 ; \boldsymbol{n}=1554\end{array}$ & \multicolumn{2}{|c|}{$\begin{array}{l}\text { Child's perception of safety in } \\
\text { her neighbourhood (scale } \\
\text { based on } 4 \text { items) }\end{array}$} & $\begin{array}{l}\text { Perceived } \\
\text { neighbourhood }\end{array}$ & Yes & $\begin{array}{l}\text { BMI, overweight (incl } \\
\text { obesity), obesity } \\
\text { (CDC) }\end{array}$ \\
\hline $\begin{array}{l}\text { Franzini et } \\
\text { al. (2009) }\end{array}$ & XS SEM & $\begin{array}{l}\text { US ( } 3 \text { large cities); } \\
\text { Grade } 5 \text { in } \\
2003 ; n=544\end{array}$ & \multicolumn{2}{|c|}{$\begin{array}{l}\text { Social environment-latent } \\
\text { construct (perceived by } \\
\text { parent): Neighbourhood } \\
\text { scales for (i) social cohesion, } \\
\text { (ii) informal social control, (iii) } \\
\text { collective sociailization of } \\
\text { children, (iv)social } \\
\text { exchanges, (v) social ties, } \\
\text { and (vi) safety }\end{array}$} & $\begin{array}{l}\text { Perceived } \\
\text { neighbourhood }\end{array}$ & Yes & $\begin{array}{l}\text { Ordinal obesity status- } \\
\text { underweight or normal } \\
\text { weight, overweight, } \\
\text { obese (CDC) }\end{array}$ \\
\hline $\begin{array}{l}\text { Grafova } \\
(2008)\end{array}$ & XS I & $\begin{array}{l}\text { US (NR); } 5-18 \text { years } \\
\text { in 2002/03; } n=2482\end{array}$ & \multicolumn{2}{|r|}{ Parental } & $\begin{array}{l}\text { Census tract (1, } \\
2,3, \text { and 5) Street } \\
\text { block (4) } \\
\text { Perceived } \\
\text { neighbourhood } \\
\text { (6) }\end{array}$ & Yes & Obesity (CDC) \\
\hline
\end{tabular}

Confounders and statistical analysis

Child race/ethnicity;

household income;

mothers' education an

Child race and sex

No

Child age and sex

measured at the family-

Census tract; Child

age, sex, race/ethnicity,

TV watching, an
extracurricular

activities; parental

nativity, marital status,

BMI, and education

type, working status,

and health insurance

status

State, school, schoo

SES; child

race/ethnicity and non-

school PA;

Child age,

race/ethnicity, and sex

family type, parental

income and

education; physical

environment-latent

construct (see Table

(composite score);

adjusted for clustering

within schools

Child age, sex, an

race/ethnicity;

household SES, \#

headed; mother's BM

No

No

\section{Addressed}

mobility

No

$\varnothing$ for safety with both outcomes

$\varnothing$ for both predictors

tor

for all 4 SES predictors

Tor all 4 SES predictors

(1)

$$
\begin{aligned}
& \text {-for collective } \\
& \text { efficacy with all } 3 \\
& \text { measures (BMI, } \\
& \text { overweight, } \\
& \text { obesity) }
\end{aligned}
$$

(2)

$$
\begin{aligned}
& \varnothing \text { for tract } \\
& \text { disadvantage } \\
& \text { with all three } \\
& \text { measures (BMI, } \\
& \text { overweight, } \\
& \text { obesity) }
\end{aligned}
$$

No

$\varnothing$ for safety with all outcomes (BMI, overweight and obesity)

- for PA with weight status where social environmen
was + with PA

\begin{tabular}{l|ll}
$\begin{array}{l}\text { Residential } \\
\text { mobility } \\
\text { patterns did } \\
\text { not differ by } \\
\text { obesity } \\
\text { status }\end{array}$ & (1) & $\begin{array}{l}\text {-for economic } \\
\text { deprivation }\end{array}$ \\
+for lack of social \\
control
\end{tabular}

contro 


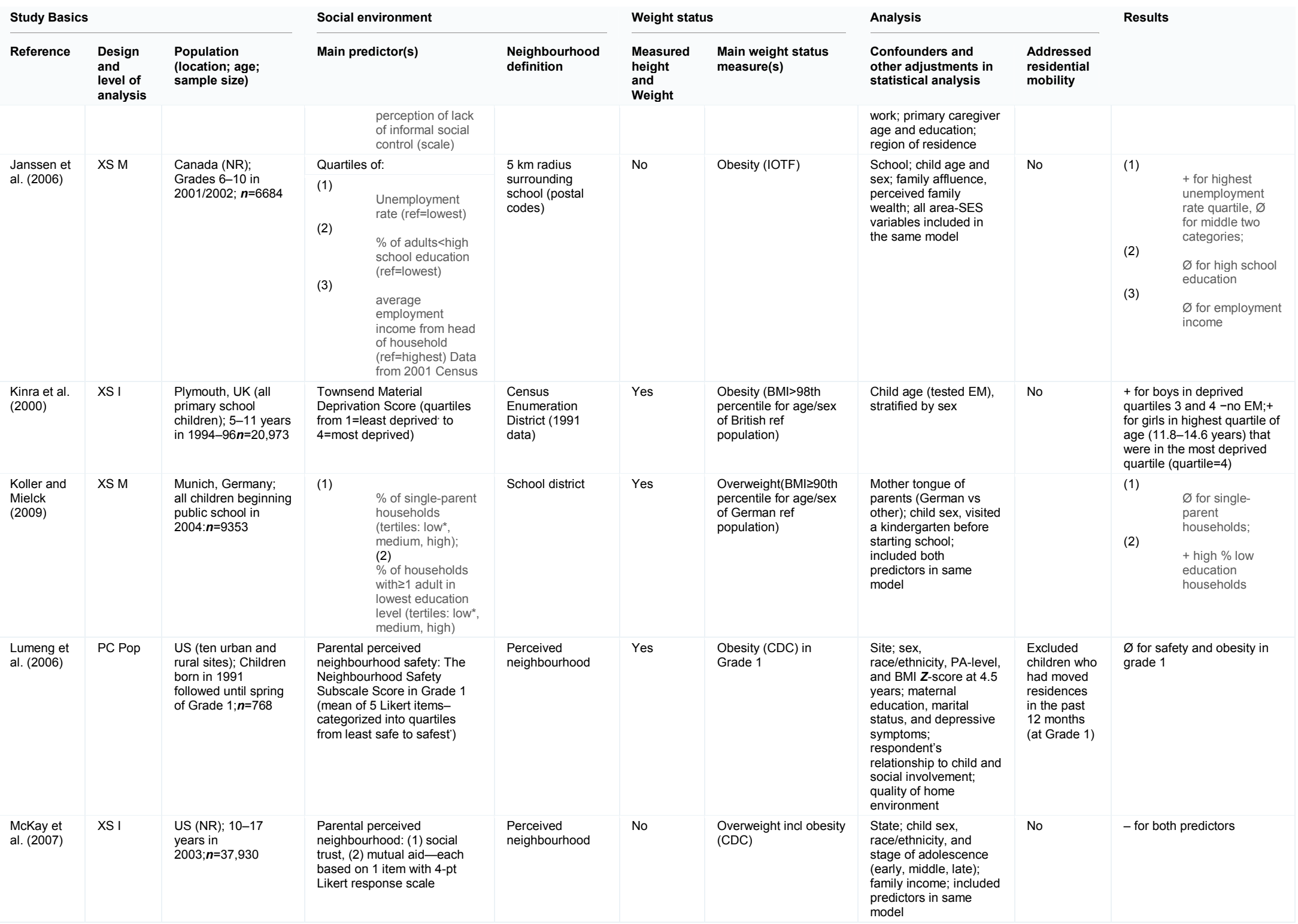




\begin{tabular}{|c|c|c|c|}
\hline \multicolumn{3}{|c|}{ Study Basics } & \multirow{2}{*}{$\begin{array}{l}\text { Social environment } \\
\text { Main predictor(s) }\end{array}$} \\
\hline Reference & $\begin{array}{l}\text { Design } \\
\text { and } \\
\text { level of } \\
\text { analysis }\end{array}$ & $\begin{array}{l}\text { Population } \\
\text { (location; age; } \\
\text { sample size) }\end{array}$ & \\
\hline $\begin{array}{l}\text { O'Brien et } \\
\text { al. (2007) }\end{array}$ & PCM & $\begin{array}{l}\text { Same population as } \\
\text { Lumeng et al. } \\
\text { (2006); However, } \\
\text { children were } \\
\text { followed until Grade } \\
6 \text { (12 years)n }=960\end{array}$ & $\begin{array}{l}\text { Same as Lumeng et al. } \\
(2006) \text { Mean of } \\
\text { measurements taken in } \\
\text { grade } 1,3 \text { and } 5\end{array}$ \\
\hline $\begin{array}{l}\text { Oliver and } \\
\text { Hayes } \\
\text { (2008) }\end{array}$ & PC M & $\begin{array}{l}\text { Canada (NR); } 2-3 \\
\text { years (1994) } \\
\text { followed to 10-11 } \\
\text { years (2002);n=2152 }\end{array}$ & $\begin{array}{l}\text { Neighbourhood low-income } \\
\text { (least poor, middle', most } \\
\text { poor) }\end{array}$ \\
\hline $\begin{array}{l}\text { Oliver and } \\
\text { Hayes } \\
(2005)\end{array}$ & XS M & $\begin{array}{l}\text { Canada (NR); } 5-17 \\
\text { years in } \\
2000 / 01 ; n=11,455\end{array}$ & $\begin{array}{l}\text { Neighbourhood SES (high; } \\
\text { mid-high, mid-low, low); }\end{array}$ \\
\hline $\begin{array}{l}\text { Scott et al. } \\
(2007)\end{array}$ & XS M & $\begin{array}{l}\text { Same population as } \\
\text { in Evenson et al. } \\
\text { (2007) }\end{array}$ & $\begin{array}{l}\text { SES index score based on } 5 \\
\text { indicators from } 2000 \text { Census } \\
\text { (lower scores indicate more } \\
\text { deprivation) }\end{array}$ \\
\hline $\begin{array}{l}\text { Singh et al. } \\
\text { (2008) }\end{array}$ & XSI & $\begin{array}{l}\text { Same population as } \\
\text { McKay et al. } \\
\text { (2007); } \boldsymbol{n}=46,707\end{array}$ & $\begin{array}{l}\text { Parental perceived } \\
\text { neighbourhood social capital } \\
\text { ( } 4 \text { items) Index ranges } 4-16 \\
\text { and categorized into quartiles } \\
\text { from lowest to highest social } \\
\text { capital }\end{array}$ \\
\hline $\begin{array}{l}\text { Timperio et } \\
\text { al. (2005) }\end{array}$ & XsI & $\begin{array}{l}\text { Melbourne, } \\
\text { Australia; 5-6 and } \\
10-12 \text { years in } \\
2001 ; \boldsymbol{n}=292(5-6 \\
\text { years), } \boldsymbol{n}=916(10- \\
12 \text { years) }\end{array}$ & $\begin{array}{l}\text { Parental perceived } \\
\text { neighbourhood safety ( } 5 \\
\text { items-Likert-type response) }\end{array}$ \\
\hline $\begin{array}{l}\text { Veugelers } \\
\text { et al. } \\
\text { (2008) }\end{array}$ & XS M & $\begin{array}{l}\text { Nova Scotia, } \\
\text { Canada; Grade } 5 \text { in } \\
\text { 2003; } \boldsymbol{n}=4298\end{array}$ & $\begin{array}{l}\text { Parental perception of safe } \\
\text { places for children to play } \\
\text { during the day- } 5 \text { pt scale } \\
\text { aggregated by } \\
\text { neighbourhood and } \\
\text { categorized into tertiles: } \\
\text { poor', average, and excellent } \\
\text { access }\end{array}$ \\
\hline
\end{tabular}

\section{Weight status}

Neighbourhood

definition

Perceived

ourhood

(a)

Measured
height
and
Weight
Yes

Census

Enumeration

(based on posta
code in 1994)

Census

Dissemination
Area (CDA)

Area (CDA)
based on posta

code

$1 / 2$ mile radius

around girl's

Perceived

Perceived

Pes

neighbourhood

School catchment

area based on

student residence

Yes

No

BMI Z-score (CDC)

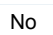

Yes

BMI

Obesity (CDC)

(c)

Overweight (incl

obesity) and Obesity
(IOTF)

Overweight (incl

(Desity) and obesity

(IOTF)

\section{Analysis}

\section{Confounders and}

other adjustments in

ind

Child sex, ethnicity, TV time spent in day-care; family income and structure; maternal education; indicators of parenting quality

Time; child age and sex; family income an structure; mother's density

CDA, family; age and sex; family income;
parental education

State, school, \% of 6th-8th graders

receiving free or
reduced price lunch; child's race

\section{Child sex}

race/ethnicity, TV household poverty status, and highes education level;
adjusted for clustere survey design

School area SES; child sex; family SES, and \# for clustering by schoo, and stratified by age group of child

Residential area; child sex; parental

education, household

by urban/rural status of by urban/rural status
school location
Results

Addressed residential

multiple measures of
safety over time

$\varnothing$ for average safety with$$
\text { (n) }
$$

Assumed did not move from age 2-
3 years?

+ for most poor, $\varnothing$ for least poor;

+ for all SES categories; association from mid-high to low

No

- for area SES

No

+ for low social capital (all

5-6 years: $\varnothing$ for all
predictors in unadjusted
analysis, no adjusted
analyses; $10-12$ years:+ for
perception of heavy traficin in
streets with overweight; for
concerned with road safety
with obesity
$\varnothing$ for safety with both
outcomes (overweight and
obesity)




\section{Study Basics}

Reference

\section{Design Population}

and (location; age

level of
analysis

XS M

Veugelers

Fitzgerald
(2005)

Wardle et
al. (2006)

England; 11-12

\section{Social environment}

Main predictor(s)

Same population as

Veugelers et al.

(2008)

Average, per-school, postal-

code level means of

Census) Tertiles-lowest'

middle, highest

\section{Townsend Material}

years in 1999

followed until 15-
years; $n=5863$

nd Material

from least deprived to most

deprived)

\section{Weight status}

height

and

Yes

Same as above

ensus

District
Analysis

Confounders and

other adjustments
statistical analysis

Frequency of school

PA classes; child sex,

frequency of family

suppers, parental

education

School and school

ear; child sex and

ethnicity
Results

\section{Addressed}

residential

No

- for highest income group

No

+ for BMI SD scores in the

most deprived group;,+for

waist circumference SD scores in the most deprived

population; K=kindergarten; M=multi-level; NR=nationally representative sample; $\mathrm{PA}=$ physical activity; $\mathrm{PC}=$ =prospective cohort; Pop=population-level; RC=retrospective cohort; SES=socioeconomic status; SEM=structural equation modeling; SE=standard error; $\mathrm{SD}=$ standard deviation; $\mathrm{XS}=$ cross-sectional; $\varnothing=$ no association; +=positive association; -=negative association; * ${ }^{*}$ reference group. 


\subsection{Neighbourhood social environment}

Twenty-one studies in this review examined at least one feature of the neighbourhood social environment and its relation to child adiposity (Table 2). Thirty-one associations were analyzed across the 21 studies. Eleven studies investigated the relationship between neighbourhood socioeconomic disadvantage and child adiposity (Chen and Paterson, 2006; Cohen et al., 2006; Grafova, 2008; Janssen et al., 2006; Kinra et al., 2000; Koller and Mielck, 2009; [Oliver and Hayes, 2005] and [Oliver and Hayes, 2008]; Scott et al., 2007;Veugelers and Fitzgerald, 2005; Wardle et al., 2006). They tended to find that increasing disadvantage was related to increasing adiposity levels, regardless of the disadvantage or adiposity measure employed. One out of the 11 studies, however, reported a null effect (Cohen et al., 2006). Another found that the significance of disadvantage to predict adiposity was modified by age in girls but not boys (Kinra et al., 2000). Seven out of the 21 studies (33\%) examined neighbourhood safety and child adiposity ( [Burdette and Whitaker, 2004] and [Burdette and Whitaker, 2005]; Evenson et al., 2007; Lumeng et al., 2006; O’Brien et al., 2007; Timperio et al., 2005; Veugelers et al., 2008). Only one of these reported significant results (Timperio et al., 2005), but this was for only two out of the five indicators analyzed, and was modified by age. For example, neighbourhood safety did not significantly affect overweight and obesity among 5-6-year-olds, but was positively related to overweight and obesity among 10-12-year-olds. Specifically, parental perception of heavy traffic in streets predicted overweight (but not obesity), and high parental concern with road safety in the neighbourhood predicted obesity (but not overweight).

Four studies analyzed the relationship between indicators of social capital, such as collective efficacy and social disorder, with child adiposity (Cohen et al., 2006; Grafova, 2008; McKay et al., 2007; Singh et al., 2008). All four found that as neighbourhood social capital increased, adiposity significantly decreased (or vice versa, as social capital decreased, indicated by increasing social disorder, adiposity increased).

Finally, one study derived a latent construct for the neighbourhood social environment that incorporated many of the variables that have been described in this section (see Table 2) (Franzini et al., 2009). The authors of this study used structural equation modeling to determine the relationship between the latent construct and obesity through mediation by level of PA. They found that a more favourable social environment was positively associated with PA; which was negatively associated with obesity, after controlling for individual sociodemographic factors.

\subsection{Combined measures}

Using cluster analysis, one study in this review combined measures of the physical and social environment into one overall measure of the neighbourhood environment, in order to determine neighbourhood typologies that significantly predicted childhood obesity (Table 3) (Nelson et al., 2006). Indicators describing income/wealth, race/ethnicity, crime, road type, street connectivity, and recreation facilities for PA resulted in six neighbourhood typologies which the authors labelled Rural Working Class, Exurban, Newer Suburban, Upper-middle Class, Older Suburban, Mixed-race Urban, and Low SES Inner-city. The referent typology was New Suburban which was characterized as having a high SES/low minority population, recently built housing units, low access to PA amenities, very poor street connectivity, and very few roadways overall. Children living in a Rural Working Class neighbourhood (low SES, moderate to low minority, little mobility, low connectivity, low access to PA amenities, and very low density of roadways) were $38 \%$ more likely to be obese than those in New Suburban neighbourhoods. Similarly, those in Exurban (moderate SES, low minority, high percentage of recently built housing, high percentage of population commuting to work outside their county of residence, low access to PA amenities, low street connectivity, low crime, and large number of arterial roadways) and Mixed-race Urban neighbourhoods (low SES, high poverty, moderate 
access to PA amenities, moderate to high street connectivity and crime, and high density of local roadways) were approximately $30 \%$ more likely to be obese than those living in New Suburban neighbourhoods.

\section{Discussion}

Among the studies that examined features of the neighbourhood physical environment, it was difficult to discern a clear relationship with adiposity, particularly given the variability in exposure measures used. On the other hand, from the studies that examined the neighbourhood social environment, deprivation seems to be important in explaining child adiposity, above and beyond individual socioeconomic characteristics. High social capital of neighbourhoods also appears to be protective of child adiposity.

Across studies, there was much heterogeneity in terms of population age, methods employed for analysis, derivation of predictor and outcome variables, neighbourhood definition, and covariates included in statistical models, which may explain inconsistent and null results. This also made it impossible to conduct a meta-analysis. Additionally, studies have found that self-reported height and weight can yield overweight and obesity measures that act differently in associational analysis compared to those based on directly measured height and weight (Shields et al., 2008). Thus, inconsistent results may have arisen from the eight studies that relied on self-reported data.

Only five studies reviewed were cohort studies, the remaining 22 were cross-sectional, which increases the likelihood for reverse causation and residual confounding. There is a relative lack of 'true' longitudinal studies in this area of research; most of these cohort studies used cross-sectional methods in their analysis, and only one study actually used longitudinal regression methods. Even epidemiologic studies of individual-level characteristics and childhood obesity generally fail to examine how these factors affect adiposity over time (Reilly et al., 2007). Epidemiologic studies at individual andmulti-levels should examine how factors relate to different adiposity trajectories (for example, always obese or never obese). This not only provides for more robust evidence of causation (given its longitudinal design) but also better illustrates how these factors influence adiposity development and maintenance, given that body weight relative to height varies tremendously in growing children (Reilly et al., 2007). The quality of both types of studies, particularly cross-sectional, if a cohort study is not feasible, can be enhanced by including measures of exposure length, accounting for change in exposure, or at least including an indicator of residential mobility. Only five studies considered this bias, and two were cohort studies. Additionally, none of these studies adjusted for early life factors known to be related to childhood obesity, such as breastfeeding, birth weight, gestational age, parental smoking during pregnancy and mother's pregnancy BMI (Dubois and Girard, 2006; Harder et al., 2005; Oken and Gillman, 2003; Power and Jefferis, 2002).

From the body of research reviewed here, it is unclear as to whether authors formulated and followed a priori theories. The general failure to account for early life factors, as well as lack of consideration for time exposed demonstrates this fact. Furthermore, many studies of the neighbourhood physical environment controlled for children's PA levels (but interestingly not dietary intake). Physical activity and dietary intake are intermediate steps in the pathway from physical environment to overweight or obesity. Even though a confounder may be related to both physical environment and to adiposity, it cannot be an intermediate step in a causal pathway. Thus, studies that controlled for PA likely over-controlled, potentially leading to null findings. Finally, very few studies investigated the possibility that the effect of the neighbourhood social and physical environments on adiposity may be moderated by age. Neighbourhood factors may become more influential as children get older; they are more independent and therefore, more able to access their surroundings. This would seem to be especially important among studies with populations containing large age ranges. 
Table 3. Characteristics of a study that examined the relationship between a combined measure of the neighbourhood physical and social environment with child adiposity.

Study basics

Reference

\section{Design and lever}

analysis

Nelson et
Combined measures of the neighbourhood environment Population
(location; age (location; age;
sample size)

US (NR); Grades 1995; $\boldsymbol{n}=19,029$
Main predictor(s)

\section{6 neighbourhood patterns based on} access to PA facilities, area SES indicators, crime rate, road type, an street connectivity: (1)

Rural working class

(2) Exurban, mid-SES;

(3) Newer suburban*;

(4) Older suburban, upper-

(5)

$$
\begin{aligned}
& \text { Older subu } \\
& \text { mid-SES; }
\end{aligned}
$$

Mixed-race urban, low

Inner-city, low SES

Neighbourhood

definition

$3 \mathrm{~km}$ buffer around

sidential address

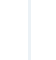

Weight status

Measured

height and

o

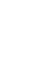

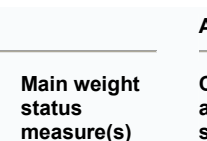

Obesity (CDC)

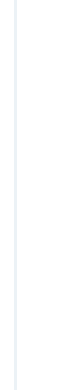

\section{Analysis}

Confounders and other Addressed adjustments in $\quad$ residential

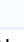

Child age, race/ethnicity;
household income and

household income and:
parental education;

adjusted for cluste sampling design

\section{Results}

\section{+ for (1) Rural, (2) Exurban, and (5)} Mixed-race urb
for (4) Older suburban, and(6) Inner-city

BMI=body mass index; $C D C=$ Centers for Disease Control and Prevention definitions (overweight: BMI 285th \%ile for age and sex; obese: BMI 295 th \%ile for age and sex); EM=effect modification; FF=fast food restaurant; FS=fullservice restaurant; I=individual-level; IOTF=International Obesity Task Force definitions (age and sex-specific based on extrapolating adult overweight $\left(B M l \geq 20 \mathrm{~kg} / \mathrm{m}^{2}\right)$ and obesity $\left(B M l \geq 30 \mathrm{~kg} / \mathrm{m}^{2}\right)$ definitions to a reference population; K=kindergarten; M=multi-level; NR=nationally representative sample; $\mathrm{PA}=$ physical activity; $\mathrm{PC}=$ prospective cohort; Pop=population-level; RC=retrospective cohort; SES=socioeconomic status; SEM=structural equation modeling; $\mathrm{SE}=$ standard error; $\mathrm{SD}=$ =standard deviation; $\mathrm{XS}=$ cross-sectional; $\varnothing=$ =no association; +=positive association; -=negative association; " =reference group. 
Employing ecosocial theory, which considers accumulation of risk over the lifecourse, can allow researchers to better understand, at a population level, why certain children become and remain obese and why others do not. It is a holistic perspective acknowledging that disease development, in this case child adiposity, cannot be studied in individual isolated parts -rather individual behaviours and characteristics, settings (work, school, home, neighbourhood etc.), contexts (at the local, to inter and supra-national levels), and their interrelationships must be considered simultaneously at multiple scales of time and space ( [Krieger, 1994] and [Krieger, 2008]). Although statistical modeling is unlikely to capture all processes involved in the development of child adiposity, multi-level modeling is a promising strategy that can incorporate ecosocial theory by helping us to better understand the extent of interactions between individual characteristics and features of place, namely the neighbourhood, over time, in relation to child adiposity. Researchers in this area should continue to use multi-level modeling, but need to better utilize theory in model development.

To aid in cross-study comparisons, future studies may consider examining multiple adiposity measures (such as BMI, overweight, and obesity), as well as include IOTF definitions for childhood overweight and obesity, in addition to national definitions. Where possible, the heights and weights of children should be directly measured instead of self-or parent-reported. As an alternative to 'reinventing the wheel,' researchers might also consider making use of previously developed exposure and neighbourhood definitions, and geographic methods. Defining neighbourhood boundaries based on participants' perceptions should also be considered. And finally, although only a few studies reviewed here used school location as a proxy for children's neighbourhood of residence, future studies should base neighbourhood exposure measurements on where the child actually lives. This reduces the likelihood for misclassification bias.

The results of this appraisal should be interpreted in light of two similar reviews that did not focus specifically on children. Papas et al. (2007) examined the relationship between the physical or built environment and obesity. They found that $85 \%(17 / 20)$ of studies reported a statistically significant positive association with at least one measure of the physical environment. Black and Macinko (2008) reviewed studies that examined the relationship between obesity and the neighbourhood social environment, physical environment, and food availability. The results of the 22 studies that examined the physical environment and food availability were mixed. For the social environment, their findings from the 16 studies reviewed coincide with those of this appraisal; neighbourhood-level SES, measured in a variety of ways, was inversely associated with obesity, even after controlling for individual-level characteristics.

A few limitations of this critical appraisal also bear mentioning. Drawing any type of conclusion may be somewhat premature, given the heterogeneity of the studies reviewed here and elsewhere. This may be a sign that the literature on neighbourhood and childhood adiposity (and possibly adult obesity) is not yet sufficiently extensive to support a review. Thus, a clearer picture may emerge as more studies are completed. On the other hand, considering studies that were not published in peer-reviewed scientific journals, or were written in languages other than English or French, may have further clarified relationships. This was, however, beyond the scope of this appraisal.

\section{Conclusion}

Twenty-seven primary studies that examined the relationship between physical and/or social environmental features of the neighbourhood with child adiposity were included in this critical appraisal. Socioeconomic disadvantage at the neighbourhood level was consistently found to relate to increased child adiposity, irrespective of exposure or outcome definition. High social capital appeared to act as a protective factor. It is unclear at this time if and how other neighbourhood environmental features, such as safety, street layout and block design, availability/accessibility of amenities etc., play a role. The heterogeneity across 
studies, in terms of population age, methods employed for analysis, derivation of predictor and outcome variables, neighbourhood definition, and covariates included in statistical models, may account for these mixed and null results. The general reliance on the cross-sectional study design, failure to address the potential for exposure bias, over controlling, and residual confounding should also be considered when trying to draw any overall conclusions.

Basing analytical models on a priori theories that originate from an ecosocial perspective will improve our understanding of this complex public health problem. Researchers are also encouraged to facilitate comparability across studies by analyzing multiple adiposity measures that include the IOTF definitions of overweight and obesity.

This is an exciting area of research that has only just started to ramp up within the last 10 years. By nature, it crosses many different disciplines such as epidemiology, urban planning, sociology, and geography, to name a few. Thus, research conducted by transdisciplinary teams can only add to the quality of future studies.

\section{Acknowledgements}

The first author received the Canada Graduate Scholarship from the Canadian Institutes for Health Research in support of this work. The authors would also like to thank Celine Pullen for help with editing.

\section{References}

Barnes et al., 2006

J. Barnes, I. Katz, J. Korbin, M. O’Brien

Children and Families in Communities: Theory, Research, Policy \& PracticeJohn Wiley \& Sons, Ltd., Chichester, England (2006)

Bell et al., 2008

J.F. Bell, J.S. Wilson, G.C. Liu

Neighborhood greenness and 2-year changes in body mass index of children and youth

American Journal of Preventive Medicine, 35 (6) (2008), pp. 547-553

Bernard et al., 2007

P. Bernard, R. Charafeddine, K.L. Frohlich, M. Daniel, Y. Kestens, L. Potvin

Health inequalities and place: a theoretical conception of neighbourhood

Social Science \& Medicine, 65 (9) (2007), pp. 1839-1852

Black and Macinko, 2008

J.L. Black, J. Macinko

Neighborhoods and obesity

Nutrition Reviews, 66 (1) (2008), pp. 2-20

Burdette and Whitaker, 2004

H.L. Burdette, R.C. Whitaker

Neighborhood playgrounds, fast food restaurants, and crime: relationships to overweight in low-income preschool children Preventive Medicine, 38 (1) (2004), pp. 57-63

Burdette and Whitaker, 2005

H.L. Burdette, R.C. Whitaker

A national study of neighborhood safety, outdoor play, television viewing, and obesity in preschool children

Pediatrics, 116 (3) (2005), pp. 657-662

Chaskin, 1997 
R. Chaskin

Perspectives on neighbourhood and community: a review of the literature

Social Service Review (1997), pp. 521-547

Chen and Paterson, 2006

E. Chen, L.Q. Paterson

Neighborhood, family, and subjective socioeconomic status: how do they relate to adolescent health?

Health Psychology, 25 (6) (2006), pp. 704-714

Cohen et al., 2006

D.A. Cohen, B.K. Finch, A. Bower, N. Sastry

Collective efficacy and obesity: the potential influence of social factors on health

Social Science \& Medicine, 62 (3) (2006), pp. 769-778

Crawford et al., 2008

D.A. Crawford, A.F. Timperio, J.A. Salmon, L. Baur, B. Giles-Corti, R.J. Roberts, M.L. Jackson, N. Andrianopoulos, K. Ball Neighbourhood fast food outlets and obesity in children and adults: the CLAN Study

International Journal of Pediatric Obesity, 3 (4) (2008), pp. 249-256

Cummins et al., 2007

S. Cummins, S. Curtis, A.V. Diez- Roux, S. Macintyre

Understanding and representing 'place' in health research: a relational approach

Social Science \& Medicine, 65 (9) (2007), pp. 1825-1838

Davis and Carpenter, 2009

B. Davis, C. Carpenter

Proximity of fast-food restaurants to schools and adolescent obesity

American Journal of Public Health, 99 (3) (2009), pp. 505-510

Dubois and Girard, 2006

L. Dubois, M. Girard

Early determinants of overweight at $\mathbf{4 . 5}$ years in a population-based longitudinal study

International Journal of Obesity, 30 (4) (2006), pp. 610-617

Evenson et al., 2007

K.R. Evenson, M.M. Scott, D.A. Cohen, C.C. Voorhees

Girls' perception of neighborhood factors on physical activity, sedentary behavior, and BMI

Obesity, 15 (2) (2007), pp. 430-445

Franzini et al., 2009

L. Franzini, M.N. Elliott, P. Cuccaro, M. Schuster, M.J. Gilliland, J.A. Grunbaum, F. Franklin, S.R. Tortolero Influences of physical and social neighborhood environments on children's physical activity and obesity

American Journal of Public Health, 99 (2) (2009), pp. 271-278

Gouvernement du Québec, 2008

Gouvernement du Québec

Funding for Education in Québec at the Preschool, Elementary and Secondary School Levels: 2008-2009 School Year

Ministère de l'Éducation, du Loisir et du Sport, Québec (2008), pp. 73-0532A

Grafova, 2008

I.B. Grafova

Overweight children: assessing the contribution of the built environment

Preventive Medicine, 47 (3) (2008), pp. 304-308

Harder et al., 2005

T. Harder, R. Bergmann, G. Kallischnigg, A. Plagemann

Duration of breastfeeding and risk of overweight: a meta-analysis 
American Journal of Epidemiology, 162 (5) (2005), pp. 397-403

Janssen et al., 2006

I. Janssen, W.F. Boyce, K. Simpson, W. Pickett

Influence of individual- and area-level measures of socioeconomic status on obesity, unhealthy eating, and physical inactivity in Canadian adolescents

American Journal of Clinical Nutrition, 83 (1) (2006), pp. 139-145

Kinra et al., 2000

S. Kinra, R.P. Nelder, G.J. Lewendon

Deprivation and childhood obesity: a cross sectional study of 20,973 children in Plymouth, United Kingdom

Journal of Epidemiology \& Community Health, 54 (6) (2000), pp. 456-460

Koller and Mielck, 2009

D. Koller, A. Mielck

Regional and social differences concerning overweight, participation in health check-ups and vaccination. Analysis of data from a whole birth cohort of 6-year old children in a prosperous German city

BMC Public Health, 9 (2009), p. 43

Krieger, 1994

N. Krieger

Epidemiology and the web of causation: has anyone seen the spider?

Social Science \& Medicine, 39 (7) (1994), pp. 887-903

Krieger, 2008

N. Krieger

Proximal, distal, and the politics of causation: what's level got to do with it?

American Journal of Public Health, 98 (2) (2008), pp. 221-230

Law et al., 2007

C. Law, C. Power, H. Graham, D. Merrick

Obesity and health inequalities

Obesity Reviews, 8 (Suppl. 1) (2007), pp. 19-22

Liu et al., 2007

G.C. Liu, J.S. Wilson, R. Qi, J. Ying

Green neighborhoods, food retail and childhood overweight: differences by population density

American Journal of Health Promotion, 21 (4 Suppl.) (2007), pp. 317-325

Lumeng et al., 2006

J.C. Lumeng, D. Appugliese, H.J. Cabral, R.H. Bradley, B. Zuckerman

Neighborhood safety and overweight status in children

Archives of Pediatrics \& Adolescent Medicine, 160 (1) (2006), pp. 25-31

Macintyre et al., 2002

S. Macintyre, A. Ellaway, S. Cummins

Place effects on health: how can we conceptualise, operationalise and measure them?

Social Science \& Medicine, 55 (1) (2002), pp. 125-139

McKay et al., 2007

C.M. McKay, B.A. Bell-Ellison, K. Wallace, J.M. Ferron

A multilevel study of the associations between economic and social context, stage of adolescence, and physical activity and body mass index

Pediatrics, 119 (Suppl. 1) (2007), pp. S84-S91

Nelson et al., 2006

M.C. Nelson, P. Gordon-Larsen, Y. Song, B.M. Popkin 
Built and social environments associations with adolescent overweight and activity

American Journal of Preventive Medicine, 31 (2) (2006), pp. 109-117

Nykiforuk et al., 2007

C. Nykiforuk, S. Campbell, R. Cameron, S. Brown, J. Eyles

Relationships between community characteristics and municipal smoke-free bylaw status and strength

Health Policy, 80 (2) (2007), pp. 358-368

O'Brien et al., 2007

M. O'Brien, P.R. Nader, R.M. Houts, R. Bradley, S.L. Friedman, J. Belsky, E. Susman

The ecology of childhood overweight: a 12-year longitudinal analysis

International Journal of Obesity, 31 (9) (2007), pp. 1469-1478

Ogden et al., 2006

C.L. Ogden, M.D. Carroll, L.R. Curtin, M.A. McDowell, C.J. Tabak, K.M. Flegal

Prevalence of overweight and obesity in the United States, 1999-2004

Journal of the American Medical Association, 295 (13) (2006), pp. 1549-1555

Oken and Gillman, 2003

E. Oken, M.W. Gillman

Fetal origins of obesity

Obesity Research, 11 (4) (2003), pp. 496-506

Oliver and Hayes, 2005

L.N. Oliver, M.V. Hayes

Neighbourhood socio-economic status and the prevalence of overweight Canadian children and youth

Canadian Journal of Public Health, Revue Canadienne de Sante Publique., 96 (6) (2005), pp. 415-420

Oliver and Hayes, 2008

L.N. Oliver, M.V. Hayes

Effects of neighbourhood income on reported body mass index: an eight year longitudinal study of Canadian children BMC Public Health, 8 (2008), p. 16

Papas et al., 2007

M.A. Papas, A.J. Alberg, R. Ewing, K.J. Helzlsouer, T.L. Gary, A.C. Klassen

The built environment and obesity

Epidemiologic Reviews, 29 (2007), pp. 129-143

Power and Jefferis, 2002

C. Power, B.J. Jefferis

Fetal environment and subsequent obesity: a study of maternal smoking

International Journal of Epidemiology, 31 (2) (2002), pp. 413-419

Reilly et al., 2007

J.J. Reilly, A.R. Ness, A. Sherriff

Epidemiological and physiological approaches to understanding the etiology of pediatric obesity: finding the needle in the haystack

Pediatric Research, 61 (6) (2007), pp. 646-652

Rooney et al., 2006

P. Rooney, W. Hussar, M. Planty, S. Choy, G. Hampden-Thompson, S. Provasnik, M.A. Fox

The Condition of Education 2006National Center for Education Statistics, Institute of Education Sciences, US Department of Education, Washington, DC, (2006) NCES 2006-071

Scott et al., 2007

M.M. Scott, D.A. Cohen, K.R. Evenson, J. Elder, D. Catellier, J.S. Ashwood, A. Overton

Weekend schoolyard accessibility, physical activity, and obesity: the Trial of Activity in Adolescent Girls (TAAG) study 
Preventive Medicine, 44 (5) (2007), pp. 398-403

Shields, 2006

M. Shields

Overweight and obesity among children and youth

Health Reports, 17 (3) (2006), pp. 27-42

Shields et al., 2008

M. Shields, G.S. Connor, M.S. Tremblay

Effects of measurement on obesity and morbidity

Health Reports, 19 (2) (2008), pp. 77-84

Shrewsbury and Wardle, 2008

V. Shrewsbury, J. Wardle

Socioeconomic status and adiposity in childhood: a systematic review of cross-sectional studies 1990-2005

Obesity, 16 (2) (2008), pp. 275-284

Singh et al., 2008

G.K. Singh, M.D. Kogan, P.C. Van Dyck

A multilevel analysis of state and regional disparities in childhood and adolescent obesity in the United States Journal of Community Health, 33 (2) (2008), pp. 90-102

Spence et al., 2008

J.C. Spence, N. Cutumisu, J. Edwards, J. Evans

Influence of neighbourhood design and access to facilities on overweight among preschool children

International Journal of Pediatric Obesity, 3 (2) (2008), pp. 109-116

Timperio et al., 2005

A. Timperio, J. Salmon, A. Telford, D. Crawford

Perceptions of local neighbourhood environments and their relationship to childhood overweight and obesity

International Journal of Obesity, 29 (2) (2005), pp. 170-175

Tremblay et al., 2002

M.S. Tremblay, P.T. Katzmarzyk, J.D. Willms

Temporal trends in overweight and obesity in Canada, 1981-1996

International Journal of Obesity \& Related Metabolic Disorders, 26 (4) (2002), pp. 538-543

Veugelers et al., 2008

P. Veugelers, F. Sithole, S. Zhang, N. Muhajarine

Neighborhood characteristics in relation to diet, physical activity and overweight of Canadian children

International Journal of Pediatric Obesity, 3 (3) (2008), pp. 152-159

Veugelers and Fitzgerald, 2005

P.J. Veugelers, A.L. Fitzgerald

Prevalence of and risk factors for childhood overweight and obesity

CMAJ Canadian Medical Association Journal, 173 (6) (2005), pp. 607-613

Wang and Beydoun, 2007

Y. Wang, M.A. Beydoun

The obesity epidemic in the United States-gender, age, socioeconomic, racial/ethnic, and geographic characteristics: a systematic review and meta-regression analysis

Epidemiologic Reviews, 29 (2007), pp. 6-28

Wardle et al., 2006

J. Wardle, N.H. Brodersen, T.J. Cole, M.J. Jarvis, D.R. Boniface

Development of adiposity in adolescence: five year longitudinal study of an ethnically and socioeconomically diverse sample of young people in Britain 
BMJ, 332 (7550) (2006), pp. 1130-1135

World Health Organization, 2000

World Health Organization

Obesity: Preventing and Managing the Global Epidemic: Report of a Who ConsultationWorld Health Organization, Geneva (2000)

Copyright @ 2009 Elsevier Ltd. All rights reserved. 


\subsection{An update to Section 3.1}

\section{Introduction and methods}

The following literature review was undertaken to update the previous review on neighbourhoods and child adiposity, but focused on the place factors of interest in this thesis (material and social deprivation, social cohesion, disorder, and living location). A systematic search strategy was not employed and only PubMed was searched; however, the search terms used in the first review were used again here. The literature was searched up until April 30, 2012. Given that indicators of living location or population type/compactness (e.g. urban/rural status, population density/size, and indices of sprawl) are often defined at larger geographical levels than neighbourhood, the review was expanded to include studies assessing place factors defined up to areas described by county, zip code, and larger census areas such as census metropolitan areas (CMA) or census agglomerations (CAs); areas such as regions, provinces/states, countries, and beyond were excluded. The previous eligibility criteria remained the same (see page 48 in Section 3.1).

\section{Results}

In total, twenty-two unique studies were retrieved (see Tables 1- 4). The majority were published in 2008 or after (16/22). Almost 60\% (13/22) were published using US samples of children. Canadian samples comprised three studies, two studies used English samples of children, two studies examined Australian children, one study was conducted on French children, and one examined Swedish children. The vast majority of studies were crosssectional (17/22), and only five were longitudinal. Approximately 64\% (14/22) used directly measured heights and weights to derive weight indicators, while $8 / 22$ used self or parentreported heights and weights. The ages of the samples varied considerably from study to 
Table 1: Characteristics of reviewed studies that examined the relationship between area deprivation and child excess weight

\begin{tabular}{|c|c|c|c|c|c|c|c|c|c|}
\hline \multicolumn{3}{|c|}{ Study basics } & \multicolumn{2}{|c|}{ Deprivation } & \multicolumn{2}{|c|}{ Weight status } & \multicolumn{2}{|l|}{ Analysis } & \multirow[t]{2}{*}{$\underline{\text { Results }}$} \\
\hline Reference & $\begin{array}{l}\text { Design } \\
\& \text { level } \\
\text { of } \\
\text { analysis }\end{array}$ & $\begin{array}{l}\text { Population } \\
\text { (location; age; } \\
\text { sample size) }\end{array}$ & Main predictor(s) & Place boundary & $\begin{array}{l}\text { Measured } \\
\text { height and } \\
\text { weight? }\end{array}$ & $\begin{array}{l}\text { Main weight } \\
\text { status } \\
\text { measure(s) }\end{array}$ & $\begin{array}{l}\text { Confounders and } \\
\text { other statistical } \\
\text { adjustments }\end{array}$ & $\begin{array}{l}\text { Addressed } \\
\text { residential } \\
\text { mobility? }\end{array}$ & \\
\hline $\begin{array}{l}\text { Burdette \& } \\
\text { Needham, } \\
2012 \text { (1) }\end{array}$ & $\begin{array}{l}\text { PC, ML, } \\
\text { SCRS }\end{array}$ & $\begin{array}{l}\text { US (NR), children } \\
\text { in grades } 7-12 \text { in } \\
1995 \text {-followed in } \\
1996,2001 \text {, and } \\
\text { 2008; RR = 79\%; } \\
\text { analytical n = } \\
9,115 ;\end{array}$ & $\begin{array}{l}\text { Disadvantage index } \\
\text { standardized and } \\
\text { summed: } \\
\text {-Proportion of female- } \\
\text { headed households } \\
\text {-Unemployment rate } \\
\text {-Proportion of } \\
\text { households receiving } \\
\text { public assistance } \\
\text {-Proportion of African } \\
\text { Americans } \\
\text {-Proportion below } \\
\text { poverty line }\end{array}$ & $\begin{array}{l}1990 \text { US Census } \\
\text { tracts }\end{array}$ & Yes & $\begin{array}{l}\text { BMI } \\
\text { (1996,2001, } \\
\text { and 2008) }\end{array}$ & $\begin{array}{l}\text { ML linear regression by } \\
\text { year } \\
\text { Survey weights and } \\
\text { design, age, sex } \\
\text { race/ethnicity, parent } \\
\text { education, household } \\
\text { income, family structure, } \\
\text { nhood disorder, nhood } \\
\text { safety }\end{array}$ & No & $\begin{array}{l}\text { + at } 1996 \\
+ \text { longitudinal }\end{array}$ \\
\hline $\begin{array}{l}\text { Grow et al, } \\
2010(2)\end{array}$ & $\begin{array}{l}\mathrm{XS}, \mathrm{ML} \text {, } \\
\text { all clinics } \\
\text { of } \\
\text { primary } \\
\text { health } \\
\text { care } \\
\text { provider }\end{array}$ & $\begin{array}{l}\text { King County } \\
\text { Washington, US; } \\
6-18 \text { y age }(6 \\
\text { months prior to } \\
\left.\text { July } 31^{\text {st }}, 2006\right) \mathrm{N} \\
=8616 ; \text { RR? }\end{array}$ & $\begin{array}{l}\text { 1) Median household } \\
\text { income } \\
\text { 2) \% population residing } \\
\text { in home they own } \\
\text { 3) \% females with high } \\
\text { school or less } \\
\text { 4) } \% \text { single parent } \\
\text { 5) } \% \text { white race }\end{array}$ & $\begin{array}{l}\text { Administrative } \\
\text { (census tract) } \\
\text { based on child's } \\
\text { residence }\end{array}$ & Yes & Obese (CDC) & $\begin{array}{l}\text { ML logistic regression } \\
\text { with Conditional } \\
\text { Autoregressive } \\
\text { Regression (CAR) } \\
\text { correlation structure } \\
\text { (accounts for correlation } \\
\text { between adjacent } \\
\text { census tracts) } \\
\text { Age, sex, health plan } \\
\text { status (indicator of } \\
\text { individual SES) }\end{array}$ & No & $\begin{array}{l}\text { - for 1) median } \\
\text { income } \\
\text { + for 2) home } \\
\text { ownership }\end{array}$ \\
\hline $\begin{array}{l}\text { Lovasi et al, } \\
2011 \text { (3) }\end{array}$ & $\mathrm{XS}, \mathrm{ML}$ & $\begin{array}{l}\text { New York City, } \\
\text { US; Head Start } \\
\text { participants (low } \\
\text { income) 2-5 y age } \\
\text { in 2003-2005; N = } \\
\text { 428; RR? }\end{array}$ & $\begin{array}{l}\text { 1) \% living in poverty } 2 \text { ) } \\
\% \text { black } \\
\text { 3) \% foreign born }\end{array}$ & $\begin{array}{l}\text { Children living } \\
\text { within } 2 \mathrm{~km} \text { of } \\
\text { Head Start } \\
\text { Center: } 0.5 \mathrm{~km} \\
\text { buffer around } \\
\text { straight line from } \\
\text { center to home; } \\
\text { Children living } \\
\text { outside } 2 \mathrm{~km}: 0.5 \\
\mathrm{~km} \text { circular buffer } \\
\text { around home and } \\
\text { center }\end{array}$ & Yes & $\begin{array}{l}\text { A) BMI Z- } \\
\text { score (CDC) } \\
\text { B) Sum of } \\
\text { triceps and } \\
\text { subscapular } \\
\text { skinfolds }\end{array}$ & $\begin{array}{l}\text { GEE by center } \\
\text { Child (age, sex, } \\
\text { race/ethnicity); Mother } \\
\text { (age, birth outside US, } \\
\text { use of Spanish, } \\
\text { employment/student } \\
\text { status); Household (\# of } \\
\text { rooms in home); Nhood } \\
\text { (population density, } \\
\text { land-use mix, subway } \\
\text { stop density, bus stop } \\
\text { density, intersection } \\
\text { density, homicide rate, } \\
\text { pedestrian-auto injury } \\
\text { rate, traffic volume, \% } \\
\text { sidewalks rated as filthy, } \\
\% \text { vacant housing, }\end{array}$ & No & $\varnothing$ for all \\
\hline
\end{tabular}


Table 1: Characteristics of reviewed studies that examined the relationship between area deprivation and child excess weight

\begin{tabular}{|c|c|c|c|c|c|c|c|c|c|}
\hline \multirow[b]{2}{*}{ Reference } & \multicolumn{2}{|c|}{ Study basics } & \multicolumn{2}{|c|}{ Deprivation } & \multicolumn{2}{|c|}{ Weight status } & \multicolumn{2}{|l|}{ Analysis } & \multirow[t]{2}{*}{ Results } \\
\hline & $\begin{array}{l}\text { Design } \\
\& \text { level } \\
\text { of } \\
\text { analysis }\end{array}$ & $\begin{array}{l}\text { Population } \\
\text { (location; age; } \\
\text { sample size) }\end{array}$ & Main predictor(s) & Place boundary & $\begin{array}{c}\text { Measured } \\
\text { height and } \\
\text { weight? }\end{array}$ & $\begin{array}{l}\text { Main weight } \\
\text { status } \\
\text { measure(s) }\end{array}$ & $\begin{array}{l}\text { Confounders and } \\
\text { other statistical } \\
\text { adjustments }\end{array}$ & $\begin{array}{l}\text { Addressed } \\
\text { residential } \\
\text { mobility? }\end{array}$ & \\
\hline $\begin{array}{l}\text { Schwartz et } \\
\text { al, } 2011(4)\end{array}$ & $\begin{array}{l}\text { XS, ML, } \\
\text { all clinics } \\
\text { of } \\
\text { primary } \\
\text { health } \\
\text { care } \\
\text { provider }\end{array}$ & $\begin{array}{l}\text { Pennsylvania, } \\
\text { US; } 5-18 \text { y age } \\
\text { from } 2001 \text { to Feb } \\
2008 ; N= \\
48,402 ; \\
\text { RR = } 80.2 \%\end{array}$ & $\begin{array}{l}\text { Modified Townsend } \\
\text { Index ( } 2000 \text { Census) } \\
\text {-less than high school } \\
\text {-not in labour force } \\
\text {-in poverty } \\
\text { - on public assistance } \\
\text { - civilian unemployment } \\
\text {-does not own a car }\end{array}$ & $\begin{array}{l}\text { Administrative } \\
\text { boundaries -- } \\
\text { Mixed MCD } \\
\text { (Towns, } \\
\text { Boroughs, } \\
\text { Census tracts for } \\
\text { cities) }\end{array}$ & Yes & $\begin{array}{l}\text { BMI Z-score } \\
\text { (CDC) } \\
\text {-Most recent } \\
\text { measure }\end{array}$ & $\begin{array}{l}\text { street tree density, park } \\
\text { access, playground } \\
\text { access) } \\
\text { ML linear regression } \\
\text { Stratified by age } \\
\text { categories; Child (sex, } \\
\text { race/ethnicity); Area } \\
\text { (geocode scores) }\end{array}$ & No & $\begin{array}{l}+ \text { for all age } \\
\text { strata }\end{array}$ \\
\hline $\begin{array}{l}\text { Slater et al, } \\
2010(5)\end{array}$ & $\begin{array}{l}\text { XS, ML, } \\
\text { SCRS } \\
\text { (school) }\end{array}$ & $\begin{array}{l}\text { US }(N R) ; 8^{\text {th }} \text { and } \\
10^{\text {th }} \text { graders in } \\
2001-2003 ; \\
\text { analytical } n= \\
16,016 ?\end{array}$ & $\begin{array}{l}\text { Area median income } \\
\text { level (Census 2000) }\end{array}$ & $\begin{array}{l}\text { School catchment } \\
\text { area }\end{array}$ & No & $\begin{array}{l}\text { A) BMI } \\
\text { B) Obese } \\
\text { (CDC) }\end{array}$ & $\begin{array}{l}\text { Random effects logistic } \\
\text { regression by } \\
\text { catchment area } \\
\\
\text { Survey weights; Area } \\
\text { (outdoor PA settings } \\
\text { scale, commercial PA } \\
\text { facilities, nhood } \\
\text { disorder, nhood safety, } \\
\text { local compactness } \\
\text { index, traffic danger); } \\
\text { Child (sex, grade, race/ } \\
\text { ethnicity, income, } \\
\text { working status); Parents } \\
\text { ( education level, } \\
\text { mother's working } \\
\text { status), region, year of } \\
\text { data collection, private } \\
\text { vs public school }\end{array}$ & No & $\begin{array}{l}\text { - for BMI and } \\
\text { obesity }\end{array}$ \\
\hline $\begin{array}{l}\text { Townsend et } \\
\text { al, } 2012 \text { (6) }\end{array}$ & $\begin{array}{l}\text { XS, CCL, } \\
\text { Census } \\
\text { (primary/ } \\
\text { middle } \\
\text { schools) }\end{array}$ & $\begin{array}{l}\text { England (NCMP); } \\
4-5 \text { and } 10-11 \text { y } \\
\text { olds in } 2007 / 08 ; \\
\mathrm{N}=974,678 ; \mathrm{RR} \\
=88 \% ; \text { analytic } \mathrm{n} \\
=788,525\end{array}$ & $\begin{array}{l}\text { 1) Area deprivation => } \\
\text { child Well-being index } \\
\text { (material well-being, } \\
\text { health, education, } \\
\text { crime, housing, } \\
\text { environment, \& children } \\
\text { in need) } \\
\text { 2) School deprivation } \\
=>\% \text { of students } \\
\text { eligible for free school } \\
\text { meals }\end{array}$ & $\begin{array}{l}\text { 1) LSOA } \\
\text { (residential postal } \\
\text { code) } \\
\text { 2) School }\end{array}$ & Yes & $\begin{array}{l}\text { BMI Z-score } \\
\text { (UK 1990) }\end{array}$ & $\begin{array}{l}\text { CCL linear regression } \\
\text { Stratified by age group; } \\
\text { Child (age, sex, } \\
\text { ethnicity, month of } \\
\text { measurement); LSOA } \\
\text { (urban/rural status); } \\
\text { School (\# of pupils, type } \\
\text { of school); Primary Care } \\
\text { Trust level (participation } \\
\text { rate, indicator of } \\
\text { proportion that rounded } \\
\text { height/weight) }\end{array}$ & No & $\begin{array}{l}\text { + for both 1) } \\
\text { area } \\
\text { deprivation and } \\
\text { 2) school } \\
\text { deprivation }\end{array}$ \\
\hline
\end{tabular}


Table 1: Characteristics of reviewed studies that examined the relationship between area deprivation and child excess weight

\begin{tabular}{|c|c|c|c|c|c|c|c|c|c|}
\hline \multicolumn{3}{|c|}{ Study basics } & \multicolumn{2}{|c|}{ Deprivation } & \multicolumn{2}{|c|}{ Weight status } & \multicolumn{2}{|c|}{ Analysis } & \multirow[t]{2}{*}{ Results } \\
\hline Reference & $\begin{array}{l}\text { Design } \\
\& \text { level } \\
\text { of } \\
\text { analysis }\end{array}$ & $\begin{array}{l}\text { Population } \\
\text { (location; age; } \\
\text { sample size) }\end{array}$ & Main predictor(s) & Place boundary & $\begin{array}{c}\text { Measured } \\
\text { height and } \\
\text { weight? }\end{array}$ & $\begin{array}{l}\text { Main weight } \\
\text { status } \\
\text { measure(s) }\end{array}$ & $\begin{array}{l}\text { Confounders and } \\
\text { other statistical } \\
\text { adjustments }\end{array}$ & $\begin{array}{l}\text { Addressed } \\
\text { residential } \\
\text { mobility? }\end{array}$ & \\
\hline $\begin{array}{l}\text { Voorhees et } \\
\text { al, } 2009 \text { (7) }\end{array}$ & $\begin{array}{l}\text { XS, ML, } \\
\text { SRS }\end{array}$ & $\begin{array}{l}\text { US }(6 \text { states); } \\
\text { grade } 6 \text { females } \\
\text { in } 2003 ; \text { RR }= \\
80 \% ; \text { analytic } n= \\
1,554\end{array}$ & $\begin{array}{l}\text { Townsend Index (2000 } \\
\text { US Census) } \\
\text {-\%workforce } \\
\text { unemployed } \\
\text {-avg \# persons per } \\
\text { household } \\
\text {-\%houses not owner } \\
\text { occupied } \\
\text {-\% households with no } \\
\text { vehicle }\end{array}$ & $\begin{array}{l}1 / 2 \text { mile buffer } \\
\text { surrounding girls' } \\
\text { residence } \\
\text { (index weighted } \\
\text { by block-group } \\
\text { area within } \\
\text { nhood) }\end{array}$ & Yes & BMI & $\begin{array}{l}\text { Mixed linear models by } \\
\text { state and school } \\
\text { Parental (employment, } \\
\text { education); Child (self- } \\
\text { reported free/reduced } \\
\text { price lunch, } \\
\text { race/ethnicity); School } \\
\text { (\% free/reduced price } \\
\text { lunch participants) }\end{array}$ & No & $\varnothing$ \\
\hline
\end{tabular}

$\mathbf{+}=$ a positive/direct statistically significant association; - = a negative/inverse statistically significant association; $\varnothing$ = a null statistical association; BMI = body mass index; CS = Convenience sample; $\mathbf{C C L}=$ Cross-classified multi-level model; $\mathbf{C D C}=$ Centers for Disease Control and Prevention overweight/obesity definitions; CMA=Census metropolitan area; GEE = Generalized

estimating equations; GMM = Growth mixture modeling; I = individual-level; IOTF = International Obesity Task Force overweight/obesity definitions; LSOA = Lower super output area; $\mathbf{M C D}=$

Minor civil division; $\mathbf{M L}=$ Multi-level; $\mathbf{N C M P}=$ National Child Measurement Programme Nhood $=$ neighbourhood; $\mathbf{N R}=$ nationally representative; $\mathbf{P C}=$ prospective cohort study; Ref $=$ reference

group; $\mathbf{R R}=$ response rate; $\mathbf{S C R S}=$ Stratified cluster random sample; $\mathbf{S R S}=$ stratified random sample; USDA=United States Department of Agriculture; $\mathbf{X S}=$ cross-sectional design 
study. Broadly speaking, seven studies examined young children, seven examined adolescents, six considered samples that ranged in age, and two studies stratified their samples, which included a range of ages.

\section{Material Deprivation}

Seven studies were found to examine the relationship between some measure of area deprivation and child excess weight (1-7) (Table 1). None examined social deprivation. Five out of these seven studies found a positive statistical association between area deprivation and child excess weight $(1 ; 2 ; 4-6)$, whereas two did not have significant results (3;7). Most studies used administrative boundaries to define place, although one used school catchment area (5), and two used buffers (3;7). Interestingly, the two studies that used buffers were the ones that did not find a significant association. Grow et al (2010) examined both median household income and percentage of residents owning their own home at the census tract level. They uncovered expected associations when they did not include the other place variables in the model (e.g. when both increased, obesity decreased); however, when the other place variables were included, the percentage of residents owning their own home became significant in the opposite direction, perhaps a result of multicollinearity (2). Only one of these studies was longitudinal, following a representative sample of American adolescents into young adulthood (1). The authors of this study found that deprivation was positively associated with BMI at baseline but was also related to a higher rate of BMI increase over time (1). Also of interest is the study by Townsend et al (2012), which examined almost one million children living in England. They found a significant positive cross-sectional association between both area and school deprivation and BMI Z-score in 4-5 and 10-11 year olds, with stronger effect sizes seen for the older age group (6). 
Table 2: Characteristics of reviewed studies that examined the relationship between social capital and/or disorder with child excess weight

\begin{tabular}{|c|c|c|c|c|c|c|c|c|c|}
\hline \multicolumn{3}{|c|}{ Study basics } & \multicolumn{2}{|c|}{ Social capital/disorder variables } & \multicolumn{2}{|c|}{ Weight status } & \multicolumn{2}{|l|}{ Analysis } & \multirow[t]{2}{*}{ Results } \\
\hline Reference & $\begin{array}{l}\text { Design } \\
\& \text { level } \\
\text { of } \\
\text { analysis }\end{array}$ & $\begin{array}{l}\text { Population } \\
\text { (location; age; } \\
\text { sample size) }\end{array}$ & Main predictor(s) & $\begin{array}{l}\text { Place } \\
\text { boundary }\end{array}$ & $\begin{array}{c}\text { Measured } \\
\text { height and } \\
\text { weight? }\end{array}$ & $\begin{array}{l}\text { Main weight } \\
\text { status } \\
\text { measure(s) }\end{array}$ & $\begin{array}{l}\text { Confounders and other } \\
\text { statistical adjustments }\end{array}$ & $\begin{array}{c}\text { Addressed } \\
\text { residential } \\
\text { mobility? }\end{array}$ & \\
\hline $\begin{array}{l}\text { Veitch et al, } \\
2012(8)\end{array}$ & PC, ML, & $\begin{array}{l}\text { Melbourne, AUZ; } 8- \\
9 \text { and } 13-15 \text { y of } \\
\text { age in } 2004, \\
\text { followed until } 2006 ; \\
\text { analytic } n=430 ; \\
\text { RR }=44 \%\end{array}$ & $\begin{array}{l}\text { Nhood social cohesion } \\
\text { Scale with five statements } \\
\text { about neighbors in the } \\
\text { nhood, Likert-type response } \\
\text { (average score) }\end{array}$ & $\begin{array}{l}\text { Nhood } \\
\text { perceived by } \\
\text { parent }\end{array}$ & $\begin{array}{l}\text { Yes } \\
\text { (although } \\
\text { some 6-7\% } \\
\text { parent- } \\
\text { reported) }\end{array}$ & BMI in 2006 & $\begin{array}{l}\text { ML linear regression by school } \\
\text { BMI in 2004, age, sex (did not } \\
\text { include maternal or area SES } \\
\text { because not associated in } \\
\text { bivariate analysis) }\end{array}$ & No & - \\
\hline $\begin{array}{l}\text { Burdette \& } \\
\text { Needham, } \\
2012 \text { (1) }\end{array}$ & $\begin{array}{l}\text { PC, ML, } \\
\text { SCRS } \\
\text { (school) }\end{array}$ & $\begin{array}{l}\text { US (NR), children in } \\
\text { grades } 7-12 \text { in } 1995 \\
\text {-followed in 1996, } \\
\text { 2001, and 2008; RR } \\
=79 \% ; \text { analytical n } \\
=9,115\end{array}$ & $\begin{array}{l}\text { Nhood disorder scale: } \\
\text { Degree that problems such } \\
\text { as trash on sidewalks, drug } \\
\text { dealers/users present in } \\
\text { nhood (summed items) }\end{array}$ & $\begin{array}{l}\text { Nhood } \\
\text { perceived by } \\
\text { parent in } \\
1996 ?\end{array}$ & Yes & $\begin{array}{l}\text { BMI } \\
\text { (1996,2001, } \\
\text { and 2008) }\end{array}$ & $\begin{array}{l}\text { ML linear regression by year } \\
\text { Survey weights and design, age, } \\
\text { sex race/ethnicity, parent } \\
\text { education, household income, } \\
\text { family structure, nhood } \\
\text { disadvantage, nhood safety }\end{array}$ & No & $\begin{array}{l}\text { + at } 1996 \\
\text { only } \\
=>\text { no long } \\
\text { association }\end{array}$ \\
\hline $\begin{array}{l}\text { Slater et al, } \\
2010(5)\end{array}$ & $\begin{array}{l}\text { XS, ML, } \\
\text { SCRS } \\
\text { (school) }\end{array}$ & $\begin{array}{l}\text { US (NR); } 8^{\text {th }} \text { and } \\
10^{\text {th }} \text { graders in } \\
2001-2003 ; \\
\text { analytical } n= \\
16,016 ?\end{array}$ & $\begin{array}{l}\text { Nhood disorder scale } \\
\text { (objectively measured): } \\
\text { Presence or absence of: } \\
\text { homeless people loitering, } \\
\text { bars on windows, } \\
\text { unkempt/dilapidated } \\
\text { buildings, security barriers } \\
\text { around properties, } \\
\text { vandalism or graffiti, teens } \\
\text { hanging out causing trouble } \\
\text { Disorder vs no disorder }\end{array}$ & $\begin{array}{l}\text { School } \\
\text { catchment } \\
\text { area }\end{array}$ & No & $\begin{array}{l}\text { A) BMI } \\
\text { B) Obese } \\
\text { (CDC) }\end{array}$ & $\begin{array}{l}\text { Random effects logistic regression } \\
\text { by catchment area } \\
\text { Survey weights; Area (outdoor PA } \\
\text { settings scale, commercial PA } \\
\text { facilities, nhood disorder, nhood } \\
\text { safety, local compactness index, } \\
\text { traffic danger); Child (sex, grade, } \\
\text { race/ ethnicity, income, working } \\
\text { status); Parents ( education level, } \\
\text { mother's working status), region, } \\
\text { year of data collection, private vs } \\
\text { public school }\end{array}$ & No & $\begin{array}{l}\text { + for both } \\
\text { BMl and } \\
\text { obesity }\end{array}$ \\
\hline
\end{tabular}

$+=$ a positive/direct statistically significant association; - = a negative/inverse statistically significant association; $\varnothing=$ a null statistical association; BMI = body mass index; CS = Convenience sample; CCL= Cross-classified multi-level model; $\mathbf{C D C}=$ Centers for Disease Control and Prevention overweight/obesity definitions; $\mathbf{C M A}=$ Census metropolitan area; $\mathbf{G E E}=\mathrm{Generalized} \mathrm{estimating} \mathrm{equations;}$ GMM = Growth mixture modeling; I = individual-level; IOTF = International Obesity Task Force overweight/obesity definitions; LSOA = Lower super output area; MCD = Minor civil division; ML = Multilevel; NCMP= National Child Measurement Programme; Nhood = neighbourhood; NR = nationally representative; PC = prospective cohort study; Ref = reference group; RR = response rate; $\mathbf{S C R S ~ = ~}$ Stratified cluster random sample; SRS = stratified random sample; USDA=United States Department of Agriculture; XS = cross-sectional design 


\section{Social capital and disorder}

Of the three studies retrieved (Table 2), one examined an indicator of social capital, social cohesion (8), while the other two focused on neighbourhood disorder $(1 ; 5)$. Veitch et al (2012), in their longitudinal study of Australian pre-teens and teenagers, estimated an inverse association between neighbourhood social cohesion, as perceived by the child's parent in 2004, and BMI measured in 2006. In their longitudinal study of American adolescents, Burdette \& Needham (2012) found that neighbourhood disorder, as perceived by the parent, was positively related to BMI at baseline but not over time (1). Finally, in a large representative sample of American adolescents, Slater et al (2010) estimated a positive cross-sectional association between objectively measured neighbourhood disorder, and BMI and obesity (5).

\section{Living location}

The majority of the studies included in this update (18/22) examined an indicator of living location or a related indicator of compactness, such as population size, population density, or county sprawl. Twelve of the 18 studies examined living location; an indicator of urban-rural status based on administrative boundaries, similar to that used in this thesis

(Table 3). Only two of these 12 were longitudinal and exactly half did not directly measure heights and weights to derive the excess weight indicator. Two studies were also based on the same data set, although they used slightly different age ranges $(9 ; 10)$. When comparing rural to urban living, 7/11 studies estimated a positive association between rural living and excess weight (9-15); however in one of these studies, this was among boys only (15). The remaining four had null results (16-19). In contrast, a study that compared urban 
Table 3: Characteristics of reviewed studies that examined the relationship between living location and child excess weight

\begin{tabular}{|c|c|c|c|c|c|c|c|c|c|}
\hline \multicolumn{3}{|c|}{ Study basics } & \multicolumn{2}{|c|}{ Living location } & \multicolumn{2}{|c|}{ Weight status } & \multicolumn{2}{|l|}{ Analysis } & \multirow[t]{2}{*}{ Results } \\
\hline Reference & $\begin{array}{l}\text { Design \& } \\
\text { level of } \\
\text { analysis }\end{array}$ & $\begin{array}{l}\text { Population } \\
\text { (location; age; } \\
\text { sample size) }\end{array}$ & Main predictor(s) & $\begin{array}{l}\text { Neighbourhood } \\
\text { boundary }\end{array}$ & $\begin{array}{l}\text { Measured } \\
\text { height and } \\
\text { weight? }\end{array}$ & $\begin{array}{l}\text { Main weight } \\
\text { status } \\
\text { measure(s) }\end{array}$ & $\begin{array}{l}\text { Confounders and other } \\
\text { statistical adjustments }\end{array}$ & $\begin{array}{l}\text { Addressed } \\
\text { residential } \\
\text { mobility? }\end{array}$ & \\
\hline $\begin{array}{l}\text { Bruner et al, } \\
2008 \text { (11) }\end{array}$ & $\mathrm{XS}, \mathrm{ML}$ & $\begin{array}{l}\text { Canada (NR); } \\
11-15 \text { y in 2001-02; } \\
\mathrm{n}=4,851 \\
\mathrm{RR}=?\end{array}$ & $\begin{array}{l}\text { Urban-rural status } \\
\text { based on Beale } \\
\text { coding system: } \\
\text {-Large metro regions } \\
\text { (Ref) } \\
\text {-Medium metro } \\
\text { regions } \\
\text {-Small metro } \\
\text { regions } \\
\text {-Non-metro adjacent } \\
\text { regions } \\
\text {-Rural region }\end{array}$ & $\begin{array}{l}\text { Census division } \\
\text { (based on postal } \\
\text { codes of schools) }\end{array}$ & No & $\begin{array}{l}\text { A) Overweight } \\
\text { incl obesity } \\
\text { (IOTF) } \\
\text { B) } \\
\text { Obese } \\
\text { (IOTF) }\end{array}$ & $\begin{array}{l}\text { Generalized Estimating } \\
\text { Equations - binomial } \\
\text { Age, sex, SES, } \\
\text { geographic region, PA } \\
\text { level, dietary intake, } \\
\text { amount of screen time }\end{array}$ & No & $\begin{array}{l}\text { A) } \\
\text { + for Non- } \\
\text { metro } \\
\text { adjacent } \\
\text { + Rural region } \\
\text { B) } \\
\text { + for Non- } \\
\text { metro } \\
\text { adjacent } \\
\text { + Rural region }\end{array}$ \\
\hline $\begin{array}{l}\text { Cleland et al, } \\
2010(16)\end{array}$ & XS, I, SRS & $\begin{array}{l}\text { Victoria, AUZ; } \\
\text { Children aged 5-12 } \\
\text { y living in } \\
\text { disadvantaged } \\
\text { areas from 2007- } \\
08 ; n=636(R R= \\
41 \%)\end{array}$ & $\begin{array}{l}\text { Living in a rural area } \\
\text { (areas outside of } \\
\text { metropolitan } \\
\text { Melbourne, and } \\
\text { outside a } 25 \mathrm{~km} \\
\text { radius of rural cities) }\end{array}$ & $\begin{array}{l}\text { Australian Bureau } \\
\text { of Statistics } \\
\text { definitions }\end{array}$ & Yes & $\begin{array}{l}\text { Overweight } \\
\text { (IOTF) }\end{array}$ & $\begin{array}{l}\text { Logistic regression } \\
\text { Child age, maternal } \\
\text { education level, marital } \\
\text { status, and BMI }\end{array}$ & No & $\varnothing$ \\
\hline $\begin{array}{l}\text { Ismailov \& } \\
\text { Leatherdale, } \\
2010 \text { (17) }\end{array}$ & $\begin{array}{l}\text { XS, CS of } \\
\text { schools, I }\end{array}$ & $\begin{array}{l}\text { Ontario, Canada; } \\
\text { grades } 9-12 \text { in } \\
2005-2006 ; n= \\
25,416 ; R R= \\
73.5 \%\end{array}$ & $\begin{array}{l}\text { Urban-rural status } \\
\text {-Urban } \\
\text {-Suburban } \\
\text {-Rural (Ref) } \\
\text { (unclear what each } \\
\text { means) }\end{array}$ & $\begin{array}{l}\text { School administer } \\
\text { description of } \\
\text { region of school } \\
\text { (unclear) }\end{array}$ & No & $\begin{array}{l}\text { A) } \\
\text { Overweight } \\
\text { (not incl } \\
\text { obesity?) } \\
\text { (CDC) } \\
\text { B) } \\
\text { Obese (CDC) }\end{array}$ & $\begin{array}{l}\text { Logistic regression } \\
\text { Grade, PA level, screen } \\
\text { time, perception of body } \\
\text { weight, } \\
\text { Stratified by sex, No } \\
\text { adjustment for clustering } \\
\text { within schools, or SES at } \\
\text { the individual or area level }\end{array}$ & No & $\begin{array}{l}\text { Boys } \\
\text { A) } \varnothing \\
\text { B) } \varnothing \\
\text { Girls } \\
\text { A) - for } \\
\text { suburban } \\
\text { B) - for } \\
\text { suburban }\end{array}$ \\
\hline $\begin{array}{l}\text { Lewis et al, } \\
2006(12)\end{array}$ & $\begin{array}{l}\text { XS, } \\
\text { SCRS, I }\end{array}$ & $\begin{array}{l}\text { Georgia, US; } 4^{\text {th }} \\
8^{\text {th }} \text { and } 11^{\text {th }} \text { graders } \\
\text { in } 2002 ; n=3,114 ; \\
R R=54 \%\end{array}$ & $\begin{array}{l}\text { Urban-rural status } \\
\text {-Urban (Ref) } \\
\text {-Suburban } \\
\text {-Rural growth } \\
\text {-Rural decline }\end{array}$ & $\begin{array}{l}\text { Administrative } \\
\text { boundary (County) }\end{array}$ & Yes & Obese (CDC) & $\begin{array}{l}\text { Logistic regression } \\
\text { Grade, sex, race, sex-race } \\
\text { interaction, county } \\
\text { economic tier }\end{array}$ & No & $\begin{array}{l}\text { + for Rural } \\
\text { growth } \\
+ \text { for Rural } \\
\text { decline }\end{array}$ \\
\hline $\begin{array}{l}\text { Liu et al, } 2008 \\
\text { (9) }\end{array}$ & XS, I, NR & $\begin{array}{l}\text { US; } 10-17 \text { of age in } \\
2003 ; n= \\
45,082\end{array}$ & $\begin{array}{l}\text { Urban (Ref) } \\
\text { vs Rural } \\
\text { Defined based on }\end{array}$ & $\begin{array}{l}\text { Administrative } \\
\text { boundary (County) }\end{array}$ & No & Obese (CDC) & $\begin{array}{l}\text { Logistic regression } \\
P A \text { level, age categories, } \\
\text { sex, race/ethnicity, health }\end{array}$ & No & $\begin{array}{l}\text { + for Rural } \\
\text { living }\end{array}$ \\
\hline
\end{tabular}


Table 3: Characteristics of reviewed studies that examined the relationship between living location and child excess weight

\begin{tabular}{|c|c|c|c|c|c|c|c|c|c|}
\hline \multicolumn{3}{|c|}{ Study basics } & \multicolumn{2}{|c|}{ Living location } & \multicolumn{2}{|c|}{ Weight status } & \multicolumn{2}{|l|}{ Analysis } & \multirow[t]{2}{*}{ Results } \\
\hline Reference & $\begin{array}{l}\text { Design \& } \\
\text { level of } \\
\text { analysis }\end{array}$ & $\begin{array}{c}\text { Population } \\
\text { (location; age; } \\
\text { sample size) }\end{array}$ & Main predictor(s) & $\begin{array}{c}\text { Neighbourhood } \\
\text { boundary }\end{array}$ & $\begin{array}{l}\text { Measured } \\
\text { height and } \\
\text { weight? }\end{array}$ & $\begin{array}{c}\text { Main weight } \\
\text { status } \\
\text { measure(s) }\end{array}$ & $\begin{array}{l}\text { Confounders and other } \\
\text { statistical adjustments }\end{array}$ & $\begin{array}{l}\text { Addressed } \\
\text { residential } \\
\text { mobility? }\end{array}$ & \\
\hline $\begin{array}{l}\text { Lutfiyya et al, } \\
2007 \text { (10) }\end{array}$ & $X S, I$ & $\begin{array}{l}\text { US (NR); } 5-18 \text { y in } \\
2003-2004 ; n= \\
46,396 \text { (used same } \\
\text { survey as Liu et al, } \\
2007 \text { ) }\end{array}$ & $\begin{array}{l}=>\text { Urban - living } \\
\text { inside a Metro or } \\
\text { Micropolitan Statistical } \\
\text { Area (MSA) } \\
\text { Ref } \\
\text { =>Rural - not living in } \\
\text { a MSA }\end{array}$ & $\begin{array}{l}\text { Administrative } \\
\text { boundaries (census } \\
\text { definitions) }\end{array}$ & No & $\begin{array}{l}\text { Overweight incl } \\
\text { obesity (CDC) }\end{array}$ & $\begin{array}{l}\text { status, electronic media } \\
\text { use, household poverty } \\
\text { status, parental education, } \\
\text { number of children in the } \\
\text { family, neighbourhood } \\
\text { safety, parental PA level, } \\
\text { region of residence } \\
\text { Logistic regression } \\
\\
\text { PA level, household } \\
\text { income, sex, sports team } \\
\text { participation, health plan } \\
\text { status, race, health care } \\
\text { access, health status, } \\
\text { non-school computer-use, } \\
T V \text {-use }\end{array}$ & No & $\begin{array}{l}+ \text { for living in a } \\
\text { rural area }\end{array}$ \\
\hline $\begin{array}{l}\text { McMurray et } \\
\text { al, } 1999(13)\end{array}$ & $\begin{array}{l}\text { XS, } \\
\text { SCRS, }\end{array}$ & $\begin{array}{l}3^{\text {rd }} \text { and } 4^{\text {th }} \text { grade in } \\
\text { 1996?; North } \\
\text { Carolina (US); } n= \\
2,207 \text { (analytic } n= \\
2,113) ; R R=60 \%\end{array}$ & $\begin{array}{l}\text { =>Urban - living } \\
\text { inside a Standard } \\
\text { Metropolitan } \\
\text { Statistical Area } \\
\text { (SMSA) and a city } \\
\text { with } 50,000+\text { people } \\
\text { Ref } \\
=>\text { Rural - not living in } \\
\text { a SMSA, in a } \\
\text { community }<2,500 \\
\text { people }\end{array}$ & $\begin{array}{l}\text { Administrative } \\
\text { boundaries (census } \\
\text { definitions c. 1982) } \\
\text { determined by } \\
\text { school location }\end{array}$ & Yes & $\begin{array}{l}\text { Obesity } \\
\text { (BMI and } \\
\text { skinfolds }>90 \text { th } \\
\text { percentile for } \\
\text { age and } \\
\text { sex) }\end{array}$ & $\begin{array}{l}\text { Logistic regression } \\
\text { Survey design, sex, race, } \\
\text { PA level, family income }\end{array}$ & No & $\begin{array}{l}+ \text { for living in a } \\
\text { rural area }\end{array}$ \\
\hline $\begin{array}{l}\text { Nonnemaker } \\
\text { et al, } 2009 \\
\text { (18) }\end{array}$ & PC & $\begin{array}{l}\text { US; } \\
12-17 y \text { of age } \\
\text { followed to } 18-23 \text { y } \\
(1997-2003) ; \mathrm{N}= \\
8,917\end{array}$ & $\begin{array}{l}\text { => Living in a Central } \\
\text { Metro Statistical Area } \\
\text { (CMSA) } \\
=>\text { Living outside a } \\
\text { CMSA (Ref) }\end{array}$ & $\begin{array}{l}\text { Administrative } \\
\text { boundaries } \\
\text { (Metropolitan } \\
\text { Statistical Areas) }\end{array}$ & No & BMI & $\begin{array}{l}\text { GMM (variation across } \\
\text { classes only), multinomial } \\
\text { regression } \\
\text { Race, mother's education, } \\
\text { parent's BMI, smoking } \\
\text { status, marijuana user, } \\
\text { adoption status, family } \\
\text { structure, household size, } \\
\text { income (unclear if } \\
\text { pertained to child) }\end{array}$ & $\begin{array}{l}\text { Unable to } \\
\text { account for } \\
\text { changes in } \\
\text { place } \\
\text { variables } \\
\text { over time }\end{array}$ & $\varnothing$ \\
\hline
\end{tabular}


Table 3: Characteristics of reviewed studies that examined the relationship between living location and child excess weight

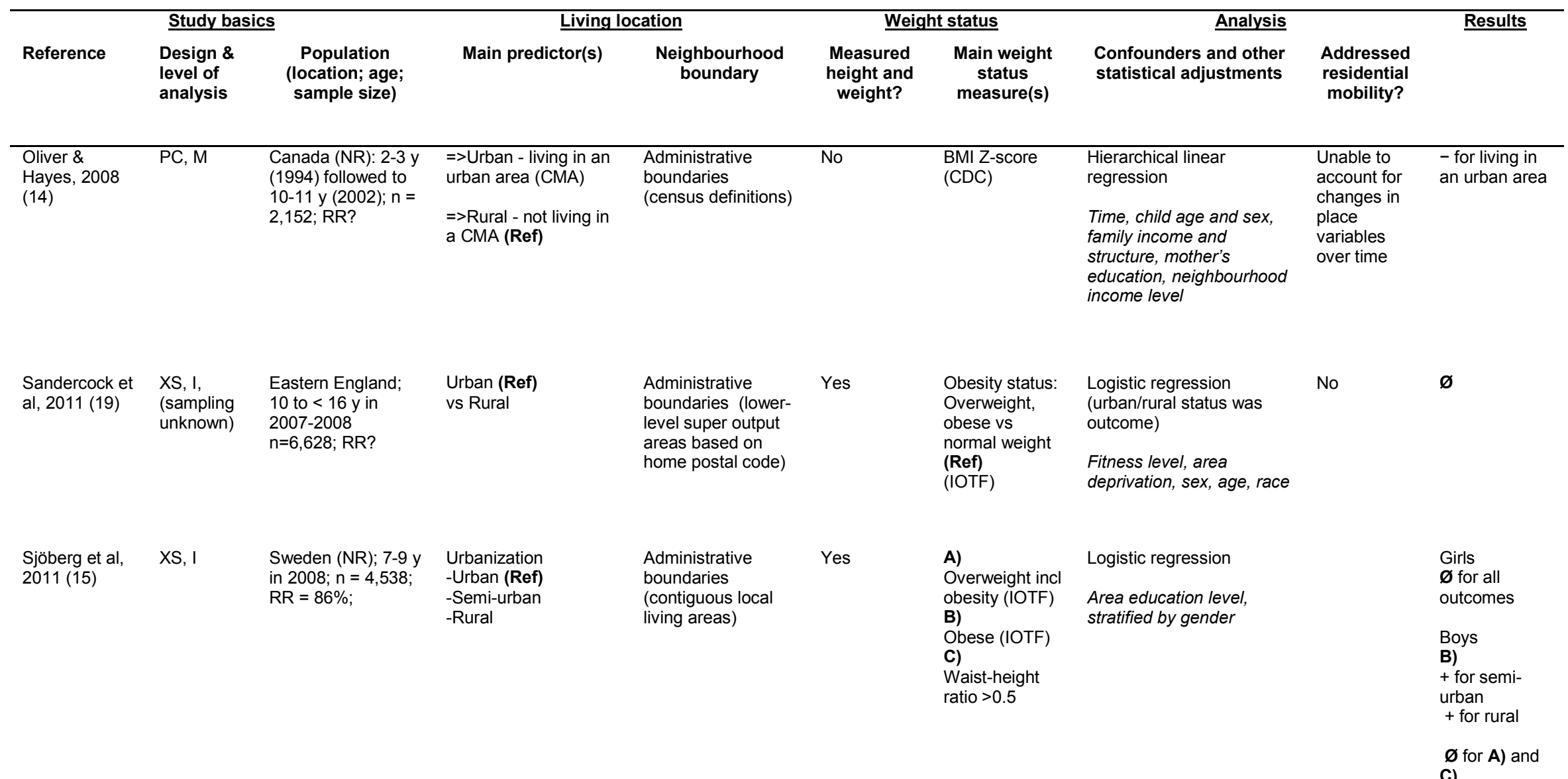


Table 3: Characteristics of reviewed studies that examined the relationship between living location and child excess weight

\begin{tabular}{|c|c|c|c|c|c|c|c|c|c|}
\hline \multicolumn{3}{|c|}{ Study basics } & \multicolumn{2}{|c|}{ Living location } & \multicolumn{2}{|c|}{ Weight status } & \multicolumn{2}{|l|}{ Analysis } & \multirow[t]{2}{*}{ Results } \\
\hline Reference & $\begin{array}{l}\text { Design \& } \\
\text { level of } \\
\text { analysis }\end{array}$ & $\begin{array}{l}\text { Population } \\
\text { (location; age; } \\
\text { sample size) }\end{array}$ & Main predictor(s) & $\begin{array}{l}\text { Neighbourhood } \\
\text { boundary }\end{array}$ & $\begin{array}{c}\text { Measured } \\
\text { height and } \\
\text { weight? }\end{array}$ & $\begin{array}{l}\text { Main weight } \\
\text { status } \\
\text { measure(s) }\end{array}$ & $\begin{array}{l}\text { Confounders and other } \\
\text { statistical adjustments }\end{array}$ & $\begin{array}{c}\text { Addressed } \\
\text { residential } \\
\text { mobility? }\end{array}$ & \\
\hline $\begin{array}{l}\text { Verger et al, } \\
2007(20)\end{array}$ & $\begin{array}{l}\text { XS, } \\
\text { SCRS, ML }\end{array}$ & $\begin{array}{l}\text { Southeastern } \\
\text { France; children } \\
3.5-4.5 \text { y of age } \\
\text { attending nursery } \\
\text { schools from 2002- } \\
2003 ; n=2,496 ; \\
\text { RR }=84 \%\end{array}$ & $\begin{array}{l}\text { Urban-rural status } \\
\text {-Rural or semi urban } \\
\text { (Ref) } \\
\text {-Urban }\end{array}$ & Municipality & Yes & $\begin{array}{l}\text { A) } \\
\text { Overweight } \\
\text { (not incl } \\
\text { obesity)(IOTF) } \\
\text { B) } \\
\text { Obese (IOTF) }\end{array}$ & $\begin{array}{l}\text { Hierarchical regression } \\
\text { (logistic for A and Poisson } \\
\text { for B) } \\
\text { Sex, mother's working } \\
\text { status, child in centre- } \\
\text { based care, other children } \\
\text { in household, type of } \\
\text { father's occupation (did } \\
\text { not adjust for area } \\
\text { disadvantage due to } \\
\text { multicollinearity) }\end{array}$ & & $\begin{array}{l}\text { A) } \varnothing \\
\text { B) + for urban } \\
\text { living }\end{array}$ \\
\hline
\end{tabular}

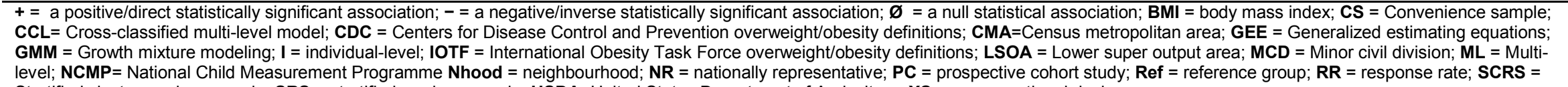
Stratified cluster random sample; $\mathbf{S R S}=$ stratified random sample; USDA=United States Department of Agriculture; $\mathbf{X S}=$ cross-sectional design 
to rural/semi-rural living, found that urban living was positively related to obesity in 3.5 4.5 year old French children (20).

Among those that compared suburban (or semi-urban) to urban living $(n=3)$, one study found a positive association between suburban living and both overweight and obesity in a sample of adolescents (11). Another study, based on children aged 7-9 years, estimated a similar association for obese boys, but not for overweight boys, or overweight or obese girls (15). The third study, which examined children in grades four, eight and 11, did not find a significant association (12). Finally, a large study of adolescents living in the province of Ontario, Canada compared suburban living to rural living. Results for boys were not significant, but among girls, suburban living was found to relate to decreased overweight and obesity (17).

Six out of the 18 studies examined indicators related to living location (Table 4). Burdette \& Needham (2012), in their longitudinal study of American adolescents, did not find that neighbourhood population size was related to BMI (1). Among the three studies that examined population density, two had null findings $(3 ; 21)$ and the third uncovered an inverse association with BMI Z-score in the 10-13 year old age group, but not the other two age groups they examined (5-9 year olds or 14-18 year olds) (4). Three studies examined sprawl or area compactness. Schwartz et al (2011) found that among the oldest age groups (10-13 and 14-18 years), but not the youngest group (5-9 years), county sprawl was positively related to BMI Z-score (4). Slater et al (2010) found that as area compactness increased, BMI and obesity decreased among adolescents in grades eight and 10 (5). In contrast to these cross-sectional studies, a longitudinal study conducted by Ewing et al 
Table 4: Characteristics of reviewed studies that examined the relationship between exposures related to living location and child excess weight

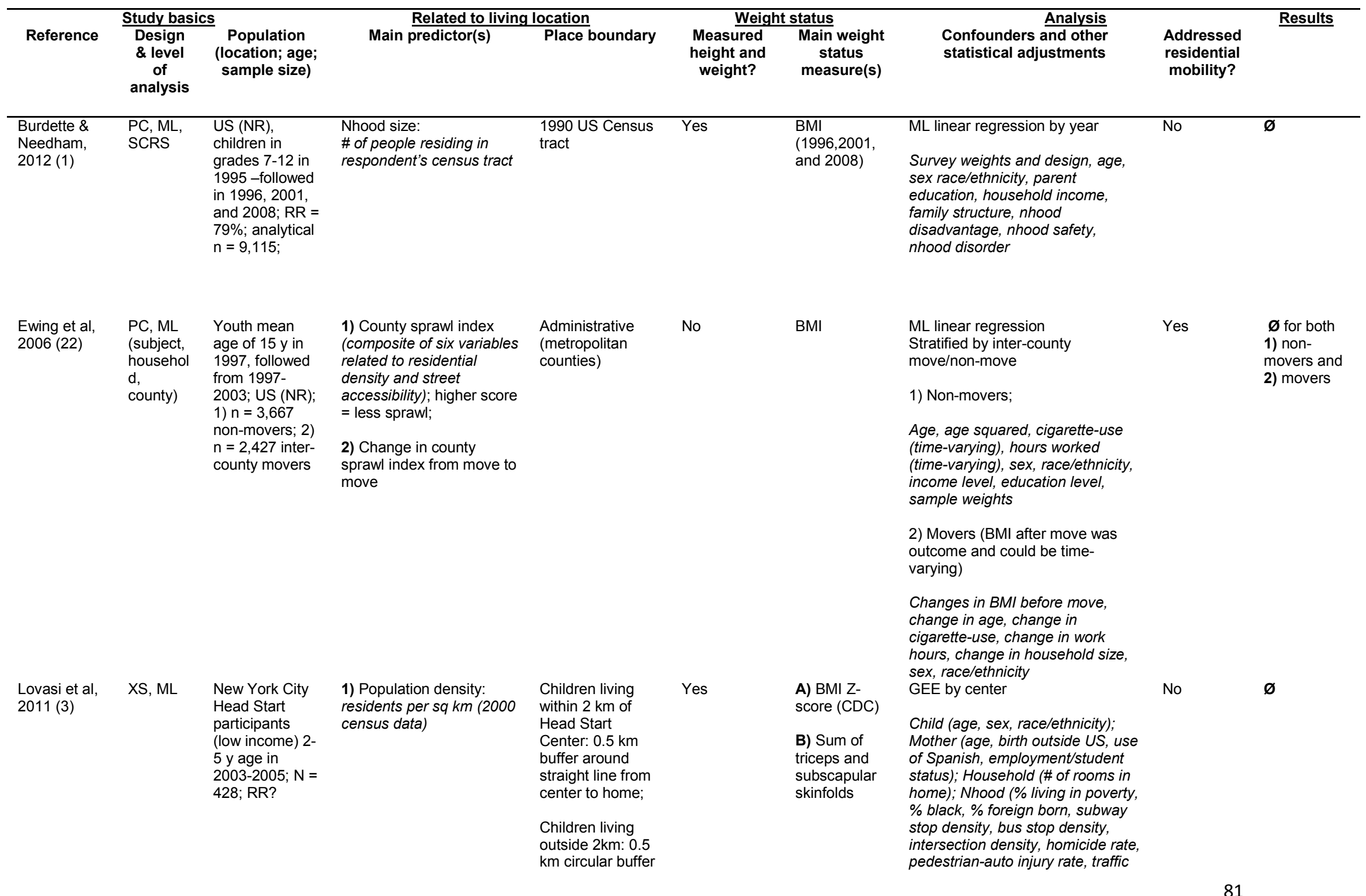


Table 4: Characteristics of reviewed studies that examined the relationship between exposures related to living location and child excess weight

\begin{tabular}{|c|c|c|c|c|c|c|c|c|c|}
\hline \multicolumn{3}{|c|}{ Study basics } & \multicolumn{2}{|c|}{ Related to living location } & \multicolumn{2}{|c|}{ Weight status } & \multicolumn{2}{|l|}{ Analysis } & \multirow[t]{2}{*}{ Results } \\
\hline Reference & $\begin{array}{l}\text { Design } \\
\& \text { level } \\
\text { of } \\
\text { analysis }\end{array}$ & $\begin{array}{l}\text { Population } \\
\text { (location; age; } \\
\text { sample size) }\end{array}$ & Main predictor(s) & Place boundary & $\begin{array}{l}\text { Measured } \\
\text { height and } \\
\text { weight? }\end{array}$ & $\begin{array}{l}\text { Main weight } \\
\text { status } \\
\text { measure(s) }\end{array}$ & $\begin{array}{l}\text { Confounders and other } \\
\text { statistical adjustments }\end{array}$ & $\begin{array}{l}\text { Addressed } \\
\text { residential } \\
\text { mobility? }\end{array}$ & \\
\hline & & & & $\begin{array}{l}\text { around home and } \\
\text { center }\end{array}$ & & & $\begin{array}{l}\text { volume, \% sidewalks rated as } \\
\text { filthy, \% vacant housing, street } \\
\text { tree density, park access, } \\
\text { playground access) }\end{array}$ & & \\
\hline $\begin{array}{l}\text { Liu et al, } \\
2007(21)\end{array}$ & $X S, I$ & $\begin{array}{l}\text { Indianapolis, } \\
\text { US; } 3-18 \text { y age } \\
\text { in } 2000 ; n= \\
7,334\end{array}$ & $\begin{array}{l}\text { Population density }(2000 \\
\text { Census data) } \\
\text {-Sparse }(0-149 \text { persons/ } \\
\text { sq km) } \\
\text {-Moderate }(150-499) \\
\text {-Dense }(\geq 500)\end{array}$ & $\begin{array}{l}\text { Administrative } \\
\text { (Township) }\end{array}$ & Yes & $\begin{array}{l}\text { Ordinal } \\
\text { obesity index } \\
\text { - BMl } \\
\text { categorized } \\
\text { (CDC) as } \\
4:>98^{\text {th }} \% \text { ile } \\
3:>95^{\text {th } \% \text { ile }} \\
2:>85^{\text {th }} \% \text { ile } \\
1: \leq 85^{\text {th } \% \text { ile }}\end{array}$ & $\begin{array}{l}\text { Cumulative logistic regression } \\
\text { Sex, race/ethnicity, age, average } \\
\text { block-group median family income } \\
\text { in nhood }\end{array}$ & No & $\varnothing$ \\
\hline $\begin{array}{l}\text { Schwartz et } \\
\text { al, } 2011 \text { (4) }\end{array}$ & $\begin{array}{l}\mathrm{XS}, \mathrm{ML}, \\
\text { all clinics } \\
\text { of a } \\
\text { primary } \\
\text { health } \\
\text { care } \\
\text { provider }\end{array}$ & $\begin{array}{l}\text { Pennsylvania, } \\
\text { US; } 5-18 \text { y age } \\
\text { from } 2001 \text { to } \\
\text { Feb 2008; } N= \\
48,402 ; \\
R R=80.2 \% ; \\
\text { analytical } n= \\
47,769\end{array}$ & $\begin{array}{l}\text { 1) Population density } \\
\text { (\#/sq mile) } \\
\text { 2) Country sprawl index } \\
\text { (gross population density, } \\
\% \text { living at low population } \\
\text { densities, \% living at high } \\
\text { population densities, } \\
\text { urbanized density, } \\
\text { average block size, small } \\
\text { block size) } \\
\text { Higher score = more } \\
\text { sprawl }\end{array}$ & $\begin{array}{l}\text { Two definitions } \\
\text { compared for 1) } \\
\text { i) } 0.5 \text { mile buffer } \\
\text { ii) Mixed MCD } \\
\text { (Towns, } \\
\text { boroughs, census } \\
\text { tracts in cities) } \\
\text { County for (2) }\end{array}$ & Yes & $\begin{array}{l}\text { BMI Z-score } \\
\text { (CDC) } \\
\text {-Most recent } \\
\text { measure }\end{array}$ & $\begin{array}{l}\text { ML linear regression } \\
\text { Stratified by age categories (5-9, } \\
\text { 10-13, 14-18y); Child (sex, } \\
\text { race/ethnicity); Area (geocode } \\
\text { scores, deprivation) }\end{array}$ & No & $\begin{array}{l}\text { 1) } \\
- \text { for i) in } \\
10-13 \text { y age } \\
\text { group only } \\
\text { 2) } \\
+ \text { in all ages } \\
\text { except 5-9 }\end{array}$ \\
\hline
\end{tabular}


Table 4: Characteristics of reviewed studies that examined the relationship between exposures related to living location and child excess weight

\begin{tabular}{|c|c|c|c|c|c|c|c|c|c|}
\hline \multicolumn{3}{|c|}{ Study basics } & \multicolumn{2}{|c|}{ Related to living location } & \multicolumn{2}{|c|}{ Weight status } & \multicolumn{2}{|l|}{ Analysis } & \multirow[t]{2}{*}{ Results } \\
\hline Reference & $\begin{array}{c}\text { Design } \\
\text { \& level } \\
\text { of } \\
\text { analysis }\end{array}$ & $\begin{array}{l}\text { Population } \\
\text { (location; age; } \\
\text { sample size) }\end{array}$ & Main predictor(s) & Place boundary & $\begin{array}{l}\text { Measured } \\
\text { height and } \\
\text { weight? }\end{array}$ & $\begin{array}{l}\text { Main weight } \\
\text { status } \\
\text { measure(s) }\end{array}$ & $\begin{array}{l}\text { Confounders and other } \\
\text { statistical adjustments }\end{array}$ & $\begin{array}{l}\text { Addressed } \\
\text { residential } \\
\text { mobility? }\end{array}$ & \\
\hline $\begin{array}{l}\text { Slater et al, } \\
2010 \text { (5) }\end{array}$ & $\begin{array}{l}\mathrm{XS}, \mathrm{ML} \text {, } \\
\text { SCRS } \\
\text { (school) }\end{array}$ & $\begin{array}{l}\text { US (NR); } 8^{\text {th }} \\
\text { and } 10^{\text {th }} \\
\text { graders in } \\
2001-2003 ; \\
\text { analytical } n= \\
16,016 ?\end{array}$ & $\begin{array}{l}\text { Local compactness scale } \\
\text { (mean of 100, SD of 25) } \\
\text { Based on residential } \\
\text { density and street } \\
\text { connectivity (intersection } \\
\text { density and ratio of 4-way } \\
\text { to other types of } \\
\text { intersections) }\end{array}$ & $\begin{array}{l}\text { School catchment } \\
\text { area }\end{array}$ & No & $\begin{array}{l}\text { A) BMI } \\
\text { B) Obese } \\
\text { (CDC) }\end{array}$ & $\begin{array}{l}\text { Random effects logistic regression } \\
\text { by catchment area } \\
\text { Survey weights; Area (outdoor PA } \\
\text { settings scale, commercial PA } \\
\text { facilities, nhood disorder, nhood } \\
\text { safety, local compactness index, } \\
\text { traffic danger); Child (sex, grade, } \\
\text { race/ ethnicity, income, working } \\
\text { status); Parents (education level, } \\
\text { mother's working status), region, } \\
\text { year of data collection, private vs } \\
\text { public school }\end{array}$ & No & $\begin{array}{l}\text { - for BMI } \\
\text { and obesity }\end{array}$ \\
\hline
\end{tabular}

$+=$ a positive/direct statistically significant association; - = a negative/inverse statistically significant association; $\varnothing$ = a null statistical association; BMI = body mass index; CS = Convenience sample; CCL= Cross-classified multi-level model; CDC = Centers for Disease Control and Prevention overweight/obesity definitions; I = individual-level; IOTF = International Obesity Task Force

overweight/obesity definitions; LSOA = Lower super output area; $\mathbf{M C D}=$ Minor civil division; $\mathbf{M L}=$ Multi-level; NCMP= National Child Measurement Programme Nhood = neighbourhood; NR =

nationally representative; $\mathbf{P C}=$ prospective cohort study; $\mathbf{R e f}=$ reference group; $\mathbf{R R}=$ response rate; $\mathbf{S C R S}=\mathbf{S t r a t i f i e d ~ c l u s t e r ~ r a n d o m ~ s a m p l e ; ~} \mathbf{S R S}=$ stratified random sample; $\mathbf{X S}=$ cross-sectional

design 
(2006) did not find that sprawl was related to BMI among adolescents, even when taking into consideration whether adolescents had moved to a county with a different sprawl index (22).

\section{Discussion}

A number of studies have been published on place and child excess weight since the original review was conducted. Most studies have examined living location or a related indicator, although some are a result of expanding the geographic area considered (e.g. they were not new but not included in the original review).

Results for area material deprivation continue to support those found in the original review; that living in a deprived area is positively related to child excess weight. Social capital and disorder continue to be underexplored place factors, with only three studies being conducted. However, most studies to date have tended to find a significant association with excess weight. Finally, the relationship between living location and related measures of area compactness appears to be mixed, with null associations, and those in both expected and unexpected directions.

Despite these results, this area of research continues to lack well-conducted longitudinal studies, which limits what we can say about place-child weight associations. Overall, studies are again heterogeneous in terms of exposures, age ranges examined, place boundaries, and covariates considered in multivariate models. Those that have examined living location are perhaps less heterogeneous in terms of both exposures and place boundaries; on the other hand, many do not include some measure of area SES or deprivation to control for confounding. In regards to the longitudinal studies included here, 
some limitations noted include timing of exposure measurement (and in many instances this was not clear) (1), not controlling for area SES in multivariable models (8), and inability to control for changes in exposures $(1 ; 8 ; 14 ; 18)$.

This review provides an update and slight expansion to the review previously published on the association between neighbourhood characteristics and child excess weight. This was not a systematic review and was not conducted to the rigour of the original review; thus, relevant studies have likely been missed. Nonetheless, this update provides an overview of recent research and provides sufficient detail to assess research gaps and make recommendations for future research. In brief, longitudinal studies are needed that control for area SES and are able to adjust for changes in place exposures. Those that examine social capital and/or disorder would fill a gap in the current literature.

\section{Reference List}

(1) Burdette AM, Needham BL. Neighborhood environment and body mass index trajectories from adolescence to adulthood. J Adolesc Health 2012; 50(1):30-7.

(2) Grow HM, Cook AJ, Arterburn DE, Saelens BE, Drewnowski A, Lozano P. Child obesity associated with social disadvantage of children's neighborhoods. Soc Sci Med 2010; 71(3):584-91.

(3) Lovasi GS, Jacobson JS, Quinn JW, Neckerman KM, Ashby-Thompson MN, Rundle A. Is the environment near home and school associated with physical activity and adiposity of urban preschool children? J Urban Health 2011; 88(6):1143-57.

(4) Schwartz BS, Stewart WF, Godby S, Pollak J, Dewalle J, Larson S, et al. Body mass index and the built and social environments in children and adolescents using electronic health records. Am J Prev Med 2011; 41(4):e17-e28.

(5) Slater SJ, Ewing R, Powell LM, Chaloupka FJ, Johnston LD, O'Malley PM. The association between community physical activity settings and youth physical activity, obesity, and body mass index. J Adolesc Health 2010;47(5):496-503.

(6) Townsend N, Rutter H, Foster C. Age differences in the association of childhood obesity with area-level and school-level deprivation: cross-classified multilevel analysis of crosssectional data. Int J Obes 2012; 36(1):45-52. 
(7) Voorhees CC, Catellier DJ, Ashwood JS, Cohen DA, Rung A, Lytle L, et al. Neighborhood socioeconomic status and non school physical activity and body mass index in adolescent girls. J Phys Act Health 2009; 6(6):731-40.

(8) Veitch J, van Stralen MM, Chinapaw MJ, Te Velde SJ, Crawford D, Salmon J, et al. The neighborhood social environment and body mass index among youth: a mediation analysis. Int J Behav Nutr Phys Act 2012; 9:31.

(9) Liu J, Bennett KJ, Harun N, Probst JC. Urban-rural differences in overweight status and physical inactivity among US children aged 10-17 years. J Rural Health 2008; 24(4):407-15.

(10) Lutfiyya MN, Lipsky MS, Wisdom-Behounek J, Inpanbutr-Martinkus M. Is rural residency a risk factor for overweight and obesity for U.S. children? Obesity 2007; 15(9):2348-56.

(11) Bruner MW, Lawson J, Pickett W, Boyce W, Janssen I. Rural Canadian adolescents are more likely to be obese compared with urban adolescents. Int J Pediatr Obes 2008; 3(4):205-11.

(12) Lewis RD, Meyer MC, Lehman SC, Trowbridge FL, Bason JJ, Yurman KH, et al. Prevalence and degree of childhood and adolescent overweight in rural, urban, and suburban Georgia. J Sch Health 2006; 76(4):126-32.

(13) McMurray RG, Harrell JS, Bangdiwala SI, Deng S. Cardiovascular disease risk factors and obesity of rural and urban elementary school children. J Rural Health 1999; 15(4):365-74.

(14) Oliver LN, Hayes MV. Effects of neighbourhood income on reported body mass index: an eight year longitudinal study of Canadian children. BMC Public Health 2008; 8:16.

(15) Sjoberg A, Moraeus L, Yngve A, Poortvliet E, Al-Ansari U, Lissner L. Overweight and obesity in a representative sample of schoolchildren - exploring the urban-rural gradient in Sweden. Obes Rev 2011; 12(5):305-14.

(16) Cleland V, Hume C, Crawford D, Timperio A, Hesketh K, Baur L, et al. Urban-rural comparison of weight status among women and children living in socioeconomically disadvantaged neighbourhoods. Med J Aust 2010; 192(3):137-40.

(17) Ismailov RM, Leatherdale ST. Rural-urban differences in overweight and obesity among a large sample of adolescents in Ontario. Int J Pediatr Obes 2010;5(4):351-60.

(18) Nonnemaker JM, Morgan-Lopez AA, Pais JM, Finkelstein EA. Youth BMI trajectories: evidence from the NLSY97. Obesity 2009; 17(6):1274-80.

(19) Sandercock GR, Ogunleye A, Voss C. Comparison of cardiorespiratory fitness and body mass index between rural and urban youth: findings from the East of England Healthy Hearts Study. Pediatr Int 2011; 53(5):718-24.

(20) Verger P, Saliba B, Guagliardo V, Bouhnik AD, Eichenbaum-Voline S. Individual social characteristics, municipal environment and the prevalence of weight problems in early childhood: a multilevel analysis. Rev Epidemiol Sante Publique 2007; 55(5):347-56. 
(21) Liu GC, Wilson JS, Qi R, Ying J. Green neighborhoods, food retail and childhood overweight: differences by population density. Am J Health Promot 2007;21(4 Suppl):31725.

(22) Ewing R, Brownson RC, Berrigan D. Relationship between urban sprawl and weight of United States youth. Am J Prev Med 2006; 31(6):464-74. 


\subsection{Place and food insecurity: a critical review and synthesis of the literature - Manuscript 2}

Authors: Megan Ann Carter $^{1}$, Lise Dubois ${ }^{1,2}$, Mark S. Tremblay ${ }^{3,4}$

1. Institute of Population Health, University of Ottawa

2. Department of Epidemiology and Community Medicine, University of Ottawa

3. Healthy Active Living and Obesity Research, Children's Hospital of Eastern Ontario Research Institute

4. Department of Pediatrics, University of Ottawa

This manuscript was written and published in accordance to the specifications for submission to the peer-reviewed journal Public Health Nutrition. It has been accepted and appears here in its uncorrected format.

Carter MA, Dubois L, Tremblay MS. Place and food insecurity: a critical review and synthesis of the literature. Public Health Nutrition, 2013 (C) The Nutrition Society, published by Cambridge University Press, reproduced with permission. 


\section{Abstract}

Objective: In high income countries, a sizable proportion of households are estimated to be food insecure. It is well known that food insecurity varies between countries and is strongly tied to household income level. The local environment may be another level of influence that has been relatively understudied. This review sought to synthesize and critically appraise the existing literature examining local environmental characteristics in relation to individual/ household-level food insecurity in the general population.

Design: A systematic search strategy was used to search MEDLINE, MEDLINE In process and Other Non-indexed, EMBASE, PsychINFO, Social Services Abstracts, and Sociological Abstracts databases for studies examining local place characteristic(s) in relation to self-reported food insecurity.

Setting: Studies could be experimental or observational, but had to be published in a peer-reviewed journal in French or English, and involve subjects from developed countries. 'Place' was defined locally, as ranging from the street to the county-level.

Subjects: The target population for the review included non-institutionalized individuals in the general population.

Results: After obtaining full-text articles, 18 primary studies met the eligibility criteria. Most studies were conducted in the US and all but one was cross-sectional. Seven of the 11 studies that examined location of residence found that rural living was inversely associated with food insecurity. Mixed results were seen for other place measures such as social capital and distance to food stores.

Conclusions: Studies were heterogeneous and had various limitations that preclude definitive conclusions from being drawn. Recommendations for future research are provided.

\section{Introduction}

The Canadian government prioritized the right to food in 1998 in response to the 1996 World Food Summit ${ }^{(1)}$, and since 1948 has signed many agreements emphasizing food as a human right ${ }^{(2)}$. Yet in 2007-2008, 7.7\% of Canadian households (almost one million) were

food insecure ${ }^{(3)}$; a concerning public health problem that is echoed in other high income countries such as the US ${ }^{(4)}$ and Australia ${ }^{(5)}$. In the US, for instance, one of the richest countries in the world, $14 \cdot 5 \%$ of American households (17.2 million) were food insecure at some point during 2010. On average, these households experienced food insecurity for seven out of the 12 months of the year ${ }^{(4)}$. 
Food insecurity exists when there is limited or uncertain access to nutritionally adequate and safe foods or limited or uncertain ability to acquire acceptable foods in socially acceptable ways ${ }^{(6)}$. There are different stages of severity starting with not being able to buy and eat what one would like due to income-related resource constraints ${ }^{(7)}$. This incorporates issues of food quality including variety, safety, and nutrient content. The next stage involves a decrease in quantity and attempts to make food last until there is money to buy more.

Decreases in food quantity may then lead to the physical sensation of hunger ${ }^{(7)}$. Finally, the most severe stage is the complete absence of food intake. In addition to quality and quantity elements, psychological distress (e.g. worry or concern about not having enough to eat) and social-familial perturbations (e.g. resorting to socially unacceptable ways of getting food) are also important dimensions of food insecurity ${ }^{(8-10)}$.

Studies conducted, for the most part, in the US have uncovered health correlates of food insecurity that include increased depression ${ }^{(11)}$ and nutritional inadequacies ${ }^{(12,13)}$ among adults, and psychosocial ${ }^{(14,15)}$ and physical ${ }^{(16,17)}$ developmental problems among children. Food insecurity has been found to relate to overweight or obese; however, results are more consistent among women, compared to men and children ${ }^{(18,19)}$. There is also some evidence that food insecurity is related to cardiovascular disease risk factors ${ }^{(20,21)}$. And finally, those dealing with food insecurity may also be more likely to postpone needed medications and medical care, in order to make sure that basic needs are addressed first ${ }^{(22)}$. Since most of these studies are based on the US population, correlates may be different in different countries. This may be especially true for postponing needed medications and medical care, as healthcare systems differ between high income countries. 
The major determinant of food insecurity is well understood to be a lack of financial resources ${ }^{(23)}$. Active public policies to decrease poverty and protect the vulnerable non-poor are major ways society can meet the needs of citizens ${ }^{(24)}$; yet, in countries such as Canada, the social safety net is shrinking ${ }^{(2)}$. Responsibility is largely left up to now institutionalized, short-term solutions, such as food banks and other charitable organizations, that cannot reach all of those in need ${ }^{(25)}$. In 2010, food bank use across Canada was the highest on record, and did not decrease in $2011^{(26)}$. This is concerning for Canadians, especially when taking into consideration the current world economic outlook, high food prices, and high food price volatility $^{(27)}$.

Considering multiple levels of potential societal influence is consistent with a socialecological approach to understanding public health problems. The link between macro socio-political and individual-level economic factors with food insecurity is relatively well established. What is less well known is how attributes of the local environment may be implicated. A focus on developing an understanding of local environment in relation to food insecurity therefore deepens our overall understanding of this complex public health problem.

Recent research attempting to elucidate the effects of local social and physical characteristics of place on PA, diet, and weight status of community residents, may be relevant for identifying factors that can promote or prevent food insecurity (see ${ }^{(28)}$ for an example). In the US, there is convincing evidence of the existence of food deserts; area-level disparities in affordable, healthy food access by income and race ${ }^{(29)}$, which could translate into increased food insecurity for area residents. Availability of supermarkets has been linked to healthier eating ${ }^{(30)}$, and supermarkets have also been shown to have lower food 
prices compared to smaller stores ${ }^{(31)}$. Food quality may also vary depending on affluence of the area and living location ${ }^{(32)}$. Areas with high social capital, in particular, trust, reciprocity, shared norms and the willingness to enforce these norms, may allow residents to obtain food from neighbours or other institutions more easily in times of need, and to act collectively to address food insecurity issues ${ }^{(33)}$. Disintegrating aesthetics of an area due to anti-social activity, may act to dissuade food service establishments and other institutional supports from locating in particular areas, and perceived danger may prevent residents from accessing nearby food resources ${ }^{(34)}$.

Finally, there is some evidence from the US to show that community-based initiatives such as community gardens ${ }^{(35)}$ may increase the consumption of fruits and vegetables among disadvantaged participants. Thus, interventions or programs that are place-based, may increase the availability, accessibility, and utilization of food to local residents, and therefore work to decrease individual/household food insecurity.

The purpose of this paper, therefore, was to conduct a comprehensive and critical review of the published literature in order to shore up the knowledge base on place and food insecurity. The intent was not to conduct a systematic review, rather to undertake a review which may serve to inform future reviews and identify research gaps for further study. The specific research review question was: among experimental and observational studies, have local physical and social environmental factors been found to significantly relate to individual/household-level food insecurity in the general population?

\section{Methods}

\section{Eligibility criteria}


Research studies were considered for inclusion if they examined the relationship between features of place and self-reported food insecurity (either at the household/family or individual-level). The target population for the review included non-institutionalized individuals in the general population, but did not exclude studies that focused specifically on demographic sub-groups. Only those studies that examined populations living in countries: 1) with a democratic political system, and 2) defined as 'very high human development' by the United Nations ${ }^{(36)}$ were included.

Place was broadly defined as having a spatial or area component beyond an individual's residence; although, the scale of place considered in this review ranged from the street to the county-level. Studies examining larger areas were excluded. Place predictors could be perceived by individuals or objectively measured. Specific measures of interest included social capital (various definitions), crime, safety, density/distance to food stores, quality and prices at these local food stores, population/residential density, socioeconomic status (SES)/deprivation, and local infrastructure making access to food easier (e.g. availability of public transportation, well maintained sidewalks, route connectivity and directness, traffic, etc). The outcome, food insecurity, had to be self-reported by the participating individual, on behalf of him or herself, or on behalf of the household, and measured by a survey/questionnaire touching on one or more dimensions of not getting enough to eat due to lack of financial resources (e.g. food quality and variety, food quantity, physical hunger, anxiety/psychological distress, social aspects affected such as stealing, or not inviting people over for dinner). Studies that used proxy measures for food insecurity such as food stampuse, poverty status, food bank-or pantry use, were excluded. Those that assessed community food insecurity as the outcome were also excluded. 
Individual socio-demographic/economic characteristics may act as confounders in the place - food insecurity relationship; thus, studies that did not adjust for some measure of household or individual SES were excluded. Considering that studies had to conduct multivariate analysis, those that had small sample sizes $(\mathrm{N}<100)$ were excluded. Only primary studies and reviews that used systematic search methods were considered for inclusion.

Study designs could be observational, as long as there was a comparison group or groups that were either not exposed to the place predictor, or had varying levels of exposure. Intervention studies of different programs/initiatives were included if they were newly implemented or modified, local in scope and delivered on a community-wide scale, helped to increase food availability and accessibility, and used (at the very least) a before-after design. Qualitative studies were excluded. Finally, due to resource and time constraints articles that were not written in French or English, or not published in peer-reviewed scientific journals were excluded.

\section{Search strategy \& identification of studies}

Six electronic databases were searched in December 2011 using a systematic search strategy. MEDLINE In-process and Other Non-indexed Citations, MEDLINE, EMBASE, and PsychINFO were searched using the OvidSP interface, while Social Services Abstracts and Sociological Abstracts were searched using the ProQuest interface. No restrictions on time-period were imposed. The search strategy was developed first in OvidSP and then refined as appropriate in ProQuest to account for changes in indexing of subheadings. Both free-text terms and indexed subheadings were used. The full search strategy for MEDLINE is available in the appendix. 
In OvidSP, all four databases were search simultaneously and duplicates removed. Citations were saved and imported directly into Reference Manager (v.12). Given ProQuest's difficulty in downloading a large number of citations, the two social databases (Social Services Abstracts and Sociological Abstracts) were searched separately; citations were handled in the same way as OvidSP. All studies downloaded into Reference Manager first underwent a duplicate search. The first screen involved examining the titles and abstracts to determine if studies met eligibility criteria. Full-text articles were then obtained for those studies that appeared to meet the eligibility criteria and for those where it was unclear. Eligibility was assessed again, based on information in the entire article. Handsearching the reference lists of included studies was also undertaken in order to retrieve studies missed from the original search strategy. Reviews were included solely for this purpose, as data from the review itself were not collected.

\section{Data abstraction}

Details on the study characteristics were abstracted to provide a summary of implementation and results, and a critical overview of study quality. Information abstracted included study design (e.g. cross-sectional, ecological, case-control, cohort, experimental/intervention), sampling strategy, survey/questionnaire administration mode (e.g. face to face interviews, telephone interviews, self-administered questionnaires), level of analysis (e.g. individual or multi-level), sample characteristics (e.g. age, country, ethnicity, income level), total and effective/analytic sample sizes, cooperation and/or response rate(s), definition of the place characteristic as well as the area described by the characteristic, definition of food insecurity, statistical method used and the confounders included, results, 
and other unique aspects of the study that warranted special attention, specifically in regards to potential limitations.

\section{Results}

\section{Literature search and general overview}

A total of 2502 potential articles were retrieved from the six databases. Of these, 18 primary studies, and one review ${ }^{(37)}$ met the eligibility criteria (Figure 1). Four of the included studies resulted from hand-searching the reference lists of other included studies ${ }^{(38-}$ ${ }^{41)}$, while two studies were included based on prior knowledge using other search tools and journals (these had not yet been indexed in Ovid's MEDLINE) $)^{(42,43)}$.

Almost three quarters (13/18) of the included primary studies were conducted in the US, three were conducted in Australia, one in Canada, and one in the UK (Table 1). All except one study was conducted in the year 2000 or later. The cross-sectional research design was almost exclusively used. Sample sizes across studies ranged from 330 to 70,942. Only four studies conducted multi-level analyses, while the rest conducted analyses at the individuallevel. For the most part, the areas defining the place characteristics were either based on administrative boundaries or perceived by the respondent.

In terms of characteristics of the target populations studied, 7/18 studies examined adults of varying ages ${ }^{(38-40,44-47)}$, seven explicitly examined families with children (sometimes with data collected using the child as the sampling unit) ${ }^{(41,43,48-52)}$, three focused on seniors ${ }^{(42,53,54)}$, and one sampled a range of ages (children and adults) $)^{(55)}$. Seven out of the 18

studies (39\%) focused exclusively on low income or ethnic subgroups ${ }^{(40,45,47,49-52)}$. 
Almost all included studies either used validated tools to measure food insecurity, or used individual questions from validated tools. Four studies used the United States Department of Agriculture's (USDA) 18-item Food Security Scale ${ }^{(41,45,49,52)}$, although Kirkpatrick and Tarasuk ${ }^{(49)}$ applied Health Canada's thresholds to define moderate and severe food insecurity. Five studies used the 6-item short form of the USDA Food Security Scale ${ }^{(38-40,43,48)}$, three studies used items from the Community Childhood Hunger Identification Project (CCHIP) in the National Health and Nutrition Examination (NHANES) III survey ${ }^{(47,51,54)}$, and one study was based on items administered in the Behavioral Risk Factor Surveillance System ${ }^{(42)}$. The three Australian studies ${ }^{(46,53,55)}$ and Dean et al. (2011) ${ }^{(44)}$ adapted and used items from the Radimer/Cornell measure, while Sharkey et al. (2011) used an adapted version of the complete Radimer/Cornell measure ${ }^{(50)}$. Eight studies investigated different types or degrees of severity of food insecurity, either by using more than one questionnaire item, or using different thresholds for the USDA 18-item Food Security Scale or the Radimer/Cornell Scale ${ }^{(42,44-46,49-52)}$.

Four general types of place factors emerged from the synthesis. For brevity and integration of findings, results of included studies are discussed under the relevant subheadings below. Table 1 details the characteristics of each included study.

\section{Living location}

The most common place characteristic examined was living location, as measured on the urban-rural continuum; 11 studies assessed the potential impact of this area-level exposure on food insecurity ${ }^{(38-41,44,46,48,51-54)}$. Most often, this place factor was simply defined as urban versus rural with no clear explanation of the administrative boundaries or criteria used. 
Seven studies uncovered a potential protective effect of rural living on food insecurity. Garasky et al. (2006) compared two subject-perceived definitions of rural living to urban living. They found that living outside of the city on a farm was related to decreased food insecurity compared to living within the city limits, but no difference between living outside of the city (not on a farm) and living within the city limits ${ }^{(38)}$. In a study of Oregon adults, the percentage of the county considered rural was inversely related to food insecurity ${ }^{(39)}$. Similarly, the percentage of people living in urban areas as defined by zip-code was positively related to food insecurity in a study of Wisconsin families ${ }^{(48)}$. When examining two types of food insecurity (household and individual) based on two questions, Radimer et al. (1997) found that urban living in Australia was associated with increased odds for both types of food insecurity, versus rural living ${ }^{(46)}$. Among a Hispanic population, living in a non-metropolitan area relative to a metropolitan area was inversely related to food insecurity, as defined by cutting of children's or adult's meals, but not by an individual child feeling like he/she does not have enough to eat ${ }^{(51)}$. In a study of low-income families, Bartfeld \& Ahn (2011) compared various types of towns/cities with respect to population size, defined by zip-code ${ }^{(52)}$. Compared to rural areas outside MSAs (Metropolitan Statistical Areas), low income families living in small towns, mid-sized suburbs, or midsized cities were more likely to be food insecure. Those living in large cities, large suburbs, large towns, or rural area within a MSA were no different than those living in rural areas outside of a MSA. Finally, in a large, nationally representative sample of US families, living in a central city versus an 'other' metropolitan area was associated with increased odds of food insecurity, while living in a rural area was associated with decreased odds ${ }^{(41)}$. 
Three of the 11 studies uncovered null results, whereas one uncovered a positive association between rural living and food insecurity. Two of the three null studies were conducted on older adults ${ }^{(53,54)}$. One of these used dichotomous indicators of living location (metropolitan versus non metropolitan living) ${ }^{(54)}$, while the other examined four different types of areas ${ }^{(53)}$. The third null study did not find that living in town differed from living in the country-side in two high poverty Iowa counties with a mean age of $56 \mathrm{y}^{(40)}$. In contrast to the seven studies described above, Dean et al (2011) uncovered a positive association between rural living and food insecurity ${ }^{(44)}$. They conducted multinomial analysis with the response categories serving as an indication of the severity of food insecurity. A significant association was seen only for those in the most severe response category.

\section{Social environment}

The nature of social interactions within residential areas was the second most studied $(\mathrm{n}=8 / 18)$ place factor in this review, and included various measures of social capital, such as social cohesion, informal social control, collective efficacy, civic structure, and related measures such as religious affiliation, residential mobility, and neighborhood safety $(39,40,42,44,45,47,49,55)$. Two studies examined characteristics of the social environment at both the individual and neighborhood levels ${ }^{(45,47)}$, while the remainder focused solely on the individual-level. Both of these studies aggregated individual measures up to the neighborhood-level based on specified boundaries and focused on low income populations. Brisson \& Altschul (2011) examined collective efficacy as measured by indices for social cohesion and informal social control. Social cohesion, but not informal social control, was inversely related to food insecurity at the neighborhood level ${ }^{(47)}$. In the second study, scoring high on a social capital index was found to inversely relate to severe food insecurity 
(hunger present) but not food insecurity without hunger (of which the authors did not report the results) ${ }^{(45)}$.

At the individual-level, four out of the eight studies estimated a potential protective effect of high social capital ${ }^{(40,44,45,47)}$. Increasing scores on a civic structure index was related to decreased odds for food insecurity in a study of two rural, high poverty counties (40). And in another study, scoring low or medium on a social capital index was related to increased odds for 'sometimes' being food insecure versus food secure, as compared to high social capital in a mostly rural population of adults ${ }^{(44)}$. Interestingly, low social capital, but not medium, was related to being 'often' food insecure ${ }^{(44)}$. Brisson \& Altschul (2011) and Martin et al (2004) estimated similar associations at the individual level as at the neighborhood-level ${ }^{(45,47)}$.

The four null studies contained a variety of measures. For example, Foley et al (2010) examined single items measuring trust in neighbors, and safety of the neighborhood ${ }^{(55)}$; Bernell et al (2005) examined the proportion of the county having a religious affiliation, as well as the proportion that moved within the last five years ${ }^{(39)}$; Chung et al (2011) included indices of neighborhood safety and cohesion for three different food insecurity definitions ${ }^{(42)}$; and finally, Kirkpatrick \& Tarasuk (2010) did not find an association between a social capital index and two types of food insecurity severity ${ }^{(49)}$. Population characteristics of these studies were similarly mixed.

\section{Food Environment}

Five studies investigated the potential influence of characteristics in the local food environment that could impact on food insecurity ${ }^{(38,42,48-50)}$; although only three uncovered 
significant associations. In their study of Wisconsin families with children, Bartfeld et al (2010) estimated a positive association between living 15-22 miles from the nearest supermarket or grocery store versus less than 2 miles ${ }^{(48)}$. However, distances longer than two miles, but shorter than 15 , were not related to being food insecure. Similarly, distance to the main store for purchasing groceries increased the odds for adult food insecurity, but not household or child food insecurity, in a study of Spanish-speaking women of Mexican origin, living in a poor area of Texas ${ }^{(50)}$. This same study also found that those who perceived little variety in the types of foods that could be purchased in local stores were more likely to report child food insecurity, but not adult or household food insecurity (although the odds ratios were high and in the same direction for both types). In terms of features of the built environment that could improve access to food, Chung et al (2011) estimated an inverse association between 'walkability' of older adults' neighborhoods and two measures of food insecurity (concern about not having enough to eat, and hungry because could not get out to buy food), and marginally with a third (eating less because of lack of money, $P=0 \cdot 056)^{(42)}$. In a similar vein, Bartfeld et al (2010) found that household perceived access to public transit decreased the odds for food insecurity ${ }^{(48)}$.

Two of the five studies were unable to detect any significant effects of the food environment ${ }^{(38,49)}$. In a low income population, Kirkpatrick \& Tarasuk (2010) investigated the association between food insecurity and living within two kilometres of a number of food resources, including discount supermarkets, food banks, community kitchens, and community gardens ${ }^{(49)}$. No significant associations emerged, even after considering severe food insecurity, or when using continuous distances, or a shorter cutoff (one kilometre or 
less). Other null results included perceived adequacy/number of local food stores in three studies ${ }^{(38,49,50)}$ and perceptions/estimations of high food prices in one study ${ }^{(50)}$.

\section{Socioeconomic environment}

Three out of three studies that investigated rent prices at the area level estimated a positive association with food insecurity ${ }^{(39,48,52)}$; although two of these were conducted by the same lead author. One study uncovered a positive association between an index of area deprivation and food insecurity ${ }^{(43)}$, while one study that used a similar index ${ }^{(55)}$ and another that focused on poverty level ${ }^{(48)}$ did not find any significant associations. Bernell et al (2005) also examined percentage of the county unemployed and average wage, with null results ${ }^{(39)}$.

\section{Discussion}

Among the studies included in this review, a range of place factors were examined. Summarizing the results by type of place factor revealed a potential protective effect of rural living on food insecurity that may or may not be applicable among older adults. Studies on the quality of the social environment, namely social capital, also suggest a possible protective role; however, half found no significant associations, while those with positive findings tended to focus only on low income populations. Among studies investigating the food and socioeconomic environments, relationships were less clear.

\section{Potential limitations of included studies}

As a result of conducting this critical review and from the perspective of furthering knowledge about place and food insecurity, consideration of some of the limitations of the existing research is warranted. The most common limitations are summarized below, but also refer to the last column in Table 1 for unique study concerns. 
The most obvious limitation of this body of research is the exclusive reliance on the cross-sectional study design. It is not so much the time-order of events that is the problem, as place attributes are of sufficiently long duration compared to food insecurity, meaning that they are more likely to exist prior to food insecurity. Rather, it is the inability to control for reasons why people decide to live in particular areas versus others (self-selection), and other unobserved confounders that are fixed over time.

Almost half of included studies used the 18-item or 6-item USDA Food Security Scale and recommended cut offs to define food insecurity. Benefits of using this measure include rigorous development and validity/reliability testing that has spanned a number of years ${ }^{(8)}$, as well as increased comparability across studies. Many studies, on the other hand, relied on single question measures, often for secondary data analyses of large population-based surveys. While these questions were largely based on previously validated work and/or derived from items in the USDA Food Security Scale or the Radimer/Cornell measure of food insecurity, they are not likely to measure food insecurity comprehensively, and make it difficult or impossible to compare across studies ${ }^{(8)}$. Given that measures with many items are burdensome to respondents, especially so when administered as part of a large scale population-based survey, the USDA Food Security Scale 6-item short form may be an ideal candidate for more widespread use in future intervention and observational studies, instead of simply relying on single item measures. The shorter length of the questionnaire does not appear to affect its discriminatory power ${ }^{(56)}$. However, this measure does not directly ask about child food insecurity and cannot measure the most severe form of adult food insecurity, where children's intake is likely to be reduced ${ }^{(57)}$. In addition to single item measures, some studies used multiple questions as more than one outcome. This can 
increase the likelihood of estimating a significant association by chance, and makes overall interpretation of results more difficult. Analyzing types or severity of food insecurity (e.g. household, adult, and child) as individual outcomes or in multinomial logistic regression analysis, without a priori hypotheses and context, also makes results difficult to interpret.

Many studies did not control for sex of the respondent. Given societal gender roles, men and women often perceive situations differently. For example, females are generally responsible for food management in the household, and therefore, would likely be more attuned to problems with food security. Gender differences may also affect how the surrounding environment is perceived. Some studies that did not adjust for sex selected respondents who were primarily responsible for buying and cooking food in the household, which could partially adjust for this difference (e.g. Kirkpatrick \& Tarasuk, 2010). Additionally, it would be less concerning if there was very little variability in the sex of the respondent; however, no studies appeared to discuss this. In addition to sex, several studies did not adjust for area level income, SES, or some other measure incorporating relative area disadvantage (even in low income populations). In some cases, this data would likely not be available, but nevertheless, could confound place - food insecurity relationships.

There was much heterogeneity among measures of the food environment, and clearly there lacks a critical mass of studies examining the same or similar features in order to make any type of conclusions about the potential effect of the food environment on food insecurity. Additionally, there needs to be more discussion about how some of these measures were derived, particularly with respect to respondent perceptions; questions seemed vague, not always tested, and thus open to bias as an explanation for findings. 
Interestingly, area SES was underexplored, perhaps because a large portion of included studies (39\%) limited populations to low income or certain ethnic groups, or because of the well-known link between individual income/SES level and food insecurity. Nonetheless, there still may be some variability in area SES to explain differences in individual food security status, even among low income populations. Certainly, among population-based samples, area SES should continue to be explored. And as discussed previously, in any study on place and food insecurity, area SES should be considered as a potential confounder, or even effect modifier, when analyzing other features of place.

Sample selection, along with generalizability should be kept in mind when interpreting the results of this review. Limiting sample populations to a particular demographic subgroup reduces generalizability of the results. Generalizability is especially problematic when attempting to synthesize information from a relatively new area of research, with few studies, and even more so when most of those studies are conducted in one country; here the reader is cautioned that most studies were conducted in the US. Once a larger evidence base is established, future reviews should conduct sensitivity analyses to determine potential differences among population subgroups. Limiting to particular subgroups also makes it difficult to detect important significant differences, due to less variability within the sample compared to if a population-based sample had been analyzed.

Of the individual-level studies that relied on some form of cluster sampling method, not all adjusted for potential correlations between individuals within a cluster, which could bias results. Additionally, sampling frames were sometimes based on telephone lists. This likely resulted in an underestimation of food insecurity, as having a telephone land-line is related to income, which is related to being food insecure. Lower study power and decreased ability to 
generalize are likely outcomes of this sampling method. Selection bias may also result if under-coverage is related to the place characteristic(s) under study. Selection bias is also a concern when certain participants are excluded because of missing data. A discussion of the impact of missingness was lacking overall in this body of research.

While the results of this review suggest a potential protective effect of rural living, the measures of living location were generally crude, encompassed large areas (counties), heterogeneous, and often not the main interest of the study. Given this, one can only speculate as to what it is about rural environments that may protect against food insecurity. More precise definitions and comparisons may yield different results.

Finally, exposures may not be the same for individuals living in the same area. For example, living in a disadvantaged area may not actually be an important exposure for a particular individual, depending on his/her own compositional factors such as income and car ownership, as well as interacting contextual factors such as social capital, high income neighborhoods located close by, or availability of subsidized school meals, to name a few. Given the complexities of exploring these types of interactions, it is not surprising that none of the included studies conducted this analysis. A handful of studies did discuss car ownership and/or other transportation methods ${ }^{(38,49,50)}$ and some did adjust for other place factors in multivariable models. A relational understanding of place that takes into account spatial and temporal mobility, has been recommended in the literature ${ }^{(58)}$ and is likely applicable in this area of research, at least with respect to the development of theory and study design. 


\section{Limitations of this review}

In addition to the limitations of included studies, the review itself has a number of limitations that may have affected which studies were and were not included. The grey literature was not searched; another recent review on environmental characteristics and food insecurity uncovered several papers that were not published in scientific journals ${ }^{(37)}$. These studies, for the most part, did not examine place as defined in this review, and so would not have been eligible for inclusion. Conference proceedings and abstracts, as well as dissertations were not included; it is therefore possible that studies with null or non-intuitive findings were not included. Hand-searching the reference lists of included articles was conducted, but not for entire journals in the field, and only one person (MC) selected articles based on a priori eligibility criteria, and abstracted the data. Thus, pertinent studies may have been missed. Studies may have also been missed if they analyzed a place factor which was not part of the main objective(s) (e.g. it would not have been evident from the title or abstract and then potentially screened out). This review did not focus on household environments or the broader socioeconomic environment, both of which may play a role in reducing food insecurity ${ }^{(59)}$.

\section{Recommendations and conclusions}

This critical appraisal and synthesis of published research allowed for the formulation of recommendations for future research studies, which should help to drive the field forward. These are detailed below.

Sampling methods should avoid using telephone lists to recruit participants whenever possible. Some variant of cluster random sampling may be most appropriate, where surveys are administered in person. Population-based samples that do not focus exclusively on low 
income and/or largely rural populations may be most informative, especially from a policymaking perspective. In order to reduce respondent burden, make use of a solid evidencebase, and avoid basing measurement of food insecurity on one question, authors of future studies may consider using, at the very least, the USDA Food Security Scale 6-item short form. This will help to increase comparability across studies. Finer grained definitions and a specific focus on place are also needed; especially with respect to living location. Including housing/residential density, land-use mix, farming, social capital, as well as exploring how car ownership and other transportation methods, can influence food insecurity in the context of rural and urban living, is required. Well-conducted longitudinal observational studies are preferred to cross-sectional studies, and testing for interaction with the place variables of interest, could help to make results more robust and informative. Finally, adjustment for sex as well as other confounders, such as individual and area SES, is necessary to reduce bias in the resulting associations between the place factors and food insecurity.

Finally, community-based initiatives, such as community gardens, were not evaluated in this review because none included measures of individual/household food insecurity as outcomes. Studies that were screened out consisted mostly of process evaluations of single programs. This area of research could benefit immensely from applying more rigorous experimental and quasi-experimental methods and evaluating changes in individual/household-level food security status of area residents. Randomized communitywide interventions that are not necessarily programmatic in nature (e.g. changes to the physical environment) are also important areas for further research. Place and food insecurity is a fairly new and evolving area of research. Given that continued access to healthy, acceptable food, regardless of income, is a moral imperative, and that developing 
redistributive income and other equitable policies is socio-politically complex, time consuming, and contentious in some high income democratic countries, focusing on how the immediate local environments may improve or inhibit food security could be a potentially fruitful area of research, especially in today's economic climate. The literature synthesized in this review points to rural living as a potential protective factor, although a number of methodological limitations prevent any decisive conclusions from being made at this time. Recommendations have been formulated and presented in an attempt to improve the quality of research in this field. However, research quality can only be improved if these recommendations are used in conjunction with the work of interdisciplinary teams, including: sociologists, social workers, epidemiologists, biostatisticians, dietitians, public health professionals, urban planners, and the like, that each contributes their relative expertise.

Conflict of interest: The authors declare that they have no conflicts of interest.

\section{Reference List}

(1) Canada's Action Plan for Food Security: In response to the World Food Summit Plan of Action. Government of Canada 1998 [cited 2011 Jan 10];Available from: URL: http://www.agr.gc.ca/misb/fsec-seca/pdf/action_e.pdf

(2) Rideout K, Riches G, Ostry A, et al. (2007) Bringing home the right to food in Canada: challenges and possibilities for achieving food security. Public Health Nutr 10, 6:566-73.

(3) Household Food Insecurity In Canada in 2007-2008: Key Statistics and Graphics. Health Canada 2011 [cited 2011 Oct 12];Available from: URL: http://www.hc-sc.gc.ca/fnan/surveill/nutrition/commun/insecurit/key-stats-cles-2007-2008-eng.php

(4) Coleman-Jensen A, Nord M, Andrews M, et al. Household Food Security in the United States in 2010. USDA, Economic Research Service 2011 [cited 2012 Feb 2];Available from: URL: http://www.ers.usda.gov/Publications/ERR125/ERR125.pdf 
(5) Rosier K. Food insecurity in Australia: What is it, who experiences it and how can child and family services support families experiencing it? Australian Institute of Family Studies 2011 [cited 2012 Feb 2];Available from: URL:

http://www.aifs.gov.au/cafca/pubs/sheets/ps/ps9.pdf

(6) Andersen SA, Editor. (1990) Life Sciences Research Office Report: Core Indicators of Nutritional State for Difficult-to-Sample Populations. J Nutr 120, 11 Suppl:1555-600.

(7) Tarasuk V. Discussion Paper on Household and Individual Food Insecurity. Health Canada 2001Available from: URL: http://www.hc-sc.gc.ca/fn-an/alt_formats/hpfbdgpsa/pdf/nutrition/food_sec_entire-sec_aliments_entier-eng.pdf

(8) Radimer KL. (2002) Measurement of household food security in the USA and other industrialised countries. Public Health Nutr 5, 6A:859-64.

(9) Hamelin AM, Beaudry M, Habicht JP. (2002) Characterization of household food insecurity in Quebec: food and feelings. Soc Sci Med 54, 1:119-32.

(10) Radimer KL, Olson CM, Campbell CC. (1990) Development of indicators to assess hunger. J Nutr 120, Suppl 11:1544-8.

(11) Heflin CM, Siefert K, Williams DR. (2005) Food insufficiency and women's mental health: findings from a 3-year panel of welfare recipients. Soc Sci Med 61, 9:1971-82.

(12) Kirkpatrick SI, Tarasuk V. (2008) Food insecurity is associated with nutrient inadequacies among Canadian adults and adolescents. J Nutr 138, 3:604-12.

(13) Rose D, Oliveira V. (1997) Nutrient intakes of individuals from food-insufficient households in the United States. Am J Pub Health 87, 12:1956-61.

(14) Slopen N, Fitzmaurice G, Williams DR, et al. (2010) Poverty, food insecurity, and the behavior for childhood internalizing and externalizing disorders. J Am Acad Child Adolesc Psychiatry 49, 5:444-52.

(15) Alaimo K, Olson CM, Frongillo EA, Jr. (2001) Food insufficiency and American schoolaged children's cognitive, academic, and psychosocial development. Pediatrics 108, 1:4453.

(16) Kirkpatrick SI, McIntyre L, Potestio ML. (2010) Child hunger and long-term adverse consequences for health. Arch Pediatr Adolesc Med 164, 8:754-62.

(17) Casey PH, Szeto KL, Robbins JM, et al. (2005) Child health-related quality of life and household food security. Arch Pediatr Adolesc Med 159, 1:51-6.

(18) Larson NI, Story MT. (2011) Food insecurity and weight status among U.S. children and families: a review of the literature. Am J Prev Med 40, 2:166-73.

(19) Eisenmann JC, Gundersen C, Lohman BJ, et al. (2011) Is food insecurity related to overweight and obesity in children and adolescents? A summary of studies, 1995-2009. Obes Rev 12, 5:e73-e83. 
(20) Parker ED, Widome R, Nettleton JA, et al. (2010) Food security and metabolic syndrome in U.S. adults and adolescents: findings from the National Health and Nutrition Examination Survey, 1999-2006. Ann Epidemiol 20, 5:364-70.

(21) Seligman HK, Laraia BA, Kushel MB. (2010) Food insecurity is associated with chronic disease among low-income NHANES participants. $J$ Nutr 140, 2:304-10.

(22) Kushel MB, Gupta R, Gee L, et al. (2006) Housing instability and food insecurity as barriers to health care among low-income Americans. J Gen Intern Med 21, 1:71-7.

(23) Rose D. (1999) Economic determinants and dietary consequences of food insecurity in the United States. J Nutr 129, 2 Suppl:517S-20S.

(24) Barrett CB. (2010) Measuring food insecurity. Science 327, 5967:825-8.

(25) Raine K, McIntyre L, Dayle JB. (2003) The failure of charitable school- and communitybased nutrition programmes to feed hungry children. Critical Public Health 13, 2:155-69.

(26) Hunger count 2011: A comprehensive report on hunger and food bank use in Canada, and recommendations for change. Food Banks Canada 2012Available from: URL: http://www.foodbankscanada.ca/getmedia/dc2aa860-4c33-4929-ac36fb5d40f0b7e7/HungerCount-2011.pdf.aspx?ext=.pdf

(27) OECD/FAO. OECD-FAO Agricultural Outlook 2011. OECD Publishing and FAO 2011 [cited 2012 May 3];Available from: URL: http://dx.doi.org/10.1787/agr_outlook-2011-en

(28) Leal C, Chaix B. (2011) The influence of geographic life environments on cardiometabolic risk factors: a systematic review, a methodological assessment and a research agenda. Obes Rev 12, 3:217-30.

(29) Beaulac J, Kristjansson E, Cummins S. (2009) A systematic review of food deserts, 19662007. Preventing Chronic Disease 6, 3:A105.

(30) Moore LV, Diez Roux AV, Nettleton JA, et al. (2008) Associations of the local food environment with diet quality--a comparison of assessments based on surveys and geographic information systems: the multi-ethnic study of atherosclerosis. Am J Epidemiol 167, 8:917-24.

(31) Drouin S, Hamelin AM, Ouellet D. (2009) Economic access to fruits and vegetables in the greater Quebec City: do disparities exist? Can J Public Health 100, 5:361-4.

(32) Cummins S, Smith DM, Taylor M, et al. (2009) Variations in fresh fruit and vegetable quality by store type, urban-rural setting and neighbourhood deprivation in Scotland. Public Health Nutr 12, 11:2044-50.

(33) Kawachi I., Subramanian SV., Kim D., editors Social Capital \& Health. New York: Springer; 2008.

(34) Macintyre S, Ellaway A, Cummins S. (2002) Place effects on health: How can we conceptualise, operationalise and measure them? Soc Sci Med 55, 1:125-39. 
(35) Public Health Agency of Canada. Best Practice Interventions. Food Security: Gardens and Farmers Markets Impact. Government of Canada 2011 April [cited 2012 Jul 19];Available from: URL: http://66.240.150.14/topic/determinants/26/page/1

(36) United Nations Development Program. Human Development Reports: Indices \& Data. United Nations 2011 [cited 2012 Dec 1];Available from: URL: http://hdr.undp.org/en/statistics/

(37) Gorton D, Bullen CR, Mhurchu CN. (2010) Environmental influences on food security in high-income countries. Nutr Rev 68, 1:1-29.

(38) Garasky S, Morton LW, Greder KA. (2006) The effects of the local food environment and social support on rural food insecurity. Journal of Hunger \& Environmental Nutrition 1, 1:83-103.

(39) Bernell SL, Weber BA, Edwards ME. (2006) Restricted opportunities, personal choices, ineffective policies: What explains food insecurity in Oregon? Journal of Agricultural and Resource Economics 31, 2:193-211.

(40) Morton LW, Bitto EA, Oakland MJ, et al. (2005) Solving the problems of Iowa food deserts: Food insecurity and civic structure. Rural Sociology 70, 1:94-112.

(41) Bartfeld JS, Dunifon R. (2006) State-level predictors of food insecurity among households with children. Journal of Policy Analysis \& Management 25, 4:921-42.

(42) Chung WT, Gallo WT, Giunta N, et al. (2011) Linking neighborhood characteristics to food insecurity in older adults: The role of perceived safety, social cohesion, and walkability. Journal of Urban Health Early Online.

(43) Pilgrim A, Barker M, Jackson A, et al. (2011) Does living in a food insecure household impact on the diets and body composition of young children? Findings from the Southampton Women's Survey. J Epidemiol Community Health. Early Online.

(44) Dean WR, Sharkey JR. (2011) Food insecurity, social capital and perceived personal disparity in a predominantly rural region of Texas: an individual-level analysis. Soc Sci Med 72, 9:1454-62.

(45) Martin KS, Rogers BL, Cook JT, et al. (2004) Social capital is associated with decreased risk of hunger. Soc Sci Med 58, 12:2645-54.

(46) Radimer KL, Allsopp R, Harvey PW, et al. (1997) Food insufficiency in Queensland. Australian \& New Zealand Journal of Public Health 21, 3:303-10.

(47) Brisson D, Altschul I. (2011) Collective Efficacy Predicting Experience of Material Hardship in Low-Income Neighborhoods. Urban Affairs Review 47, 4:541-63.

(48) Bartfeld JS, Ryu JH, Wang L. (2010) Local Characteristics Are Linked to Food Insecurity Among Households With Elementary School Children. Journal of Hunger \& Environmental Nutrition 5, 4:471-83. 
(49) Kirkpatrick SI, Tarasuk V. (2010) Assessing the relevance of neighbourhood characteristics to the household food security of low-income Toronto families. Public Health Nutr 13, 7:1139-48.

(50) Sharkey JR, Dean WR, Johnson CM. (2011) Association of household and community characteristics with adult and child food insecurity among Mexican-origin households in colonias along the Texas-Mexico border. International Journal for Equity in Health 10, 19.

(51) Mazur RE, Marquis GS, Jensen HH. (2003) Diet and food insufficiency among Hispanic youths: acculturation and socioeconomic factors in the third National Health and Nutrition Examination Survey. Am J Clin Nutr 78, 6:1120-7.

(52) Bartfeld JS, Ahn HM. (2011) The School Breakfast Program strengthens household food security among low-income households with elementary school children. J Nutr 141, $3: 470-5$.

(53) Quine S, Morrell S. (2006) Food insecurity in community-dwelling older Australians. Public Health Nutr 9, 2:219-24.

(54) Lee JS, Frongillo EA, Jr. (2001) Factors associated with food insecurity among U.S. elderly persons: importance of functional impairments. Journals of Gerontology Series BPsychological Sciences \& Social Sciences 56, 2:S94-S99.

(55) Foley W, Ward P, Carter P, et al. (2010) An ecological analysis of factors associated with food insecurity in South Australia, 2002-7. Public Health Nutr 13, 2:215-21.

(56) Blumberg SJ, Bialostosky K, Hamilton WL, et al. (1999) The effectiveness of a short form of the Household Food Security Scale. Am J Pub Health 89, 8:1231-4.

(57) Food Security in the United States: Household Survey Tools. USDA 2011 [cited 2012 Feb 2];Available from: URL:

http://www.ers.usda.gov/briefing/foodsecurity/surveytools.htm\#six

(58) Cummins S, Curtis S, Diez-Roux AV, et al. (2007) Understanding and representing 'place' in health research: A relational approach. Soc Sci Med 65, 9:1825-38.

(59) Nord M, Parker L. (2010) How adequately are food needs of children in low-income households being met? Children and Youth Services Review 9:1175-85. 


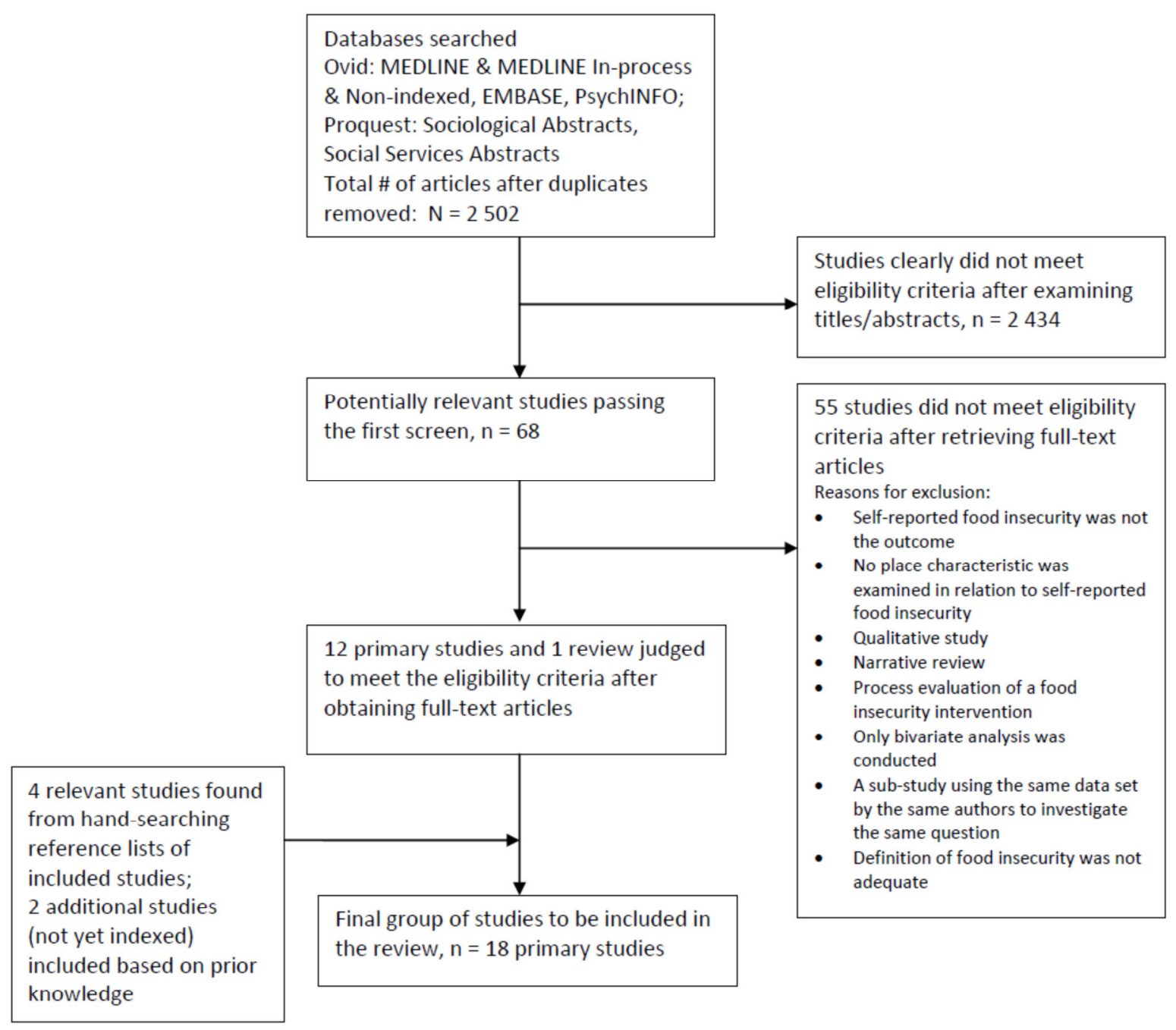

Figure 1. Flow diagram of study selection 
Table 1. Characteristics of included studies

\begin{tabular}{|c|c|c|c|c|c|c|c|c|}
\hline Study & Design & Sample & Place factor(s) & $\begin{array}{l}\text { Place } \\
\text { boundary } \\
\text { definition }\end{array}$ & Food insecurity & $\begin{array}{l}\text { Statistical Method \& } \\
\text { Adjustments }\end{array}$ & Results & $\begin{array}{l}\text { Notes and Potential } \\
\text { Limitations }\end{array}$ \\
\hline $\begin{array}{l}\text { Bartfeld \& } \\
\text { Ahn }^{52}\end{array}$ & $\begin{array}{l}\text { XS, I, NRS, } \\
\text { TQ for } \\
\text { parents }\end{array}$ & $\begin{array}{l}3^{\text {rd }} \text { graders in wave } \\
5 \text { (2002) of the } \\
\text { Early Childhood } \\
\text { Longitudinal } \\
\text { Survey- } \\
\text { Kindergarten cohort } \\
\text { (US); limited to low } \\
\text { income (< } 185 \% \text { of } \\
\text { the poverty line); } \\
\text { info from parent } \\
\text { and school } \\
\text { administrator } \\
\text { surveys used; } n= \\
3010 \text {; total survey } \\
\mathrm{N} \text { not reported }\end{array}$ & $\begin{array}{l}\text { (1) Median rent } \\
\text { (USD/month) } \\
\text { (2)Living location: } \\
\text {-large city } \\
\text {-mid-sized city } \\
\text { - large suburban } \\
\text { - mid-sized } \\
\text { suburban } \\
\text {-large town } \\
\text {-small town } \\
\text {-rural area in MSA } \\
\text { (Metropolitan } \\
\text { Statistical Area) } \\
\text {-rural area outside a } \\
\text { MSA (Ref) }\end{array}$ & $\begin{array}{l}\text { (1) Zip-code } \\
\text { level } \\
\text { (2)Unclear }\end{array}$ & $\begin{array}{l}18 \text { item USDA } \\
\text { Food Security } \\
\text { Scale: } \\
\text { A) food secure vs } \\
\text { food insecure } \\
\text { (replied } \\
\text { affirmatively to at } \\
\text { least } 3 / 18 \text { items); } \\
\text { B) fully food } \\
\text { secure vs } \\
\text { marginally food } \\
\text { secure (replied } \\
\text { affirmatively to } \\
\text { any of the } 18 \\
\text { items) }\end{array}$ & $\begin{array}{l}\text { Probit regression; } \\
\text { Survey weights, clustering } \\
\text { of households within } \\
\text { schools (robust SE), } \\
\text { school breakfast } \\
\text { availability; household } \\
\text { income, education, family- } \\
\text { type/employment status, } \\
\text { and ownership status; } \\
\text { parent's health status, \# of } \\
\text { children in household; } \\
\text { race/ethnicity of child; } \\
\text { school offers after-school } \\
\text { child care, has a } \\
\text { free/reduced price meal } \\
\text { certification, or receives } \\
\text { Title I funds (measures of } \\
\text { school disadvantage); } \\
\text { other place factor, region } \\
\text { of residence }\end{array}$ & $\begin{array}{l}\frac{\mathbf{A}}{(\mathbf{1})}+ \\
\beta=0 \cdot 0005, \mathrm{SE}= \\
0 \cdot 0002, P<0 \cdot 05 ; \\
(\mathbf{2}) \\
+ \text { small towns, } \beta= \\
0 \cdot 415, \mathrm{SE}=0 \cdot 126, \\
P<0 \cdot 01 ; \\
+ \text { mid-sized suburbs, } \\
\beta=0 \cdot 383, \mathrm{SE}=0 \cdot 138, \\
P<0 \cdot 01 ; \\
+ \text { mid-sized cities, } \beta= \\
0 \cdot 224, \mathrm{SE}=0 \cdot 113, \\
P<0 \cdot 05 \\
\text { B } \\
\varnothing \text { for (1) and (2) for } \\
\text { all types vs Ref }\end{array}$ & $\begin{array}{l}\text { Living location not the } \\
\text { main objective; sex of } \\
\text { parent respondent not } \\
\text { controlled; large \# of } \\
\text { children }(n=3840) \\
\text { excluded because } \\
\text { they were missing } \\
\text { parent and/or } \\
\text { administrator surveys; } \\
\text { school disadvantage } \\
\text { was controlled but } \\
\text { area disadvantage } \\
\text { may be a confounding } \\
\text { factor }\end{array}$ \\
\hline $\begin{array}{l}\text { Bartfeld et } \\
\text { al. }{ }^{48}\end{array}$ & $\begin{array}{l}\text { XS, CS of } \\
\text { schools, } \\
\text { SAQ }\end{array}$ & $\begin{array}{l}\text { Parents/guardians } \\
\text { of elementary } \\
\text { school children } \\
\text { attending } 65 \\
\text { schools in } 26 \\
\text { counties in } \\
\text { Wisconsin (US); } \\
\text { recruitment lasted } \\
\text { from } 2003 \text { - 2005; } \\
\mathrm{N}=8396 \text {; mean RR } \\
\text { across schools = } \\
69 \% \text { (range: } 30 \text { - } \\
91 \% \text { ) }\end{array}$ & $\begin{array}{l}\text { (1) Median monthly } \\
\text { rent (increments of } \\
\$ 100 \text { ) } \\
\text { (2) Access to public } \\
\text { transit (yes/no); } \\
\text { (3) Distance to } \\
\text { nearest } \\
\text { supermarket or } \\
\text { grocery store: } \\
-<2 \text { miles } \\
-2 \text { to }<5 \text { miles } \\
\text { (Ref) } \\
-5 \text { to }<10 \text { miles } \\
-10 \text { to }<15 \text { miles } \\
-15-22 \text { miles; } \\
\text { (4) Proportion living } \\
\text { in poverty (US } 2000 \\
\text { Census data def); } \\
\text { (5) Proportion living } \\
\text { in an urban area } \\
\text { (US } 2000 \text { Census } \\
\text { data def) }\end{array}$ & $\begin{array}{l}(1,4,5) \text { ZIP } \\
\text { code } \\
\text { (2) Perceived } \\
\text { (3) Straight line } \\
\text { distance from } \\
\text { geographic } \\
\text { center of ZIP } \\
\text { code }\end{array}$ & $\begin{array}{l}\text { USDA } 6 \text { item } \\
\text { Food Security } \\
\text { Scale short-form: } \\
\text {-Food insecure } \\
\text { (responded } \\
\text { affirmatively to } \geq \\
2 \text { items) }\end{array}$ & $\begin{array}{l}\text { Logistic regression; } \\
\text { Clustering of households } \\
\text { within schools (robust } \\
\text { SE), income, household } \\
\text { structure, \# of children, } \\
\text { housing tenure, education, } \\
\text { \# of employed persons, } \\
\text { ownership of a working } \\
\text { vehicle, other place } \\
\text { factors }\end{array}$ & $\begin{array}{l}(1)+ \\
O R=1.21, P<0.01 \\
(2)- \\
O R=0.68, P<0.01 \\
(3)+\text { for } 15-22 \text { miles } \\
O R=1.67, P<0.01 \\
(4) \varnothing \\
O R=1.98, P>0.05 \\
(5)+ \\
O R=1.44, P<0.05\end{array}$ & $\begin{array}{l}\text { NG and CS are } \\
\text { potential limitations; } \\
\text { could not adjust for } \\
\text { race/ethnicity; did not } \\
\text { control for sex of the } \\
\text { respondent; distance } \\
\text { to nearest } \\
\text { supermarket/store } \\
\text { was not based on } \\
\text { respondents' } \\
\text { residence (correlation } \\
\text { was not strong with } \\
\text { self-reported distance, } \\
r=0 \cdot 27 \text { ); could year } \\
\text { of interview or } \\
\text { differences in RR } \\
\text { across schools have } \\
\text { influenced results? }\end{array}$ \\
\hline
\end{tabular}




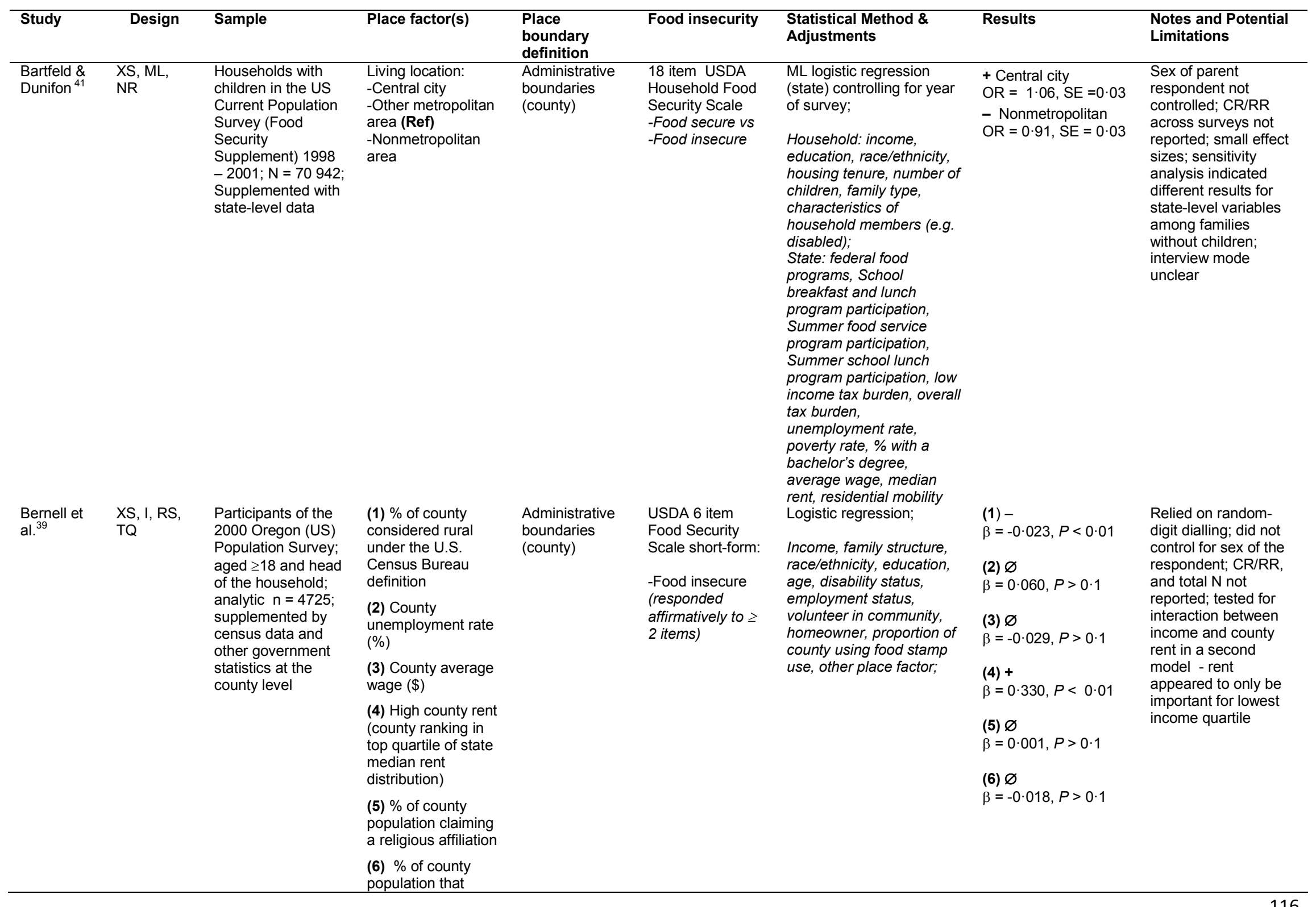




\begin{tabular}{|c|c|c|c|c|c|c|c|c|}
\hline Study & Design & Sample & Place factor(s) & $\begin{array}{l}\text { Place } \\
\text { boundary } \\
\text { definition }\end{array}$ & Food insecurity & $\begin{array}{l}\text { Statistical Method \& } \\
\text { Adjustments }\end{array}$ & Results & $\begin{array}{l}\text { Notes and Potential } \\
\text { Limitations }\end{array}$ \\
\hline $\begin{array}{l}\text { Brisson \& } \\
\text { Altschul }^{47}\end{array}$ & $\begin{array}{l}\text { XS, ML, } \\
\text { CS of } \\
\text { nhoods } \\
\text { within } 10 \\
\text { US cities, } \\
\text { then SRS } \\
\text { of } \\
\text { households } \\
;\end{array}$ & $\begin{array}{l}\text { Low income } \\
\text { residents (median } \\
\text { age of } 40 \mathrm{y} \text { ) } \\
\text { participating in the } \\
\text { Making } \\
\text { Connections } \\
\text { Initiative 2002- } \\
2003 ; \mathrm{N}=7496\end{array}$ & $\begin{array}{l}\text { moved wiithin the } \\
\text { last } 5 \text { y } \\
\text { Collective efficacy: } \\
\text { two subscales } \\
\text { developed by } \\
\text { Sampson et al. } \\
\text { (1997) - } 5 \text { items per } \\
\text { subscale measured } \\
\text { on a 5-point Likert- } \\
\text { type scale (1 } \\
\text { strongly disagree to } \\
5 \text { strongly agree); : } \\
\text { (1) Social cohesion } \\
\text { - individual; } \\
\text { (2) Social cohesion } \\
\text { aggregated by } \\
\text { nhood; } \\
\text { (3) Informal social } \\
\text { control - individual; } \\
\text { (4) Informal social } \\
\text { control aggregated } \\
\text { by nhood }\end{array}$ & $\begin{array}{l}\text { Nhood } \\
\text { boundaries that } \\
\text { conformed to } \\
\text { socially } \\
\text { accepted } \\
\text { norms (census } \\
\text { blocks) }\end{array}$ & $\begin{array}{l}\text { "In the last } 12 \\
\text { months...was } \\
\text { your family ever } \\
\text { without enough } \\
\text { money to buy } \\
\text { food?" (yes/no) }\end{array}$ & $\begin{array}{l}\text { ML structural equation } \\
\text { modelling using probit } \\
\text { regression(nhood); } \\
\text { Individual level: race, } \\
\text { poverty, access to credit, } \\
\text { savings, other place } \\
\text { factors }\end{array}$ & $\begin{array}{l}\text { (1) }- \\
\beta=-0 \cdot 176, S E= \\
0.037, P<0.001 \\
(2)- \\
\beta=-1 \cdot 42, S E=0.672, \\
P<0.05 \\
\text { (3) } \varnothing \\
\beta=0.056, S E=0.035 \\
\text { (4) } \varnothing \\
\beta=1.13, S E=0.651\end{array}$ & $\begin{array}{l}\text { NG and selection of } \\
\text { nhoods are potential } \\
\text { limitations; missing } \\
\text { some potential } \\
\text { confounders (e.g. sex } \\
\text { of the respondent, } \\
\text { household structure); } \\
\text { interview mode } \\
\text { unclear; no CR/RR } \\
\text { given; nhood } \\
\text { explanatory variables } \\
\text { such as SES and } \\
\text { homeownership were } \\
\text { dropped because } \\
\text { model fit decreased; } \\
\text { food insecurity } \\
\text { assessed with } 1 \\
\text { question; clustering } \\
\text { effect of city was not } \\
\text { considered; could } \\
\text { non-normality of } \\
\text { subscales affect } \\
\text { results? }\end{array}$ \\
\hline $\begin{array}{l}\text { Chung et } \\
\text { al. }^{42}\end{array}$ & $\begin{array}{l}\text { XS, ML, } \\
\text { CRS (with } \\
\text { stratificatio } \\
\text { n), F2F }\end{array}$ & $\begin{array}{l}\text { Older adults } \geq 60 \text { y } \\
\text { attending seniors } \\
\text { centers April - Nov } \\
2008 \text { (Health } \\
\text { Indicators Project) } \\
\text { in New York City; } \\
N=1870 ; \text { analytic } \\
\text { sample = } 1650 ; \\
\text { RR }=76 \cdot 7 \%\end{array}$ & $\begin{array}{l}\text { (1) Nhood } \\
\text { walkability scale - } 8 \\
\text { items with binary } \\
\text { responses summed } \\
\text { to derive scale } \\
\text { score (continuous } \\
\text { paved sidewalks, } \\
\text { curb cuts, crossable } \\
\text { sections, lighting at } \\
\text { night, benches on } \\
\text { which to sit, cracks } \\
\text { in sidewalks, } \\
\text { uneven sidewalks, } \\
\text { and excessive noise } \\
\text { from traffic/car } \\
\text { alarms/trains) }\end{array}$ & (1-3) Perceived & 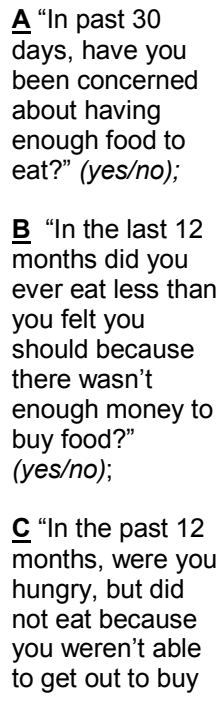 & $\begin{array}{l}\text { ML logistic regression } \\
\text { (seniors' center); } \\
\text { Individual level: age, sex, } \\
\text { married or partnered, } \\
\text { race/ethnicity, education } \\
\text { level, physical disability, } \\
\text { mental health status, } \\
\text { chronic condition status, } \\
\text { social support, income } \\
\text { level (income not included } \\
\text { for model with B as } \\
\text { outcome); other place } \\
\text { factors }\end{array}$ & 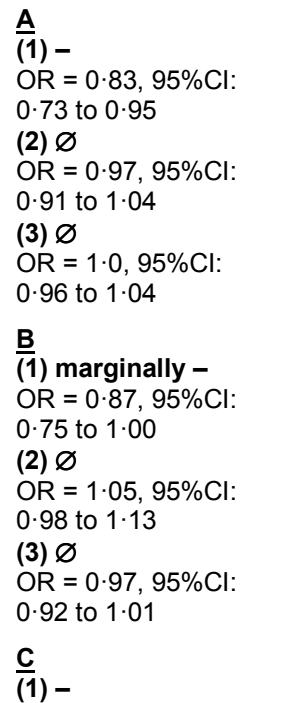 & $\begin{array}{l}\text { Low internal } \\
\text { consistency of } \\
\text { walkability scale; } \\
\text { unclear if the } \\
\text { distribution of the } \\
\text { scales were highly } \\
\text { skewed, especially for } \\
\text { safety and cohesion; } \\
\text { used multiple } \\
\text { imputation for the } \\
\text { three nhood factors; } \\
\text { questions ask about } \\
\text { nhood but clustering } \\
\text { accounts for senior's } \\
\text { center; no nhood level } \\
\text { variables in the } \\
\text { model, although } \\
\text { stratification in } \\
\text { sampling accounts for } \\
\text { size of senior's center }\end{array}$ \\
\hline
\end{tabular}




\begin{tabular}{|c|c|c|c|c|c|c|c|c|}
\hline Study & Design & Sample & Place factor(s) & $\begin{array}{l}\text { Place } \\
\text { boundary } \\
\text { definition }\end{array}$ & Food insecurity & $\begin{array}{l}\text { Statistical Method \& } \\
\text { Adjustments }\end{array}$ & Results & $\begin{array}{l}\text { Notes and Potential } \\
\text { Limitations }\end{array}$ \\
\hline & & & $\begin{array}{l}\text { summed to derive } \\
\text { scale score; } \\
\text { (3) Nhood social } \\
\text { cohesion }-5 \text { items } \\
\text { measured on a } 4 \mathrm{pt} \\
\text { Likert scale ( } 1= \\
\text { very true to } 4=\text { not } \\
\text { at all true) summed } \\
\text { to derive scale } \\
\text { score; }\end{array}$ & & food?" (yes/no) & & $\begin{array}{l}\text { OR }=0 \cdot 84,95 \% \mathrm{Cl}: \\
0 \cdot 70 \text { to } 0.99 \\
\text { (2) } \varnothing \\
\text { OR }=1 \cdot 07,95 \% \mathrm{Cl} \text { : } \\
0.96 \text { to } 1 \cdot 20) \\
\text { (3) } \varnothing \\
\text { OR }=0.96,95 \% \mathrm{Cl}: \\
0.90 \text { to } 1.03\end{array}$ & \\
\hline $\begin{array}{l}\text { Dean et } \\
\text { al. }^{44}\end{array}$ & $\begin{array}{l}X S, I, R S \\
S A Q\end{array}$ & $\begin{array}{l}\text { Adults living in } \\
\text { Texas (US), } \\
\text { participating as part } \\
\text { of the } 2006 \text { Brazos } \\
\text { Valley Health } \\
\text { Assessment ; RR }= \\
73 \cdot 8 \%(2584 / 3501) \text {; } \\
\mathrm{n} \text { for analytic } \\
\text { sample }=1803 \\
\text { (slightly more } \\
\text { women) }\end{array}$ & $\begin{array}{l}\text { (1) Community } \\
\text { social capital index } \\
\text { of Burdine et al. } \\
\text { (1999) } \\
6 \text {-items measured } \\
\text { on a 5-point scale } \\
\text { => strongly agree to } \\
\text { strongly disagree; } \\
\text { quartiles from } \\
\text { standardized score } \\
\text { calculated and used } \\
\text { to form } 3 \\
\text { categories: } \\
\text {-Low social capital } \\
\text { (highest quartile) } \\
\text {-Medium social } \\
\text { capital (middle two } \\
\text { quartiles) } \\
\text {-Ref High social } \\
\text { capital (lowest } \\
\text { quartile); }\end{array}$ & $\begin{array}{l}\text { (1) Perceived; } \\
\text { (2) Unclear }\end{array}$ & $\begin{array}{l}\text { Food depletion } \\
\text { item from the } \\
\text { Radimer-Cornell } \\
\text { hunger and food } \\
\text { insecurity } \\
\text { instrument: } \\
\text { Within the last } \\
\text { month.." the food } \\
\text { that we bought } \\
\text { didn't last and we } \\
\text { didn't have } \\
\text { enough money to } \\
\text { buy more" => } 3 \\
\text { response } \\
\text { categories: } \\
\text { A "often true", } \\
\text { B "sometimes } \\
\text { true", } \\
\text { Ref "never true" }\end{array}$ & $\begin{array}{l}\text { Multinomial logistic } \\
\text { regression - modelled all } \\
\text { variables, then stratified } \\
\text { by rural/urban (results did } \\
\text { not differ so not presented } \\
\text { here) } \\
\text { Education, age, gender, } \\
\text { ethnicity, income level, } \\
\text { perceived personal } \\
\text { disparity, other place } \\
\text { factor }\end{array}$ & $\begin{array}{l}\frac{\mathbf{A}}{(\mathbf{1})} \varnothing \text { Medium } \\
\text { OR }=0 \cdot 73,95 \% \mathrm{Cl} \text { : } \\
0 \cdot 41 \text { to } 1 \cdot 20 \\
+ \text { Low } \\
\text { OR }=1 \cdot 87,95 \% \mathrm{Cl} \text { : } \\
1 \cdot 51 \text { to } 4 \cdot 63 \\
(2)+ \\
\mathrm{OR}=1 \cdot 83,95 \% \mathrm{Cl} \text { : } \\
1 \cdot 10 \text { to } 3 \cdot 06 \\
\frac{\mathrm{B}}{(1)}+\mathrm{Medium} \\
\mathrm{OR}=1 \cdot 73,95 \% \mathrm{Cl} \text { : } \\
1 \cdot 17 \text { to } 2 \cdot 57 \\
+ \text { Low } \\
\text { OR }=2 \cdot 90,95 \% \mathrm{Cl} \text { : } \\
1 \cdot 91 \text { to } 4 \cdot 41 \\
\text { (2) } \varnothing \\
\text { OR }=1 \cdot 10,95 \% \mathrm{Cl} \text { : } \\
0 \cdot 81 \text { to } 1 \cdot 50\end{array}$ & $\begin{array}{l}\text { Possible over/under- } \\
\text { sampling of certain } \\
\text { areas; food insecurity } \\
\text { assessed by only } 1 \\
\text { question; sampling } \\
\text { based on random- } \\
\text { digit dialling (although } \\
\text { authors indicate } \\
\text { coverage was over } \\
95 \% \text {, based on } 2000 \\
\text { census); no control for } \\
\text { area-level SES }\end{array}$ \\
\hline $\begin{array}{l}\text { Foley et } \\
\text { al. }^{55}\end{array}$ & $\begin{array}{l}\text { XS, I, RS, } \\
\text { TQ }\end{array}$ & $\begin{array}{l}\text { Respondents from } \\
\text { the South Australia } \\
\text { Monitoring and } \\
\text { Surveillance } \\
\text { System (all ages) } \\
\text { from July } 2002 \text { - } \\
\end{array}$ & $\begin{array}{l}\text { (2) Rural vs Urban } \\
\text { (Ref) } \\
\text { (1) Neighbors trust } \\
\text { each other (yes/no) } \\
\text { (2) Live in a safe } \\
\text { nhood (yes/no) }\end{array}$ & $\begin{array}{l}\text { (1,2) Perceived } \\
\text { (3) Postcode }\end{array}$ & $\begin{array}{l}\text { "In the last twelve } \\
\text { months, were } \\
\text { there any times } \\
\text { that the food you } \\
\text { have bought just } \\
\text { didn't last, and }\end{array}$ & $\begin{array}{l}\text { Logistic regression; } \\
\text { Survey weights, sex, age } \\
\text { group, education, work } \\
\text { status, household income, } \\
\text { capacity to save, housing }\end{array}$ & $\begin{array}{l}\varnothing \text { for (1), (2), and (3) } \\
\text { and were excluded } \\
\text { during multivariable } \\
\text { analysis, results not } \\
\text { given }\end{array}$ & $\begin{array}{l}\text { Used phone \# lists to } \\
\text { select sample; no } \\
\text { adjustment for survey } \\
\text { year/cycle; only half of } \\
\text { the main survey } \\
\text { sample had data on }\end{array}$ \\
\hline
\end{tabular}




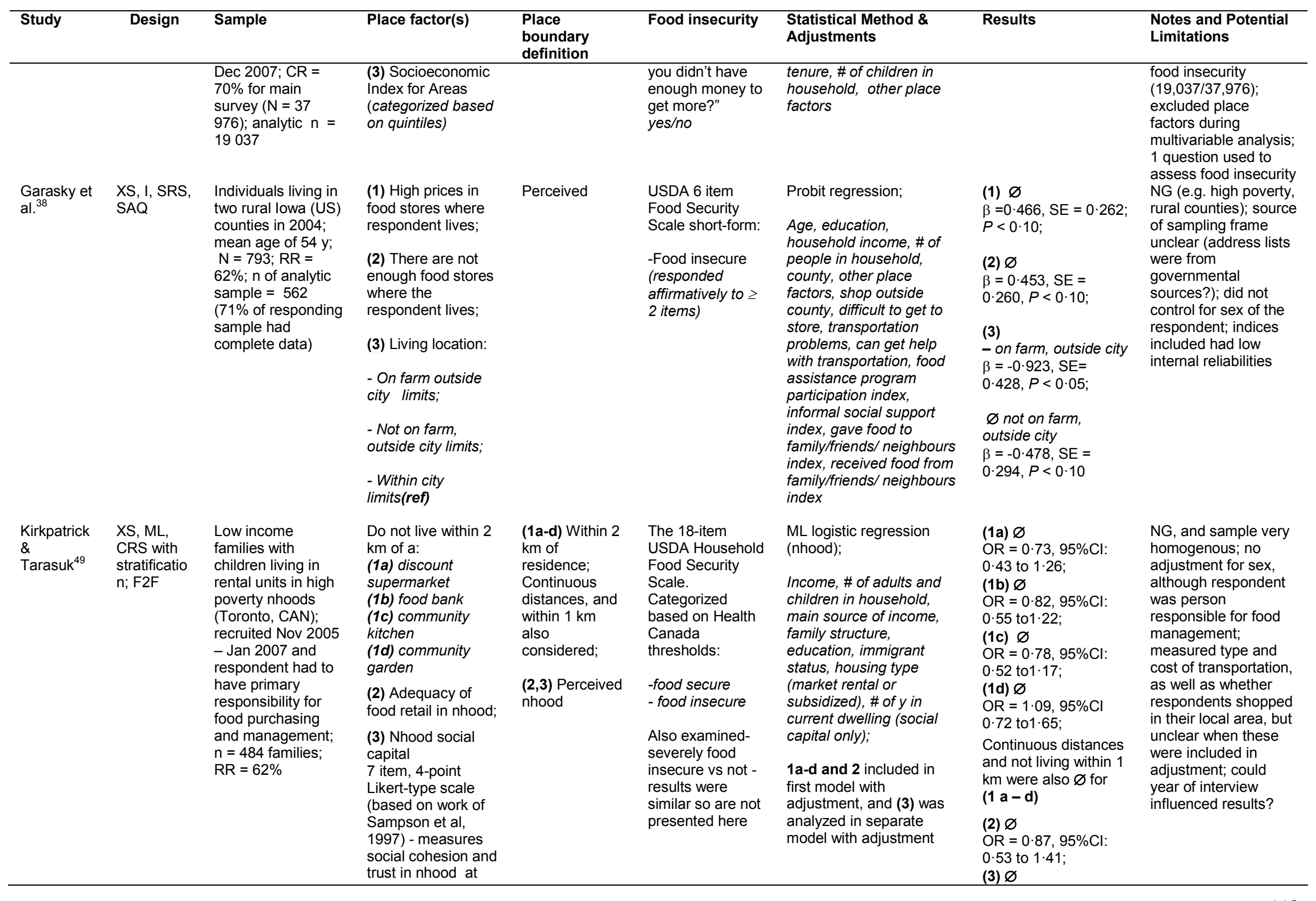




\begin{tabular}{|c|c|c|c|c|c|c|c|c|}
\hline Study & Design & Sample & Place factor(s) & $\begin{array}{l}\text { Place } \\
\text { boundary } \\
\text { definition }\end{array}$ & Food insecurity & $\begin{array}{l}\text { Statistical Method \& } \\
\text { Adjustments }\end{array}$ & Results & $\begin{array}{l}\text { Notes and Potential } \\
\text { Limitations }\end{array}$ \\
\hline $\begin{array}{l}\text { Lee \& } \\
\text { Frongillo } 54\end{array}$ & $\begin{array}{l}\text { XS, I, NRS } \\
+ \text { a state- } \\
\text { level } \\
\text { survey } \\
\text { (sampling } \\
\text { is unclear); } \\
\text { F2F for } \\
\text { NHANES } \\
\text { III; survey- } \\
\text { mode } \\
\text { unclear for } \\
\text { the state- } \\
\text { level } \\
\text { survey }\end{array}$ & $\begin{array}{l}\text { Elderly persons } \\
\text { aged } 60-90 \mathrm{y} \text { in the } \\
\text { NHANES III }(\mathrm{N}= \\
6596, \text { and } \mathrm{n}=6558 \\
\text { for analytic sample) } \\
\text { plus elderly } \\
\text { persons aged } 60- \\
96 \text { in the } 1994 \\
\text { Nutrition Survey of } \\
\text { the Elderly New } \\
\text { York State }(\mathrm{N}=553 ; \\
\mathrm{n} \text { for analytic } \\
\text { sample }=406)\end{array}$ & $\begin{array}{l}\text { the household level: } \\
\text {-Dichotomized } \\
\text { based on a score of } \\
3 \\
\text { - Low vs } \\
\text { - Medium/high } \\
\text { (Ref) } \\
\text { (1) Living in metro } \\
\text { area versus non- } \\
\text { metro (Ref) in } \\
\text { NHANES III; } \\
\text { (2) Living in New } \\
\text { York City vs outside } \\
\text { of New York City } \\
\text { (Ref) }\end{array}$ & Unclear & $\begin{array}{l}\text { NHANES III } \\
\text { "Do you have } \\
\text { enough food to } \\
\text { eat, sometimes } \\
\text { not enough to } \\
\text { eat, or often not } \\
\text { enough to eat?" } \\
\text { food insecure } \\
\text { =sometimes or } \\
\text { often } \\
1994 \text { NY Survey } \\
\geq 1 \text { affirmative } \\
\text { response to } 3 \\
\text { questions } \\
\text { assessing: } \\
\text {-enough money } \\
\text { to buy food, } \\
\text { - skipping meals } \\
\text { because not } \\
\text { enough food, } \\
\text { - choosing } \\
\text { between buying } \\
\text { food or paying } \\
\text { bills/essential } \\
\text { items }\end{array}$ & $\begin{array}{l}\text { Separate logistic } \\
\text { regression models by } \\
\text { survey; } \\
\text { Survey weights and } \\
\text { design, age, poverty } \\
\text { status, race/ethnicity, } \\
\text { education, health status, } \\
\text { social isolation, living } \\
\text { arrangement, physical } \\
\text { functioning, food } \\
\text { assistance }\end{array}$ & $\begin{array}{l}\text { (1) } \varnothing \\
\text { OR= } 0 \cdot 75,95 \% \mathrm{Cl} \text { : } \\
0 \cdot 50 \text { to } 1 \cdot 11 ; \\
\text { (2) } \varnothing \\
O R=0.62,95 \% \mathrm{Cl}: \\
0 \cdot 30-1 \cdot 03\end{array}$ & $\begin{array}{l}\text { Possible } \\
\text { underreporting of food } \\
\text { insecurity; food } \\
\text { insecurity based on } \\
\text { few questions; sex } \\
\text { was assessed in } \\
\text { exploratory analysis } \\
\text { but unclear if included } \\
\text { in the multivariate } \\
\text { model }\end{array}$ \\
\hline $\begin{array}{l}\text { Martin et } \\
\text { al. }{ }^{45}\end{array}$ & $\begin{array}{l}\text { XS, I, RS, } \\
\text { F2F }\end{array}$ & $\begin{array}{l}\text { Low income } \\
\text { families in City of } \\
\text { Hartford (US); } \\
\text { unclear who was } \\
\text { targeted as the } \\
\text { respondent; } N= \\
330 ; \mathrm{CR}=55 \% ; \mathrm{RR} \\
=34 \%\end{array}$ & $\begin{array}{l}\text { (1) Nhood social } \\
\text { capital: } \\
7 \text { item, 4-point } \\
\text { Likert-type scale } \\
\text { (based on work of } \\
\text { Sampson et al, } \\
\text { 1997) - measures } \\
\text { social cohesion and } \\
\text { trust in nhood at } \\
\text { the household level: } \\
\\
\text { Dichotomized } \\
\text { based on median }\end{array}$ & $\begin{array}{l}\text { (1) Perceived } \\
\text { (2) } 14 \\
\text { residential } \\
\text { nhoods with } \\
\text { geographic } \\
\text { boundaries } \\
\text { defined by the } \\
\text { City Council in } \\
1970\end{array}$ & $\begin{array}{l}18 \text { item USDA } \\
\text { Household Food } \\
\text { Security Scale } \\
4 \text { categories } \\
\text { (defined by Bickel } \\
\text { et al, 2000): } \\
\\
\text { a - food secure, } \\
\text { b - food insecure } \\
\text { with risk of } \\
\text { hunger, } \\
\text { c - food insecure } \\
\text { with moderate }\end{array}$ & $\begin{array}{l}\text { Logistic regression; } \\
\text { Member of an } \\
\text { organization, length of } \\
\text { time in apartment, child } \\
\text { under age 18, elderly } \\
\text { member, single mother, } \\
\text { race/ethnicity, income, } \\
\text { education, employment } \\
\text { status }\end{array}$ & $\begin{array}{l}(1)- \\
\text { OR }=0 \cdot 87,95 \% \mathrm{Cl} \text { : } \\
0 \cdot 76 \text { to } 0 \cdot 99, P< \\
0 \cdot 05 ; \\
\text { (2) }- \\
\text { OR }=0 \cdot 47,95 \% \mathrm{Cl} \text { : } \\
0 \cdot 28 \text { to } 0 \cdot 81, P<0.05\end{array}$ & $\begin{array}{l}\text { NG; no adjustment for } \\
\text { clustering within } \\
\text { nhood for outcome } \\
\text { (2); low CR; small n; } \\
\text { did not control for sex } \\
\text { of the respondent; } \\
\text { used hunger vs no } \\
\text { hunger as outcome } \\
\text { after finding null } \\
\text { results for the less } \\
\text { severe outcome food } \\
\text { insecure vs food } \\
\text { secure; measured car }\end{array}$ \\
\hline
\end{tabular}




\begin{tabular}{|c|c|c|c|c|c|c|c|c|}
\hline Study & Design & Sample & Place factor(s) & $\begin{array}{l}\text { Place } \\
\text { boundary } \\
\text { definition }\end{array}$ & Food insecurity & $\begin{array}{l}\text { Statistical Method \& } \\
\text { Adjustments }\end{array}$ & Results & $\begin{array}{l}\text { Notes and Potential } \\
\text { Limitations }\end{array}$ \\
\hline & & & $\begin{array}{l}\text { (score of 3): } \\
\text {-Low(Ref) vs } \\
\text {-High } \\
\text { (2) Nood social } \\
\text { capital from } \\
\text { individuals, } \\
\text { aggregated up to } \\
\text { the nhood level } \\
\text { (mean of each } \\
\text { nhood). Unclear if } \\
\text { dichotomized based } \\
\text { on a score of } 3\end{array}$ & & $\begin{array}{l}\text { hunger (at least } \\
\text { one adult), } \\
\text { d-food insecure } \\
\text { with severe } \\
\text { hunger (at least } \\
\text { one child); } \\
\text { Dichotomized } \\
\text { into Hunger (c, d) } \\
\text { vs No hunger (a, } \\
\text { b) }\end{array}$ & & & $\begin{array}{l}\text { ownership but did not } \\
\text { seem to control for it }\end{array}$ \\
\hline $\begin{array}{l}\text { Mazur et } \\
\text { al. }^{51}\end{array}$ & $\begin{array}{l}\text { XS, I, NRS, } \\
\text { F2F }\end{array}$ & $\begin{array}{l}4-16 \text { y old Hispanic } \\
\text { children } \\
\text { participating in the } \\
\text { NHANES III; } \\
N=2985\end{array}$ & $\begin{array}{l}\text { Residential area: } \\
\text {-Metropolitan (Ref) } \\
\text { a central county of a } \\
\text { metropolitan area } \\
\text { with a population } \geq 1 \\
\text { million vs } \\
\text {-Non-metropolitan } \\
\text { area }\end{array}$ & $\begin{array}{l}\text { Administrative } \\
\text { boundaries } \\
\text { (counties) }\end{array}$ & $\begin{array}{l}\text { A) "Do you have } \\
\text { enough food to } \\
\text { eat, sometimes } \\
\text { not enough to } \\
\text { eat, or often not } \\
\text { enough to eat?" } \\
\text { enough vs } \\
\text { sometimes/ often } \\
\text { not enough; } \\
\text { B) Meal sizes } \\
\text { had to be cut for } \\
\text { an adult because } \\
\text { of lack of money } \\
\text { for food } \\
\text { C) Meal sizes } \\
\text { had to be cut for } \\
\text { a child because } \\
\text { of lack of money } \\
\text { for food }\end{array}$ & $\begin{array}{l}\text { Logistic regression; } \\
\text { Survey weights and } \\
\text { cluster design, sex, age, } \\
\text { Spanish used at home, } \\
\text { low income, interaction } \\
\text { between Spanish used at } \\
\text { home and low income, } \\
\text { household head's } \\
\text { education \& occupation, } \\
\text { female-headed } \\
\text { household, family receives } \\
\text { food stamps, child uses } \\
\text { vitamin or mineral } \\
\text { supplements, parents } \\
\text { living } \leq 10 \text { y in present } \\
\text { house }\end{array}$ & 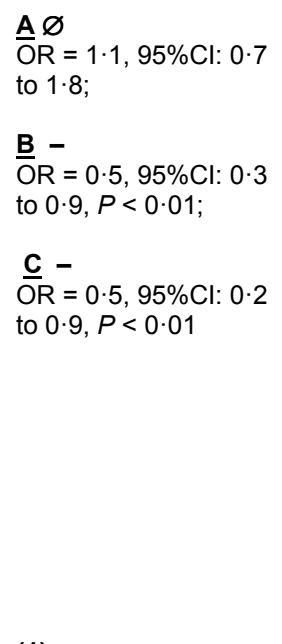 & $\begin{array}{l}\text { Questions } 2 \text { and } 3 \text { not } \\
\text { asked in the first } \\
\text { phase and their } \\
\text { effective n's were } \\
1120 \text { and } 1123 \\
\text { respectively } \\
\text { (compared to } 2345 \text { for } \\
\text { question 1); few } \\
\text { questions to asses } \\
\text { food insecurity; } \\
\text { proxies responded for } \\
\text { children } 4-11 \text { y while } \\
\text { children > } 11 \text { y } \\
\text { responded } \\
\text { themselves }\end{array}$ \\
\hline $\begin{array}{l}\text { Morton et } \\
\text { al. }^{40}\end{array}$ & $\begin{array}{l}\text { XS, I, SRS, } \\
\text { SAQ }\end{array}$ & $\begin{array}{l}\text { Residents (mean } \\
56 \text { y) of } 2 \text { high } \\
\text { poverty, rural } \\
\text { counties in lowa } \\
\text { (US) with } \leq 4 \\
\text { grocery stores } \\
\text { (defined as a 'food } \\
\text { desert') in } 2003 \text {; } \\
N=720 ; \text { RR }= \\
49 \%, C R=60 \% \text {; } \\
\text { analytic } n=656\end{array}$ & $\begin{array}{l}\text { (1) Civic structure } \\
\text { index: } 7 \text { items with } \\
\text { a } 1-4 \text { response } \\
\text { scale (low to high) } \\
\text { summed and / } 7 \\
\text { Measures extent to } \\
\text { which respondents } \\
\text { perceive that local } \\
\text { institutions and } \\
\text { leaders are working } \\
\text { to solve food } \\
\text { access problems in } \\
\text { the community; }\end{array}$ & $\begin{array}{l}\text { (1) Perceived } \\
\text { community; } \\
\text { (2) Perceived } \\
\text { spatial location } \\
\text { relative to } \\
\text { closest town }\end{array}$ & $\begin{array}{l}\text { USDA } 6 \text { item } \\
\text { Food Security } \\
\text { Scale short-form: } \\
\text {-Food insecure } \\
\text { (responded } \\
\text { affirmatively to } \geq \\
2 \text { items) }\end{array}$ & $\begin{array}{l}\text { Logistic regression; } \\
\text { Age, income, education, } \\
\text { give food to family or } \\
\text { friends, acquire meals } \\
\text { from a senior meal site, } \\
\text { acquire food from family } \\
\text { or friends, other place } \\
\text { factor }\end{array}$ & $\begin{array}{l}\text { (1) }- \\
\mathrm{OR}=0 \cdot 20, P=0 \cdot 021 \\
\text { (2) } \varnothing \\
\mathrm{OR}=1 \cdot 26, P=0.762\end{array}$ & $\begin{array}{l}\text { NG (e.g. rural, only } \\
\text { two counties, older } \\
\text { population); did not } \\
\text { adjust for county or } \\
\text { sex of respondent; } \\
\text { low RR; unclear if the } \\
\text { distribution of the civic } \\
\text { index was skewed }\end{array}$ \\
\hline
\end{tabular}




\begin{tabular}{|c|c|c|c|c|c|c|c|c|}
\hline Study & Design & Sample & Place factor(s) & $\begin{array}{l}\text { Place } \\
\text { boundary } \\
\text { definition }\end{array}$ & Food insecurity & $\begin{array}{l}\text { Statistical Method \& } \\
\text { Adjustments }\end{array}$ & Results & $\begin{array}{l}\text { Notes and Potential } \\
\text { Limitations }\end{array}$ \\
\hline $\begin{array}{l}\text { Pilgrim et } \\
\text { al. }{ }^{43}\end{array}$ & $\mathrm{PC}, \mathrm{I}, \mathrm{F} 2 \mathrm{~F}$ & $\begin{array}{l}\text { Women aged } 20- \\
34 \text { y registered with } \\
\text { general } \\
\text { practitioners in } \\
\text { Southampton (UK) } \\
\text { from } 1998-2002 ; \\
\text { RR }=75 \% \text {; follow- } \\
\text { up for those eligible } \\
\text { (had singleton } \\
\text { births) was } 83 \% \text {; } \\
=1640 \text {; analytic } \\
\text { sample = } 1618 \\
\text { when child was } 3 \text { y } \\
\text { of age }\end{array}$ & $\begin{array}{l}\text { (2) Place of } \\
\text { residence: } \\
\text { live in town vs } \\
\text { in country-side } \\
\text { (Ref) } \\
\text { Index of Multiple } \\
\text { Deprivation Score } \\
\text {-Analyzed as } \\
\text { continuous and as a } \\
\text { categorical variable } \\
\text {-less deprived (Ref) } \\
\text {-more deprived } \\
\text {-most deprived }\end{array}$ & Post codes & $\begin{array}{l}\text { Adapted version } \\
\text { of the USDA } 6 \\
\text { item Food } \\
\text { Security Scale } \\
\text { short-form: } \\
\\
\text { Women scoring } \\
\geq 2 \text { categorized } \\
\text { as food insecure }\end{array}$ & $\begin{array}{l}\text { Logistic regression; } \\
\text { Maternal age, benefit } \\
\text { receipt, social class, } \\
\text { smoking status, } \\
\text { educational attainment, } \\
\text { cohabitation status }\end{array}$ & $\begin{array}{l}\text { Continuous (trend) } \\
+ \\
P \text { for linear trend }= \\
0.033 \\
\text { Categorical } \\
\text { - more deprived } \varnothing \\
\text { OR }=1.39(95 \% \mathrm{Cl} \text { : } \\
0.63 \text { to } 3.04) \\
\text {-most deprived } \varnothing \\
\text { OR }=1.95(95 \% \mathrm{Cl} \text { : } \\
0.91 \text { to } 4 \cdot 19)\end{array}$ & $\begin{array}{l}\text { Vague description of } \\
\text { place factor; NG } \\
\text { (clinic-based sample } \\
\text { of women); socio- } \\
\text { economic/demographi } \\
\text { c and place variables } \\
\text { measured before } \\
\text { pregnancy but did not } \\
\text { adjust for moving; } \\
\text { also do not know if } \\
\text { mother was already } \\
\text { food insecure at } \\
\text { baseline }\end{array}$ \\
\hline $\begin{array}{l}\text { Quine \& } \\
\text { Morrell }^{53}\end{array}$ & $\begin{array}{l}\text { XS, I, SRS, } \\
\text { TQ }\end{array}$ & $\begin{array}{l}\text { Non- } \\
\text { institutionalized } \\
\text { older adults } \geq 65 \text { y } \\
\text { of age living in New } \\
\text { South Wales, AUS } \\
\text { from late } 1999- \\
\text { early } 2000 \text { (Older } \\
\text { Person's Health } \\
\text { Survey); } N=8881 ; \\
\text { CR/RR }=70 \cdot 7 \%\end{array}$ & $\begin{array}{l}\text { Type of living } \\
\text { location: } \\
\text {-Urban } \\
\text {-Large, urbanized } \\
\text { rural center, } \\
\text {-Small rural centers, } \\
\text {-Other }\end{array}$ & Unclear & $\begin{array}{l}\text { "In the last } 12 \\
\text { months, were } \\
\text { there any times } \\
\text { that you ran out } \\
\text { of food and } \\
\text { couldn't afford to } \\
\text { buy more?" } \\
\text { (yes/no) }\end{array}$ & $\begin{array}{l}\text { Logistic regression; } \\
\text { Survey weights/design, } \\
\text { sex, age, housing tenure, } \\
\text { living arrangement, private } \\
\text { health insurance, } \\
\text { perceived financial } \\
\text { situation, need household } \\
\text { or personal help, self- } \\
\text { rated healthy lifestyle }\end{array}$ & $\begin{array}{l}\varnothing \text {, statistics not } \\
\text { reported }\end{array}$ & $\begin{array}{l}\text { Low prevalence of } \\
\text { food insecurity (due to } \\
\text { possible } \\
\text { underreporting in this } \\
\text { group, TQ method of } \\
\text { data collection, and/or } \\
\text { use of only } 1 \text { question } \\
\text { to assess food } \\
\text { insecurity) }\end{array}$ \\
\hline $\begin{array}{l}\text { Radimer et } \\
\text { al. }^{46}\end{array}$ & $\begin{array}{l}\text { XS, I, SRS, } \\
\text { TQ }\end{array}$ & $\begin{array}{l}\text { Individuals aged } \\
\geq 18 \text { y residing in } 13 \\
\text { health regions in } \\
\text { Queensland, AUS } \\
\text { March - Oct } 1993 \text {, } \\
N=10,451 ; \text { RR/CR } \\
\text { ranged from } 75- \\
80 \% \text { across strata } \\
\text { (health regions); } \\
\text { analytic sample } \\
\text { was reduced to } \\
70 \% \text { of } N \text { due to } \\
\text { missing data }\end{array}$ & $\begin{array}{l}\text { Living location: } \\
\text { Urban vs Rural } \\
\text { (Ref) }\end{array}$ & $\begin{array}{l}\text { Administrative } \\
\text { boundaries } \\
\text { (Australian } \\
\text { Department of } \\
\text { Health, } \\
\text { Housing and } \\
\text { Community } \\
\text { Services Rural } \\
\text { and Remote } \\
\text { Classification) }\end{array}$ & $\begin{array}{l}\text { A) Household: } \\
\text { "In the last } 12 \\
\text { months were } \\
\text { there times that } \\
\text { your household } \\
\text { ran out of food } \\
\text { and there wasn't } \\
\text { money to buy any } \\
\text { more food?" } \\
\text { (yes/no) } \\
\text { B) Individual: } \\
\text { "In the last } 12 \\
\text { months has } \\
\text { anyone in your } \\
\text { household eaten } \\
\text { less than they } \\
\text { should because }\end{array}$ & $\begin{array}{l}\text { Logistic regression; } \\
\text { Survey weights, aged } \leq 50 \\
\text { y, low income, sex } \\
\text { employment status, single } \\
\text { parent household, single, } \\
\text { separated (including, } \\
\text { divorced or widowed), } \\
\text { shared housing }\end{array}$ & $\begin{array}{l}\frac{\mathrm{A}+}{\mathrm{O}} \mathrm{R}=1 \cdot 3,95 \% \mathrm{Cl}: 1 \cdot 1 \\
\text { to } 1 \cdot 6 \\
\mathrm{~B}^{+} \\
\mathrm{O}^{\mathrm{R}}=1 \cdot 3,95 \% \mathrm{Cl}: 1 \cdot 0 \\
\text { to } 1 \cdot 6\end{array}$ & $\begin{array}{l}P \text {-values not given for } \\
\text { ORs (outcome B may } \\
\text { only be marginally } \\
\text { significant); relied on } \\
\text { random-digit dialling } \\
\text { in } 5 \text { regions where \% } \\
\text { of unlisted \#s was } \\
\text { high ( } 8-14 \% \text { ), and on } \\
\text { phone lists in } \\
\text { remaining regions; } \\
\text { food insecurity based } \\
\text { on only } 2 \text { questions } \\
\text { that were validated in } \\
\text { the same study; } 30 \% \\
\text { not included in } \\
\text { multivariate models - } \\
\text { unclear if these } \\
\text { participants differed }\end{array}$ \\
\hline
\end{tabular}




\begin{tabular}{|c|c|c|c|c|c|c|c|c|}
\hline Study & Design & Sample & Place factor(s) & $\begin{array}{l}\text { Place } \\
\text { boundary } \\
\text { definition }\end{array}$ & Food insecurity & $\begin{array}{l}\text { Statistical Method \& } \\
\text { Adjustments }\end{array}$ & Results & $\begin{array}{l}\text { Notes and Potential } \\
\text { Limitations }\end{array}$ \\
\hline $\begin{array}{l}\text { Sharkey et } \\
\text { al. }^{50}\end{array}$ & $\begin{array}{l}\text { XS, I, CRS } \\
\text { with } \\
\text { stratificatio } \\
\text { n, F2F }\end{array}$ & $\begin{array}{l}\text { Adult Spanish- } \\
\text { speaking women } \\
\text { responsible for food } \\
\text { prep living in one of } \\
44 \text { high poverty } \\
\text { colonias in S. Texas } \\
\text { (Colonia Household } \\
\text { and Community } \\
\text { Food Resource } \\
\text { Assessment, Sept } \\
\text { - Oct } 2009 \text { ); N = } \\
610 ; \mathrm{RR}=97 \cdot 3 \text { - } \\
99 \cdot 4 \% \text { based on } \\
\text { stratification by two } \\
\text { towns (La Feria and } \\
\text { Progreso) }\end{array}$ & $\begin{array}{l}\text { (1) Distance to main } \\
\text { store for purchasing } \\
\text { groceries; } \\
\text { (2) Quality of food } \\
\text { environment => 4- } \\
\text { point Likert scale (1 } \\
\text { = strongly agree to } \\
4=\text { strongly } \\
\text { disagree): } \\
\text { (2a) Little variety in } \\
\text { types of foods that } \\
\text { can be purchased; } \\
\text { (2b) Few grocery } \\
\text { stores or } \\
\text { supermarkets; } \\
\text { (2c) Food prices are } \\
\text { high }\end{array}$ & $\begin{array}{l}\text { (1) Absolute } \\
\text { distance } \\
\text { (2) Perceived }\end{array}$ & 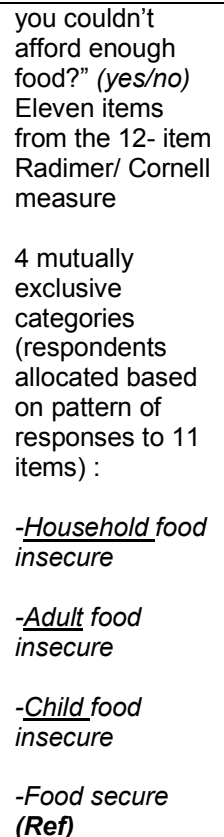 & $\begin{array}{l}\text { Multinomial regression; } \\
\text { Other place factors, } \\
\text { Mexican-born, household } \\
\text { composition, income, } \\
\text { employment status of } \\
\text { spouse or partner, } \\
\text { participation in food } \\
\text { assistance programs, } \\
\text { eating behaviours, } \\
\text { alternative food sources }\end{array}$ & $\begin{array}{l}\text { (1) } \\
+ \text { for Adult } \\
\text { OR }=1 \cdot 19, P \leq 0.01 \\
\varnothing \text { for Household (OR } \\
=1 \cdot 08 \text { ) and for Child } \\
\text { food insecurity (OR = } \\
1 \cdot 09) \\
\text { (2a) } \\
+ \text { for Child } \\
\text { OR }=3 \cdot 32, P \leq 0.01 \\
\varnothing \text { for Household (OR } \\
=2 \cdot 59 \text { ) and for Adult } \\
\text { food insecurity (OR = } \\
1.98) \\
\text { (2b) and (2c) } \\
\varnothing \text { for all forms of } \\
\text { food insecurity } \\
\text { relative to food } \\
\text { secure, results not } \\
\text { reported }\end{array}$ & $\begin{array}{l}\text { NG; definition and } \\
\text { enumeration of } \\
\text { colonias using a } \\
\text { 'windshield survey' by } \\
\text { interviewers (issues of } \\
\text { standardization); did } \\
\text { not appear to } \\
\text { consider potential } \\
\text { clustering effect, at } \\
\text { least by town; may } \\
\text { not be generalizable } \\
\text { to rest of colonias in } \\
\text { S.Texas as only small } \\
\text { area sampled; } \\
\text { transportation was } \\
\text { considered but taken } \\
\text { out of the final model } \\
\text { due to non- } \\
\text { significance; unclear } \\
\text { how scales were } \\
\text { dichotomized }\end{array}$ \\
\hline
\end{tabular}

+ = a significant positive/proportionate association; - = a significant negative/inverse association; $\varnothing=$ a null association; BRFSS= US Centers for Disease Control's Behavioral Risk Factor Surveillance
System; $\mathbf{C l}=$ confidence interval; $\mathbf{C R}=$ cooperation rate (\# responding/\#eligible and able to contact);CRS = cluster random sample; $\mathbf{C S}=$ convenience sample; $\mathbf{F 2 F}=$ face-to-face interviews; I = individual

level; ML = multi-level; NHANES III = Third US National Health and Nutrition Examination Survey (1998-1994); NG = not generalizable; Nhood = neighborhood; NRS = nationally representative sample; OR = odds ratio; PC: prospective cohort; Ref = reference category; RR = response rate (\#responding/\#eligible); RS = simple random sample; $\mathbf{S A Q}=$ self-administered paper questionnaire; $\mathbf{S R S}=$ stratified random sample; TQ = Questionnaire/survey administered over telephone; USDA = US Department of Agriculture; $\mathbf{X S}=$ Cross-sectional design; 


\section{Appendix: Search strategy for OvidSP}

1. exp Residence Characteristics/

2. "residen* characteristics".tw.

3. "built environment".tw.

4. "urban design".tw.

5. "mixed land use".tw.

6. walkab*.tw.

7. "road network".tw.

8. place.tw.

9. Population density/

10. (neighborhood* or neighbourhood*).tw.

11. "social capital".tw.

12. "collective efficacy".tw.

13. "social norm*".tw.

14. "local area*".tw.

15. ((food or farmer*) adj market).tw.

16. food supply/

17. ((food* or shopping or retail) adj desert*).tw.

18. safe*.tw.

19. exp crime/

20. crim*.tw.

21. communit*.tw.

22. "social environment".tw.

23. (depriv* or disadvantage*).tw.

24. exp Socioeconomics/ or exp Socioeconomic Factors/ or exp Sociocultural Factors/ or exp Socioeconomic Status/

25. "census tract".tw.

26. supermarket*.tw.

27. "convenience store*".tw.

28. "fast food".tw.

29. "grocery store*".tw.

30. (street adj (vendor* or food*)).tw.

31. "gas station".tw.

32. "housing density".tw.

33. "residential density".tw.

34. housing.tw.

35. "food insecur*".tw.

36. "food secur*".tw.

37. hunger/

38. hungry.tw.

39. food deprivation/

40. "food insuffic*".tw.

41.35 or 36 or 37 or 38 or 39 or 40

42. "intersection density".tw.

43. "streetscape".tw. 
44. "social disorder".tw.

45. "social cohesion".tw.

46. "social disorganization".tw.

47. ((food* or grocer*) adj3 (availability or affordability or pric* or cost* or access*)).tw.

48. "food environment".tw.

49. "nutrition environment".tw.

50. "physical environment".tw.

51. "ecological analys*".tw.

52. (food adj (store* or shop* or outlet* or retail)).tw.

53. "street-level".tw.

54. sidewalk*.tw.

55.1 or 2 or 3 or 4 or 5 or 6 or 7 or 8 or 9 or 10 or 11 or 12 or 13 or 14 or 15 or 16 or 17 or 18 or 19 or 20 or 21 or 22 or 23 or 24 or 25 or 26 or 27 or 28 or 29 or 30 or 31 or 32 or 33 or 34 or 42 or 43 or 44 or 45 or 46 or 47 or 48 or 49 or 50 or 51 or 52 or 53 or 54

56.41 and 55

57. limit 56 to human

58. limit 57 to (english or french)

59. remove duplicates from 58 


\section{Chapter 4 - Methodological Background \& Overview}

\subsection{Introduction}

This chapter describes the methods used to conduct the three studies that were central to achieving the objectives of this thesis. These descriptions are similar to those provided in each of the respective manuscripts presented in Chapter 5. However, additional information is provided in this chapter to give the reader a more nuanced understanding of the methods used, as well as a solid background in what is commonly employed in the literature. This includes a more in-depth discussion of: the data source used, and the place factors of interest that were available in the data source; measurement methods commonly used to measure the primary outcomes (child excess weight and family food insecurity), along with a discussion of measuring change in these variables over time; the measurement methods used to measure the primary outcomes in this thesis; and an overview and theoretical discussion of the statistical methods employed in this thesis. For child excess weight specifically, the rationale for using two different analytical approaches is also provided. Even though this thesis was an analysis of secondary data, an ethics certificate was needed from the University of Ottawa Research Ethics Board. The ethics certificate can be found in the appendix.

\subsection{Data source - Québec Longitudinal Study of Child Development}

The QLSCD is a government-based cohort study conducted by the Institut de la statistique du Québec (ISQ) that provides a unique opportunity to explore the proposed objectives. The purpose of the QLSCD is to identify factors in early childhood that affect the social adjustment and academic performance of young Quebeckers (1). It is a rich source of data describing the development of children as they grow from infancy into adolescence. 
In the QLSCD, children were randomly selected based on a three-stage, stratified design (1). The territory covered by the survey was first divided into primary sampling units (PSUs) based on broad regions of Québec. The PSUs were then divided into two groups, remote or non-remote. Stage one involved sampling two out of the four remote PSUs and all 11 nonremote PSUs. The selected PSUs were then divided into secondary sampling units (SSUs) based on one or two county regional municipalities. These were then divided into high birth areas and low birth areas (based on 1996 birth registry data). A fixed number of SSUs were randomly selected from the low birthrate group, and all SSUs were selected from the high birthrate group. A fixed number of children were randomly selected from the selected SSUs, based on the 1997/1998 Québec Birth Registry in the third and final sampling stage (1). Sampling occurred throughout the year to minimize the potential impact of seasonal influences. Twins, children with major diseases at birth, and those living in Northern Québec, Cree or Inuit territory, or Indian reserves were excluded.

Of the 2675 families who could be reached in 1997-1998, 2223 (83\%) agreed to participate; 2120 comprised the longitudinal sample (1). Data were collected annually from participating children and their families from five months to eight years of age, and biannually thereafter, in order to reduce respondent burden and subsequent attrition. A variety of data collection instruments have been used to collect health, socioeconomic/demographic, and behavioural data describing the child and his/her environment, from the child him/herself, the person most knowledgeable of the child (generally the mother), the mother's spouse/partner, and the biological parent not residing in the household (if applicable) (1). 
Many variables have been collected in all or more than one data collection cycle, making possible longitudinal analysis. Unlike other longitudinal studies such as the National Longitudinal Survey of Children and Youth (NLSCY), the QLSCD routinely collects directly measured heights and weights, and indicators of not only hunger, but less severe measures of food insecurity from the same children over time. Indicators describing different aspects of families' local environments were also collected over time.

Data for most of the variables in the QLSCD were collected via computer assisted personal interviewing conducted in the child's home. All training of interviewers was provided by ISQ and took place only a few days before the start of each data collection cycle. This ensured that interviewers were up to date on the methodology required. The ISQ used various quality assurance and quality control measures during data collection to ensure high data quality. These included, for example, listening in on interviews, follow-up of the electronic files after the interview, and examination of inter-interviewer variation and bias (2).

Strategies such as regular distribution of newsletters to inform parents of research results and activities related to the study, and involving parents in the planning of future data collection initiatives were used to keep the cohort attrition rate as low as possible. Out of the original 2,120 children that started the survey at five months of age, 1,402 (66\%) responded in cycle 11 (3) (cycles one to 11 were considered in this thesis), yielding an attrition rate of $34 \%$. Note that longitudinal regression methods allow retention of respondents with some missing data, thus a higher proportion of children can be included in each of the analyses than would be possible had we limited the sample to just those responding in cycle 11. With 
all exclusions for various methodological reasons, the percentage of original cohort included in the three studies of this thesis was $75 \%, 65 \%$, and $82 \%$ respectively.

\subsection{Describing place variables derived in the QLSCD}

The main objectives of this thesis related to examining place factors in relation to child weight status and family food insecurity status. Five variables describing the local environment were of interest and available for use in the QLSCD. All place variables were derived by statisticians working either for the ISQ or directly for QLSCD principle researchers. The size of the local area described depended on particular variable definitions, and was not constant across variables. For instance living location covers large census areas at or above the municipality level; neighbourhood social cohesion and disorder cover the mother's perceived neighbourhood; and material and social deprivation cover census enumeration areas, which represent areas equivalent to one or more city blocks. These variables are described in more detail below, under three main subheadings. Raw area information such as postal codes was not available to use in this thesis.

\subsubsection{Material and social deprivation}

\subsubsection{Definition and measurement method used in this thesis}

In this thesis, area deprivation was measured via an index developed by Pampalon and colleagues, which measures two dimensions of deprivation: material and social (4). The material dimension captures inability to get the goods and services that are a part of everyday life, and the social dimension captures social isolation and the fragility of the household structure within the neighbourhood (5). 
The deprivation index was derived by ISQ scientists based on linking children's postal codes, measured in 1998 (at approximately five months of age), to 1996 census data aggregated to the enumeration area, and conducting principal components analysis. The enumeration area was chosen because it was the smallest geographical unit for which census data were available in the 1996 Canadian census (with an average population of 750 residents) (4). Factor scores for each dimension were calculated from aggregate census indictors of residents $\geq 15$ years of age. These indicators are described in Table 4.1 below.

\begin{tabular}{|c|c|}
\hline Material deprivation & Social deprivation \\
\hline - Mean income & $\begin{array}{l}\text { Percentage of single parent } \\
\text { families }\end{array}$ \\
\hline $\begin{array}{l}\text { Percentage of people with no high } \\
\text { school diploma }\end{array}$ & $\begin{array}{l}\text { Percentage of divorced, } \\
\text { widowed, or separated } \\
\text { persons }\end{array}$ \\
\hline $\begin{array}{l}\text { - Ratio of employed individuals to } \\
\text { total population }\end{array}$ & $\begin{array}{l}\text { - Percentage of persons living } \\
\text { alone }\end{array}$ \\
\hline
\end{tabular}

On both dimensions, enumeration area scores were divided into population quintiles, from quintile 1 (least disadvantaged) to 5 (most disadvantaged). For this thesis, we dichotomized both material and social deprivation into 'deprived' (quintiles 4 and 5) versus 'not deprived' (quintiles 1-3), as has been done elsewhere (6).

Both of these variables were also considered time-stable as they were not available in other cycles, mainly because the Canadian census is conducted once every five years. An update, based on the 2001 census, linked to postal codes was not available for this study, but descriptive data showed that these measures remained largely unchanged from 1996-2001 (7). Children could also have moved to a different enumeration area (this became 
dissemination area in the 2001 census) over time; however these changes in material deprivation and social deprivation were not derived in the QLSCD every time a child moved.

Pampalon and colleagues tested the reliability of the two dimensions for Québec as a whole, by deriving the two dimensions (using the same principal components analysis) for four distinct areas in Québec: the Montreal CMA, other CMAs in Québec, CAs, and the metropolitan influenced zones (MIZ) or small/rural towns (4). In every case, they found the same factorial structure, with two principal components accounting for $72-75 \%$ of variation in the indicators for the CMAs and CAs, and 62\% for the indicators in small/rural towns (4). They also tested the index using three Québec information systems covering mortality, hospitalizations, and births. They found that both forms of deprivation can have differing impacts on health, where the impact is increased when the two forms are found together (4).

\subsubsection{Overview of measurement methods in the literature}

Deprivation is more often examined in relation to child weight status than to family food insecurity (see Chapter 3). A comparable and often used measure is the Townsend Index of Material Deprivation. In fact, the material deprivation dimension in the Pampalon Index, discussed previously, is largely based on the work of Peter Townsend (4). Studies also often use single measures like neighbourhood median income, either separately or with other measures like percentage of neighbourhood residents who do not have a high school diploma. Using single measures can miss capturing other potential social influences, and using single measures in combination can create problems of collinearity in multivariable models. Indices can ameliorate this problem but do not allow for one to decipher which particular components of the index are most important in variable relationships. 


\subsubsection{Neighbourhood social cohesion and disorder}

\subsubsection{Definition and measurement method used in this thesis}

Neighbourhood social cohesion and disorder measure two aspects of the perceived local social environment. Disorder may also characterize the physical environment given that questions relate to both physical and social disorder. Both variables were measured via scales based on the mother's responses to specific questionnaire items. These items have been taken and adapted from sections of Dr. Jacqueline Barnes' revised version of the Neighbourhood Characteristics Questionnaire, which was originally developed by Simcha and Schwartz in1986 (8). Barnes revised the questionnaire in order to make it more relevant for use in studies of families with young children (9).

In consultation with Dr. Barnes, scientists at Statistics Canada have further revised the questionnaire for use in the NLSCY (10). Questionnaire items in the QLSCD are the same as those in the NLSCY. However, after the first round of data collection, researchers at the ISQ dropped two items in the disorder scale ('Burglary of homes or apartments' and 'Unrest due to ethnic or religious differences') and recalculated the score for the first collection period with these two items dropped (11).

Questionnaire items were administered by the interviewer, face-to-face to the mother (in almost all cases), every other data collection cycle starting with cycle one, when children were five months of age. The scale for neighbourhood cohesion ranges from 1 to 4 where higher scores indicate a less cohesive neighbourhood. Scores for neighbourhood disorder range from 1 to 3 with a lower score indicating the presence of problems. Table 4.2 shows the items (with their response categories) that make up each of the scales. For both scales, scores were derived by calculating the mean response. In order to derive a score for each 
scale, respondents must have given a valid response for three out of the five items making up the cohesion scale, and three out of the four items for the disorder scale.

Table 4.2: Neighbourhood Social Scale Items (11)

\begin{tabular}{|c|c|}
\hline Scale & Response Categories \\
\hline \multicolumn{2}{|l|}{$\begin{array}{l}\text { Social cohesion } \\
\text { Please tell me whether you strongly agree, agree, disagree, or strongly disagree } \\
\text { about the following statement... }\end{array}$} \\
\hline $\begin{array}{l}\text { 1. If there is a problem around here, the neighbours get together to deal with it } \\
\text { 2. There are adults in the neighbourhood that children can look up to } \\
\text { 3. People around here are willing to help their neighbours } \\
\text { 4. You can count on adults in this neighbourhood to watch out that children are } \\
\text { 5. When I'm away from home, I know that my neighbours will keep their eyes } \\
\text { open for possible trouble }\end{array}$ & $\begin{array}{l}\text { STRONGLY AGREE }=1 \\
\text { AGREE }=2 \\
\text { DISAGREE }=3 \\
\text { STRONGLY DISAGREE }=4\end{array}$ \\
\hline \multicolumn{2}{|l|}{$\begin{array}{l}\text { Disorder } \\
\text { How much of a problem is the following in this neighbourhood:... }\end{array}$} \\
\hline $\begin{array}{l}\text { 1. Litter, broken glass or garbage? } \\
\text { 2. Selling or using drugs? } \\
\text { 3. Alcoholics and excessive drinking in public? } \\
\text { 4. Groups of young people who cause trouble? }\end{array}$ & $\begin{array}{l}\text { A BIG PROBLEM }=1 \\
\text { SOMEWHAT OF A PROBLEM }=2 \\
\text { NO PROBLEM }=3\end{array}$ \\
\hline
\end{tabular}

Kohen et al (1998) used the social cohesion scale in their examination of neighbourhood and family SES influences on school readiness among children 2-5 years old participating in the NLSCY (12). Individual responses were collapsed into a 3-point Likert scale in order to reduce skewness, ensuring that each response category had at least a $10 \%$ response rate. The authors reported that the scale had high reliability in both the toddler $(2-3$ years; $n=3,701)$ and pre-school (4-5 years; $n=3,350)$ age groups (alpha $=0.87$ for both) (12).

Curtis et al (2004) also conducted an analysis of NLSCY data using the neighbourhood social scales (13). They compared neighbourhood problems identified by persons most knowledgeable ${ }^{5}$ of children 4-11 years old (using the disorder scale) and those that the interviewer identified by systematically observing the child's neighbourhood $(n=11,037)$.

\footnotetext{
${ }^{5}$ In most cases this was the mother so any reference to the 'Person Most Knowledgeable' is replaced with mother
} 
Results showed that mothers were more likely to report a problem (garbage, groups hanging out or drinking in the neighbourhood) than the interviewer (39.2\% versus $10.9 \%)$ (13). The mother and interviewer agreed $8.6 \%$ of the time when reporting problems and $57.8 \%$ of the time when reporting no problems. In only $2.8 \%$ of instances did the interviewer report a problem but not the mother, whereas for $30.8 \%$ of observations, mothers reported a problem when the interviewer did not. When comparing the two (mother-reported and observed measures) in multivariate analysis with child well-being indicators as outcomes (conduct disorder, hyperactivity, emotional disorders, and injuries), they found that the mother's assessment of neighbourhood problems was associated with worse child outcomes than interviewers' systematic observations. This demonstrates that the scale potentially provides more information than direct observation and has already been linked to other child health outcomes.

In the first wave of the QLSCD, when children were five months old, a factor analysis was conducted on the items making up the two neighbourhood scales. The internal consistency of both scales was acceptable; a Cronbach's alpha of 0.86 and 0.75 for the cohesion and disorder scales respectively (14). The two items making up a separate neighbourhood safety scale, however, were included in the cohesion scale during this analysis ('It is safe to walk alone after dark', and 'It is safe for children to play outside during the day') but later dropped (15). Additionally, the two items 'Burglary of homes or apartments' and 'Unrest due to ethnic or religious differences' in the initial NLSCY disorder scale were included at this time but also dropped. Both scales were found to be significantly related to a composite measure of SES in conceptually meaningful directions; a low level of 
safety/cohesion was inversely related to SES $(r=-0.23, \mathrm{p}<0.05)$, and perceiving low disorder was positively related to SES $(r=0.20, \mathrm{p}<0.05)(14)$.

\subsubsection{Overview of measurement methods in the literature}

There have been studies on child weight status and food insecurity that have examined similar measures of social cohesion and disorder. Reviews of these studies were presented

in Chapter 3. The scale that is most often used (or adapted) is that developed by Sampson et al (1997), which measures collective efficacy of neighbourhoods, including subscales of social cohesion and informal social control (16). This measure, however, does not capture disorder; only its hypothesized predecessor, informal social control. In the child excess weight literature, disorder is measured via scales that ask about physical and social disorder in the neighbourhood, often with no discussion of how the scale was derived and validated.

\subsubsection{Living location}

\subsubsection{Definition and measurement method used in this thesis}

Analysts at the ISQ constructed the living location variable by linking individual postal codes to census data describing geographical areas using Statistics Canada's postal code conversion file. The variable was derived for each data collection cycle except cycle five (when children were four years of age) - postal codes collected at that time were not valid due to changes in the timing of data collection. According to the linked census information, children were categorized into one of four categories: 1) Montréal CMA, 2) other CMAs containing 100,000 or more inhabitants, 3) CAs containing 10,000 to less than 100,000 inhabitants, and 4) small or rural towns - municipalities containing less than 10,000 inhabitants (17). Consistent with other studies, three categories (urban, semi-urban, and rural) were used in this thesis, by combining the original categories of 1) and 2) to form 
urban areas (high population size); 3) was considered semi-urban (medium population size); and 4) was considered rural (low population size).

\subsubsection{Overview of measurement methods in the literature}

In studies of child weight status and family food insecurity, living location is often defined using national statistical definitions at similar geographical levels (see Chapter 3). This is usually a dichotomous measure, with categorization as living in an urban or rural area dependent on population size definitions and administrative boundaries for the particular country. Fewer studies include a category of semi-urban living. Other variables that have been examined, which tap aspects of living location, include population density and indices of sprawl. These two measures are much more nuanced than living location, as there may be different population densities within different living locations, but they cannot provide information on the type of population center a respondent lives in.

\subsection{Primary outcome 1: child weight status}

\subsubsection{Background}

\subsubsection{Body mass index and three definitions of child excess weight}

At a population level, childhood overweight and obesity are most often defined based on individual body mass index $\left(\mathrm{BMI}=\right.$ weight in $\mathrm{kg} /$ height in $\left.\mathrm{m}^{2}\right)$, using one of three different methods that make comparisons to a normative sample, based on age and sex. A recent study has shown the ability of BMI to estimate increases in adiposity, not musculature, at a population level over time (18); thus, indicating its suitability as a surveillance measure of excess weight. 
The first group of childhood obesity definitions is from the CDC revised growth charts, which were developed based on recommendations of an expert committee in 1998. This committee, convened by the US government, recommended the use of the $85^{\text {th }}$ and $95^{\text {th }}$ percentiles to define 'at risk for overweight' and 'overweight' respectively, based on US national BMI reference data (19). It was determined that children at or above the $95^{\text {th }}$ percentile tended to remain overweight and had a greater risk for the development of adverse health problems both in the short term and long term. These reference data were based on national surveys conducted between the years 1963 and 1994, before the onset of the obesity epidemic, and have been used to create the CDC revised growth charts for US children and adolescents, including BMI-for-age charts for males and females aged 2-20 years (19). The Committee has since changed the wording so that definitions have been relabelled 'overweight' and 'obese,' respectively (20).

In 2000, an expert group convened by the IOTF developed overweight and obesity cutpoints for children, in order to facilitate international comparisons (21). These cut-points are for children aged 2 - 18 years and are based on six large nationally representative crosssectional surveys conducted in Brazil, UK, Hong Kong, the Netherlands, Singapore and the US. The approach used the World Health Organization (WHO) adult definitions of overweight and obesity, BMI of $25 \mathrm{~kg} / \mathrm{m}^{2}$ and $30 \mathrm{~kg} / \mathrm{m}^{2}$ respectively, and extrapolated back from 18 years of age to equivalent BMI percentiles in children. These cut-points represent increased disease risk in adults, but the health consequences for children above the cut-off points may differ from those in adults (21). Unlike the CDC definition, at the time that this thesis was conducted, this definition could not be used to calculate percentiles or Z-scores. 
The final group of definitions were developed and released by the WHO in 2006 and 2007. Growth curves were generated for children who were $0-5$ years of age in 1997-2003, living in designated areas of Brazil, Ghana, India, Norway, Oman, and the US (22). These children were included in the sample if they were being brought up in a socioeconomic environment that was favourable to optimal growth (i.e. breast-fed, transition to healthy diet after breast-feeding, non-smoking mother, basic immunization, and access to healthcare). For children aged $5-19$ years, smoothed growth curves were generated by combining the data from the WHO 0 -5 years growth curves and data from the National Health Examination Survey (NHES) II (6-11 years) and III (12-17 years) and NHANES I (1 to 24 years) (23). Based on these growth curves, the WHO recommends that for children five years or older, those with BMIs more than one standard deviation (SD) above the mean be considered overweight, and that those with BMIs over two SDs be considered obese (24).

Definitions for the WHO are different from the CDC and IOTF definitions in that they are prescriptive rather than descriptive (25). In other words, they describe how children should grow in optimal conditions. Shields \& Tremblay (2010) compared WHO, IOTF and CDC estimates using the 2004 Canadian Community Health Survey (CCHS) (25). Table 4.3 has been adapted from Tables I and II (from the original article) with permission of the authors. In all age groups, the WHO definition identifies more children who are overweight (including obese) compared to the IOTF and CDC definitions. For obesity, the WHO and CDC definitions yield similar prevalence estimates, especially among children aged 12-17 years and when looking at children overall without considering age. The IOTF definition, by far, provides the most conservative overweight and obesity estimates. 
Canadian research has highlighted the importance of using directly measured heights and weights for estimating the prevalence of obesity in children $(26 ; 27)$. Childhood obesity based on parent-reported height and weight tends to be overestimated regardless of age, due in large part to the underestimation of height. Overestimation is much more dramatic in early ages $(\sim 14 \%)$ compared to older ages $(\sim 4 \%)(26)$. Research has also shown that these inaccuracies may bias results in multivariable analyses of risk factors (27). Therefore, only measured heights and weights were considered in this thesis.

Table 4.3. Percentage overweight (including obesity) and obese by sex and age group using WHO, IOTF, and CDC cutpoints and data from the 2004 CCHS - adapted from Shields \& Tremblay, 2010 (25)

\begin{tabular}{|c|c|c|c|c|c|c|}
\hline & \multicolumn{2}{|c|}{ WHO } & \multicolumn{2}{|c|}{ IOTF } & \multicolumn{2}{|c|}{ CDC } \\
\hline & Overweight & Obese & Overweight & Obese & Overweight & Obese \\
\hline \multicolumn{7}{|l|}{$2-5 y$} \\
\hline Boys & 37.2 & 11.8 & 19.4 & 6.3 & 31.0 & 15.0 \\
\hline Girls & 31.7 & 9.4 & 23.6 & 6.4 & 29.3 & 12.4 \\
\hline Total & 34.5 & 10.6 & 21.5 & 6.3 & 30.2 & 13.7 \\
\hline \multicolumn{7}{|l|}{$6-11 y$} \\
\hline Boys & 39.5 & 16.1 & 25.4 & 8.5 & 29.2 & 13.8 \\
\hline Girls & 33.5 & 12.5 & 26.3 & 7.5 & 26.6 & 11.0 \\
\hline Total & 36.5 & 14.3 & 25.8 & 8.0 & 27.9 & 12.4 \\
\hline \multicolumn{7}{|l|}{$12-17 y$} \\
\hline Boys & 37.0 & 15.1 & 32.3 & 11.1 & 31.3 & 14.3 \\
\hline Girls & 29.0 & 9.4 & 25.8 & 7.4 & 24.3 & 9.6 \\
\hline Total & 33.2 & 12.4 & 29.2 & 9.4 & 28.0 & 12.1 \\
\hline \multicolumn{7}{|c|}{ Total (2-17 y) } \\
\hline Boys & 31.3 & 14.8 & 27.0 & 9.1 & 30.5 & 14.3 \\
\hline Girls & 34.7 & 10.6 & 25.5 & 7.2 & 26.3 & 10.7 \\
\hline Total & 38.0 & 12.7 & 26.2 & 8.2 & 28.4 & 12.5 \\
\hline
\end{tabular}

Since the CDC definitions yield overweight and obesity prevalence estimates in between the WHO and the IOTF, and allows Z-scores to be calculated, these definitions were used in this thesis. Section 4.4.2 specifically discusses how child weight status was measured and analyzed in this thesis. 


\subsubsection{Measuring change in child weight status}

Longitudinal studies examining changes in child weight status in the same children over time generally use one of two methods: 1) time-point to time-point comparisons or construction of a 'change' categorical/taxonomical variable coupled with use of crosssectional correlation methods, or 2) single growth curve modeling (longitudinal parametric regression methods) (28). The first method provides little information on developmental trajectories and is severely limited by missing data. Some studies using taxonomical methods suggest that children's weight status may change between measurements. For example, in the QLSCD, 73.5\% of children were not overweight or obese at ages four, six, and seven years, $19 \%$ were overweight or obese at four, six, or seven years of age, and $7.6 \%$ were overweight or obese at all three ages (17).

Single growth curve methods assume all children follow the same (homogeneous or averaged) trajectory over time. There are various techniques depending on the nature of the outcome (e.g. dichotomous versus continuous) and target population (e.g. population versus subject-specific), but all can account for correlations between repeated outcome measures, provide estimations of the mean level of an outcome at a particular time point (intercept), mean rate of change over age/time (slope), can account for time-varying and time-stable covariates, and can handle missing data. The shapes of trajectories are highly dependent on the weight status definition and the time-frame examined. For example, studies assessing BMI generally find that it linearly increases over time (28), as this is a normal part of growth and development in childhood.

Multiple growth curve methods are an alternative way to view change in weight status over time and may provide another means to detect risk factors for the development of 
excess weight during childhood. A few recent studies have identified specific weight status trajectory/transition groups using methods such as group-based trajectory modeling, growth mixture modeling, and latent transition analysis (28). These methods differ in important ways but all classify children into distinctive subgroups with similar patterns of response over time using the expectation-maximization algorithm method (EM); they are also able to account for uncertainty in group assignment, and can incorporate covariates to determine risk factors for membership in particular groups. According to Table 4.4, which provides a summary of these studies, four subgroups of growth are most commonly estimated. However, there is much heterogeneity across studies in terms of outcome definitions (e.g. continuous BMI or BMI Z-score, dichotomous obesity), self-/parent- report versus directly measured height/weight, time-frame examined, traditional versus accelerated longitudinal design, sample size, and consequently the shapes of the trajectories themselves. Results described in this table suggest that a large proportion of children do not develop excess weight, and a much smaller proportion (e.g. $4.4-19 \%$ ) are either always at excess weight or develop excess weight very early on in the trajectory. In some samples, children who are initially at excess weight return to normal weight over time, and children who are initially at normal weight develop excess weight mid to late in the time period examined.

With respect to single versus multiple growth curve methods, there is not a single method that is inherently better than any other (29). Both offer different perspectives on weight change. Using both methods to examine child weight change may provide more insight into potential risk factors than one method on its own. This thesis therefore uses both longitudinal statistical methods, along with BMI Z-score as the outcome, and compares the results. 
Table 4.4: Longitudinal studies statistically estimating multiple weight status trajectory or transition groups in children

\begin{tabular}{|c|c|c|c|c|}
\hline Study & Description of sample & Method Used & OUTCOME & $\begin{array}{l}\text { Trajectory/transition groups (prevalence in } \\
\text { cohort) }\end{array}$ \\
\hline $\begin{array}{l}\text { Mustillo et al } \\
(2003)(30)\end{array}$ & $\begin{array}{l}=991 ; \text { US; } \\
9 \text {-16 y of age (1993- } \\
2000)\end{array}$ & $\begin{array}{l}\text { Group-based } \\
\text { trajectory } \\
\text { modeling }\end{array}$ & $\begin{array}{l}\text { Obesity }(\mathrm{CDC}) \\
\text { directly } \\
\text { measured }\end{array}$ & $\begin{array}{l}\text { 1. Never obese }(73 \%) \\
\text { 2. Always obese (15\%) } \\
\text { 3. Grew out of obesity (5\%) } \\
\text { 4. Developed obesity }(7 \%)\end{array}$ \\
\hline Li et al (2007)(31) & $\begin{array}{l}N=1739 ; \text { US; } \\
2-12 \text { y of age (born in } \\
1984-1990)\end{array}$ & $\begin{array}{l}\text { Growth mixture } \\
\text { modeling }\end{array}$ & $\begin{array}{l}\text { Obesity }(C D C) \\
\text { directly } \\
\text { measured }\end{array}$ & $\begin{array}{l}\text { 1. Never obese }(84 \%) \\
\text { 2. Early onset obesity }(11 \%) \\
\text { 3. Late-onset obesity }(5.2 \%)\end{array}$ \\
\hline $\begin{array}{l}\text { O'Brien et al } \\
(2007)(32)^{*}\end{array}$ & $\begin{array}{l}N=960 ; \text { US; } 2-12 \text { y of } \\
\text { age (1991-2001) }\end{array}$ & $\begin{array}{l}\text { Latent transition } \\
\text { analysis }\end{array}$ & $\begin{array}{l}\text { Overweight } \\
(\mathrm{CDC}) \text {; directly } \\
\text { measured }\end{array}$ & $\begin{array}{l}\text { 1. Never overweight }(60 \%) \\
\text { 2. Preschool- onset overweight (19\%) } \\
\text { 3. Elem school-onset overweight (10\%) } \\
\text { 4. Early-onset overweight } \downarrow \text { to normal }(7.4 \%)\end{array}$ \\
\hline $\begin{array}{l}\text { Ventura et al } \\
(2007)(33)\end{array}$ & $\begin{array}{l}\mathrm{N}=182 ; \text { US; } \\
\text { Non-Hispanic white } \\
\text { girls; } \\
5-15 \text { y of age }\end{array}$ & $\begin{array}{l}\text { Growth mixture } \\
\text { modeling } \\
\text { (variation across } \\
\text { classes only) }\end{array}$ & $\begin{array}{l}\text { BMI; directly } \\
\text { measured }\end{array}$ & $\begin{array}{l}\text { 1. } \uparrow \text { \%ile crossing (14\%) } \\
\text { 2. Delayed } \downarrow \text { \%ile crossing (20\%) } \\
\text { 3. } 50^{\text {th }} \% \text { ile tracking (37\%) } \\
\text { 4. } 60^{\text {th }} \% \text { ile tracking }(29 \%)\end{array}$ \\
\hline $\begin{array}{l}\text { Hejazi et al } \\
(2009)(34)\end{array}$ & $\begin{array}{l}\text { CAN; } 2-8 \text { y of age } \\
(1996 / 97-2002 / 03) \\
\text { Girls } N=490 ; \text { Boys } N \\
=482\end{array}$ & $\begin{array}{l}\text { Group-based } \\
\text { trajectory } \\
\text { modeling }\end{array}$ & $\begin{array}{l}\text { BMI; parent- } \\
\text { reported }\end{array}$ & $\begin{array}{l}\text { Girls } \\
\text { 1. Stable normal BMI ( } 64 \%) \\
\text { 2. Early high BMI, } \downarrow \text { early to normal (8\%) } \\
\text { 3. Early high BMI, } \downarrow \text { late to normal ( } 14 \%) \\
\text { 4. Accelerating rise of BMI to obesity (14\%) } \\
\text { Boys } \\
\text { 1. Stable normal BMI ( } 70 \%) \\
\text { 2. Variable BMI (19\%) } \\
\text { 3. J-curve rise in BMI to obesity ( } 11 \%)\end{array}$ \\
\hline $\begin{array}{l}\text { Nonnemaker et al } \\
(2009)(35)\end{array}$ & $\begin{array}{l}N=8917 ; \text { US; } \\
12-17 y \text { of age } \\
\text { followed to } 18-23 \text { y } \\
(1997-2003)\end{array}$ & $\begin{array}{l}\text { Growth mixture } \\
\text { modeling } \\
\text { (variation across } \\
\text { classes only) }\end{array}$ & BMI; self-report & $\begin{array}{l}\text { 1. High risk for obesity }(4.3 \%) \\
\text { 2. Mod-high risk for obesity }(15.9 \%) \\
\text { 3. Low-mod risk for obesity ( } 35.6 \%) \\
\text { 4. Low risk for obesity }(44.1 \%)\end{array}$ \\
\hline Jun et al (2011)(36) & $\begin{array}{l}1996-2001 \\
(9-14 \text { y of age at } \\
\text { baseline); US } \\
\text { Boys } N=5124 \text {; Girls N } \\
=6288\end{array}$ & $\begin{array}{l}\text { Growth mixture } \\
\text { modeling }\end{array}$ & BMI; self-report & $\begin{array}{l}\text { Boys } \\
\text { 1. Healthy growth }(83.7 \%) \\
\text { 2. Healthy to obese }(7.1 \%) \\
\text { 3. Steady overweight }(7.6 \%) \\
\text { 4. Consistent obese }(1.7 \%) \\
\text { Girls } \\
\text { 1. Healthy growth }(87.8 \%) \\
\text { 2. Healthy to obese }(7.4 \%) \\
\text { 3. Steady overweight }(3.5 \%) \\
\text { 4. Consistent obese }(1.3 \%)\end{array}$ \\
\hline $\begin{array}{l}\text { Pryor et al } \\
(2011)(37)\end{array}$ & $\begin{array}{l}N=1957 ; \text { CAN } \\
5 \text { months }-8 \text { y of age } \\
(1998-2005)\end{array}$ & $\begin{array}{l}\text { Group-based } \\
\text { trajectory } \\
\text { modeling }\end{array}$ & $\begin{array}{l}\text { BMI; parent- } \\
\text { reported and } \\
\text { directly } \\
\text { measured }\end{array}$ & $\begin{array}{l}\text { 1. Low-stable }(54.5 \%) \\
\text { 2. Moderate }(41 \%) \\
\text { 3. High-rising }(4.5 \%)\end{array}$ \\
\hline $\begin{array}{l}\text { Smith et al } \\
(2011)(38)\end{array}$ & $\begin{array}{l}\mathrm{N}=1373 ; 3-14 \text { y of } \\
\text { age; AUZ (children } \\
\text { born from } 1989- \\
\text { 1991) }\end{array}$ & $\begin{array}{l}\text { Group-based } \\
\text { trajectory } \\
\text { modeling }\end{array}$ & $\begin{array}{l}\text { BMI Z-score } \\
\text { (CDC); unclear } \\
\text { but likely directly } \\
\text { measured }\end{array}$ & $\begin{array}{l}\text { 1. Very low (slight linear increase: } 4.2 \% \text { ) } \\
\text { 2. Low ( } 23.6 \%) \\
\text { 3. Average (slight initial decrease: } 33.6 \% \text { ) } \\
\text { 4. Below to above average (6.5\%) } \\
\text { 5. Moderate high (slight increase: } 26.1 \%) \\
\text { 6. High }(6.0 \%)\end{array}$ \\
\hline
\end{tabular}

\footnotetext{
${ }^{*}$ Had a fifth group called 'variable pattern' (3.6\%) but dropped from all analysis because of small cell size
} 


\subsubsection{Child weight status as defined in this thesis}

The main outcome to assess the relationship between place and change in child weight status in this thesis was BMI Z-score, which is BMI standardized for age and sex based on the CDC reference population discussed previously (19). Changes in BMI are part of normal growth in childhood, and depend on age and sex. In the QLSCD birth cohort, which contains both boys and girls, children are not all the exact same age in months. A comparison to a reference population is needed to take into account these differences. Standardization allows for the characterization of weight status, such that children can be categorized as underweight, normal weight, or excess weight depending on their calculated Z-score or percentile. Must \& Anderson (2006) recommend the use of BMI Z-scores over BMI-percentiles for longitudinal analysis (39). Raw BMI values are sometimes suggested for longitudinal analysis, along with adjustment for age and sex. However, this approach is likely to decrease interpretability as an internal rather than external standardization for age and sex is used (39).

BMI Z-scores in this thesis are based on response points where heights and weight were directly measured (at four, six, seven, eight, and 10 years of age) by trained interviewers. Body weight was measured in kilograms on scales set back to zero for each measurement, and height was measured in metres; children wore light clothing and no shoes (17). The distribution of BMI Z-scores was checked for normality and biologically implausible values using the CDC SAS macro (40). Those observations that were flagged were deleted from the sample; this equated to 32 response points (not respondents), with most occurring at four years of age $(\mathrm{n}=23)$. Additionally, some children had BMI measurements but no age in month measurements (needed to compute the BMI Z-score) at certain response points. These 
response points were therefore deleted $(n=113)$. Table 4.5 below shows the number of respondents by the number of repeated measures. Thus, 1799 children had at least one BMI Z-score measure.

\begin{tabular}{|c|c|}
\hline $\begin{array}{l}\text { \# of repeated } \\
\text { measures }\end{array}$ & N (\%) \\
\hline 0 & 321 (15.1) \\
\hline 1 & $233(11.0)$ \\
\hline 2 & $169(8.0)$ \\
\hline 3 & $221(10.4)$ \\
\hline 4 & $431(20.3)$ \\
\hline 5 & 745 (35.1) \\
\hline Total & 2120 \\
\hline
\end{tabular}

\subsubsection{Multivariable analyses to address Thesis Objective 1}

In order to carry out both parts of Objective 1 (estimating the association of the place factors with change in BMI Z-score over time, while controlling for other important explanatory variables) two different longitudinal multivariable analyses were conducted. Figure 4.1 highlights the conceptual model that guided both analyses.

The following sections provide a theoretical overview of the statistical methods used and a description and rationale for the other explanatory variables included in the multivariable models. Specific detail on modeling and modeling results is provided in Manuscripts 3 and 4, which can be found in Chapter 5 .

\subsubsection{Overview of statistical methods}

\subsection{Model 1 - single growth curve modeling}

Linear mixed effects modeling was used to estimate a single growth curve in childhood BMI Z-score. The underlying premise is that the mean response is assumed to be a 
combination of population characteristics that are shared by all individuals (fixed effects) and subject-specific effects that are unique to a particular individual (random effects) (41). The model assumes a normal response distribution, and that correlations between repeated measurements arise because each subject has an underlying (or latent) level of response, which is constant over time and influences all repeated measurements on that subject (41).
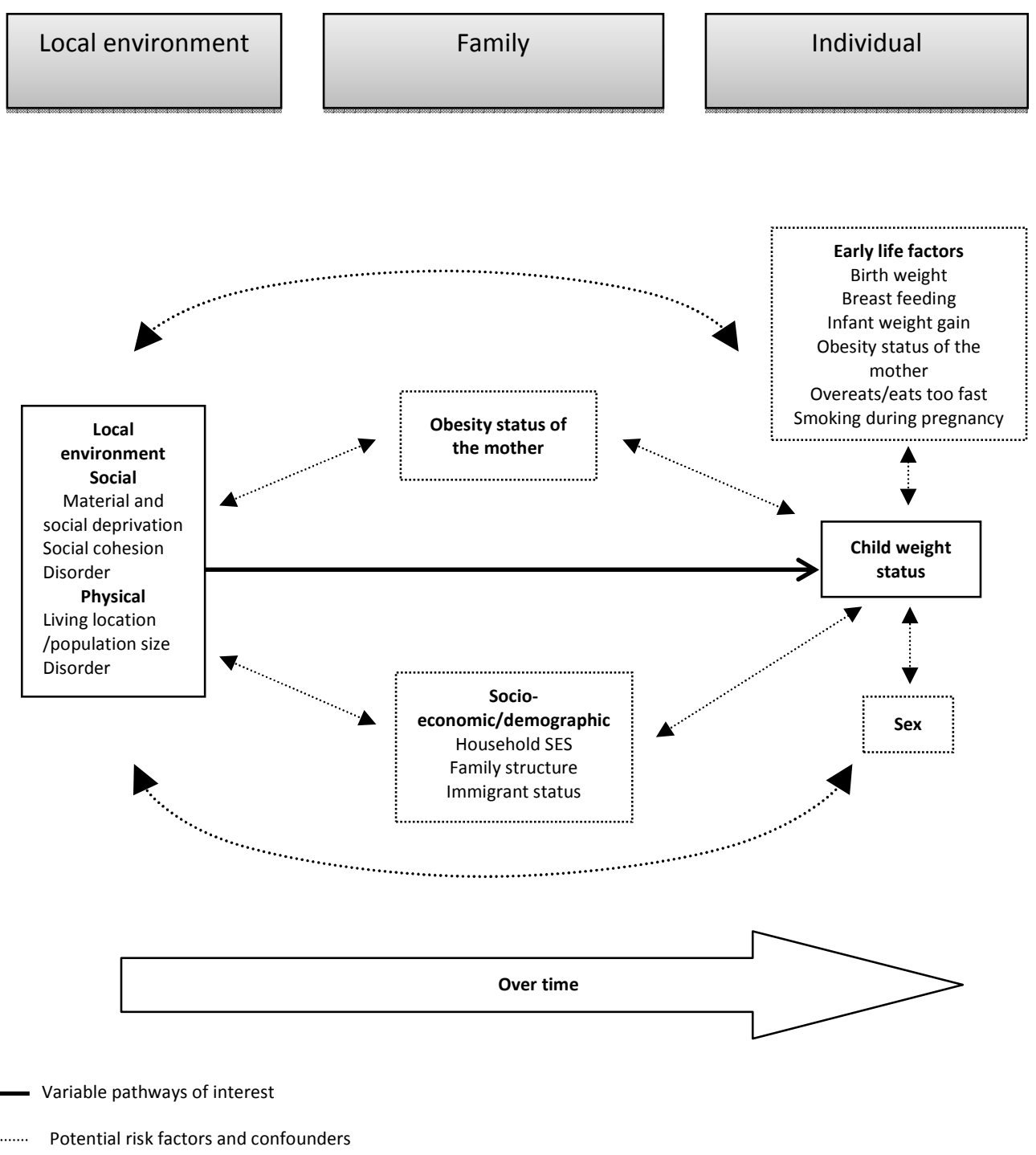

Figure 4.1: Conceptual model of relationship between local environmental factors of interest and child weight status 
The random coefficients model was used, which assumes that each subject varies both in the baseline level of response as well as in their changes over time, allowing intercepts and slopes to randomly vary. The mixed effects model takes into consideration correlations between the repeated measures of BMI Z-score. In this thesis, the fixed effects were of interest, whereas the random effects or within person correlations were considered nuisance factors that needed to be controlled but whose estimation was not of substantive interest.

The random coefficients model is a two-level model where we distinguish between:

\section{Level 1 or subject-specific mean: ${ }^{6}$}

$E\left(Y_{i j} / b_{i}\right)=\left(B_{0}+b_{0 i}\right)+\left(B_{k}+b_{k i}\right) t i m e_{i j}+e_{i j}$

\section{Level 2 or the marginal mean averaged over the random effects: ${ }^{7}$}

$E\left(Y_{i j}\right)=B_{0}+B_{k}$ time $_{i j}+\varepsilon_{i j}$

An important advantage of using the mixed effects approach is that the number of repeated measures does not have to be equal across subjects - such that subjects with missing responses can be included in the analysis. The model can also be used when subjects are not measured at the same time points (such as the case here as children were not all the exact same age in months), and it can take into account both time-dependent and time-independent covariates (41). The mixed effects approach was implemented in SAS version 9.2 using PROC MIXED.

\footnotetext{
${ }^{6}$ Where $\left(B_{0}+b_{0 i}\right)=$ intercept for the $\mathrm{i}$-th individual, $\left(B_{k}+b_{k i}\right)=$ slope for a particular variable $X$ for the i-th invidual. This model describes within individual change over time

${ }^{7}$ Where $B_{0}$ and $B_{k}$ are interpreted in the usual way - population intercept and slope for a particular variable $X$. This model assesses if explanatory variables (place, individual/family-level) are related to inter-individual differences in change.
} 


\subsection{Model 2 - multiple growth curve modeling}

Group-based trajectory modeling, sometimes called semiparametric growth mixture modeling, was used in the second approach to Objective 1 (42). Group-based trajectory modeling relaxes the single growth curve (mixed model) assumption that all individuals are drawn from a single population with common parameters and allows for differences in growth parameters across unobserved subpopulations. It does this by using latent trajectory classes (categorical latent variables), which allow for different groups of growth trajectories with different intercepts and slopes, and population-level prevalence (43). Multinomial logistic regression relates the categorical latent class variable to the time-stable explanatory variables. Posterior probabilities obtained through maximum likelihood iterations are calculated for each individual. These probabilities are used to assign individuals to a particular class, based on the highest fractional probability of class membership (43).

Like the linear mixed model approach, group-based trajectory modeling can accommodate both time-stable and time-dependent explanatory variables, and can include individuals with intermittently missing time-dependent explanatory and outcome variables. Time-dependent explanatory variables are linked to the trajectory classes via a latent polynomial function (44). Parameters are group-specific and are interpreted the same way as in a conventional regression (measures the change in the response variable associated with change in the explanatory variable).

Figure 4.2 depicts the group-based trajectory model used in this thesis. Time-stable variables contribute only to determination of group membership, whereas time-dependent variables contribute only to the estimation of trajectories. The group-based approach was employed using a SAS macro called PROC TRAJ (42). 


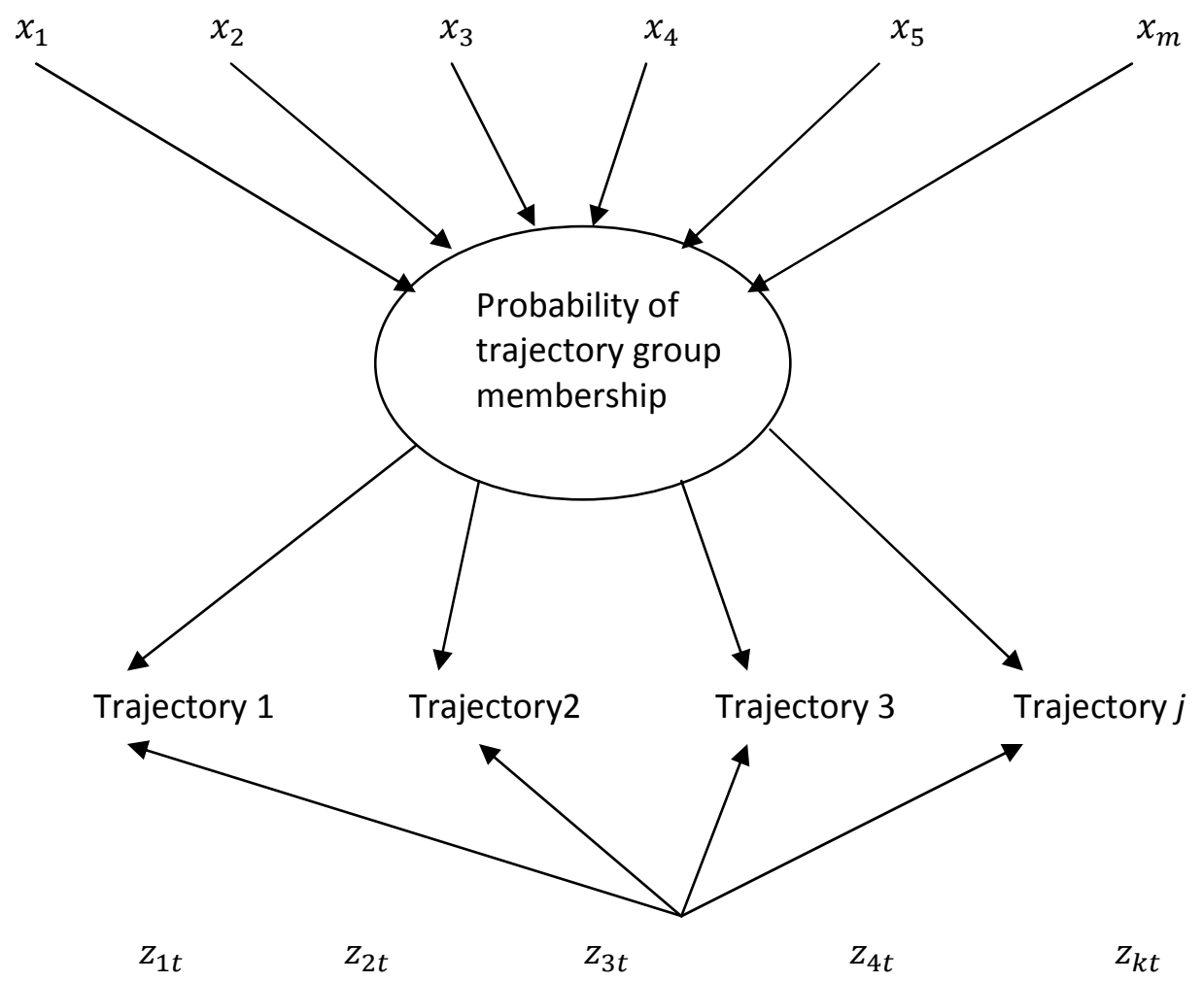

Figure 4.2: The group-based trajectory model with time-stable $\left(x_{m}\right)$ and time-dependent explanatory variables $\left(z_{k t}\right)$

\subsubsection{Other explanatory variables}

In order to gain a clear picture of the relative importance of place factors on child weight status, other variables were added to the multivariable models (see Figure 4.1). These other explanatory variables were chosen based on prior evidence of an association with child excess weight in the QLSCD $(45 ; 46)$. Taking a lifecourse perspective, important early life factors were included to adjust for prior exposures, and to take into account changes in other important explanatory variables. Other variables, such as the mother's obesity status and the child's overeating behaviour could also serve as proxies, although imperfect, for genetic/biological influences. In the case of overeating behaviour, prior research indicates 
that over half the genetic influence on weight status operates through appetite $(47 ; 48)$. In addition to genetic/biological influences, the mother's obesity status could also serve as an indicator of potential influences in the family environment. Experts in the field of social capital also recommend controlling for social variables such as SES and ethnicity in epidemiologic studies on social capital (in this study this was measured by social cohesion and a related measure, social deprivation) (49). Table 4.6 provides a description of these variables and how they were used in modeling.

Table 4.6: Definitions of explanatory variables included in analyses to address Objectives 1a and 1b

\begin{tabular}{|c|c|c|}
\hline Variable & Definition $^{a}$ & $\begin{array}{l}\text { Timing of data collection } \\
\text { (age of child) }{ }^{\text {b }}\end{array}$ \\
\hline \multicolumn{3}{|l|}{ Individual-level } \\
\hline Male sex & Yes/no & 5 months \\
\hline Overeating phenotype & $\begin{array}{l}\text { 'Often' eats too much and/or 'sometimes' or 'often' } \\
\text { eats too fast }\end{array}$ & 4 years \\
\hline Breast-feeding status & Never; $\geq 3$ months; other & 5 months \\
\hline Mother smoked during pregnancy & Yes/no & 5 months \\
\hline Mother's obesity status (WHO) & $\mathrm{BMI} \geq 30$ based on self-reported height and weight & 1.5 years \\
\hline Birth weight & $\begin{array}{l}\text { Low ( }<2.5 \mathrm{~kg}) \text {; Normal }(2.5 \mathrm{~kg} \geq \text { but } \leq 4 \mathrm{~kg}) \text {; High }>4 \\
\mathrm{~kg} \text { ) }\end{array}$ & 5 months \\
\hline Rapid infant weight gain $0-5$ months & $\begin{array}{l}\text { Highest two quintiles of average monthly weight gain } \\
\text { from } 0 \text { to } 5 \text { months }\end{array}$ & 5 months \\
\hline \multicolumn{3}{|l|}{ Family/household } \\
\hline Low SES ${ }^{c d}$ & $\begin{array}{l}\text { Calculated based on gross household income, and } \\
\text { mother's and father's education level, and job } \\
\text { prestige; categorized into tertiles - low, middle, and } \\
\text { high }\end{array}$ & Time-dependent \\
\hline Single parent family & Yes/no & Time-dependent \\
\hline Mother is an immigrant & Yes/no & 5 months \\
\hline
\end{tabular}

\subsection{Primary outcome 2: family food insecurity}

\subsubsection{Background}

\subsubsection{Definitions commonly used in the literature}

The USDA FSSM has involved extensive research and validity testing, spanning over a decade (51), and has been used to monitor US food insecurity since 1995 (52). The FSSM 
is considered 'state of the art' in food security measurement (53). It contains items from earlier food insecurity measures, mainly from the CCHIP and the Radimer/Cornell instruments, and it uses an optional screener based on the USDA Food Insufficiency Measure (51).

Health Canada has used the USDA FSSM (HFSSM) since 2004 to monitor food insecurity (although with different cut-points) (54). Earlier national surveys included more extreme measures of food insecurity such as food insufficiency (discussed below) and child hunger, but have yielded much lower prevalence estimates than surveys incorporating multiple dimensions of food insecurity, such as that measured by the HFSSM (55).

Table 4.7 details each of the HFSSM's items (54). The scale contains 18 questions that ask about food security in the household over the last 12 months, where each item refers to lack of money or not being able to afford food with respect to the condition or behaviour being discussed. Therefore, voluntary fasting or dieting to lose weight are excluded from the measure. Items range in severity from worrying about running out of food, to children not eating for a whole day. Ten of the questions refer specifically to adults in the household, and eight are specific to children. Even though questions are specific to adults or children, it should be noted that this is a measure of household food insecurity, not individual food insecurity status (53).

The Rasch measurement model, a non-linear statistical method, is used by the USDA and Statistics Canada to combine the 10 adult questions and the eight child questions into two separate scales (Adult Food Security Scale and Child Food Security Scale, respectively). Based on the number of indications of food insecurity reported on each scale, Canadian 
households are classified into three categories of food security: "food secure," "moderately food insecure," and "severely food insecure."

Table 4.7 Household Food Security Survey Module (HFSSM) Adult and Child Scales *

Adult Scale

You and other household members worried food would run out before you got money to buy more

Food you and other household members bought didn't last and there wasn't any money to get more

You and other household members couldn't afford to eat balanced meals

You or other adults in your household ever cut size of meals or skipped meals

You or other adults in your household ever cut size of meals or skipped meals in 3 or more months

You (personally) ever ate less than you felt you should

You (personally) were ever hungry but did not eat

You (personally) lost weight

You or other adults in your household ever did not eat for whole day

You or other adults in your household ever did not eat for whole day in 3 or more months

\section{Child Scale}

You or other adults in your household relied on only a few kinds of low-cost food to feed child(ren)

You or other adults in your household couldn't feed child(ren) a balanced meal

Child(ren) were not eating enough

You or other adults in your household ever cut size of any of the child(ren)'s meals

Any of the child(ren) were ever hungry

Any of the child(ren) ever skipped meals

Any of the child(ren) ever skipped meals in 3 or more months

Any of the child(ren) ever did not eat for whole day

* The full wording of each question, asked of an adult household member, includes explicit reference to resource limitation (e.g. "...because there wasn't enough money for food").

The US uses four categories: "high food security," "marginal food security," "low food security," and "very low food security" and slightly different thresholds. Table 4.8 outlines the thresholds for defining food insecurity in the Canadian context (54). Response options differ for particular questions. Responses that are deemed affirmative include "yes"; "often" or "sometimes"; and "almost every month" or "some months but not every month." 
Table 4.8: Thresholds of food security status using the HFSSM (Canada)

\begin{tabular}{|c|c|c|c|}
\hline $\begin{array}{l}\text { Food Security } \\
\text { Status }\end{array}$ & $\begin{array}{l}\text { Adult Status (based on the } \\
\text { Adult Scale) }\end{array}$ & $\begin{array}{l}\text { Child Status (based on the } \\
\text { Child Scale) }\end{array}$ & $\begin{array}{l}\text { Household Status (derived from Adult and } \\
\text { Child Status) }\end{array}$ \\
\hline \multirow[t]{2}{*}{ Food Secure } & $\begin{array}{l}\text { no, or one, indication of } \\
\text { difficulty with income- } \\
\text { related food access }\end{array}$ & $\begin{array}{l}\text { no, or one, indication of } \\
\text { difficulty with income- } \\
\text { related food access }\end{array}$ & $\begin{array}{l}\text { Both adult status and child status are food } \\
\text { secure }\end{array}$ \\
\hline & 0 or 1 affirmative responses & 0 or 1 affirmative responses & \\
\hline \multirow[t]{2}{*}{$\begin{array}{l}\text { Food } \\
\text { Insecure, } \\
\text { Moderate }\end{array}$} & $\begin{array}{l}\text { indication of compromise in } \\
\text { quality and/or quantity of } \\
\text { food consumed }\end{array}$ & $\begin{array}{l}\text { indication of compromise in } \\
\text { quality and/or quantity of } \\
\text { food consumed }\end{array}$ & $\begin{array}{l}\text { Either adults or children, or both adults and } \\
\text { children, in the household are moderately food } \\
\text { insecure, and neither is severely food insecure }\end{array}$ \\
\hline & 2 to 5 affirmative responses & 2 to 4 affirmative responses & \\
\hline \multirow[t]{2}{*}{$\begin{array}{l}\text { Food } \\
\text { Insecure, } \\
\text { Severe }\end{array}$} & $\begin{array}{l}\text { indication of reduced food } \\
\text { intake and disrupted eating } \\
\text { patterns }\end{array}$ & $\begin{array}{l}\text { indication of reduced food } \\
\text { intake and disrupted eating } \\
\text { patterns }\end{array}$ & $\begin{array}{l}\text { Either adults or children in the household are } \\
\text { severely food insecure }\end{array}$ \\
\hline & $\geq 6$ affirmative responses & $\geq 5$ affirmative responses & \\
\hline
\end{tabular}

Development of measures used in the USDA FSSM has been based on qualitative research and a comprehensive understanding of food insecurity through the lived experiences of individuals (56). It is a continuous scale based on items from CCHIP and the Radimer/Cornell Measure. For the Radimer/Cornell items this comprehensive understanding arouse from conducting formal in-depth interviews with women experiencing food insecurity; and for the CCHIP, this was gained through regular contact of project investigators with participants experiencing food insecurity (56). In comparison to food insecurity defined based on independent assessments using multiple variables (e.g. household socio-economic/demographic characteristics, use of food programs, sources and expenditures on food and other items, household food inventories, and 24-hour dietary intake recall), both instruments have shown high sensitivity (84-89\%) and adequate specificity $(63-71 \%)(56 ; 57)$. In a similar comparison study conducted on a Québec population, agreement between categorization of food insecurity based on interviews and focus-groups versus a French version of the Radimer/Cornell measure was shown to be high 
$($ Kappa $=0.88)(58)$. The CCHIP and Radimer/Cornell instruments have also been shown to have high reliability, with Cronbach's Alphas $\geq 0.85$ (56). As a continuous scale that is based on these two instruments, the FSSM reflects well the deterministic property of scales meaning that it displays an ability to predict responses to all of its component items on the basis of its total score (57).

It is also important to discuss in this section the USDA Food Insufficiency Measure, given that it is one of the earliest and most widely used measures of food insecurity and hunger in developed countries (51). This measure has been used in different ways in numerous surveys that have also measured health, diet and economics. Different versions include a single question with a four- part response, a single question with a three- part response, and a two-question measure (51). As mentioned previously, this measure has also been used as a screener for the FSSM. The four-part variant can be found in Table 4.9.

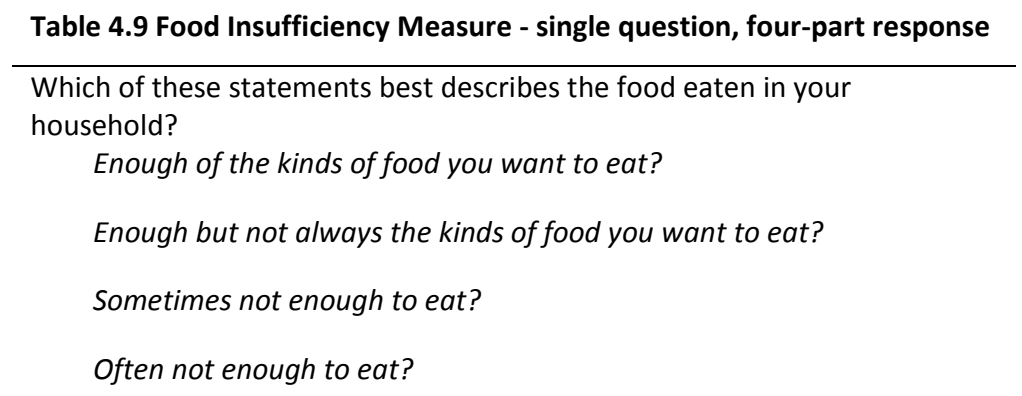

The validity of the NHANES III food insufficiency question (with a three-part response) was tested along with the CCHIP and Radimer/Cornell measures in a validation study described previously (57). Compared to the criterion measure, the NHANES III item had excellent specificity but poor sensitivity, and therefore estimated a lower prevalence of food 
insecurity (57). This demonstrates that a single-item measure cannot capture all aspects of food insecurity.

Comparing to the FSSM, the four-part response measure (Table 4.9) accurately estimates food insecurity when combing the responses of "sometimes not enough", "often not enough" and "enough but not the kinds we want" (51). For this reason, and given the historical use of the Food Insufficiency Measure, it is still useful to compare it to FSSM estimates of food insecurity (51).

\subsubsection{Measuring changes in family food insecurity over time}

Given that food insecurity is an episodic phenomenon, it is important to determine how it changes over time in the same household, and how this may be related to other explanatory variables. In the food insecurity literature, this is a relatively understudied area. Some examples are discussed in this section.

There has been some criticism about the FSSM's ability to determine the frequency and duration of households experiencing food insecurity (59). Additional information that is collected in the US Current Population Survey Supplement permit USDA researchers to estimate the chronicity of household food insecurity (e.g. on average, households with food insecurity experienced food insecurity for X months out of 12 months of the year).

However, the authors caution that the measurement method does not produce precise estimates. They emphasize that this requires collection of frequency-of-occurrence information for all items in the scale and creation of a separate scale of frequent or chronic food insecurity and hunger. Therefore a panel, set up by the National Academies to review the measure, recommended that the: 
"USDA should determine the best way to measure frequency and duration of household food insecurity. Any revised or additional measures should be appropriately tested before implementing in the Household Food Security Survey Module”(59).

Repeated measures of food insecurity, ideally using the same measure, can also provide insight into change over time. Previous studies have used taxonomical methods; categorizing respondents into change categories. Because cell sizes are small, this is usually a dichotomous measure: "ever food insecure" over the specified time period, versus "never food insecure." Using a version of the Food Insufficiency Measure administered at two time points, Dubois et al (2006) determined that $6.3 \%$ of children in the QLSCD had experienced family food insecurity at least once from 1.5 to 4.5 years of age (60). In the NLSCY, hunger due to running out food or money to buy food (considered very low food security/severe food insecurity) is measured in every data collection cycle. From cycle one to cycle five (six year period), Kirkpatrick et al (2010) constructed two categorical indicators of change in hunger among children 10-15 years of age and 16-21 years of age in cycle six (61). The first indicator consisted of three categories: never hungry, one episode of hunger, and two or more episodes. The second indicator was never hungry versus ever hungry. Given that hunger is a severe form of food insecurity, prevalence levels were low in each of the categories. Among 10-15 year olds, 3.3\% had ever experienced hunger, and 1.1\% had experienced hunger twice or more. The prevalence among 16-21 year olds was slightly higher at $3.9 \%$ and $1.4 \%$ respectively. Larger sample sizes and use of the FSSM may increase cell sizes and therefore allow for the construction of change variables with more categories. For example, in a study using the large US cohort: Early Childhood Longitudinal 
Study-Kindergarten, Howard (2010) derived eight categories of food security status change from grade one to grade five, based on food security status measured at grades one, three and five (62). The proportion of children categorized in each group is presented below:

- Persistently food secure (81\%)

- Persistently food insecure (3\%)

- Became food secure for the first time in 3rd grade (7\%)

- Became food insecure for the first time in 3rd grade (5\%)

- Became food secure for the first time in 5 th grade (1\%)

- Became food insecure for the first time in 5 th grade (4\%)

- Became food secure for the second time in 5 th grade (3\%)

- Became food insecure for the second time in 5 th grade $(2 \%)$

As discussed in the section on child weight status, sometimes taxonomical methods cannot provide a lot of detail on change in food security status over time (e.g. ever food insecure versus never food insecure). Even if a larger number of categories are possible, information is still lost when this method is used, statistical power is decreased, and categories may be difficult to understand (e.g. the Howard 2010 example above). Missing data is also a major limitation. Longitudinal regression methods such as marginal or mixed models can make use of all available data, account for correlations between repeated measures in the same respondent, and relate changes in food insecurity status to other explanatory variables. To the author's knowledge, this has not yet been conducted using food insecurity status as the outcome.

\subsubsection{Family food insecurity as defined in this thesis}

Food insecurity in this thesis was based on three questions, adapted from the Radimer/Cornell hunger instrument (63). The first question taps the qualitative component of food insecurity: "We eat the same things several days in a row because we only have a few different kinds of food on hand, and don't have enough money to buy more." The 
second question examines the quantitative aspect: "We eat less than we should because we don't have enough money for food." The last question assesses the qualitative component of food insecurity at the child level: "We can't provide balanced meals for our children because we can't afford it financially." Response options for all three questions include: "often true," "sometimes true," and "never true." For this thesis, children were considered to be living in a food insecure household if the mother answered "sometimes" or "often true" to any of the three questions. Categorizing food insecurity based on any affirmative response (sometimes or often) is consistent with previous research (64). This measure was derived when children were four, eight, and 10 years of age. Table 4.10 describes the number of children who had zero, one, two, or all three measures.

\begin{tabular}{|c|c|}
\hline \# of repeated measures & $\mathrm{N}(\%)$ \\
\hline 0 & $193(9.1)$ \\
\hline 1 & $572(27.0)$ \\
\hline 2 & $377(17.8)$ \\
\hline 3 & $978(46.1)$ \\
\hline Total & 2120 \\
\hline
\end{tabular}

This measure has been used in other Québec-wide government surveys and has been tested as part of a previous study (65-67). It cannot estimate the prevalence of food insecurity comparable to the FSSM, as it does not capture all dimensions, but it does provide an overview of important food insecurity components (67). It was implemented in the QLSCD to be able to compare estimates across different province-wide surveys in Québec. 

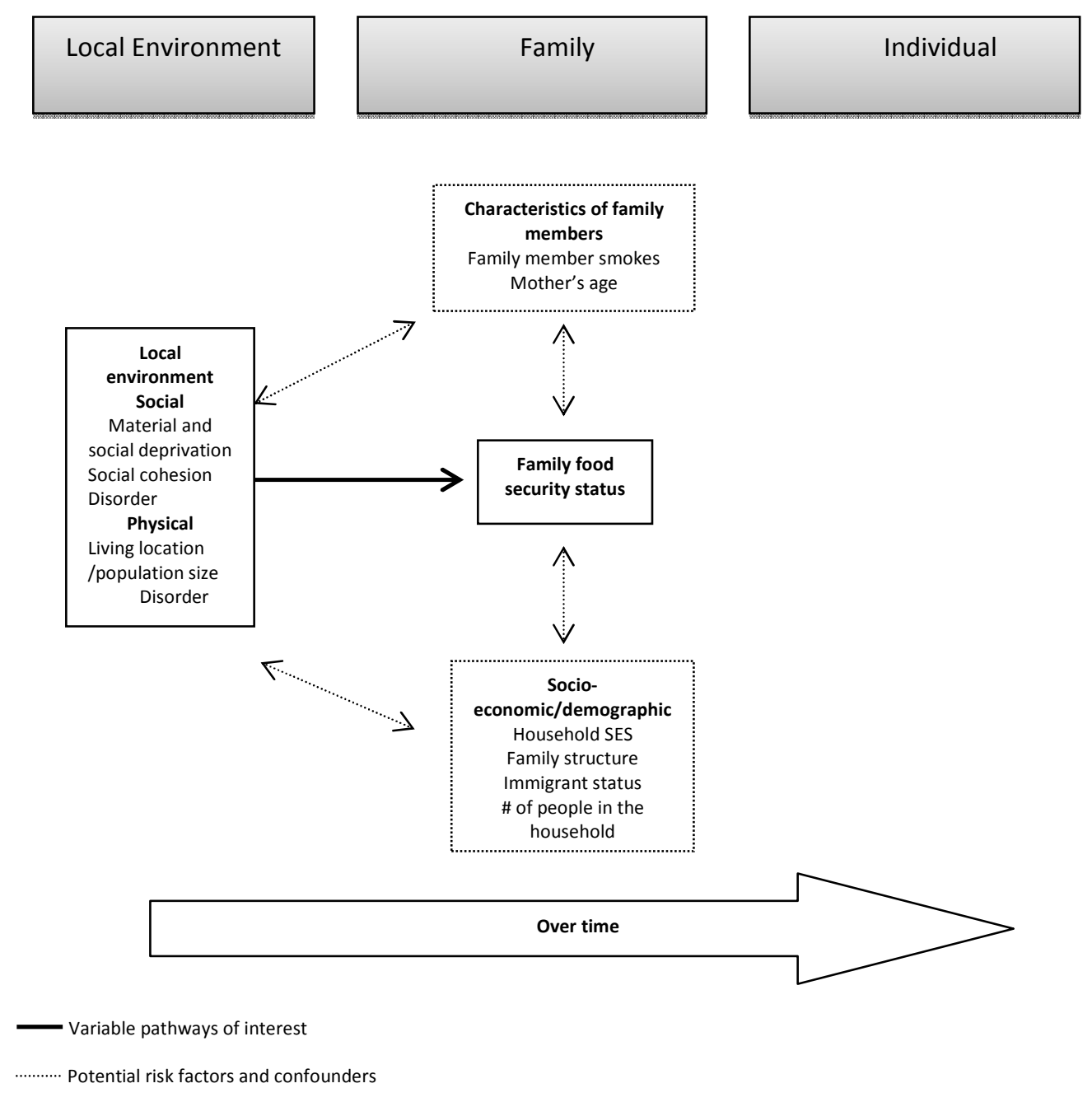

Figure 4.3: Conceptual model of relationship between local environmental factors of interest and family food security status

\subsubsection{Multivariable analysis to address Thesis Objective 2}

The second objective of this thesis was to determine if place factors were statistically related to change in food insecurity, after adjusting for other important explanatory variables. This was accomplished through the use of generalized estimating equations (GEE). The following two sections provide an overview of the statistical method used, and the rationale for including the other explanatory variables in the multivariable model, and their 
definitions. Figure 4.3 provides a graphical representation of the relationships being modeled.

\subsubsection{Overview of statistical methods}

GEE can account for correlations between repeated outcomes measured within the same subject over time using maximum likelihood estimation. It is similar to linear mixed modeling discussed previously, in that it estimates a single trend over time and it can handle time-dependent explanatory variables, incomplete data, and an unbalanced design (68). On the other hand, unlike mixed models, GEE estimates marginal models, which do not allow subjects to have their own trajectories that vary around a population mean. Marginal models give an average response for observations sharing the same explanatory variables as a function of the explanatory variables (68). Mixed models can be used for dichotomous repeated outcomes; however, interpretation of parameters is less straightforward, and estimation of random slopes is difficult when there are only a few repeated measures per subject, as is the case here.

To conduct GEE modeling, the user must specify: a) a link function, 2) the distribution of the outcome variable, and 3) the correlation structure of the outcome variable (68). In modeling the relationship between place factors and change in food insecurity over time for this thesis, PROC GENMOD in SAS v. 9.2 was used; the link function was specified as logit; the distribution was binomial; and models with different correlation structures were run and their quasilikelihood model information criterion (QIC) statistics were compared to determine the best fitting model. Even though these comparisons were made, it is also important to note that GEE is fairly robust to misspecification of the correlation structure 
(68). In estimating the relationship between the place factors and change in food insecurity over time, the general form is: ${ }^{8}$

$$
\log \left[\frac{\mu_{i j}}{1-\mu_{i j}}\right]=\beta_{0}+\beta_{1} \chi_{1 i j}+\beta_{2}(\text { time })+\beta_{3}\left(\chi_{1 i j}\right)(\text { time })
$$

\subsubsection{Other explanatory variables}

As with childhood excess weight, other explanatory variables were added to the multivariable model in order to gain an overall picture of family food insecurity. These other explanatory variables (Table 4.11) were chosen based on prior evidence of an association with food insecurity, as well as on the likelihood that they would confound the potential effect of place. Experts in the field of social capital also recommend controlling for social variables such as SES and ethnicity in epidemiologic studies on social capital (in this study this was measured by social cohesion and a related measure, social deprivation) (49).

Table 4.11: Definitions of explanatory variables included in the analysis to address Objective 2

\begin{tabular}{|c|c|c|}
\hline Variable & Definition & $\begin{array}{l}\text { Timing of data collection } \\
\text { (age of child) }{ }^{\text {a }}\end{array}$ \\
\hline \multicolumn{3}{|l|}{ Household } \\
\hline Low SES ${ }^{b c}$ & $\begin{array}{l}\text { Calculated based on gross household income, and } \\
\text { mother's and father's education level, and job } \\
\text { prestige; categorized into tertiles - low, middle, and } \\
\text { high }\end{array}$ & Time-dependent \\
\hline Single parent family & Yes/no & Time-dependent \\
\hline Mother is an immigrant & Yes/no & 5 months \\
\hline $\begin{array}{l}\text { Number of people living in the household } \\
\text { Characteristics of family members }\end{array}$ & Continuous & Time-dependent \\
\hline $\begin{array}{l}\text { At least one person in the household } \\
\text { smokes }\end{array}$ & Yes/no & 4 years \\
\hline Mother's age & Continuous & 4 years \\
\hline
\end{tabular}

\footnotetext{
${ }^{8}$ Where $\mu$ is the probability of food insecurity on the $j$-th occasion, $i$ is the $i$-th person at $j$-th occasion
} 


\subsection{Conclusion}

In this chapter, an overview of the data source (QLSCD) used to achieve the thesis objectives was provided. Detailed descriptions of the place factors of interest, along with a brief overview of similar variables examined in the literature was then presented. An indepth examination of the types of place variables that have been previously examined in relation to child weight status and food insecurity can be found in the critical appraisals presented in Chapter 3. A description of the primary outcomes addressing Objective 1a and $1 \mathrm{~b}$ (child excess weight) and Objective 2 (family food insecurity) was then provided, beginning with how they are most commonly measured in the literature. This was followed by a discussion of how changes in these variables over time can be measured. For each primary outcome description, a theoretical overview of the statistical method was provided, along with a conceptual model and the variables that were included in multivariable modeling. Specific modeling steps can be found in the three manuscripts found in Chapter5.

\subsection{Reference list}

(1) Survey Description and Methodology: 5-Month Old Infants. Longitudinal Study of Child Development in Quebec (ELDEQ 1998-2002). Institut de la Statistique du Québec; 2000. Report No.: Vol 1. No. 1.

(2) Concepts, Definitions and Operational Aspects: 5 month old enfants. QUÉBEC LONGITUDINAL STUDY OF CHILD DEVELOPMENT (QLSCD 1998-2002). Institut de la Statistique du Québec; 2001. Report No.: Vol 1. No.12.

(3) Guide de l'utilisateur de la banque de données du volet 2008. ÉTUDE LONGITUDINALE DU DÉVELOPPEMENT DES ENFANTS DU QUÉBEC - Phase II (ÉLDEQ 2003-2010). Québec: Institut de la Statistique du Québec; 2009.

(4) Pampalon R, Raymond G. A deprivation index for health and welfare planning in Quebec. Chronic Dis Can 2000; 21(3):104-13.

(5) Pampalon R, Hamel D, Gamache P, Raymond G. A deprivation index for health planning in Canada. Chronic Dis Can 2009; 29(4):178-91.

(6) Lebel A, Pampalon R, Hamel D, Theriault M. The geography of overweight in Quebec: a multilevel perspective. Can J Public Health 2009; 100(1):18-23. 
(7) Pampalon R, Hamel D, Raymond G. Indice de défavorisation pour l'étude de la santé et du bien-être au Québec - Mise à jour 2001. Institut National de Santé Publique du Québec 2004 [cited 2012 Apr 12]; INSPQ-2004-035Available from URL:

http://www.inspq.qc.ca/pdf/publications/295-IndiceDefavorisation_2001.pdf

(8) Simcha-Fagon O, Schwartz J. Neighborhood and delinquency: An assessment of contextual effects. Criminology 1986; 24(4):667-703.

(9) Barnes-McGuire J. The reliability and validity of a questionnaire describing neighborhood characteristics relevant to families and young children living in urban areas. J Community Psychology 1997; 25(6):551-66.

(10) Microdata User Guide: National Longitudinal Survey of Children and Youth - Cycle 1. Ottawa: Human Resources Development Canada and Statistics Canada; 1997.

(11) Variables dérivées de l'ÉLDEQ 1998-2006: Partie A. ÉTUDE LONGITUDINALE DU DÉVELOPPEMENT DES ENFANTS DU QUÉBEC (ÉLDEQ 2003-2010). Santé Québec; Institut de la Statistique du Québec; 2007.

(12) Kohen D, Hertzmann C, Brooks-Gunn J. Neighbourhood influences on children's school readiness. Ottawa: Strategic Policy, Applied Research Branch, Human Resources Development Canada; 1998. Report No.: W-98-15E.

(13) Curtis LJ, Dooley MD, Phipps SA. Child well-being and neighbourhood quality: evidence from the Canadian National Longitudinal Survey of Children and Youth. Soc Sci Med 2004; 58(10):1917-27.

(14) Desrosiers H. Family, childcare and neighbourhood characteristics. Longitudinal Study of Child Development in Québec (ÉLDEQ 1998-2002) 2000;1(2).

(15) Concepts, Definitions and Operational Aspects: From Birth to 29 Months. QUÉBEC LONGITUDINAL STUDY OF CHILD DEVELOPMENT (QLSCD 1998-2002). Institut de la statistique du Québec; 2003. Report No.: Vol 2. No.12.

(16) Sampson RJ, Raudenbush SW, Earls F. Neighborhoods and violent crime: a multilevel study of collective efficacy. Science 1997;2 77(5328):918-24.

(17) Desrosiers H, Dumitru V, Dubois L. Excess weight in children 4 to 7 years of age Targeting risk factors for intervention. Institut de la statistique du Québec; 2009. Report No.: 4.

(18) Tremblay MS, Shields M, Laviolette M, Craig CL, Janssen I, Connor Gorber S. Fitness of Canadian children and youth: Results from the 2007 - 2009 Canadian Health Measures Survey. Health Rep 2010; 21(1):1-5.

(19) Ogden CL. Defining overweight in children using growth charts. Md Med 2004;5(3):1921.

(20) Ogden CL, Flegal KM. Changes in terminology for childhood overweight and obesity. Natl Health Stat Report 2010;(25):1-5. 
(21) Cole TJ, Bellizzi MC, Flegal KM, Dietz WH. Establishing a standard definition for child overweight and obesity worldwide: international survey. BMJ 2000; 320(7244):1240-3.

(22) de Onis M, Onyango AW, Borghi E, Garza C, Yang H. Comparison of the World Health Organization (WHO) Child Growth Standards and the National Center for Health Statistics/WHO international growth reference: implications for child health programmes. Public Health Nutr 2006; 9(7):942-7.

(23) de Onis M, Onyango AW, Borghi E, Siyam A, Nishida C, Siekmann J. Development of a WHO growth reference for school-aged children and adolescents. Bull World Health Organ 2007; 85(9):660-7.

(24) WHO: BMI-for-age (5-19 years). World Health Organization 2007 [cited 2012 May 4]; Available from URL: http://www.who.int/growthref/who2007 bmi for_age/en/index.html

(25) Shields M, Tremblay MS. Canadian childhood obesity estimates based on WHO, IOTF and CDC cut-points. Int J Pediatr Obes 2010; 5(3):265-73.

(26) Shields M. Measured obesity: Overweight Canadian children and adolescents.Nutrition: Findings from the Canadian Community Health Survey. Statistics Canada 2005 [cited 2010 Oct 15]; Available from URL: http://www.statcan.gc.ca/pub/82-620$\underline{\mathrm{m} / 2005001 / \mathrm{pdf} / 4193660 \text {-eng.pdf }}$

(27) Shields M, Connor Gorber S, Janssen I, Tremblay MS. Obesity estimates for children based on parent-reported versus direct measures. Health Rep 2011; 22(3).

(28) Hejazi S, Dahinten S, Ratner PA, Marshall SK. Developmental trajectories of weight status in childhood and adolescence. In: Bagchi D, editor. Global Perspectives on Childhood Obesity. Academic Press; 2011. p. 21-9.

(29) Nagin DS, Tremblay RE. Further Reflections on Modeling and Analyzing Developmental Trajectories: A Response to Maughan and Raudenbush. Annals, AAPS 2005; 602:145-54.

(30) Mustillo S, Worthman C, Erkanli A, Keeler G, Angold A, Costello EJ. Obesity and psychiatric disorder: developmental trajectories. Pediatrics 2003; 111(4 Pt 1):851-9.

(31) Li C, Goran MI, Kaur H, Nollen N, Ahluwalia JS. Developmental trajectories of overweight during childhood: role of early life factors. Obesity 2007; 15(3):760-71.

(32) O'Brien M, Nader PR, Houts RM, Bradley R, Friedman SL, Belsky J, et al. The ecology of childhood overweight: A 12-year longitudinal analysis. Int J Obes 2007; 31(9):1469-78.

(33) Ventura AK, Loken E, Birch LL. Developmental trajectories of girls' BMI across childhood and adolescence. Obesity 2009; 17(11):2067-74.

(34) Hejazi S, Dahinten VS, Marshall SK, Ratner PA. Developmental pathways leading to obesity in childhood. Health Rep 2009; 20(3):63-9.

(35) Nonnemaker JM, Morgan-Lopez AA, Pais JM, Finkelstein EA. Youth BMI trajectories: evidence from the NLSY97. Obesity 2009; 17(6):1274-80. 
(36) Jun HJ, Corliss HL, Boynton-Jarrett R, Spiegelman D, Austin SB, Wright RJ. Growing up in a domestic violence environment: relationship with developmental trajectories of body mass index during adolescence into young adulthood. J Epidemiol Community Health $2011 \mathrm{Feb} 4$.

(37) Pryor LE, Tremblay RE, Boivin M, Touchette E, Dubois L, Genolini C, et al. Developmental trajectories of body mass index in early childhood and their risk factors: an 8-year longitudinal study. Arch Pediatr Adolesc Med 2011;165(10):906-12.

(38) Smith AJ, O'Sullivan PB, Beales DJ, de KN, Straker LM. Trajectories of childhood body mass index are associated with adolescent sagittal standing posture. Int J Pediatr Obes 2011; 6(2-2):e97-106.

(39) Must A, Anderson SE. Body mass index in children and adolescents: considerations for population-based applications. Int J Obes 2006; 30(4):590-4.

(40) CDC. A SAS Program for the CDC Growth Charts. Centers for Disease Control and Prevention [cited 2010 Dec 17] Available from URL: http://www.cdc.gov/nccdphp/dnpao/growthcharts/resources/sas.htm

(41) Fitzmaurice GM, Laird NM, Ware JH. Applied Longitudinal Analysis. Hoboken, New Jersey: John Wiley \& Sons, Inc.; 2004.

(42) Jones BL, Nagin D, Roeder K. A SAS procedure based on mixture models for estimating developmental trajectories. Sociological Methods Research 2001; 29:374-93.

(43) Nagin DS. Analyzing developmental trajectories: Semi-parametric, group-based approach. Psychological Methods 1999; 4(2):139-57.

(44) Nagin DS. Group-Based Modeling of Development. Cambridge, Massachusetts: Harvard University Press; 2005.

(45) Dubois L, Girard M. Early determinants of overweight at 4.5 years in a population-based longitudinal study. Int J Obes 2006; 30(4):610-7.

(46) Dubois L, Farmer AP, Girard M, Peterson K. Preschool children's eating behaviours are related to dietary adequacy and body weight. Eur J Clin Nutr 2007; 61(7):846-55.

(47) Llewellyn $\mathrm{CH}$, van Jaarsveld CH, Johnson L, Carnell S, Wardle J. Nature and nurture in infant appetite: analysis of the Gemini twin birth cohort. Am J Clin Nutr 2010; 91(5):11729.

(48) Carnell S, Wardle J. Appetitive traits in children. New evidence for associations with weight and a common, obesity-associated genetic variant. Appetite 2009; 53(2):260-3.

(49) Social Capital \& Health. Kawachi I., Subramanian SV., Kim D., editors. New York: Springer; 2008.

(50) Institut de la statistique du Québec. Variables dérivées de l'ÉLDEQ 1998-2008: Partie A. Institut de la statistique du Québec 2009 [cited 2010 Oct 15]; Available from URL: http://www.jesuisjeserai.stat.gouv.qc.ca/pdf/doc tech/E1aE11Variables_Derivees1101.pdf 
(51) Radimer KL. Measurement of household food security in the USA and other industrialised countries. Public Health Nutr 2002; 5(6A):859-64.

(52) USDA. Food Security in the United States: Definitions of Hunger and Food Security. United States Department of Agriculture 2011[cited 2012 May 4]; Available from URL: http://www.ers.usda.gov/Briefing/FoodSecurity/labels.htm

(53) Tarasuk V. Discussion Paper on Household and Individual Food Insecurity. Health Canada 2001 [cited 2012 May 3]; Available from URL: http://www.hc-sc.gc.ca/fnan/alt_formats/hpfb-dgpsa/pdf/nutrition/food_sec_entire-sec_aliments_entier-eng.pdf

(54) Health Canada. Food and Nutrition: Determining Food Security Status. Government of Canada 2010 [cited 2012 Feb 2]; Available from URL: http://www.hc-sc.gc.ca/fnan/surveill/nutrition/commun/insecurit/status-situation-eng.php

(55) Kirkpatrick SI, Tarasuk V. Food insecurity in Canada: considerations for monitoring. Can J Public Health 2008; 99(4):324-7.

(56) Frongillo EA, Jr. Validation of measures of food insecurity and hunger. J Nutr 1999; 129(2S Suppl):506S-9S.

(57) Frongillo EA, Rauschenbach BS, Olson CM, Kendall A, Colmenares AG. Estimating the Prevalence of Hunger and Food Insecurity: The Validity of Questionnaire-based Measures for the Identification of Households. Department of Nutritional Sciences, Cornell University; 1996. Report No.: Institute for Research on Poverty Discussion Paper No 1083-96.

(58) Hamelin AM, Beaudry M, Habicht JP. Characterization of household food insecurity in Quebec: food and feelings. Soc Sci Med 2002; 54(1):119-32.

(59) Panel to Review U.S Department of Agriculture's Measurement of Food Insecurity and Hunger NRC. Food Insecurity and Hunger in the United States: An Assessment of the Measure. National Council of the National Academies 2006 [cited 2012 Jul 13]; Available from URL: http://www.nap.edu/catalog.php?record id=11578

(60) Dubois L, Farmer A, Girard M, Porcherie M. Family food insufficiency is related to overweight among preschoolers. Soc Sci Med 2006; 63(6):1503-16.

(61) Kirkpatrick SI, McIntyre L, Potestio ML. Child hunger and long-term adverse consequences for health. Arch Pediatr Adolesc Med 2010; 164(8):754-62.

(62) Howard LL. Transitions between food insecurity and food security predict children's social skill development during elementary school. Br J Nutr 2011;1-10.

(63) Institut de la Statistique du Québec. Étude longitudinale du développement des enfants du Québec (ÉLDEQ 1998-2002): Sources, justifications et modifications entre les volets 2001 (E4) et 2002 (E5). Direction Santé Québec, Institut de la statistique du Québec 2004 [cited 2012 Feb 11]; Available from URL:

http://www.iamillbe.stat.gouv.qc.ca/pdf/doc tech/SourcesE4_E5 11mai2005.pdf 
(64) Kendall A, Olson CM, Frongillo EA, Jr. Validation of the Radimer/Cornell measures of hunger and food insecurity. J Nutr 1995; 125(11):2793-801.

(65) Lavallée C, Aubin J, Audet N, Berthiaume P. Enquête sociale et de santé auprès des enfants et des adolescents québécois: Cahier technique et méthodologique. Institut de la statistique du Québec 2003 Available from URL:

http://www.stat.gouv.qc.ca/publications/sante/doc technique/enf ados cahier technVoll. pdf

(66) Hamelin AM, Habicht JP, Beaudry M. Food insecurity: consequences for the household and broader social implications. J Nutr 1999;129(2Suppl):525S-8S.

(67) Daveluy C, Pica L, Audet N, Courtmanche R, Lapointe R, et autres. Enquête sociale et de santé 1998, 2e édition. Institut de la statistique du Québec 2000 [cited 2012 Apr 1];

Available from URL: http://www.stat.gouv.qc.ca/publications/sante/pdf/e_soc98v2.pdf

(68) Ballinger GA. Using Generalized Estimating Equations for Longitudinal Data Analysis. Organizational Research Methods 2004;7(2):127-50. 


\section{Chapter 5 - Results}

The next three sections of this chapter present three manuscripts that contain the results of the three analyses conducted to address Objectives $1 \mathrm{a}, 1 \mathrm{~b}$ and 2 of this thesis. 


\subsection{The influence of place on weight gain during early childhood: A}

\section{population-based longitudinal study - Manuscript 3}

Authors: Megan A. Carter ${ }^{1}$, Lise Dubois ${ }^{1,2}$, Mark S. Tremblay ${ }^{3}$, Monica Taljaard ${ }^{2,4}$

1. Institute of Population Health, University of Ottawa

2. Department of Epidemiology and Community Medicine, University of Ottawa

3. Healthy Active Living and Obesity Research, Children's Hospital of Eastern Ontario Research Institute

4. Clinical Epidemiology Program, Ottawa Hospital Research Institute

This manuscript was written and published in accordance to the specifications for submission to the peer-reviewed Journal of Urban Health. It has been published as an open access article and appears here in its published online format.

Suggested citation:

Carter MA, Dubois L, Tremblay MS, Taljaard M. The influence of place on weight gain during early childhood: A population-based longitudinal study. J Urban Health. 2012; Early online 
Journal of Urban Health

Bulletin of the New York Academy of Medicine

(C) The Author(s) 2012

$10.1007 / \mathrm{s} 11524-012-9712-8$

\section{The Influence of Place on Weight Gain during Early Childhood: A Population-Based, Longitudinal Study}

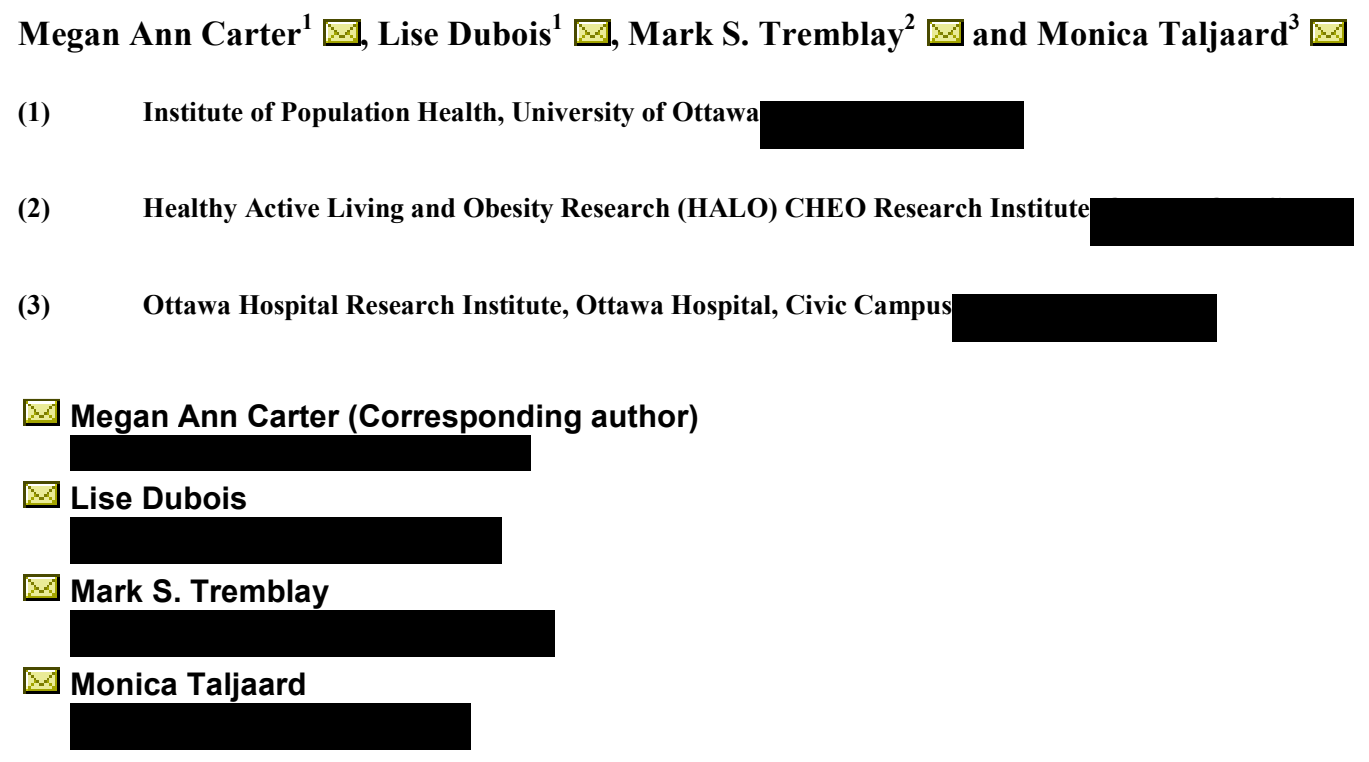

Published online: 18 July 2012

\section{Abstract}

The objective of this paper was to determine the influence of place factors on weight gain in a contemporary cohort of children while also adjusting for early life and individual/family social factors. Participants from the Québec Longitudinal Study of Child Development comprised the sample for analysis $(n=1,580)$. A mixed-effects regression analysis was conducted to determine the longitudinal relationship between these place factors and standardized BMI, from age 4 to 10 years. The average relationship with time was found to be quadratic (rate of weight gain increased over time). Neighborhood material deprivation was found to be positively related to weight gain. Social deprivation, social disorder, and living in a medium density area were inversely related, while no association was found for social cohesion. Early life factors and genetic proxies appeared to be important in explaining weight gain in this sample. This study suggests that residential 
environments may play a role in childhood weight change; however, pathways are likely to be complex and interacting and perhaps not as important as early life factors and genetic proxies. Further work is required to clarify these relationships.

Keywords Children - Neighborhood - Residential characteristics - Environment - Body weight - Body mass index Longitudinal study - Mixed-models - Social factors

\section{Introduction}

Childhood overweight and obesity have risen dramatically in the last 25 years in Canada $\underline{1}, \underline{2}$ and in many other countries. $\underline{3}, \underline{4}$ In 2004, $26 \%$ of Canadian children aged 217 years were overweight and $8 \%$ were obese. 2 From 1978/1979 to 2004, the prevalence of overweight and obesity increased twofold among 6-17-year-olds. Due to this striking increase, as well as its potential for adversely affecting health both in the short and long term, being at excess weight during childhood has become a major global public health concern.

The etiologic literature on childhood weight status has tended to focus on individual characteristics rather than on broader contextual circumstances. The high prevalence of childhood obesity has not abated, suggesting that prevention strategies, traditionally implemented at the individual level, may not be effective. Conceptualizing childhood obesity within multiple levels of influence, specifically within residential communities and over the life course, is necessary to design effective prevention strategies that shift the distribution of risk downward. This is consistent with a social-ecological theory of health. $\underline{5}$

Neighborhoods are a natural way to conceptualize "place" in terms of child health and acquiring health resources. In the context of obesity, complex interactions between individuals, families, local communities, and institutions, as well as the broader social environment, lead neighborhoods to become geographical areas that can: (1) structure opportunities/barriers for children to be physically active and to eat healthy $\underline{6}$ and (2) give rise to negative perceptions, which themselves may elicit chronic stress responses leading to weight gain. $\underline{7}$

Studies are starting to find significant relationships between different neighborhood characteristics and weight status; $\underline{8}$ however, this is a fairly new area of research where the literature is heterogeneous and mostly cross-sectional. 9 To better make the case for causation, longitudinal studies are needed that use measured heights and weights. Accounting for early life factors known to be related to childhood obesity development, as well as individual and family-level social factors and measures of the family environment can provide a more holistic picture of why and how weight status changes over time in young children.

Among the few longitudinal studies investigating the influence of place on childhood weight status, findings include significant negative relationships between change in BMI and area 
greenness/degree of vegetation, $\underline{10}$ neighborhood income/deprivation, $\underline{11}$ and perceived safety. $\underline{12}$

Using the Québec Longitudinal Study of Child Development (QLSCD), the main objective of this study was to assess the influence of place factors on change in cohort children's standardized weight for height while also accounting for other potentially important early life and individual-/family-level explanatory factors. The overall hypothesis was that unfavorable neighborhood characteristics such as high material and social deprivation, high social disorder, and low population density would be positively related to weight gain, while favorable characteristics such as high social cohesion would be inversely related to weight gain in children.

\section{Methods}

\section{Sample}

The QLSCD is a government-based cohort study conducted by the Institut de la Statistique du Québec (ISQ) to identify factors in early childhood that affect the health, social adjustment, and academic performance of young Quebeckers. 13 The cohort is comprised of a representative sample of 2,120 children born in Québec in 1997/1998, who have been followed from 5 months of age.

Cohort children were randomly selected based on a three-stage, stratified design. 14 The territory covered by the survey was first divided into primary sampling units (PSUs) based on broad regions of Québec. The PSUs were then divided into two groups: remote or nonremote. In stage 1, two out of the four remote PSUs were chosen, and all 11 nonremote PSUs were chosen. The second stage involved dividing the selected regions into secondary sampling units (SSUs) based on one or two county regional municipalities. These were further divided into two groups: areas registering a high number of births in 1996 and those registering a low number of births. A fixed number of SSUs were randomly selected from the low birthrate group, and all SSUs were selected from the high birthrate group. Finally, in the third stage, a fixed number of children were randomly selected from the selected SSUs, based on the 1997/1998 Québec Birth Registry.14 Sampling occurred throughout the year to minimize the potential impact of seasonal influences (see Figure 1 for the sampling process). Twins, children with major diseases at birth, and those living in Northern Québec, Cree or Inuit territory, or Indian reserves were excluded.

From 5 months to 8 years of age, data collection occurred annually (timing changed slightly when children began school). In order to minimize respondent burden, this changed to a biannual basis from 8 years onward. Data from 5 months to 10 years are used in the present analysis. Computer-assisted personal interviewing of the mother, in the child's home, was the primary method of data collection. $\underline{13}$ 


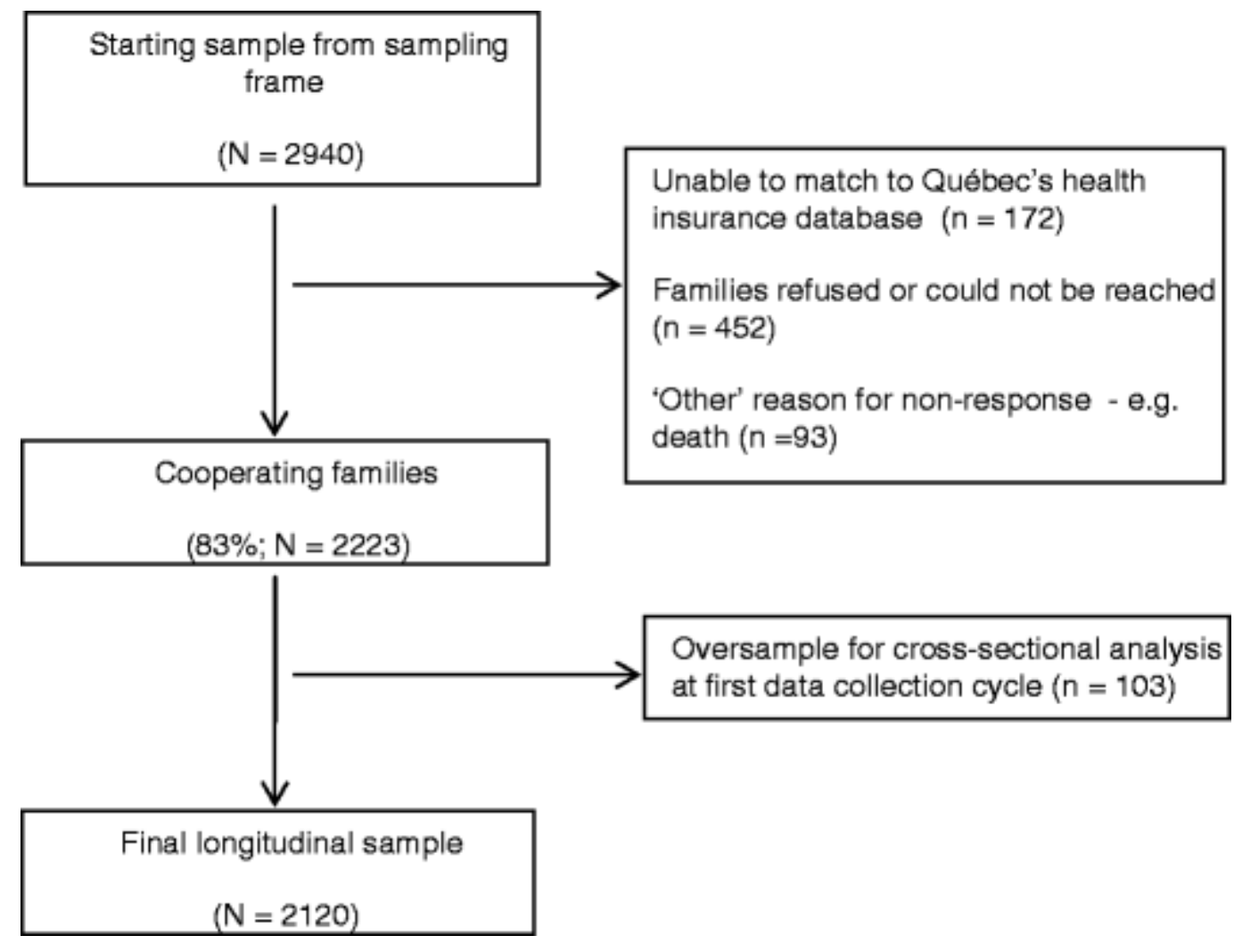

FIGURE 1. Sampling of children in the Québec Longitudinal Study of Child Development.

\section{Variables}

\section{Outcome}

The primary outcome for this study was weight relative to height, as measured by BMI $\left(\mathrm{kg} / \mathrm{m}^{2}\right)$, standardized for age and sex using the Centers for Disease Control and Prevention Growth Charts, to obtain BMI Z-scores. 15 The Z-score is the deviation of the value for an individual from the mean value of the reference population divided by the standard deviation for the reference population; in this case, the reference population has been derived from five different US surveys. 16 The use of the BMI Z-score has been recommended as superior than percentiles for use in longitudinal analyses. 17

Heights and weights were measured in the child's home by trained interviewers at the approximate ages of $4,6,7,8$, and 10 years. 18 At each data collection cycle, body weight was measured in kilograms on scales set back to zero for each measurement. Children wore light clothing and no shoes. Height was measured in meters. 


\section{Main Exposures-Place Factors}

\section{Deprivation}

Two forms of deprivation, material and social, were measured by an area-based index developed by Pampalon and Raymond, $\underline{19}$ based largely on the work of Peter Townsend. The index was derived by linking postal codes of participants at data collection cycle 1, when children were approximately 5 months of age, to census data (1996) describing enumeration areas. Principal components analysis was used to create the index using six socioeconomic indicators: proportion of persons who have no high-school diploma; ratio of employment to total population; average income; proportion of persons who are separated, divorced, or widowed; proportion of people living alone; and proportion of single-parent families. The first three indicators form the material dimension of the index. This refers to the general inability of area residents to obtain the goods and conveniences that are a part of everyday life. The latter three indicators form the social dimension of the index, which refers to the fragmentation and weakening of the household structure. The index has been previously used to assess disparities in Canadian mortality rates 20 and by the Québec Government to assess community service needs. $\underline{21}$

For ease of interpretation and consistent with another paper, both dimensions were divided into population quintiles, from quintile 1 (least disadvantaged) to 5 (most disadvantaged), and then dichotomized into "deprived" (quintiles 4 and 5) versus "not deprived" (quintiles $1-3) . \underline{22}$

\section{Perceived Neighborhood Social Cohesion and Disorder}

Neighborhood social cohesion and disorder were measured by two scales that have been adapted from the work of Barnes-McGuire 23 and the Canadian National Longitudinal Survey of Children and Youth.24 Both are based on the mother's perception of her neighborhood. Items forming the social cohesion scale assess the level of agreement to five statements about the support of neighbors, while items on the social disorder scale assess the presence and severity of four types of problems in the neighborhood. 25 The items for each of the scales can be found in Appendix 1 . Scale scores were calculated by averaging item responses for each scale. Social cohesion scores range from 1 to 4, where higher scores indicate a less cohesive neighborhood. Social disorder scores range from 1 to 3 with a lower score indicating the presence of social problems. Both scales were dichotomized to increase interpretability. Social cohesion was dichotomized based on the 50th percentile. For social disorder, children were categorized as either having a perfect score of 3 (no social problems at all in the neighborhood) versus $<3$ (social problems present). A similar approach was taken by Curtis et al.28 in their analysis of neighborhood influences on a variety of health outcomes in a Canadian sample of children. Both cohesion and disorder were available every other data collection cycle starting at cycle 1 (children were 5 months of age) and therefore were analyzed as time-dependent variables (Table 1 ). Since values were missing for all children at cycle 8 ( 7 years), the observation at the previous data collection cycle was carried forward (at 6 years) in order to be able to conduct the analysis. 
Table 1 Description of considered explanatory variables in the QLSCD

\begin{tabular}{|c|c|c|}
\hline Variable & Description & $\begin{array}{l}\text { Change over } \\
\text { time }\end{array}$ \\
\hline \multicolumn{3}{|c|}{ Socio-economic/demographic } \\
\hline Sex & Male yes/no & Invariant \\
\hline $\begin{array}{l}\text { Socioeconomic status } \\
(\mathrm{SES})^{\mathrm{a}}\end{array}$ & $\begin{array}{l}\text { Calculated based on gross household income, and mother's and } \\
\text { father's education level, and job prestige; categorized into tertiles- } \\
\text { low, middle, and high }\end{array}$ & Dependent \\
\hline Mother is an immigrant & Yes/no & Invariant \\
\hline Single parent family & Yes/no & Dependent \\
\hline \multicolumn{3}{|l|}{ Early life exposures } \\
\hline $\begin{array}{l}\text { Rapid weight gain in } \\
\text { infancy }\end{array}$ & $\begin{array}{l}\text { Highest two quintiles of average monthly weight gain from } 0 \text { to } \\
5 \text { months }\end{array}$ & Invariant \\
\hline $\begin{array}{l}\text { Mother smoked during } \\
\text { pregnancy }\end{array}$ & Yes/no & Invariant \\
\hline Breastfeeding status & $\begin{array}{l}\text { Exclusively breastfed to } 3 \text { months of age or older; never breastfed; } \\
\text { other }\end{array}$ & Invariant \\
\hline Birth weight $^{b}$ & Low $<2.5 \mathrm{~kg} ;$ normal $\geq 2.5 \mathrm{~kg}$ but $\leq 4 \mathrm{~kg} ;$ high $>4 \mathrm{~kg}$ & Invariant \\
\hline \multicolumn{3}{|l|}{ Genetic proxies $^{c}$} \\
\hline Mother is obese & Mother's BMI $\geq 30$ based on self-reported height and weight & Invariant \\
\hline Overeating phenotype ${ }^{\mathrm{d}}$ & "Often" eats too much and/or "sometimes" or "often" eats too fast & Invariant \\
\hline \multicolumn{3}{|l|}{ Place } \\
\hline Materially deprived & Highest two quintiles of the material deprivation factorial score & Invariant \\
\hline Socially deprived & Highest two quintiles of the social deprivation factorial score & Invariant \\
\hline High social cohesion & Scale score in the bottom $50 \%$ & Dependent \\
\hline High social disorder & Less than a perfect scale score $(<3)$ & Dependent \\
\hline Population density: & & Dependent \\
\hline High & Census metropolitan areas with $\geq 100,000$ inhabitants & \\
\hline Medium & Census agglomerations with 10,000 to $<100,000$ inhabitants & \\
\hline Low & Rural or small towns with $<10,000$ inhabitants & \\
\hline \multicolumn{3}{|c|}{$\begin{array}{l}\text { Time dependency reflects the fact that these variables were measured at all study time points }(4,6,7,8 \text {, and } 10 \text { years of age) where all } \\
\text { available data points were entered into the mixed models analysis. Values for social cohesion and disorder were not collected at } 7 \text { years for all } \\
\text { children so the value at } 6 \text { years was used. For SES and population density, values were not collected at } 4 \text { years for all children so the value at } \\
3.5 \text { years (fourth data collection cycle) was used. All time invariant variables were measured at the first data collection cycle of the original cohor } \\
\text { study ( } 5 \text { months) except for the genetic proxies } \\
{ }^{a} \text { For more information on how this variable was calculated and interpreted, please see Ref. } \underline{25} \\
\text { b Based on medical records at birth } \\
\text { 'Recognizing that these factors could also capture elements of the home environment, as well as lifestyle behaviors. Obesity status of the } \\
\text { mother might also be considered an early life factor as this was measured when the child was } 1.5 \text { years (at the second data collection cycle) } \\
{ }^{\mathrm{d} C} \text { Considered for inclusion based on research showing that at least half of the genetic influence on obesity operates through appetite (see } \\
\text { Refs. } \underline{26}, \underline{27} \text {; measured at } 4 \text { years }\end{array}$} \\
\hline
\end{tabular}




\section{Population Density}

The population density variable was constructed by ISQ by linking participants' postal codes to census data describing geographical areas using Statistics Canada's postal code conversion file. According to the linked census information, children were categorized as living in one of four types of geographical areas.25 For the purpose of this study, these four categories were collapsed into three, namely, census metropolitan areas containing more than 100,000 inhabitants (high density), census agglomerations containing 10,000 to $<100,000$ inhabitants (medium density), or rural/small towns containing $<10,000$ inhabitants (low density). This variable was measured in all data collection cycles (except cycle 5 when children were 4 years of age) and, thus, was analyzed as a time-dependent variable. Because no children had population density collected at 4 years of age, the observation at the previous data collection cycle was carried forward (from 3.5 years).

\section{Other Explanatory Factors}

Other potentially important explanatory factors were identified from recent systematic reviews 29,30 and results of previous studies using the QLSCD. $18,31,32$ These variables were included in order to gain a more holistic understanding of weight change, as well as to control for potential confounding. A description of these variables is given in Table 1 . The mechanism by which explanatory variables could influence weight gain was not the primary focus here. Therefore, factors like lifestyle behaviors (e.g., physical activity, diet, and sleep), family functioning, parenting styles, food security, and general well-being of parents and child were not analyzed in this study as they were considered more proximate mediators.

\section{Statistical Analysis}

In order to achieve the study's main objective, a growth-curve or random-effects analysis was conducted using PROC MIXED in SAS, version 9.2, using the restricted maximum likelihood estimation method.

First, an exploratory unadjusted analysis was conducted to examine variable distributions and identify outliers and other potential problems with the data. Graphical analysis was conducted to investigate the shape of the BMI Z-score trend and to assess, in an exploratory fashion, the importance of the considered explanatory variables. Time was treated as a continuous variable (age in years) and was centered at the mean (approximately 7 years). To determine the base model from which to conduct further multivariable modeling, four "unadjusted" models, i.e., including only age as either linear, quadratic, cubic, or spline at 7 years, were compared using likelihood ratio tests. 33 The $\mathrm{G}$ matrix was assumed to be factor analytic. 34 It was determined that the quadratic model fit the data better than the other models and was thus used in further model building. Modeling of explanatory factors involved adding all potential explanatory variables together to the unadjusted model and adding interactions between the explanatory variables and age and age $\mathrm{e}^{2}$. The interaction terms involving age and age ${ }^{2}$ were reduced by backwards elimination using $\alpha=0.05$. 
The fit of the adjusted model was checked graphically to investigate violations of assumptions about random effects or the specification of fixed effects to identify potential outliers or observations having undue influence on the model and the need to transform particular covariates. Variance inflation factors were calculated for a cross-sectional model of BMI Z-score in order to assess multicollinearity between included explanatory variables. Ethics approval to conduct this analysis was given by the University of Ottawa Research Ethics Board-certificate number H 05-10-18.

\section{Results}

Of the 2,120 cohort children, 1,799 had at least one BMI Z-score measure (out of five possible measures). Because of the cumulative effect of missing observations, 1,580 had complete data on all explanatory variables and could be included in the analysis $(75 \%$ of original sample). Almost $43 \%$ of included children had all five BMI Z-score response points, $24 \%$ had four, $12 \%$ had three, $9 \%$ had two, and $12 \%$ had one. The 540 children who were excluded were more likely to be from low socioeconomic status (SES) households, have immigrant mothers, live in materially and socially deprived neighborhoods, and exhibit the overeating phenotype compared to children who were included $\left(\chi^{2} P<0.05\right)$. Of the excluded children that had response measures, there were no differences in BMI Z-score between excluded and included children at any of the time points (ANOVA $F$ test).

Characteristics of included children are presented in Table 2 . Both mean BMI and mean BMI-Z score increased over the study period (Table $\underline{3}$ ). The increasing BMI Z-score demonstrates that, on average, children were getting heavier for their height, age, and sex.

Table 2 Baseline descriptive data (4 years) of included children $(n=1,580)^{*}$

\begin{tabular}{|l|l|}
\hline Variable & \multicolumn{1}{c|}{ Percentage $(\boldsymbol{n})$} \\
\hline Socio-economic/demographic & \\
\hline Male & $50.0(790)$ \\
\hline Low SES & $31.9(499)$ \\
\hline Middle SES & $33.9(530)$ \\
\hline High SES & $34.2(535)$ \\
\hline Mother is an immigrant & $8.5(135)$ \\
\hline Single parent family & $13.2(208)$ \\
\hline Early life exposures & \\
\hline Rapid weight gain in infancy & $38.7(611)$ \\
\hline Mother smoked during pregnancy & $24.9(394)$ \\
\hline$\geq 3$ months exclusively breastfed & $25.8(408)$ \\
\hline Never breastfed & $27.2(429)$ \\
\hline Breastfed but not exclusively $\geq 3$ months & $47.0(743)$ \\
\hline
\end{tabular}




\begin{tabular}{|l|l|}
\hline Variable & \multicolumn{1}{|c|}{ Percentage (n) } \\
\hline Low birthweight & $3.6(57)$ \\
\hline Normal birthweight & $85.7(1354)$ \\
\hline High birthweight & $10.7(169)$ \\
\hline Genetic proxies & \\
\hline Mother is obese & $9.9(157)$ \\
\hline Child overeats & $22.5(355)$ \\
\hline Place & \\
\hline Materially deprived & $37.9(599)$ \\
\hline Socially deprived & $37.1(586)$ \\
\hline High social cohesion & $47.8(732)$ \\
\hline High social disorder & $26.5(416)$ \\
\hline High population density & $66.4(1035)$ \\
\hline Medium population density & $11.2(174)$ \\
\hline Low population density & $22.5(350)$ \\
\hline${ }^{*}$ Due to missing data on time-dependent variables, denominators for these variables are slightly less than 1,580 \\
\hline
\end{tabular}

Table 3 Directly measured mean BMI and BMI Z-score by mean age for included children $(n=1,580)$

\begin{tabular}{|l|l|l|l|}
\hline Age (years) (SD) & BMI (SD) & BMI Z-score (SD) & Total $\boldsymbol{N}$ \\
\hline $4.2(0.26)$ & $15.7(1.60)$ & $0.014(1.23)$ & 1,352 \\
\hline $6.1(0.25)$ & $15.7(1.90)$ & $0.031(1.15)$ & 1,008 \\
\hline $7.1(0.25)$ & $16.1(2.27)$ & $0.043(1.10)$ & 1,296 \\
\hline $8.1(0.26)$ & $16.8(2.59)$ & $0.170(1.10)$ & 1,161 \\
\hline $10.1(0.26)$ & $18.4(3.24)$ & $0.342(0.99)$ & 1,123 \\
\hline SD standard deviation & & \\
\hline
\end{tabular}

In the unadjusted BMI Z-score trend model (Table 4 ), the linear and quadratic parameters were positive and statistically significant, indicating that the growth in BMI among these children was accelerating from approximately 4-10 years of age.

Table 4 Unadjusted and adjusted BMI Z-score trend models: significant fixed effect parameters and their $95 \%$ confidence limits $(n=1,580)$

\begin{tabular}{|l|l|l|}
\hline \multicolumn{1}{|l|}{ Fixed effects } & Parameter estimate & $\mathbf{9 5 \%}$ Confidence limits \\
\hline Unadjusted model & \multicolumn{2}{|c|}{} \\
\hline Intercept & $0.062^{*}$ & $0.011,0.114$ \\
\hline Age & $0.049^{* * *}$ & $0.039,0.060$ \\
\hline Age $^{2}$ & $0.012^{* * *}$ & $0.008,0.016$ \\
\hline
\end{tabular}




\begin{tabular}{|c|c|c|}
\hline Fixed effects & Parameter estimate & $95 \%$ Confidence limits \\
\hline \multicolumn{3}{|l|}{ Adjusted model } \\
\hline Intercept & $-0.136^{*}$ & $-0.268,-0.006$ \\
\hline \multicolumn{3}{|l|}{ Main effects } \\
\hline Age & $0.031 *$ & $0.006,0.055$ \\
\hline $\mathrm{Age}^{2}$ & $0.013 * * *$ & $0.007,0.020$ \\
\hline Male & $-0.116^{*}$ & $-0.213,-0.021$ \\
\hline Low SES ${ }^{\mathrm{a}}$ & $-0.123 * *$ & $-0.217,-0.033$ \\
\hline Middle SES ${ }^{\mathrm{a}}$ & $-0.087^{*}$ & $-0.163,-0.014$ \\
\hline Rapid weight gain in infancy & $0.333 * * *$ & $0.223,0.444$ \\
\hline Mother smoked during pregnancy & $0.135^{*}$ & $0.021,0.249$ \\
\hline High birth weight ${ }^{\mathrm{b}}$ & $0.390 * * *$ & $0.236,0.549$ \\
\hline Low birth weight ${ }^{\mathrm{b}}$ & $-0.456^{* *}$ & $-0.716,-0.197$ \\
\hline Mother is obese & $0.686 * * *$ & $0.528,0.845$ \\
\hline Child overeats & $0.422 * * *$ & $0.308,0.537$ \\
\hline Materially deprived & 0.013 & $-0.097,0.124$ \\
\hline Socially deprived & 0.088 & $-0.011,0.188$ \\
\hline High social disorder & 0.043 & $-0.025,0.110$ \\
\hline Low population density ${ }^{\mathrm{c}}$ & 0.011 & $-0.094,0.116$ \\
\hline Medium population density ${ }^{\mathrm{c}}$ & 0.005 & $-0.123,0.135$ \\
\hline \multicolumn{3}{|l|}{ Linear age effects } \\
\hline Male & $0.047 * * *$ & $0.026,0.068$ \\
\hline Low SES ${ }^{\mathrm{a}}$ & $0.050 * *$ & $0.022,0.078$ \\
\hline Middle SES ${ }^{\mathrm{a}}$ & 0.020 & $-0.005,0.046$ \\
\hline Rapid weight gain in infancy & -0.009 & $-0.032,0.014$ \\
\hline Child overeats & $-0.026^{*}$ & $-0.052,-0.000$ \\
\hline High birth weight ${ }^{b}$ & $-0.043^{*}$ & $-0.076,-0.009$ \\
\hline Low birth weight ${ }^{\mathrm{b}}$ & -0.001 & $-0.062,0.059$ \\
\hline Materially deprived & -0.004 & $-0.028,0.020$ \\
\hline Socially deprived & $-0.029 *$ & $-0.051,-0.007$ \\
\hline High social disorder & 0.020 & $-0.004,0.044$ \\
\hline Low population density ${ }^{\mathrm{c}}$ & 0.002 & $-0.026,0.030$ \\
\hline Medium population density ${ }^{\mathrm{c}}$ & $-0.050 * *$ & $-0.083,-0.016$ \\
\hline \multicolumn{3}{|l|}{ Quadratic age effects } \\
\hline Rapid weight gain in infancy & $-0.009^{*}$ & $-0.018,-0.001$ \\
\hline Materially deprived & $0.011^{* *}$ & $0.003,0.020$ \\
\hline High social disorder & $-0.012 *$ & $-0.022,-0.002$ \\
\hline
\end{tabular}


The adjusted model is also presented in Table $\underline{4}$. Smoking during pregnancy and obesity status of the mother were significantly related to higher BMI Z-scores on average but did not interact with time. In terms of linear (or uniform) change over time, being male was associated with a faster rate of weight gain compared to being female, as was being from a low SES household relative to a high SES household. Living in a socially deprived neighborhood was significantly related to a slower rate of weight gain compared to nonsocially deprived areas. This association was also seen for living in medium density (census agglomerations) compared to high density areas (census metropolitan areas), between overeaters and nonovereaters, as well as between high birth weight relative to normal birth weight children. In terms of the nonlinear or nonconstant change component of the model (quadratic or age ${ }^{2}$ ), trends significantly differed for material deprivation, high social disorder, and rapid weight gain during infancy. Specifically, living in a materially deprived neighborhood was related to a higher accelerated weight gain relative to nonmaterially deprived areas. Conversely, living in a high disorder neighborhood was related to a lower accelerated weight gain relative to living in a nondisordered area, as was experiencing rapid weight gain during infancy versus normal growth. A visual example of the associations between significant place factors and weight gain over time is provided in Figure 2 . Additionally, Figure $\underline{3}$ shows the differences in trends between levels of significant social and early life variables in the adjusted model.
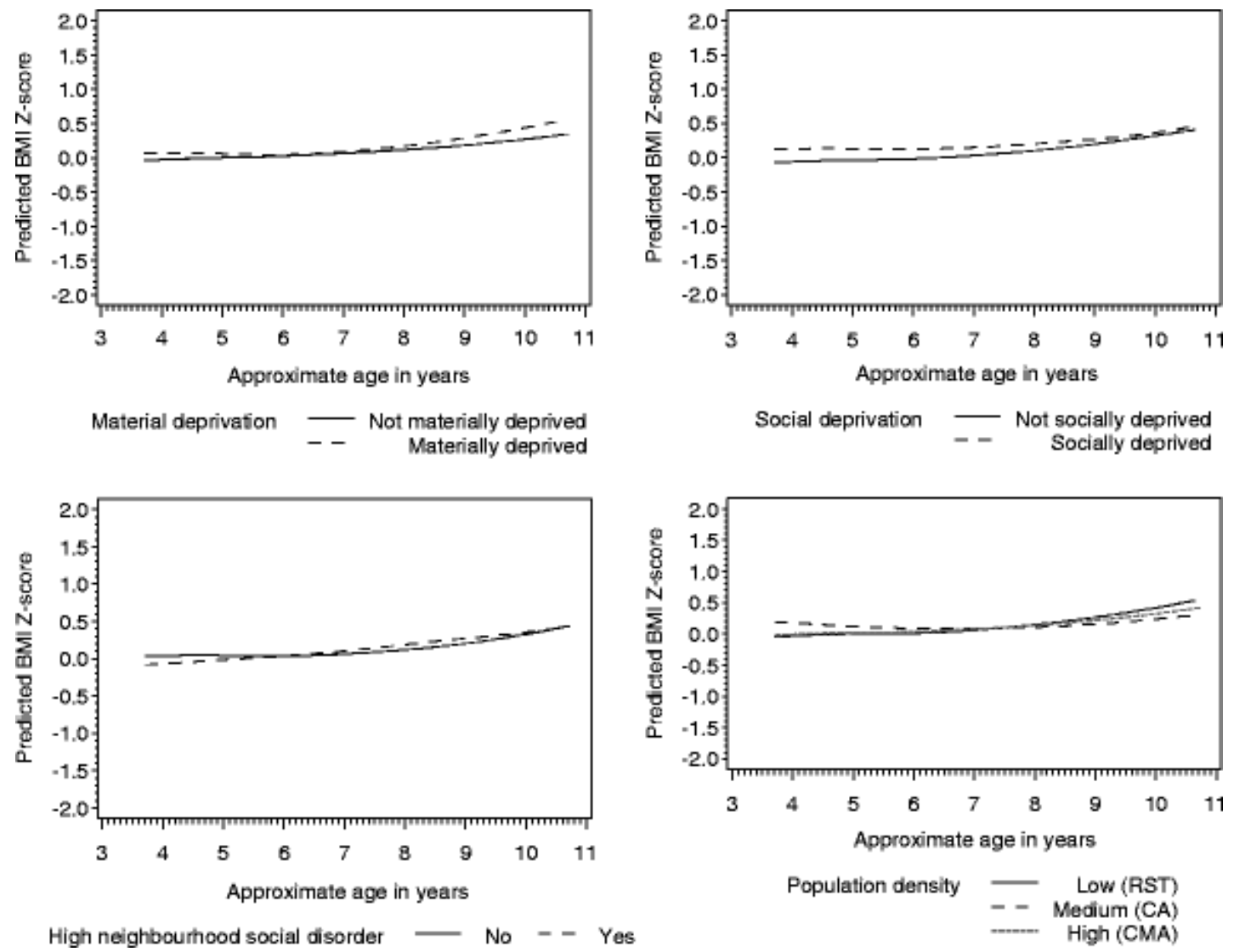

FIGURE 2. Predicted BMI Z-score smoothed individual trends by significant place factors in the QLCSD, adjusted for other model covariates. 

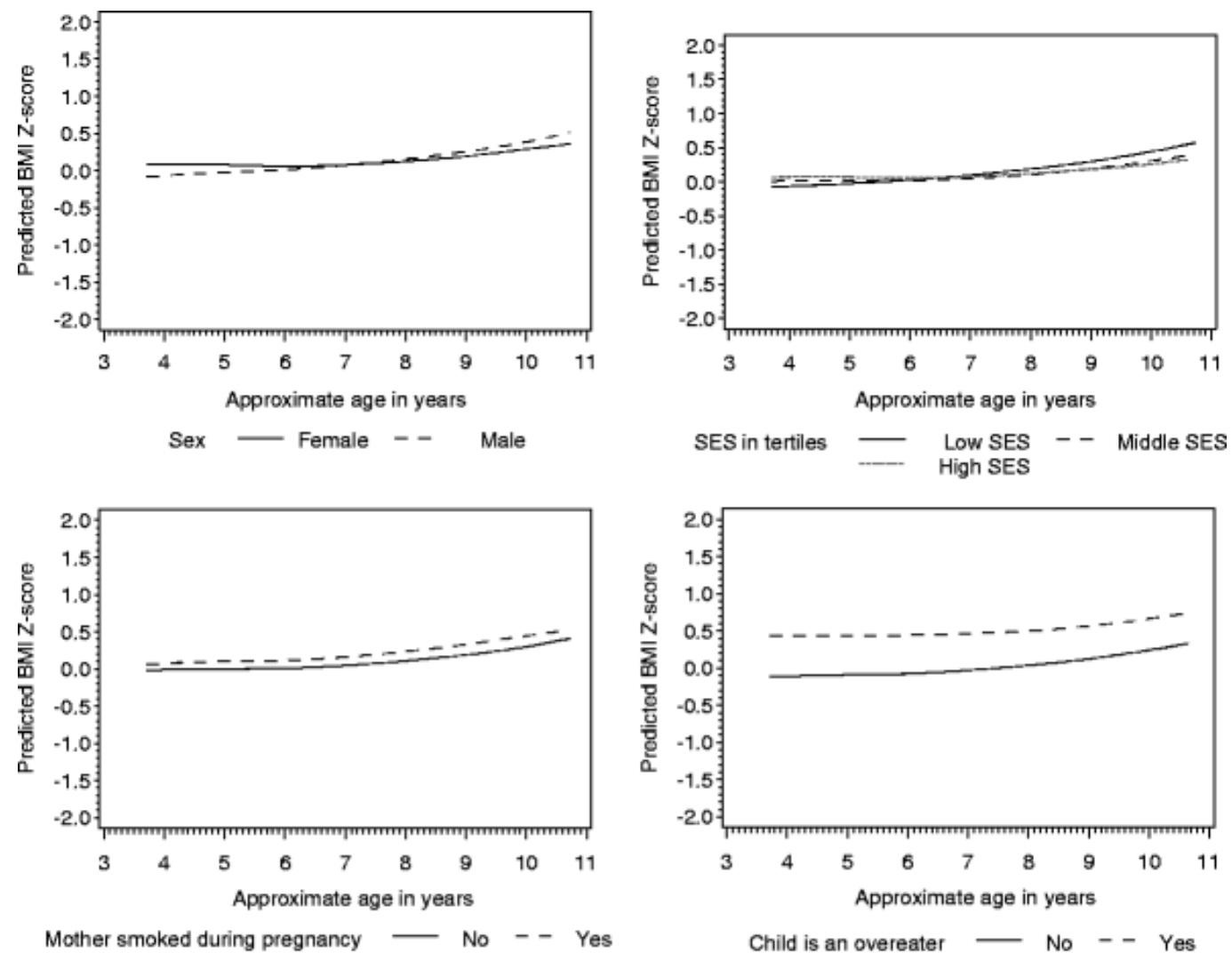

Child is an overeater $\longrightarrow$ No -- Yes
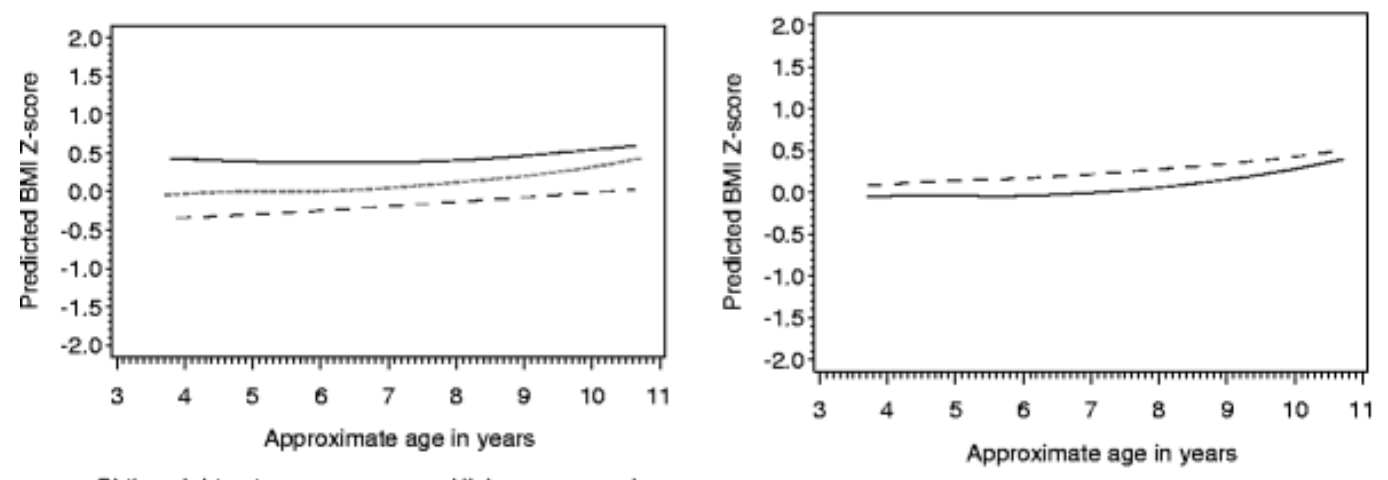

Birth weight category $=\begin{gathered}\text { High } \\ \text { Normal }\end{gathered}$ Rapid weight gain in infancy - No -- Yes

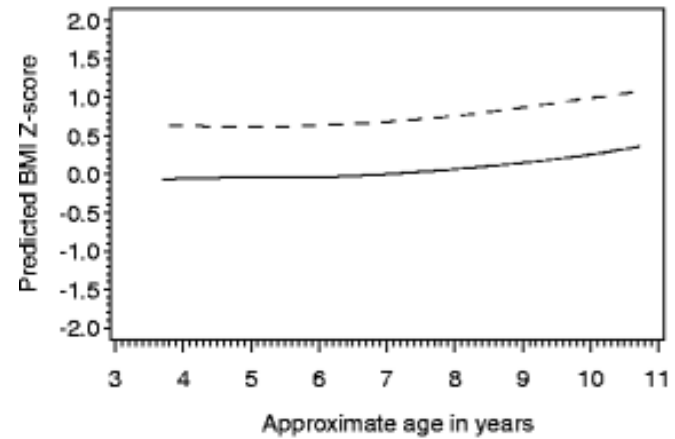

Obesity status of the mother _ _ Not obese

FIGURE 3. Predicted BMI Z-score smoothed individual trends by significant social and early life factors, adjusted for other model covariates. 
Using a method developed by Lipsitz et al., 35 the final model $R^{2}$ was calculated to be 0.80 , indicating good predictive ability. Graphical model checking did not reveal any major violations of statistical assumptions and indicated that the model adequately fit the data. Variance inflation factors did not indicate significant multicollinearity among explanatory factors.

\section{Discussion}

This study sought to examine the influence of place factors on children's weight status using longitudinal methods, while simultaneously controlling for social and early life factors, as well as genetic proxies. Significant associations were found for material and social deprivation, social disorder, and population density.

This study showed that weight change was positively related to age in this cohort of children, where rates of weight gain accelerated over time. The overall model suggests that early life factors play a role in childhood weight gain. For example, smoking during pregnancy and mother's obesity status were related to higher BMI Z-scores on average, and even though high birth weight and rapid weight gain in infancy were associated with slightly slower rates of weight change over time, children who had these characteristics had higher BMI Z-scores throughout the study compared to those without (Figure $\underline{3}$ ). Taken together, these results corroborate those of previous studies in a recent systematic review. 29

In terms of individual and family characteristics, the difference in trends between males and females found in this study is in contrast to the findings of two other longitudinal studies that did not find significant interactions with time. $11, \underline{36}$ Low SES being related to faster weight gain, on the other hand, has been demonstrated in other longitudinal studies. 37

For the main explanatory factors of interest, living in materially deprived neighborhoods was related to higher accelerated weight gain. The general positive relationship uncovered here is in line with previous cross-sectional and longitudinal studies. $\underline{9}, \underline{38}, \underline{39}$ Very few studies examining the effect of neighborhood characteristics on weight in children have actually partitioned neighborhood deprivation into two dimensions, such as was done in this study. Here, the influence of social deprivation was in contrast to that of material deprivation; the rate of weight gain among children who lived in areas with high social deprivation was slower than that of children who lived in nonsocially deprived areas. Using Québec information systems covering mortality, hospitalizations, and births, the creators of the deprivation index used in this study found that the two forms of deprivation had differing impacts on health. 19 However, a cross-sectional study that used the same index did not find that social deprivation was significantly related to overweight among Canadian adults. $\underline{22}$

Similar to high social deprivation, living in neighborhoods with high social disorder was related to lower accelerated weight gain relative to not living in such areas. Again, few 
studies have related this neighborhood characteristic to weight status in children. Rather, studies have examined a similar concept, neighborhood safety, but have met with largely null results. 9 Even though the findings for high social deprivation and high social disorder are in contrast to the original hypothesis, that they would be positively related to weight gain in children, they are interesting and informative nonetheless, and reflect the complexity of environmental influences on childhood weight status. One explanation for this finding is that such adverse social places may take longer to exert their weight promoting effects. While children are young, on the other hand, they may have the opposite effect-restricting growth, similar to what is often found in the early child development literature. $28, \underline{40}, \underline{41}$ On the other hand, it may be that these environmental influences provide protection from weight gain for reasons not yet understood.

Finally, population density was hypothesized to have a linear relationship with weight status, such that as density increased, weight gain would decrease. The findings here do not corroborate this: Children living in medium density (census agglomerations) areas exhibited slower growth than children in high density areas (census metropolitan areas), and there was no difference between low density (rural/small towns) and high density areas. Overall, the literature in this area is methodologically heterogeneous with similarly mixed results. $\underline{9}, \underline{42} \mathrm{~A}$ study conducted by Statistics Canada used nationally representative data to determine the unadjusted regional distribution of child and adolescent overweight. They did not find that the prevalence of overweight significantly differed across census metropolitan areas, census agglomerations, and rural/small towns. $\underline{43}$

The reason(s) for an inverse association between living in medium density areas and weight status may reflect a more complex reality than the original hypothesis was able to capture. For example, even though census agglomerations are less densely populated than census metropolitan areas, they have an urban core and can act like census metropolitan areas. 44 Some have high functional metropolitan scores because they act as regional centers and therefore provide a range of services. 44 Some may not have high functional scores but are located in close proximity to a census metropolitan area, benefiting from services provided close by. Thus, census agglomerations may function as more of a close-knit community than a census metropolitan area, with services close at hand, in contrast to rural/small towns whose residents must commute longer distances to access services and to go to work. The importance of population density on weight gain in children requires further study, and indeed longitudinal findings like these may not corroborate some earlier crosssectional relationships observed. It is also possible that the relationship between population density and weight may change over time. This could also be said for the other factors considered here.

The findings of the present study should be interpreted in light of some limitations. First, this was a secondary analysis, which limited us to the variables that were collected. For example, material and social deprivation were measured once at the start of the cohort study and therefore could have changed over the study period. The place factors available in the QLSCD provided a 10,000 versus $100 \mathrm{ft}$ view of the place-weight status relationship, as more direct variables such as amenities, infrastructure, etc. were not available. 
Due to the study design, some earlier time-dependent covariate data (from 5 months to 3.5 years) could not be accounted for in modeling. The study design also did not permit the use of sample weights. Therefore, the results are not necessarily generalizable to the Québec population. The overall model was fairly simplistic in regards to social-ecological theory. Other settings such as daycare and school were not included, and effect modification was not explored in order to keep the analysis manageable and parsimonious. Consideration should also be given to the importance of the place factors relative to the genetic proxies and factors operating in early life; variables such as obesity status of the mother, overeating, high birth weight, rapid weight gain in infancy, and smoking during pregnancy appear to be more strongly related to weight status than the individual socio-demographic/economic and place factors (see Figures $\underline{2}$ and $\underline{3}$ ).

Finally, children in this cohort may not follow a homogenous functional form of weight development, which can be characterized by a population-averaged model. This warrants a comparison between the results observed here and those derived from a group-based trajectory modeling approach, such as has been used in previous studies of childhood obesity. $\underline{45}-\underline{47}$

This study shows that, on average, cohort children were getting heavier over time and suggests the existence of individual and neighborhood social inequalities in childhood weight change. Further work is needed to clarify these relationships, especially for neighborhood-level factors. As in other studies, results here also point to early life as a potentially important developmental window for obesity. Future work, therefore, should also seek to determine the relationship between place characteristics during the perinatal period and these early life risk factors for obesity. Childhood obesity research is, by its very nature, complex. This merits a holistic approach where researchers should continue to focus "upstream" on the interrelationships between different contexts, settings, life stages, and generational transmission, in addition to traditional risk factors such as diet and physical activity.

\section{Acknowledgments}

This work was supported by grants from the Canadian Institutes for Health Research. The QLSCD was conducted by Santé Québec, a division of the Institut de la Statistique du Québec (ISQ) and funded by the Ministry of Health and Social Services of Québec.

\section{Disclaimer}

This analysis was based on the ISQ QLSCD master files. All computations were prepared by the lead author. The responsibility for the use and interpretation of these data is solely that of the authors, not ISQ. The opinions expressed in this paper are those of the authors and do not represent the views of the ISQ.

\section{Open Access}


This article is distributed under the terms of the Creative Commons Attribution License which permits any use, distribution, and reproduction in any medium, provided the original author(s) and the source are credited.

\section{Appendix 1}

Table 5 Neighborhood social scale items

\begin{tabular}{|c|c|}
\hline Scale & Response categories \\
\hline \multicolumn{2}{|l|}{ Social cohesion } \\
\hline \multicolumn{2}{|c|}{$\begin{array}{l}\text { Please tell me whether you strongly agree, agree, disagree, or strongly disagree about the following } \\
\text { statement... }\end{array}$} \\
\hline 1. If there is a problem around here, the neighbors get together to deal with it & Strongly agree $=1$ \\
\hline 2. There are adults in the neighborhood that children can look up to & Agree $=2$ \\
\hline 3. People around here are willing to help their neighbors & Disagree $=3$ \\
\hline $\begin{array}{l}\text { 4. You can count on adults in this neighborhood to watch out that children are safe } \\
\text { and do not get in trouble }\end{array}$ & Strongly disagree $=4$ \\
\hline $\begin{array}{l}\text { 5. When I am away from home, I know that my neighbors will keep their eyes open } \\
\text { for possible trouble }\end{array}$ & \\
\hline \multicolumn{2}{|l|}{ Social disorder } \\
\hline \multicolumn{2}{|l|}{ How much of a problem is the following in this neighbourhood... } \\
\hline 1. Litter, broken glass or garbage? & A big problem $=1$ \\
\hline 2. Selling or using drugs? & $\begin{array}{l}\text { Somewhat of a } \\
\text { problem }=2\end{array}$ \\
\hline 3. Alcoholics and excessive drinking in public? & No problem $=3$ \\
\hline 4. Groups of young people who cause trouble? & \\
\hline
\end{tabular}

\section{References}

1. Tremblay MS, Katzmarzyk PT, Willms JD. Temporal trends in overweight and obesity in Canada, 1981-1996. Int J Obes Relat Metab Disord. 2002; 26(4): 538-543.

2. Shields M. Overweight and obesity among children and youth. Health Rep. 2006; 17(3): 27-42.

3. Kohn M, Booth M. The worldwide epidemic of obesity in adolescents. Adolesc Med. 2003; 14(1): 1-9.

4. Lobstein T, Baur L, Uauy R. Obesity in children and young people: a crisis in public health. Obes Rev. 2004; 5(Suppl 1): 4-104.

5. Hertzman C. Framework for the social determinants of early child development. Encyclopedia on early child development 2010. http://www.enfantencyclopedie.com/pages/PDF/HertzmanANGxp.pdf. Accessed 1 Nov 2010. 
6. Bernard P, Charafeddine R, Frohlich KL, Daniel M, Kestens $Y$, Potvin L. Health inequalities and place: a theoretical conception of neighbourhood. Soc Sci Med. 2007; 65(9): 1839-1852.

7. Stafford M, Cummins S, Ellaway A, Sacker A, Wiggins R, Macintyre S. Pathways to obesity: identifying local, modifiable determinants of physical activity and diet. Soc Sci Med. 2007; 65(9): 1882-1897.

8. Black JL, Macinko J. Neighborhoods and obesity. Nutr Rev. 2008; 66(1): 2-20.

9. Carter MA, Dubois L. Neighbourhoods and child adiposity: a critical appraisal of the literature. Health Place. 2010; 16(3): 616-628.

10. Bell JF, Wilson JS, Liu GC. Neighborhood greenness and 2-year changes in body mass index of children and youth. Am J Prev Med. 2008; 35(6): 547-553.

11. Oliver LN, Hayes MV. Effects of neighbourhood income on reported body mass index: an eight year longitudinal study of Canadian children. BMC Public Health. 2008; 8: 16.

12. Cecil-Karb R, Grogan-Kaylor A. Childhood body mass index in community context: neighborhood safety, television viewing, and growth trajectories of BMI. Health Soc Work. 2009; 34(3): 169177.

13. Concepts, definitions and operational aspects: 5 month old enfants. Québec Longitudinal Study of Child Development (QLSCD 1998-2002). Institut de la statistique du Québec 2001, vol 1. no. 12.http://www.iamillbe.stat.gouv.qc.ca/bebe/bebe n12 pdf an.htm. Accessed 25 Oct 2010.

14. Survey description and methodology: 5-month old infants. Québec Longitudinal Study of Child Development (ELDEQ 1998-2002). Institut de la statistique du Québec 2000; vol 1, no. 1.http://www.iamillbe.stat.gouv.qc.ca/bebe/pdf/baby no1-2.pdf. Accessed 26 Oct 2010.

15. Ogden CL, Kuczmarski RJ, Flegal KM, et al. Centers for disease control and prevention 2000 growth charts for the United States: improvements to the 1977 national center for health statistics version.Pediatrics. 2002; 109(1): 45-60.

16. Kuczmarski RJ, Ogden CL, Guo SS, et al. CDC growth charts for the United States: methods and development. Vital Health Stat. 2002; 11(246):1-190.

17. Must A, Anderson SE. Body mass index in children and adolescents: considerations for population-based applications. Int J Obes. 2006; 30(4): 590-594.

18. Desrosiers H, Dumitru V, Dubois L. Excess weight in children 4 to 7 years of age-targeting risk factors for intervention. Institut de la Statistique du Québec 2009. Vol. 4, No. 3.

19. Pampalon R, Raymond G. A deprivation index for health and welfare planning in Quebec. Chron Dis Can. 2000; 21(3): 104-113.

20. Pampalon R, Hamel D, Gamache P, Raymond G. A deprivation index for health planning in Canada. Chron Dis Can. 2009; 29(4): 178-191.

21. Pampalon R, Philibert M, Hamel D. Développement d'un système d'évaluation de la défavorisation des communautés locales et des clientèles de CLSC. Montréal, Québec: Institut national de santé publique du Québec; 2004. Report no. INSPQ-2004-024.

22. Lebel A, Pampalon R, Hamel D, Theriault M. The geography of overweight in Québec: a multilevel perspective. Can J Public Health. 2009; 100(1): 18-23.

23. Barnes-McGuire J. The reliability and validity of a questionnaire describing neighborhood characteristics relevant to families and young children living in urban areas. J Community Psychol. 1997; 25(6): 551-566.

24. Statistics Canada. Microdata user guide: national longitudinal survey of children and youthcycle 1. Ottawa: Human Resources Development Canada and Statistics Canada; 1997.

25. Variables dérivées de l'ÉLDEQ 1998-2008: partie A. Institut de la statistique du Québec 2009. http://www.jesuisjeserai.stat.gouv.qc.ca/pdf/doc tech/E1aE11Variables Derivees1101.pdf. Accessed 25 Oct 2010.

26. Carnell S, Wardle J. Appetitive traits in children. New evidence for associations with weight and a common, obesity-associated genetic variant. Appetite. 2009; 53(2): 260-263.

27. Llewellyn $\mathrm{CH}$, van Jaarsveld $\mathrm{CH}$, Johnson L, Carnell S, Wardle J. Nature and nurture in infant 
appetite: analysis of the Gemini twin birth cohort. Am J Clin Nutr. 2010; 91(5): 1172-1179.

28. Curtis LJ, Dooley MD, Phipps SA. Child well-being and neighbourhood quality: evidence from the Canadian National Longitudinal Survey of Children and Youth. Soc Sci Med. 2004; 58(10): $1917-$ 1927.

29. Monasta L, Batty GD, Cattaneo A et al. Early-life determinants of overweight and obesity: a review of systematic reviews. Obes Rev. 2010;11:695-708

30. Shrewsbury V, Wardle J. Socioeconomic status and adiposity in childhood: a systematic review of cross-sectional studies 1990-2005. Obesity. 2008; 16(2): 275-284.

31. Dubois L, Farmer A, Girard M, Peterson K, Tatone-Tokuda F. Problem eating behaviors related to social factors and body weight in preschool children: a longitudinal study. Int J Behav Nutr Phys Act. 2007; 4: 9.

32. Dubois L, Girard M. Early determinants of overweight at 4.5 years in a population-based longitudinal study. Int J Obes. 2006; 30(4): 610-617.

33. Cheng J, Edwards LJ, Maldonado-Molina MM, Komro KA, Muller KE. Real longitudinal data analysis for real people: building a good enough mixed model. Stat Med. 2010; 29(4): 504-520.

34. Fitzmaurice GM, Laird NM, Ware JH. Applied longitudinal analysis. Hoboken: Wiley; 2004.

35. Lipsitz SR, Leong T, Ibrahim J, Lipshultz S. A partial correlation coefficient and coefficient of determination for multivariate normal repeated measures data. Statistician. 2001; 50(1): 87-95.

36. Wardle J, Brodersen NH, Cole TJ, Jarvis MJ, Boniface DR. Development of adiposity in adolescence: five year longitudinal study of an ethnically and socioeconomically diverse sample of young people in Britain. BMJ. 2006; 332(7550): 1130-1135.

37. Hejazi S, Dahinten S, Ratner PA, Marshall SK. Developmental trajectories of weight status in childhood and adolescence. In: Bagchi D, editor. Global perspectives on childhood obesity. New York: Academic Press; 2011. pp. 21-29.

38. Oreskovic NM, Kuhlthau KA, Romm D, Perrin JM. Built environment and weight disparities among children in high- and low-income towns. Acad Pediatr. 2009; 9(5): 315-321.

39. Grow HM, Cook AJ, Arterburn DE, Saelens BE, Drewnowski A, Lozano P. Child obesity associated with social disadvantage of children's neighborhoods. Soc Sci Med. 2010; 71(3): 584591.

40. Kohen DE, Brooks-Gunn J, Leventhal T, Hertzman C. Neighborhood income and physical and social disorder in Canada: associations with young children's competencies. Child Dev. 2002; 73(6): 1844-1860.

41. Leventhal T, Brooks-Gunn J. The neighborhoods they live in: the effects of neighborhood residence on child and adolescent outcomes. Psychol Bull. 2000; 126(2): 309-337.

42. Dunton GF, Kaplan J, Wolch J, Jerrett M, Reynolds KD. Physical environmental correlates of childhood obesity: a systematic review. Obes Rev. 2009; 10(4): 393-402.

43. Shields M, Tjepkema M. Regional differences in obesity. Health Rep. 2006; 17(3): 61-67.

44. Mendelson R, Lefebvre J. Reviewing census metropolitan areas (CMA) and census agglomerations (CA) in Canada according to metropolitan functionality. Ottawa, Canada: Statistics Canada; 2003. Report no. 2003-001.

45. Hejazi S, Dahinten VS, Marshall SK, Ratner PA. Developmental pathways leading to obesity in childhood. Health Rep. 2009; 20(3): 63-69.

46. Li C, Goran MI, Kaur H, Nollen N, Ahluwalia JS. Developmental trajectories of overweight during childhood: role of early life factors. Obesity. 2007; 15(3): 760-771.

47. Mustillo S, Worthman C, Erkanli A, Keeler G, Angold A, Costello EJ. Obesity and psychiatric disorder: developmental trajectories. Pediatrics. 2003; 111(4 Pt 1): 851-859. 


\subsection{Trajectories of childhood weight gain: the relative importance of}

local environment versus individual social and early life factors Manuscript 4

Authors: Megan A. Carter ${ }^{1}$, Lise Dubois ${ }^{1,2}$, Mark S. Tremblay ${ }^{3}$, Monica Taljaard ${ }^{2,4}$, Bobby L. Jones ${ }^{5}$

1. Institute of Population Health, University of Ottawa

2. Department of Epidemiology and Community Medicine, University of Ottawa

3. Healthy Active Living and Obesity Research, Children's Hospital of Eastern Ontario Research Institute

4. Clinical Epidemiology Program, Ottawa Hospital Research Institute

5. Behavioral Genetics Research Program, Western Psychiatric Institute and Clinic, University of Pittsburgh Medical Center

This manuscript was written in accordance to the specifications for submission to the peer-reviewed, open access journal PLoSONE. It has been accepted and is currently in the process of being published. It appears here in its accepted, uncorrected format.

\section{Suggested citation:}

Carter MA, Dubois L, Tremblay MS, Taljaard M, Jones BL. Trajectories of childhood weight gain: the relative importance of local environment versus individual social and early life factors. PLoSONE. 2012 


\section{Abstract}

Objective: To determine the association between local environmental factors with child weight status in a longitudinal study, using a semi-parametric, group-based method, while also considering social and early life factors.

Methods: Standardized, directly measured BMI from 4-10 y of age, and group-based trajectory modeling (PROC TRAJ) were used to estimate developmental trajectories of weight change in a Québec birth cohort $(n=1,566)$. Associations between the weight trajectories and living location, social cohesion, disorder, and material and social deprivation were estimated after controlling for social and early life factors.

Results: Four weight trajectory groups were estimated: low-increasing (9.7\%); low-medium, accelerating (36.2\%); medium-high, increasing (43.0\%); and high-stable (11.1\%). In the low-increasing and medium-high trajectory groups, living in a semi-urban area was inversely related to weight, while living in a rural area was positively related to weight in the highstable group. Disorder was inversely related to weight in the low-increasing group only. Other important risk factors for high-stable weight included obesity status of the mother, smoking during pregnancy, and overeating behaviors.

Conclusions: In this study, associations between local environment factors and weight differed by trajectory group. Early life factors appear to play a more consistent role in weight status. Further work is needed to determine the influence of place on child weight.

Key words: children, obesity, body mass index, residence characteristics, environment, longitudinal design

\section{Introduction}

The prevalence of childhood obesity has been increasing globally in the last few decades and is now a problem in both the developing and developed world [1]. In North America, childhood obesity has more than doubled from 1978/79 to 2004 among Canadian children aged 2-17 y [2] and almost tripled among American children aged 2-19 y in a similar time period [3]. Given this increasing prevalence and associations with adverse health outcomes, being at excess weight in childhood has become a major public health concern [4], with potentially far-reaching and long-lasting social and economic consequences [5]. 
Obesity research has typically focused on individual behaviours. While this is important, and may have played a role in the levelling off of childhood obesity in certain countries [6], it may not be enough to shift the entire population distribution of childhood obesity and related diseases downward. As such, there have been recent calls by the obesity research community to consider the environments in which people live [7]. This ecological, more holistic understanding of excess weight development will likely be necessary to develop interventions that are not only effective, but also sustainable at the population-level.

The level of material deprivation or disadvantage at the local level may explain whether healthy eating or PA resources will be available to residents, and at what cost [8]. This may have ramifications for child weight status. For example, studies assessing neighborhoodlevel material deprivation often find that children living in the most deprived areas are most likely to be overweight or obese [9-11]. The level of material deprivation may also confound the relationship between other place characteristics and childhood excess weight, and thus, is important to include in multivariable models.

Deprivation theorists also highlight the importance of including a social interaction aspect, emphasizing that deprivation cannot be reduced to a single material or economic dimension [12]. Social deprivation relates to the concepts of social capital, social fragmentation, and social isolation [12]. Areas with high social deprivation (fewer social ties) may decrease resident's access to material and non-material resources conducive to healthy living, and increase stress and decrease well-being, all of which may contribute to child excess weight. To the authors' knowledge, this has not yet been studied in relation to child excess weight. 
Social capital has no agreed upon definition but has been extensively studied in relation to adverse health outcomes such as delayed child development [13]. One definition conceptualizes social capital as a group-level attribute called social cohesion. This refers to the resources - such as trust, norms, and the exercise of sanctions - available to the members of social groups [14].

Broadly speaking, posited ways that high social cohesion may prevent childhood excess weight include increased ability to link with health relevant resources, collective action to bring needed resources into the community, and the existence of social norms that enforce healthy behaviours and prevent deviant behaviors that may lead to degradation or disorder of the physical (e.g., garbage, graffiti) and social environments (e.g. fear, crime, bad reputation). The literature on social cohesion is small but growing. These studies, for the most part, have uncovered inverse associations with child excess weight [15-17].

Areas of increasing social disorganization, characterized by increasing disorder, may promote stress, discourage healthy behaviours among residents, such as being physically active outside, and itself may negatively impact social capital. It is sometimes considered a measure of neighbourhood quality. The few studies that have examined local area disorder in relation to childhood excess weight have found positive associations between disorder and child excess weight $[10,11,18]$.

How developed an area is, with respect to living location or urban/rural status may also help to explain the development of childhood obesity. Rural areas have fewer amenities and they may be of lower quality than more populated areas. Additionally, as distance from the city centre increases, time spent in the car increases [19]. A representative cross-sectional study of Canadian children in grades 6-10 found that as the level of rurality increased, the 
odds of overweight and obesity increased [20]. Some studies have observed similar associations [21-23]. However, others have had opposite [24] or null results $[25,26]$. Assessing potential local environmental relationships with child weight status is a relatively new and burgeoning area of research. The literature is heterogeneous and there is a dearth of studies that examine measures of social deprivation, social cohesion, and disorder. Regardless of the type of local environmental characteristic being examined, few studies have used the longitudinal research design with more than two repeated measures. This greatly limits what can be said about the childhood place - weight relationship. Previous work on child excess weight development has also highlighted the potential usefulness of statistical methods that do not assume all children follow the same growth trajectory, such as group-based trajectory modeling or growth mixture modeling [26-28]. These methods account for heterogeneity in growth by grouping children together based on similar response patterns over time. Partitioning variability in growth in this way may allow for a better understanding of how weight status changes over time and provides another means of detecting risk factors, which can complement the single growth curve approach such as random effects modeling.

Therefore, the main objective of the present study was to use group-based trajectory modeling to examine change in living location and perceived neighbourhood social cohesion and disorder, in relation to change in child weight status, after controlling for area material and social deprivation and other potentially important explanatory variables. The main hypothesis was that adverse local environment factors such as rural living, high disorder, and high material and social deprivation would be related to increasing weight over time, and that high cohesion would be related to decreasing weight over time. 


\section{Methods}

\section{Sample}

Children participating in the Québec Longitudinal Study of Child Development (QLSCD) comprised the sample for analysis. The QLSCD is a government-funded cohort study conducted by the Institut de la Statistique du Québec (ISQ) in the province of Québec, Canada. It began in 1998 with the intent of collecting data describing the health and wellbeing of Québec children from infancy into young adolescence [29]. Data collection began at five months of age and occurred annually until the age of eight, after which it occurred biannually, in order to reduce respondent burden. Cohort children are currently 14 years of age. Data from five months to 10 years of age were used in the current study.

Children were selected for participation in the QLSCD based on a three-stage, stratified design, using 1997-1998 Québec Birth Registries as the sampling frame [29]. Twins, children with major diseases at birth, and those living in Northern Québec, Cree or Inuit territory, or Indian reserves were excluded. Sampling occurred throughout the year to minimize the effect of seasonality. Of the 2,675 children and their families that were possible to contact, 2,223 agreed to participate ( $83 \%$ response rate). A further 103 were dropped, as these were a cross-sectional over-sample for the first year (1998), to arrive at $\mathrm{n}=$ 2,120 for the longitudinal sample size. Computer-assisted personal interviewing of the mother, in the child's home, was the primary method for data collection. The present study is secondary analysis of data collected in the QLSCD.

\section{Outcome variable}

The dependent variable used in the analyses was body mass index (BMI) Z-score. This is BMI $\left(\mathrm{kg} / \mathrm{m}^{2}\right)$ that is standardized, based on age and sex, to a reference population; in this 
case, the Centers for Disease Control and Prevention (CDC) 2000 Growth Charts [30]. Standardization of BMI is necessary since an increase in BMI is a part of normal growth. Heights and weights were directly measured at the approximate ages of 4, 6, 7, 8, and 10 years; details of how these measurements were taken can be found elsewhere [31].

\section{Local environment factors}

Five variables describing the local environment were available for use in the QLSCD. The size of the local area described depends on particular variable definitions, and is not constant across variables. For instance living location covers large areas at the municipality level; neighbourhood social cohesion and disorder cover the mother's perceived neighbourhood, and material and social deprivation cover census enumeration areas, which represent areas equivalent to one or more city blocks. These variables are described in more detail below, under three main subheadings. Raw area information such as postal codes was not available to use in the present analysis.

\section{Living location}

Children's postal codes were linked to census geographical areas using Statistics Canada's postal code conversion file by statisticians at the ISQ. For the purposes of this study, children were classified as living in one of three different types of areas: 1) Urban: Census Metropolitan Area (CMA) with $\geq 100,000$ inhabitants; 2) Semi-urban: Census Agglomeration (CA) with 10,000 to < 100,000 inhabitants; or 3) Rural: rural area/small town with $<10,000$ inhabitants [32]. This variable was considered time-dependent as it was measured at each data collection cycle. Postal codes were not collected at age 4 years, thus the living location value at the previous data collection cycle (3.5 years) was used at 4 years of age. 


\section{Neighbourhood social cohesion and disorder}

Two scales (social cohesion, disorder), adapted from those previously used by Statistics Canada, were used in this analysis to characterize elements of neighbourhood physical and social environments $[29,32]$. Social cohesion measures the level of mutual trust and support that neighbours have for one another. The mother was asked to give her level of agreement to five statements, which were then used to derive an average score ranging from one to four; lower scores indicate higher cohesion. Disorder measures the overall quality of the neighbourhood. The mother was asked to assess the presence and severity of four types of

problems in the neighbourhood. Responses were then used to derive an average score ranging from one to three; a score of three indicates no problems. Both scales have demonstrated adequate internal consistency, as each was originally calculated to have a Cronbach's alpha of $\geq 0.75$ [33]. Items for each scale can be found in Appendix A. Both scales were dichotomized to increase interpretability. In order to maximize efficiency and minimize bias, this was based on the $50^{\text {th }}$ percentile. However, disorder was highly skewed and instead, children were categorized as either having a perfect score of three (no problems at all in the neighbourhood) versus less than three (problems present). A similar approach was taken by Curtis et al (2004) in their analysis of neighbourhood influences on a variety of health outcomes in a Canadian sample of children [34].

These variables were collected every other data collection cycle and thus available at 4 , 6,8 , and 10 years of age. To be considered a time-dependent variable in analysis, a value at 7 years was needed; thus, the value at 6 years was carried forward.

\section{Deprivation}

Material and social deprivation are two separate dimensions of a deprivation index developed to aid the Québec Government in assessing community service needs and 
monitoring social inequalities $[35,36]$. Material deprivation measures the inability to get the goods and services that are a part of everyday life (lack of human and economic capital), and social deprivation captures social isolation within the neighbourhood. This index has been derived for QLSCD children and was available for secondary data analysis. Derivation of the index in the QLSCD is discussed below.

Children's postal codes, measured in 1998 (first data collection cycle when children were five months of age), were linked to 1996 census data for residents $\geq 15$ years of age aggregated to the enumeration area level. The enumeration area was chosen because it was the smallest geographical unit for which census data were available in the 1996 Canadian census (with an average population of 750 residents) [36].

Principal components analysis was then conducted by ISQ statisticians to determine factor scores for each of the two dimensions, based on the aggregated census data at the enumeration level. Material deprivation factor scores were calculated from mean income, percentage of people with no high school diploma, and ratio of employed individuals to total population. Social deprivation factor scores were calculated from percentage of singleparent families, percentage of families split by separation, divorce, or death, and percentage of individuals living alone. On both dimensions, enumeration areas were divided into population quintiles, from quintile 1 (least disadvantaged) to 5 (most disadvantaged).

For the present secondary data analysis, both material and social deprivation were dichotomized into 'deprived' (quintiles 4 and 5) versus 'not deprived' (quintiles 1-3), as has been done elsewhere [37] (Table 1). Both were also considered time-stable as they were not available in other cycles, mainly because the Canadian census is conducted once every five years. An update, based on the 2001 census, linked to postal codes was not available for this 
study, but descriptive data showed that these measures remained largely unchanged from 1996-2001 [38]. Children could also move to a different enumeration area (this became dissemination area in the 2001 census) over time; however, these changes in material deprivation and social deprivation were not derived in the QLSCD every time a child moved.

\section{Statistical Analysis}

Group-based trajectory modeling (sometimes called latent class growth analysis or semiparametric finite mixture modeling) [39] was employed to determine relationships between the various local environment factors and weight status, using PROC TRAJ in SAS (v. 9.2) $[40,41]$. Group-based trajectory modeling assumes that there are a certain number of discrete underlying groups in the population that each have their own population prevalence, intercept and slope (trajectory shape or change in BMI Z-score) [39]. These subpopulations are not directly observable, but are estimated (latent) and should not be considered actual categories of growth. Rather, they are used to help us understand the etiological underpinnings of different developmental trajectories [42].

In general terms, the series of responses for each individual are used to determine subgroups that follow similar changes in the outcome over time. This is done in a probabilistic manner, using maximum likelihood [39]. The linkage between age (time) and the outcome occurs through a polynomial relationship that is estimated via a latent variable. Additionally, the probability of belonging to each group is calculated for each individual and is estimated from the model parameters. These are the posterior probabilities and they give an overall estimate of model uncertainty. For descriptive analyses and model-checking purposes, individuals can be assigned to the group to which they have the highest probability of belonging. 
The first step involved determining the most appropriate number of groups and the shape of their trajectories. This was done by comparing Bayesian Information Criteria (BIC) for models with one to five groups; the more complex model (one with more groups) was considered a better fit than the null model (one with fewer groups) when two times the change in the BIC was equal to or larger than previously established criteria [40,43]. After selection of the number of groups, the trajectory shapes of each of the groups was determined in a step-wise manner starting with all groups set to have a cubic order, and again comparing change in BIC and the significance of parameters, as their orders were made less complex - quadratic, linear and intercept only. Sometimes the BIC is not a good indicator of fit and will continue to decrease as more and more groups are added, even though the additional groups do not add any extra explanatory power. Therefore, the best fitting models for three, four, and five groups were compared graphically. In order to test for the presence of interactions, these steps were also carried out separately by sex to determine if the same number of groups with similar trajectory shapes emerged. The resulting final model was then assessed for goodness of fit based on standard criteria, namely: the average posterior probabilities for each of the subgroups, odds of correct classification, and comparison of actual (based on posterior probabilities) to model/estimated group prevalences [43]. According to Nagin (2005), rules of thumb for assessing adequate fit are that each group should have an average posterior probability $\geq 0.7$ and an odds of correct classification $\geq 5$, and there should be close agreement between actual and estimated group prevalences [43].

Next, profiles of each of the trajectory groups were created to explore differences in the local environment factors, other explanatory factors, and outcome at a descriptive level 
(means and proportions). No formal statistical tests were conducted at this point, as the uncertainty of group assignment needs to be taken into account by using the posterior probabilities [43].

The last step of modelling was to relate the local environment factors to the trajectories while controlling for social and early life factors. Table 1 describes the treatment of all variables in model estimation. The time-dependent explanatory variable parameters are interpreted the same way they would be in an ordinary linear regression, but within each trajectory group. In other words, time-dependent explanatory variables may be associated with a deviation in the long-term average response (BMI Z-score) of members in a particular group [43]. Regressors can be different at different time points depending on changes in the time-dependent explanatory variable. Time-stable explanatory variables (risk factors) are related to the trajectory groups via a generalized logit function [40]. Resulting log-odds can be exponentiated to get odds ratios, which are interpreted as odds of being in a certain trajectory group relative to the reference group for a level of a risk factor versus the reference level.

Unadjusted models were first estimated for the local environment factors separately, then a model with local environment and social variables together, and a final model that added early-life variables. All analyses take into consideration the uncertainty of group assignment, and in multivariable models, estimate parameters for time-dependent and timestable explanatory variables simultaneously.

Group-based trajectory modeling retains subjects with partially observed outcome and time-dependent explanatory variable data under the assumption that data are missing at random [42]. Subjects with any missing values on one or more time-stable explanatory 
variables, or those who are missing all data for a time-dependent explanatory variable are dropped from the analysis automatically. For this particular analysis, participants that had fewer than two out of the five BMI Z-score outcome variables non-missing were excluded.

Due to the cumulative effect of missing data for the explanatory variables, 1385 children were included in the multivariable model that included all explanatory variables (local environment, and social and early life factors). Compared to included children, excluded children $(n=735)$ were more likely to be male, have immigrant mothers, be from a low SES household, and experience rapid weight gain during infancy $\left(\chi^{2} \mathrm{P}\right.$-values $\left.<0.05\right)$. Of the excluded children that had BMI Z-score measures, no significant differences with included children were noted at any of the time points.

Sampling weights were not used due to the fact that children could be included even if they did not respond in all cycles. Therefore, the results here cannot be considered representative of the Québec population.

\section{Ethics Statement}

Each year, participants were provided with detailed information on the aims and procedures of the QLSCD, and consent was obtained by the interviewer from either one or both parents of the child, using a form approved by the Ethics Committee of the ISQ. Ethics approval to conduct this analysis was given by the University of Ottawa Research Ethics Board - certificate number: H 05-10-18.

\section{Results}

\section{Descriptive trajectory data}

Approximately $74 \%$ of children $(n=1566 / 2120)$ had two response points and were included in the first step of analysis: estimation of the number of groups and the shapes of 
their trajectories. According to the BIC tests, the 5-group model best fit the data, followed by the 4-group model. When fitting the trajectory shapes for the 5-group model, the prevalence of the fifth group was approximately $2 \%$, which reduces interpretability and power. This model was graphically compared to the best fitting 3-and 4-group models. The parameter estimates of the 5-group model appeared to collapse onto those of the fourth group, so for parsimony, the 4-group model was selected as the best fitting model. Model fit statistics indicated an adequately fitting model (Appendix B - group labels were assigned subjectively based on their trajectory shapes).

Table 2 and Figure 1 present descriptive information for the four trajectory groups. On average, children in the low group were underweight at baseline, with a Z-score $<-1.645$. Growth was best explained by a positive linear relationship with time. This group was therefore labelled "low, increasing." The second group, labelled "low-medium," had a mean BMI Z-score below the median at baseline. Trajectory of growth was estimated to be quadratic over time (accelerate). Group 3, labelled "medium-high," began slightly above the median at baseline and were estimated to have a linear trajectory. Finally, an intercept only relationship with time was estimated for the fourth group, labelled "high-stable," indicating that their weight did not change significantly from ages $4-10$ years (trajectory is a flat line). Mean BMI Z-score for these children at baseline was above $1.645 \mathrm{Z}$-score units $\left(95^{\text {th }}\right.$ percentile), which classifies them as obese according to the CDC definition $[30,44]$. The majority of children were estimated to belong to the low-medium or the medium-high groups. When categorizing each group as overweight $\left(\geq 85^{\text {th }}\right.$ percentile $)$ or obese $\left(\geq 95^{\text {th }}\right.$ percentile) at each age, no children in the low group and $\leq 3 \%$ of children in the lowmedium group were overweight or obese at any age. In the medium-high group, percentage 
overweight ranged from $16-33 \%$ and percentage obese from $2-7 \%$ across the five ages.

Finally, in the high-stable group, percentage overweight ranged from $85-99 \%$, and

percentage obese from $53-67 \%$ across the five ages.

Conducting a stratified analysis by sex showed no differences in the number of groups or trajectory shapes compared to the original aggregate estimate. This indicates that there were likely no substantial differences (interactions) in development by sex. Thus, to increase power, males and females were analyzed together. Descriptive information describing the characteristics of the trajectory groups are presented in Table 3.

\section{Relationship between local environment factors and weight trajectories}

In bivariable and multivariable analyses, none of the time-stable local environment factors (material and social deprivation) were associated with group membership (Table 4). On the other hand, overeating, having a mother that smoked during pregnancy, or was obese when the child was young, greatly increased the odds of following the high-stable trajectory relative to the 'normal' (medium-high, slow increasing) group. Rapid weight gain, high birth weight, and having an obese mother decreased the odds of children belonging to the two lower trajectory groups, relative to the normal group.

Among the time-dependent local environment factors, living in a rural area relative to an urban area (CMA) was associated with an increase in BMI Z-score among children in the high-stable group ( $0.274,95 \%$ CI: 0.105 to 0.443$)$ (Table 4$)$. This attenuated slightly in the multivariable analyses.

Living in a semi-urban area (CA) relative to an urban area (CMA) was associated with a decrease in BMI Z-score of the low and medium-high groups by 0.421 (95\%CI: -0.111 to $0.730)$ and 0.148 (95\%CI: -0.260 to -0.036$)$ units, respectively. Multivariable analyses 
slightly attenuated the association among the medium-high group, and strengthened the association in the low group.

High social cohesion was not significantly associated with change in weight in any group. High disorder was significantly associated with change in weight in the low group only. Living in this type of environment was associated with a mean decrease of 0.171 (95\%CI: -0.330 to -0.012 ) in BMI Z-score relative to not living in a high disorder area. Multivariable analyses slightly strengthened this association.

Of the other time-dependent explanatory variables, low SES was related to decreasing weight in the low-medium accelerating group only.

Figure 2 provides an example, using parameter estimates, of how moving from an urban (CMA) to a rural area, or from an urban (CMA) to a semi-urban (CA) area between 6-7 years relates to changes in BMI Z-score in each of the four groups.

\section{Discussion}

Four distinct trajectories of relative weight development were estimated in this cohort of children. A recent review of similar studies using group-based trajectory modeling or growth mixture modeling determined that four population subgroups were most common, with stable high and low categories, and rising and declining categories [45]. Most of the reviewed studies estimated trajectory groups based on a dichotomous indicator, such as overweight or obesity, or BMI without adjustment for age and sex. Dichotomizing the outcome can create misclassification bias in its own right, and adds to the classification uncertainty inherent in this type of analysis. Using BMI, without adjustment for age and sex, may risk missing, and therefore not accounting for, important sources of variation in growth. BMI Z-scores and percentiles, resulting from standardization to a reference 
distribution, are interchangeable [46]; however, in longitudinal population-based analyses BMI Z-scores have been preferred over use of percentiles [47].

In contrast to the results here, a recent study that examined the same cohort from 5 months to 8 years of age, uncovered three rather than four groups [48]. Approximately 5\% of children were estimated to be in a high-rising BMI group, $41 \%$ in the moderate BMI group, and over half of the sample was estimated to belong to the low-stable group. This study, however, used both mother-reported and directly measured heights and weights. A previous study on this population reported inaccuracies in mother-reported height and weight [49]. This, along with using BMI that was not standardized for age and sex, and analyzing a different time-frame (5 months -8 years of age versus $4-10$ years of age) may explain differences with the present study.

Eleven percent of children in the present study were estimated to follow a high-stable weight trajectory (group 4). This suggests that in some children, excess weight starts early, with certain risk factors that occur at or before 4 years of age, greatly increasing the likelihood of a child following this pattern of growth. In particular, this study highlights obesity status of the mother and smoking during pregnancy as potential points of intervention.

Among the other trajectory groups in the present study, there were no steep increases in weight, although all showed gradual increases in BMI Z-score over time. Early life factors related to obesity, such as high birth weight, rapid weight gain during pregnancy, and obesity status of the mother were less likely in the low and low-medium versus the medium-high weight change group. 
Other than rural living in the high-stable group, local environment factors were either not related to weight or in an opposite direction of what was expected. However, family SES was also controlled for over time, so any influence of family SES on weight that coincided with moving should be controlled for. It is unclear why rural living would increase weight in the high-stable group and not the others. Perhaps children already at excess weight are more sensitive to changes in urban/rural lifestyle, and therefore exhibit weight changes more quickly [50]. Living in a semi-urban area (CA) was related to decreasing weight in the low and medium-high weight groups. This is also unclear and might indicate influences that go beyond population size. For example, the semi-urban areas considered here (CA) have fewer inhabitants than urban (CMA) but they have an urban core [51]. Thus, they may function as the best of both worlds, providing a sense of community due to their smaller size, but also a range of services.

Longitudinal studies on living location and child weight status have been mixed [21,26]. A recent study that used growth mixture modeling to estimate relative weight change trajectories in a large US cohort of adolescents (12-17 years in 1997) did not find that living location (central metropolitan statistical area vs non-central metropolitan) predicted group membership [26]. The authors, however, did not account for change in this variable over time, used self-reported height and weight, and did not standardize BMI for age and sex. A longitudinal study of young Canadians that used a single growth curve approach, found that urban living was inversely related to weight status at initial status only; no differences in trends over time were noted [21]. Again, changes in living location could not be accounted for in this study. 
Few studies in children have specifically examined the concept of disorder in relation to weight or obesity. In general, these studies have uncovered positive associations; increasing disorder being significantly related to increasing weight and/or an increased likelihood of obesity $[10,11,18]$. This is in contrast to the results of this study where no positive associations were seen; only an inverse association in the low weight group. On the other hand, two of these studies were cross-sectional $[11,18]$. The other was longitudinal and used a single growth curve method; although, significant results were for the crosssectional association only, and the study was unable to adjust for changes in disorder over time [10]. Additionally, all of these studies were conducted in the US. Two of these studies included aspects of physical and social disorder (e.g. dilapidated buildings and teens hanging out) $[10,11]$ and one appeared to focus on physical disorder only [18]. The present study includes measures of both, although three out of the four items relate more to the social aspect of disorder, while only one captures the physical aspect of disorder. Two of the three studies were also interviewer observed $[11,18]$, rather than perceived by the respondent, as was the case in the present study.

Neighbourhood material deprivation was not related to weight status in this study. This is in contrast to fairly consistent findings from both cross-sectional and longitudinal studies that have shown positive relationships between area material disadvantage and childhood weight [9-11]. Social deprivation was also not found to relate to weight status in this study. No other studies, to the knowledge of the authors, have assessed this variable in relation to child weight status. Another study that examined area social deprivation in relation to overweight among adults living in Québec, did not uncover a significant association [37]. 
Social cohesion was also not related to weight status in this study. Previous studies on neighbourhood social cohesion that have uncovered inverse associations have been, for the most part, cross-sectional. A recent longitudinal study of Australian children found that neighbourhood parent-perceived social cohesion was inversely related to children's BMI [17]. This study was similar to the present study in that social cohesion was a perceived, not an objective measure, and the items included in the measure of social cohesion are closely related to those studied here. On the other hand, this study did not adjust for household or neighbourhood SES, or standardize BMI for age and sex. Another study conducted in Los Angeles (US) found that collective efficacy (measures both social cohesion and informal social control) was inversely related to excess weight (BMI, overweight, obesity) [16]. When comparing to the null results here, it is important to note that this study could not separate the effects of social cohesion and informal social control.

The results of the present study should be interpreted in light of some important limitations. Due to the study design, changes in area material and social deprivation could not be taken into account. Due to missing data, the final model was estimated using only $65 \%$ of the original cohort; therefore, bias cannot be ruled out as an explanation for findings here. Additionally, because the analysis did not use sample weights, the results are not necessarily generalizable to the Québec population. Mediation and moderation were also not explored. Moderation (interaction) is important to more adequately explain complexity, as the relationship between the local environment and child weight might depend on other contextual and compositional factors. Mediation is important to more clearly explain and test hypothesized causal pathways. Unfortunately, both add a large degree of modeling complexity; especially problematic in a longitudinal study. Finally, differences between the 
results seen here and those of other studies may be due to the fact that the local environment was not adequately captured via the variables available in the QLSCD.

Although there were some limitations to this study, there were also numerous strengths. The longitudinal, population-based design, spanning a large portion of early childhood, was a major strength. A plethora of developmental data was available in this cohort and allowed us to adjust for a number of important explanatory variables. Height and weight were directly measured by trained interviewers; mother-reported child anthropometric measures have been found to overestimate overweight and obesity, especially at younger ages [52].

The results here show that early life factors may be most important for explaining excess weight among young children. Longitudinal studies on local environment factors may not corroborate the findings of earlier cross-sectional studies, as may be the case here. And relationships may be different at certain life periods, perhaps due to exposure time. More high quality, longitudinal studies on the local environment and childhood obesity development are warranted; especially those that can examine changes from birth to late childhood/early adulthood. Examining the mother's local environment, in addition to behavioural factors, during the perinatal period may also be a fruitful area of obesity research.

Disclaimer: This analysis was based on the Institut de la Statistique du Québec QLSCD master files. All computations were prepared by MAC. The responsibility for the use and interpretation of these data is solely that of the authors. The opinions expressed in this paper are those of the authors and do not represent the views of the Institut de la Statistique du Québec.

\section{Reference List}

1. Wang Y, Lobstein T (2006) Worldwide trends in childhood overweight and obesity. Int J Pediatr Obes 1: 11-25.

2. Shields M, Tremblay MS (2010) Canadian childhood obesity estimates based on WHO, IOTF and CDC cut-points. Int J Pediatr Obes 5: 265-273. 10.3109/17477160903268282 [doi]. 
3. Wang Y, Beydoun MA (2007) The obesity epidemic in the United States--gender, age, socioeconomic, racial/ethnic, and geographic characteristics: a systematic review and meta-regression analysis. Epidemiol Rev 29: 6-28. mxm007 [pii];10.1093/epirev/mxm007 [doi].

4. Lobstein T, Baur L, Uauy R (2004) Obesity in children and young people: a crisis in public health. Obes Rev 5 Suppl 1: 4-104. 10.1111/j.1467-789X.2004.00133.x [doi];OBR133 [pii].

5. Reilly JJ, Kelly J (2011) Long-term impact of overweight and obesity in childhood and adolescence on morbidity and premature mortality in adulthood: systematic review. Int J Obes 35: 891-898. ijo2010222 [pii];10.1038/ijo.2010.222 [doi].

6. Olds T, Maher C, Zumin S, Peneau S, Lioret S, Castetbon K, Bellisle, de WJ, Hohepa M, Maddison R, Lissner L, Sjoberg A, Zimmermann M, Aeberli I, Ogden C, Flegal K, Summerbell C (2011) Evidence that the prevalence of childhood overweight is plateauing: data from nine countries. Int J Pediatr Obes . 10.3109/17477166.2011.605895 [doi].

7. Swinburn BA, Sacks G, Hall KD, McPherson K, Finegood DT, Moodie ML, Gortmaker SL (2011) The global obesity pandemic: shaped by global drivers and local environments. Lancet 378: 804-814. S0140-6736(11)60813-1 [pii];10.1016/S0140-6736(11)60813-1 [doi].

8. Bernard P, Charafeddine R, Frohlich KL, Daniel M, Kestens Y, Potvin L (2007) Health inequalities and place: a theoretical conception of neighbourhood. Social Science \& Medicine 65: 1839-1852. S0277-9536(07)00308-5 [pii];10.1016/j.socscimed.2007.05.037 [doi].

9. Carter MA, Dubois L (2010) Neighbourhoods and child adiposity: a critical appraisal of the literature. Health Place 16: 616-628. S1353-8292(09)00156-7 [pii];10.1016/j.healthplace.2009.12.012 [doi].

10. Burdette AM, Needham BL (2012) Neighborhood environment and body mass index trajectories from adolescence to adulthood. J Adolesc Health 50: 30-37. S1054139X(11)00097-8 [pii];10.1016/j.jadohealth.2011.03.009 [doi].

11. Slater SJ, Ewing R, Powell LM, Chaloupka FJ, Johnston LD, O'Malley PM (2010) The association between community physical activity settings and youth physical activity, obesity, and body mass index. J Adolesc Health 47: 496-503. S1054-139X(10)00173-4 [pii];10.1016/j.jadohealth.2010.03.017 [doi].

12. Pampalon R, Hamel D, Gamache P, Raymond G (2009) A deprivation index for health planning in Canada. Chronic Dis Can 29: 178-191.

13. Szreter S, Woolcock M (2004) Health by association? Social capital, social theory, and the political economy of public health. Int J Epidemiol 33: 650-667. 10.1093/ije/dyh013 [doi];dyh013 [pii].

14. Kawachi I., Subramanian SV., and Kim D. (2008) Social Capital \& Health. New York: Springer. 
15. Franzini L, Elliott MN, Cuccaro P, Schuster M, Gilliland MJ, Grunbaum JA, Franklin F, Tortolero SR (2009) Influences of physical and social neighborhood environments on children's physical activity and obesity. Am J Public Health 99: 271-278.

AJPH.2007.128702 [pii];10.2105/AJPH.2007.128702 [doi].

16. Cohen DA, Finch BK, Bower A, Sastry N (2006) Collective efficacy and obesity: the potential influence of social factors on health. Soc Sci Med 62: 769-778. S0277-9536(05)003199 [pii];10.1016/j.socscimed.2005.06.033 [doi].

17. Veitch J, van Stralen MM, Chinapaw MJ, Te Velde SJ, Crawford D, Salmon J, Timperio A (2012) The neighborhood social environment and body mass index among youth: a mediation analysis. Int J Behav Nutr Phys Act 9: 31. 1479-5868-9-31 [pii];10.1186/1479-5868-9-31 [doi].

18. Grafova IB (2008) Overweight children: assessing the contribution of the built environment. Prev Med 47: 304-308. S0091-7435(08)00213-2 [pii];10.1016/j.ypmed.2008.04.012 [doi].

19. Turcotte $\mathrm{M}$ (2008) Dependence on cars in urban neighbourhoods: Life in metropolitan areas. http://www.statcan.gc.ca/pub/11-008-x/2008001/article/10503-eng.htm\#7 Accessed: $4 / 4 / 12$

20. Bruner MW, Lawson J, Pickett W, Boyce W, Janssen I (2008) Rural Canadian adolescents are more likely to be obese compared with urban adolescents. Int J Pediatr Obes 3: 205211. 794217920 [pii];10.1080/17477160802158477 [doi].

21. Oliver LN, Hayes MV (2008) Effects of neighbourhood income on reported body mass index: an eight year longitudinal study of Canadian children. BMC Public Health 8: 16.

22. Liu J, Bennett KJ, Harun N, Probst JC (2008) Urban-rural differences in overweight status and physical inactivity among US children aged 10-17 years. J Rural Health 24: 407-415.

23. Lewis RD, Meyer MC, Lehman SC, Trowbridge FL, Bason JJ, Yurman KH, Yin Z (2006) Prevalence and degree of childhood and adolescent overweight in rural, urban, and suburban Georgia. J Sch Health 76: 126-132.

24. Verger P, Saliba B, Guagliardo V, Bouhnik AD, Eichenbaum-Voline S (2007) Individual social characteristics, municipal environment and the prevalence of weight problems in early childhood: a multilevel analysis. Rev Epidemiol Sante Publique 55: 347-356. S0398-7620(07)00235-0 [pii];10.1016/j.respe.2007.06.003 [doi].

25. Sandercock GR, Ogunleye A, Voss C (2011) Comparison of cardiorespiratory fitness and body mass index between rural and urban youth: findings from the East of England Healthy Hearts Study. Pediatr Int 53: 718-724. 10.1111/j.1442-200X.2011.03354.x [doi].

26. Nonnemaker JM, Morgan-Lopez AA, Pais JM, Finkelstein EA (2009) Youth BMI trajectories: evidence from the NLSY97. Obesity 17: 1274-1280. oby20095 [pii];10.1038/oby.2009.5 [doi]. 
27. Li C, Goran MI, Kaur H, Nollen N, Ahluwalia JS (2007) Developmental trajectories of overweight during childhood: role of early life factors. Obesity 15: 760-771. 15/3/760 [pii];10.1038/oby.2007.585 [doi].

28. Ventura AK, Loken E, Birch LL (2009) Developmental trajectories of girls' BMI across childhood and adolescence. Obesity 17: 2067-2074. oby2009123 [pii];10.1038/oby.2009.123 [doi].

29. Institut de la statistique du Québec (2001) Concepts, Definitions and Operational Aspects: 5 month old enfants. Québec Longitudinal Study of Child Development (QLSCD 19982002). Québec: Institut de la Statistique du Québec. Available:

http://www.iamillbe.stat.gouv.qc.ca/bebe/bebe_n12_pdf_an.htm Accessed: 10/15/10

30. Ogden CL (2004) Defining overweight in children using growth charts. Md Med 5: 19-21.

31. Desrosiers H., Dumitru V., Dubois L. (2009) Excess Weight in Children 4 to 7 Years of Age Targeting Risk Factors for Intervention. Montreal, Canada: Statistical Institute of Québec. Available:

http://www.iamillbe.stat.gouv.qc.ca/pdf/publications/feuillet/Fasc3Vol4_an.pdf Accessed: 3/3/11

32. Institut de la statistique du Québec (2009) Variables dérivées de l'ÉLDEQ 1998-2008: Partie A. http://www.jesuisjeserai.stat.gouv.qc.ca/pdf/doc_tech/E1aE11Variables_Derivees1101 .pdf Accessed: 10/15/10

33. Desrosiers H. (2000) Family, Child Care and Neighbourhood Characteristic: Québec Longitudinal Study of Child Development (ÉLDEQ 1998-2002). Québec: Institut de la statistique du Québec. Available:

http://www.iamillbe.stat.gouv.qc.ca/bebe/pdf/baby_no2-1.pdf Accessed: 3/2/11

34. Curtis LJ, Dooley MD, Phipps SA (2004) Child well-being and neighbourhood quality: evidence from the Canadian National Longitudinal Survey of Children and Youth. Social Science \& Medicine 58: 1917-1927. 10.1016/j.socscimed.2003.08.007 [doi];S0277953603004246 [pii].

35. Pampalon R, Philibert M, Hamel D (2004) Développement d'un système d'évaluation de la défavorisation des communautés locales et des clientèles de CLSC. Montréal, Québec: Institut national de santé publique du Québec. Available: http://www.inspq.qc.ca/pdf/publications/279_DefavorisationClientelesCLSC.pdf Accessed: 9/2/10

36. Pampalon R, Raymond G (2000) A deprivation index for health and welfare planning in Quebec. Chronic Diseases in Canada 21: 104-113.

37. Lebel A, Pampalon R, Hamel D, Theriault M (2009) The geography of overweight in Quebec: a multilevel perspective. Canadian Journal of Public Health 100: 18-23.

38. Pampalon R, Hamel D, Raymond G (2004) Indice de défavorisation pour l'étude de la santé et du bien-être au Québec - Mise à jour 2001. 
http://www.inspq.qc.ca/pdf/publications/295-IndiceDefavorisation_2001.pdf Accessed: $12 / 4 / 12$

39. Nagin DS (1999) Analyzing developmental trajectories: Semi-parametric, group-based approach. Psychological Methods 4: 139-157.

40. Jones BL, Nagin D, Roeder K (2001) A SAS procedure based on mixture models for estimating developmental trajectories. Sociological Methods Research 29: 374-393.

41. Jones BL, Nagin DS (2007) Advances in Group-based trajectory modeling and an SAS procedure for estimating them. Sociological Methods Research 35: 542-571.

42. Nagin DS, Odgers CL (2010) Group-based trajectory modeling in clinical research. Annu Rev Clin Psychol 6: 109-138. 10.1146/annurev.clinpsy.121208.131413 [doi].

43. Nagin DS (2005) Group-Based Modeling of Development. Cambridge, Massachusetts: Harvard University Press.

44. Ogden CL, Flegal KM (2010) Changes in terminology for childhood overweight and obesity. Natl Health Stat Report 1-5.

45. Hejazi S, Dahinten S, Ratner PA, Marshall SK (2011) Developmental trajectories of weight status in childhood and adolescence. In: Bagchi D, editors. Global Perspectives on Childhood Obesity. Academic Press. pp. 21-29.

46. National Center for Health Statistics (2002) 2000 CDC Growth Charts for the United States: Methods and Development. Vital \& Health Statistics 11.

47. Must A, Anderson SE (2006) Body mass index in children and adolescents: considerations for population-based applications. Int J Obes 30: 590-594. 0803300 [pii];10.1038/sj.ijo.0803300 [doi].

48. Pryor LE, Tremblay RE, Boivin M, Touchette E, Dubois L, Genolini C, Liu X, Falissard B, Cote SM (2011) Developmental trajectories of body mass index in early childhood and their risk factors: an 8-year longitudinal study. Arch Pediatr Adolesc Med 165: 906912. 165/10/906 [pii];10.1001/archpediatrics.2011.153 [doi].

49. Dubois L, Girad M (2007) Accuracy of maternal reports of pre-schoolers' weights and heights as estimates of BMI values. Int J Epidemiol 36: 132-138. 36/1/132 [pii];10.1093/ije/dyl281 [doi].

50. Williams PT (2011) Evidence that obesity risk factor potencies are weight dependent, a phenomenon that may explain accelerated weight gain in western societies. PLoS One 6: e27657. 10.1371/journal.pone.0027657 [doi];PONE-D-11-14658 [pii].

51. Mendelson R, Lefebvre J (2003) Reviewing census metropolitan areas (CMA) and census agglomerations (CA) in Canada according to metropolitan functionality. http://www.statcan.gc.ca/pub/92f0138m/92f0138m2003001-eng.pdf Accessed: 2/2/11

52. Shields M (2005) Measured obesity: Overweight Canadian children and adolescents.Nutrition: Findings from the Canadian Community Health Survey. Ottawa: Statistics Canada. 
Available: http://www.statcan.gc.ca/pub/82-620-m/2005001/pdf/4193660-eng.pdf Accessed: 10/15/10

Table 1. Definitions of explanatory variables

\begin{tabular}{|c|c|c|}
\hline Variable & Definition & $\begin{array}{l}\text { Timing of data collection } \\
\text { (age of child) }\end{array}$ \\
\hline \multicolumn{3}{|l|}{ Individual-level } \\
\hline Male sex & Yes/no & 5 months \\
\hline Overeating phenotype & $\begin{array}{l}\text { 'Often' eats too much and/or 'sometimes' or 'often' eats too } \\
\text { fast }\end{array}$ & 4 years \\
\hline Breast-fed exclusively $\geq 3$ months & Yes/no & 5 months \\
\hline Mother smoked during pregnancy & Yes/no & 5 months \\
\hline Mother's obesity status (WHO) & $\mathrm{BMI} \geq 30$ based on self-reported height and weight & 1.5 years \\
\hline High birth weight & $>4 \mathrm{~kg}$ vs $\leq 4 \mathrm{~kg}$ & 5 months \\
\hline Rapid weight gain $0-5$ months & $\begin{array}{l}\text { Highest two quintiles of average monthly weight gain from } 0 \text { to } \\
5 \text { months }\end{array}$ & 5 months \\
\hline \multicolumn{3}{|l|}{ Family/household } \\
\hline Low socioeconomic status (SES) ${ }^{\text {bc }}$ & Lowest third of SES indicator versus middle and upper tertiles & Time-dep \\
\hline Single parent family & Yes/no & Time-dep \\
\hline $\begin{array}{l}\text { Mother is an immigrant } \\
\text { Local environment }\end{array}$ & Local environment & 5 months \\
\hline Living location ${ }^{b}$ & $\begin{array}{l}\text { Categorical (Urban: Census Metropolitan Area with } \geq 100,000 \\
\text { inhabitants; Semi-urban: Census Agglomerations with 10,000 to } \\
<100,000 \text { inhabitants; and Rural: Rural or Small Towns with }< \\
10,000 \text { inhabitants) }\end{array}$ & Time-dep \\
\hline High social cohesion $^{d}$ & Scale score in the bottom $50 \%$ & Time-dep \\
\hline High disorder $^{d}$ & Scale score $<3$ & Time-dep \\
\hline Materially deprived & Two highest factorial score quintiles (4 and 5) & 5 months \\
\hline Socially deprived & Two highest factorial score quintiles (4 and 5) & 5 months \\
\hline
\end{tabular}


Table 2. Mean BMI and BMI Z-score by age and weight trajectory group $(\mathrm{N}=1566)$

\begin{tabular}{|c|c|c|c|c|c|c|c|c|c|}
\hline \multirow[b]{3}{*}{ Variable } & \multicolumn{8}{|c|}{ GROUPS } & \multirow{3}{*}{$\begin{array}{c}\text { Total } \\
\mathbf{N}\end{array}$} \\
\hline & \multicolumn{2}{|c|}{ 1. Low, increasing } & \multicolumn{2}{|c|}{$\begin{array}{l}\text { 2. Low-medium, } \\
\text { accelerating }\end{array}$} & \multicolumn{2}{|c|}{$\begin{array}{l}\text { 3. Medium-high, } \\
\text { increasing }\end{array}$} & \multicolumn{2}{|c|}{ 4. High-stable } & \\
\hline & Mean (SD) & $\mathbf{N}$ & Mean (SD) & $\mathbf{N}$ & Mean (SD) & $\mathbf{N}$ & Mean (SD) & $\mathbf{N}$ & \\
\hline BMI Z-score 4 y & $-1.90(0.88)$ & 118 & $-0.50(0.78)$ & 489 & $0.53(0.79)$ & 581 & $1.73(0.71)$ & 134 & 1322 \\
\hline BMI 4 y & $13.7(0.71)$ & & $15.0(0.84)$ & & $16.2(1.11)$ & & $18.4(1.85)$ & & \\
\hline BMI Z-score 6 y & $-1.86(1.00)$ & 102 & $-0.55(0.72)$ & 407 & $0.52(0.60)$ & 497 & $1.73(0.55)$ & 116 & 1122 \\
\hline BMI $6 y$ & $13.5(0.84)$ & & $14.7(0.87)$ & & $16.2(1.06)$ & & $19.4(2.20)$ & & \\
\hline BMI Z-score 7 y & $-1.67(0.93)$ & 133 & $-0.57(0.68)$ & 540 & $0.52(0.56)$ & 627 & $1.73(0.52)$ & 149 & 1449 \\
\hline BMI $7 \mathrm{y}$ & $13.7(0.83)$ & & $14.8(0.88)$ & & $16.5(1.14)$ & & $20.5(2.86)$ & & \\
\hline BMI Z-score 8 y & $-1.65(0.91)$ & 126 & $-0.40(0.64)$ & 477 & $0.66(0.54)$ & 566 & $1.83(0.39)$ & 135 & 1304 \\
\hline BMI 8 y & $13.8(0.87)$ & & $15.3(0.99)$ & & $17.4(1.40)$ & & $21.9(2.65)$ & & \\
\hline BMI Z-score 10 y & $-1.15(0.64)$ & 116 & $-0.18(0.63)$ & 471 & $0.77(0.61)$ & 532 & $1.77(0.46)$ & 134 & 1253 \\
\hline BMI $10 y$ & $14.9(0.95)$ & & $16.6(1.41)$ & & $19.2(2.2)$ & & $24.3(3.3)$ & & \\
\hline
\end{tabular}

Table 3. Characteristics of QLSCD children by weight trajectory group (Total $N=1566$ )

\begin{tabular}{|c|c|c|c|c|c|c|}
\hline \multicolumn{7}{|c|}{ GROUPS } \\
\hline & $\begin{array}{l}\text { 1. Low, } \\
\text { increasing }\end{array}$ & $\begin{array}{l}\text { 2. Low-medium, } \\
\text { accelerating }\end{array}$ & $\begin{array}{l}\text { 3. Medium-high, } \\
\text { increasing }\end{array}$ & 4. High-stable & Total & Missing $\mathbf{N}$ \\
\hline \multicolumn{7}{|l|}{ Social factors } \\
\hline $\begin{array}{l}\text { Male } \\
\text { SES }^{\text {b }}\end{array}$ & $54.6(78)$ & $46.9(272)$ & 46.9 (319) & $50.3(82)$ & 48.0 & 0 \\
\hline Low & $28.5(39)$ & $31.2(177)$ & $31.0(208)$ & $46.9(75)$ & 32.5 & 30 \\
\hline Middle & $35.8(49)$ & $34.3(195)$ & $34.3(230)$ & $28.8(46)$ & 33.9 & \\
\hline High & $35.8(49)$ & 34.5 (196) & $34.7(233)$ & $24.4(39)$ & 33.7 & \\
\hline Single parent family ${ }^{b}$ & $12.1(17)$ & $12.9(73)$ & $13.0(87)$ & $16.2(26)$ & 13.2 & 27 \\
\hline Mother is an immigrant & $7.7(11)$ & $7.2(42)$ & $9.3(63)$ & $9.2(15)$ & 8.4 & 1 \\
\hline \multicolumn{7}{|l|}{ Selected early life factors } \\
\hline Child overeats & $17.0(24)$ & $16.0(91)$ & $22.3(150)$ & $54.7(88)$ & 22.9 & 23 \\
\hline $\begin{array}{l}\text { Mother smoked during } \\
\text { pregnancy }\end{array}$ & $26.2(37)$ & 24.9 (144) & $23.2(157)$ & $36.4(59)$ & 25.5 & 8 \\
\hline $\begin{array}{l}\text { Exclusively breast-fed } \geq 3 \\
\text { months }\end{array}$ & $24.5(35)$ & $25.0(145)$ & $27.4(186)$ & $23.9(39)$ & 25.9 & 0 \\
\hline $\begin{array}{l}\text { Rapid weight gain in } \\
\text { infancy }\end{array}$ & $31.9(45)$ & 34.6 (197) & $41.1(274)$ & $46.5(74)$ & 38.4 & 31 \\
\hline \multicolumn{7}{|l|}{ Local environment } \\
\hline Rural & $25.6(35)$ & $25.3(143)$ & $19.8(132)$ & $26.1(42)$ & 23.0 & 34 \\
\hline Semi-urban & $6.6(9)$ & $12.9(73)$ & $13.2(88)$ & $10.6(17)$ & 12.2 & \\
\hline Urban & $67.9(93)$ & $61.8(350)$ & $67.1(448)$ & $63.4(102)$ & 64.8 & \\
\hline High social cohesion ${ }^{b}$ & $50.4(70)$ & $49.7(274)$ & $45.8(293)$ & $49.4(76)$ & 48.1 & 82 \\
\hline High disorder ${ }^{b}$ & $24.1(34)$ & $25.0(141)$ & $27.5(184)$ & $23.8(38)$ & 25.9 & 32 \\
\hline Materially deprived & $31.9(43)$ & 38.4 (209) & $38.3(245)$ & $43.5(67)$ & 38.3 & 93 \\
\hline Socially deprived & $31.1(42)$ & 34.7 (189) & $39.3(251)$ & $42.2(65)$ & 37.1 & 93 \\
\hline
\end{tabular}

${ }^{a}$ Values are percentages $(n)$

${ }^{\mathrm{b}}$ Values presented are those measured at baseline (when children were approximately $4 \mathrm{y}$ of age) 
Table 4. Results of unadjusted and multivariable group-based trajectory models estimating the relationship between timestable explanatory variables and probability of group membership, and change in average group BMI Z-score as a function of time-dependent explanatory variables (QLSCD children from 4 - 10 y of age)

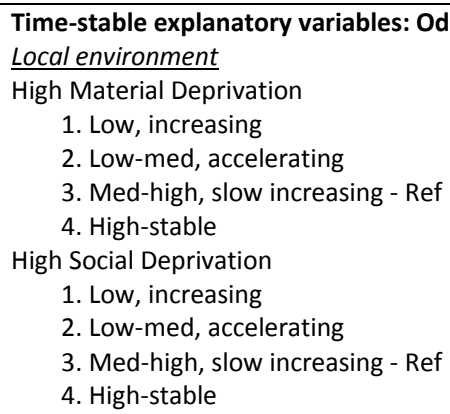
Unadjusted Model $1(n=1472)^{a}$ Model 2 ( $n=1385)$

Social factors

Male sex

1. Low, increasing

2. Low-med, accelerating

3. Med-high, slow increasing - Ref

4. High-stable

Mother is an immigrant

1. Low, increasing

2. Low-med, accelerating

3. Med-high, slow increasing - Ref

4. High-stable

$0.79(0.52,1.21)$

$0.95(0.71,1.26)$

$1.30(0.86,1.96)$

$0.70(0.46,1.07)$

$0.78(0.58,1.04)$

$1.07(0.71,1.62)$

$1.32(0.89,1.94)$

$0.97(0.74,1.28)$

$-$

$1.14(0.77,1.69)$

$0.87(0.44,1.73)$

$0.63(0.36,1.07)$

$1.12(0.58,2.15)$

$0.74(0.44,1.23)$

$0.63(0.44,0.90)^{*}$

$5.07(3.32,7.75)^{* * *}$

$1.44(0.92,2.24)$

$1.16(0.84,1.61)$

$2.31(1.52,3.50)^{* * *}$

$0.18(0.05,0.62)^{* *}$

$0.41(0.24,0.70)^{* *}$

$2.25(1.39,3.63)^{* *}$

$0.77(0.49,1.22)$

$0.82(0.61,1.11)$

$0.75(0.48,1.19)$

$0.70(0.46,1.05)$

$0.73(0.55,0.97)$ *

$1.27(0.85,1.88)$

$0.22(0.08,0.63)^{* *}$

$0.52(0.33,0.81)^{* *}$

$1.04(0.59,1.86)$

$\begin{array}{cc}0.66(0.41,1.06) & 0.64(0.39,1.06) \\ 0.91(0.66,1.24) & 0.92(0.67,1.28) \\ - & - \\ 1.09(0.71,1.67) & 0.91(0.57,1.45) \\ - & - \\ 0.75(0.47,1.18) & 0.69(0.43,1.12) \\ 0.75(0.55,1.02) & 0.72(0.53,0.99)^{*} \\ - & - \\ 1.03(0.67,1.57) & 0.91(0.57,1.44)\end{array}$

$1.03(0.67,1.57)$

$0.91(0.57,1.44)$

$1.30(0.86,1.97)$

$1.01(0.75,1.36)$

$-$

$1.14(0.76,1.73)$

$0.87(0.39,1.92)$

$0.82(0.46,1.46)$

$1.04(0.48,2.25)$

$1.62(1.04,2.53) *$

$1.24(0.91,1.68)$

-

$1.14(0.72,1.80)$

$0.53(0.20,1.42)$

$0.82(0.45,1.48)$

$0.81(0.31,2.07)$

$0.94(0.53,1.68)$

$0.76(0.51,1.14)$

$5.09(3.18,8.15)^{* * *}$

$1.39(0.83,2.34)$

$1.05(0.73,1.53)$

$-$

$2.51(1.53,4.12)^{* *}$

$0.26(0.09,0.79) *$

$0.28(0.15,0.53)^{* * *}$

$2.45(1.39,4.29)^{* *}$

$0.79(0.47,1.32)$

$0.82(0.58,1.15)$

$1.12(0.66,1.91)$

$0.46(0.29,0.75)^{* *}$

$0.63(0.45,0.87)^{* *}$

$1.35(0.83,2.19)$

$0.21(0.07,0.63)^{* *}$

$0.49(0.29,0.81)^{* *}$

$1.07(0.53,2.15)$

4. High-stable

Time-dependent explanatory variables: Linear regression parameter (SE)

Local environment

Living location (Rural)

1. Low, increasing

2. Low-med, accelerating

$-0.149(0.093)$

$0.023(0.058)$

$0.079(0.060)$

$0.274(0.086)^{* *}$
$-0.187(0.123)$

$0.026(0.083)$

$0.054(0.072)$

$0.257(0.097)^{* *}$
$-0.215(0.120)$

$-0.028(0.073)$

$-0.011(0.059)$

0.208 (0.089)* 
1. Low, increasing

2. Low-med, accelerating

3. Med-high, slow increasing

4. High-stable

High social cohesion

1. Low, increasing

2. Low-med, accelerating

3. Med-high, slow increasing

4. High-stable

High disorder

1. Low, increasing

2. Low-med, accelerating

3. Med-high, slow increasing

4. High-stable

Social Factors

Single-parent family

1. Low, increasing

2. Low-med, accelerating

3. Med-high, slow increasing

4. High-stable

Low SES

1. Low, increasing

2. Low-med, accelerating

3. Med-high, slow increasing

4. High-stable

\begin{abstract}
$-0.421(0.158)^{* *}$
$0.0480(0.065)$

$-0.148(0.057)^{* *}$

0.034 (0.098)
\end{abstract}

$0.114(0.07)$

$0.020(0.037)$

$-0.020(0.033)$

$-0.100(0.062)$

$-0.171(0.081)^{*}$

$-0.073(0.041)$

$0.017(0.036)$

$0.045(0.07)$

$-0.046(0.098)$

$-0.028(0.054)$

$0.137(0.048)^{* *}$

$0.177(0.088) *$

$-0.207(0.079)^{* *}$

$-0.102(0.045)^{*}$

0.007 (0.039)

$0.138(0.066)^{*}$

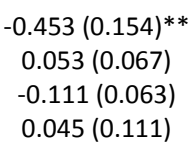

$-0.453(0.154)^{* *}$

$0.053(0.067)$

$-0.111(0.063)$

$0.045(0.111)$

$0.160(0.076)$ *

-0.015 (0.039)

$-0.021(0.036)$

$-0.064(0.066)$

$-0.175(0.086) *$

$-0.060(0.043)$

$0.015(0.040)$

0.027 (0.074)

$0.051(0.106)$

$0.039(0.061)$

$0.133(0.053)^{*}$

$0.138(0.107)$

$-0.129(0.094)$

$-0.109(0.051)^{*}$

$-0.025(0.045)$

0.055 (0.079)
$-0.541(0.161)^{* *}$

0.0415 (0.068)

$-0.134(0.059)^{*}$

$-0.008(0.107)$

$0.126(0.082)$

$-0.005(0.040)$

$-0.015(0.036)$

$-0.046(0.067)$

$-0.176(0.088)^{*}$

$-0.071(0.044)$

$0.025(0.040)$

$0.0108(0.075)$

$0.009(0.114)$

$0.017(0.062)$

$0.094(0.055)$

$0.116(0.100)$

$-0.179(0.093)$

$-0.106(0.052)^{*}$

$-0.064(0.043)$

-0.001 (0.079)

${ }^{a}$ Place factors plus social factors, model includes both time-stable (risk factors) and time-dependent explanatory variables

${ }^{b}$ Model 1, plus adjustment for early life factors; model includes both time-stable (risk factors) and time-dependent explanatory variables

${ }^{c}$ Odds ratios and $95 \%$ confidence intervals from multinomial logistic regression, reference group is the medium-high slow increasing group

${ }^{d}$ Parameters represent the average increase/decrease in BMI Z-score per year within each trajectory group based on a polynomial link function

${ }^{\mathrm{e}}$ Reference group is Urban

* $P \leq 0.05,{ }^{* *} P \leq 0.01 * * * P \leq 0.0001 ; \mathrm{Cl}=$ confidence interval; $\mathrm{SE}=$ standard error 


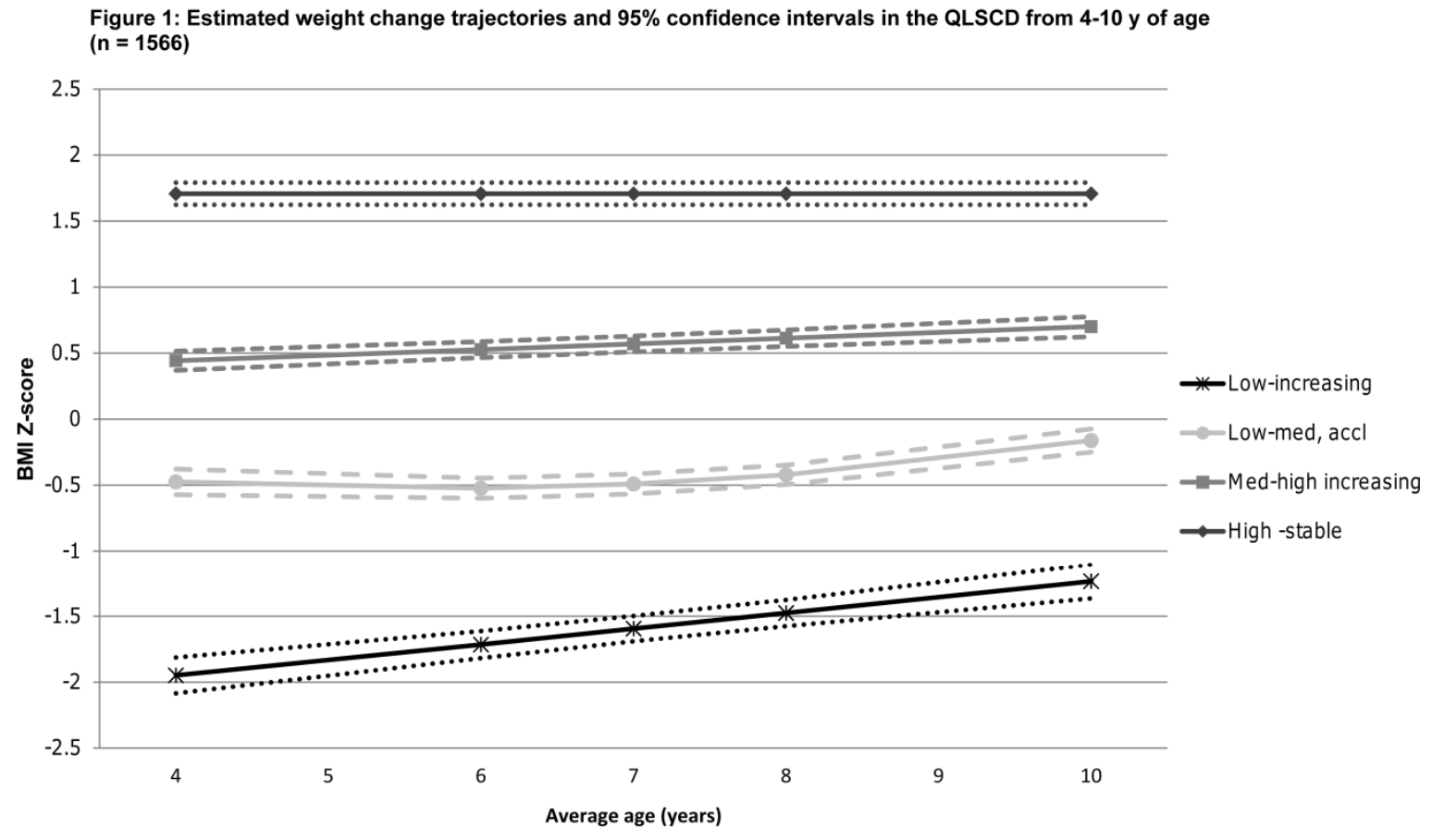

\begin{tabular}{|c|c|c|c|c|}
\hline \multicolumn{5}{|c|}{ Trajectory parameters (Standard error) ${ }^{a}$} \\
\hline & 1. Low, increasing & $\begin{array}{l}\text { 2. Low-medium, } \\
\text { accelerating }\end{array}$ & 3. Medium-high, increasing & 4. High-stable \\
\hline Intercept ${ }^{b}$ & $-1.61(0.05)$ & $-0.498(0.039)$ & $0.565(0.030)$ & $1.71(0.043)$ \\
\hline Age $^{c}$ & $0.119(0.015)$ & $0.047(0.009)$ & $0.043(0.008)$ & \\
\hline $\mathrm{Age}^{2 \mathrm{~d}}$ & & $0.019(0.004)$ & & \\
\hline$\%$ of sample (estimated) & 9.7 & 36.2 & 43.0 & 11.1 \\
\hline
\end{tabular}


1. Low -increasing

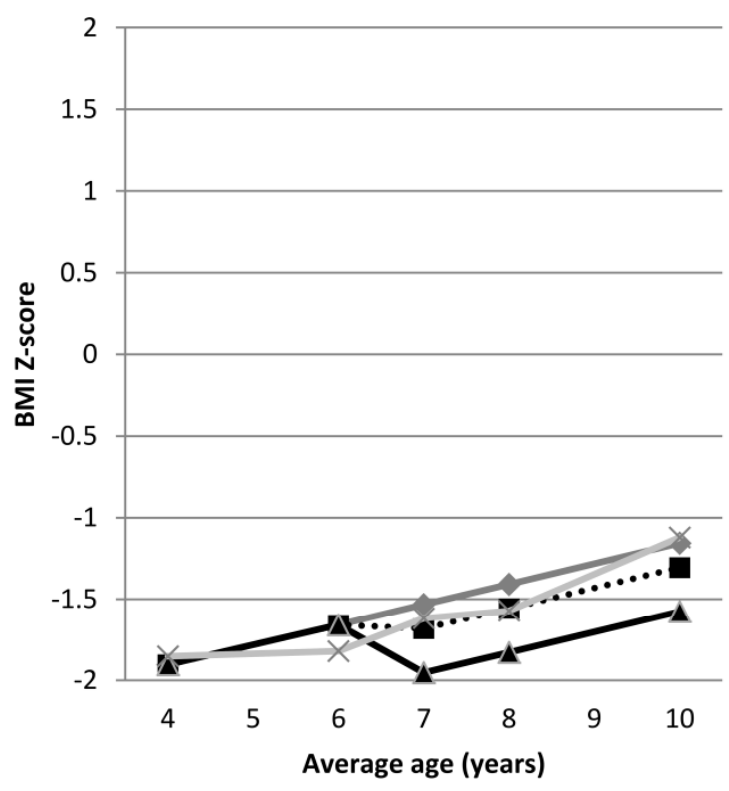

3. Medium-high, increasing

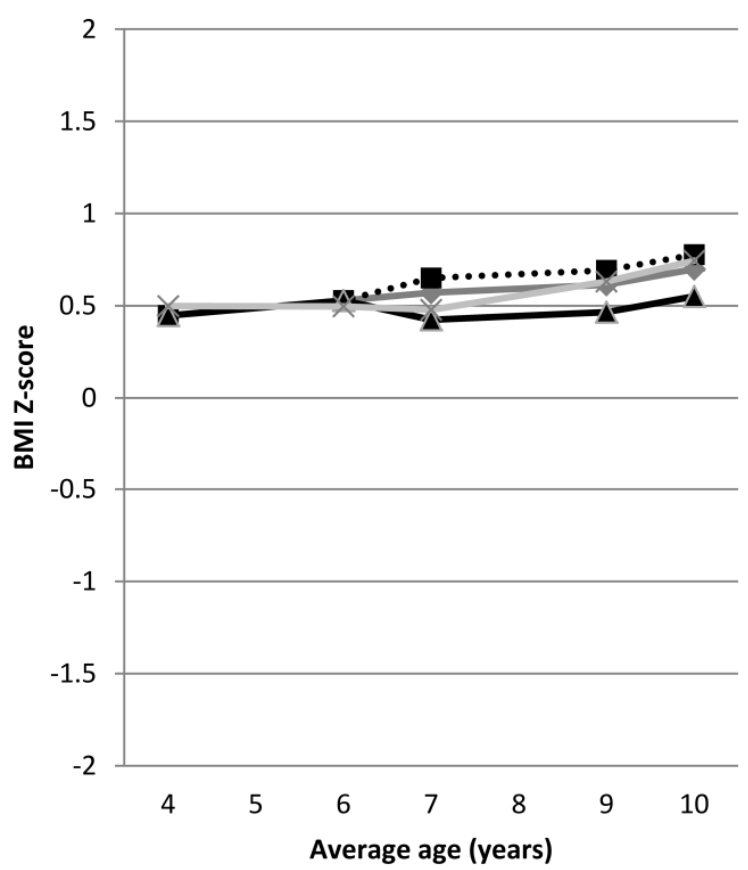

$\rightarrow$ Always urban

...… Change to rural
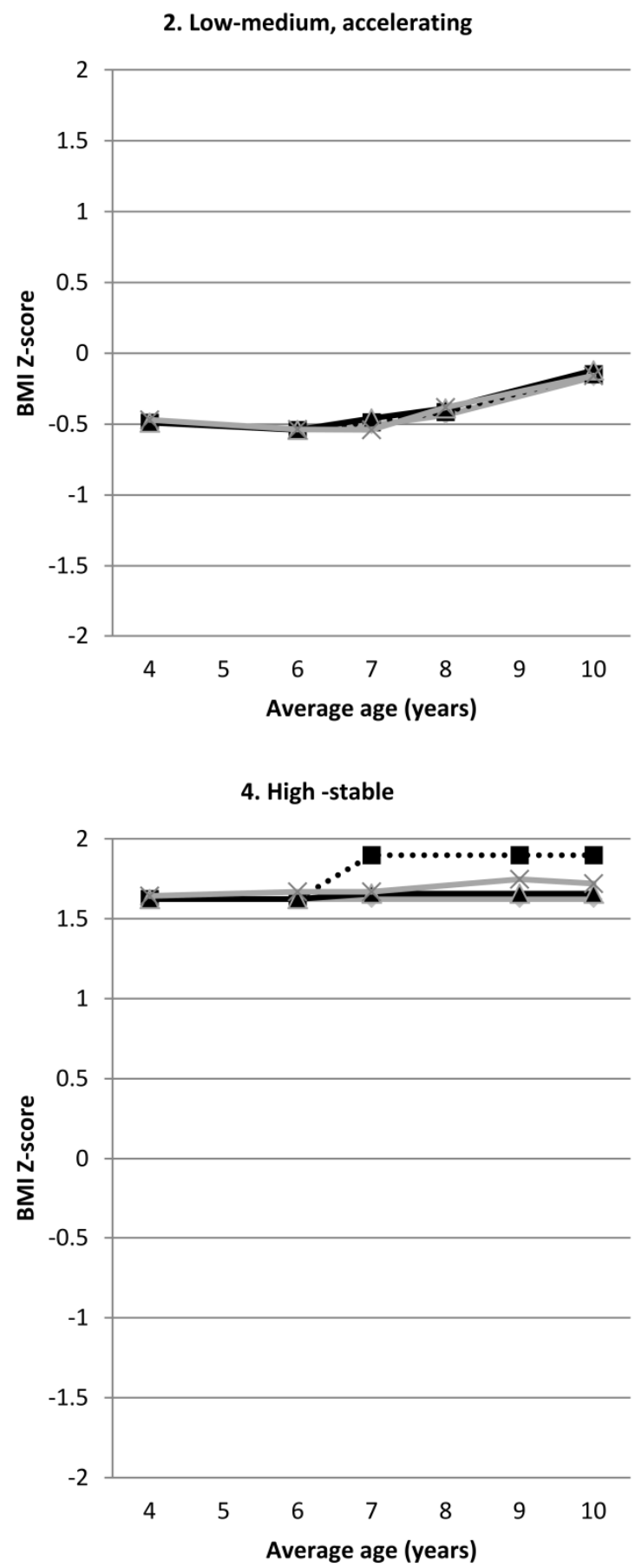

Figure 2. Example of time-varying local environment associations: effect of change in living location between 6-7 years of age on trajectory group shape (unadjusted) 
Appendix A: Neighbourhood Social Scale Items

\begin{tabular}{|c|c|}
\hline Scale & Response Categories \\
\hline \multicolumn{2}{|l|}{$\begin{array}{l}\text { Social cohesion } \\
\text { Please tell me whether you strongly agree, agree, disagree, or strongly disagree } \\
\text { about the following statement... }\end{array}$} \\
\hline $\begin{array}{l}\text { 6. If there is a problem around here, the neighbours get together to deal with it } \\
\text { 7. There are adults in the neighbourhood that children can look up to } \\
\text { 8. People around here are willing to help their neighbours } \\
\text { 9. You can count on adults in this neighbourhood to watch out that children are } \\
\text { 10. When I'm away from home, I know that my neighbours will keep their eyes } \\
\text { open for possible trouble }\end{array}$ & $\begin{array}{l}\text { STRONGLY AGREE }=1 \\
\text { AGREE }=2 \\
\text { DISAGREE }=3 \\
\text { STRONGLY DISAGREE }=4\end{array}$ \\
\hline \multicolumn{2}{|l|}{$\begin{array}{l}\text { Disorder } \\
\text { How much of a problem is the following in this neighbourhood:... }\end{array}$} \\
\hline $\begin{array}{l}\text { 5. Litter, broken glass or garbage? } \\
\text { 6. Selling or using drugs? } \\
\text { 7. Alcoholics and excessive drinking in public? } \\
\text { 8. Groups of young people who cause trouble? }\end{array}$ & $\begin{array}{l}\text { A BIG PROBLEM = } 1 \\
\text { SOMEWHAT OF A PROBLEM }=2 \\
\text { NO PROBLEM }=3\end{array}$ \\
\hline
\end{tabular}

\begin{tabular}{|c|c|c|c|c|c|}
\hline \multicolumn{6}{|c|}{ Appendix B: Fit statistics for the trajectory groups estimated in the QLSCD } \\
\hline GROUP & Frequency & Actual Percent & $\begin{array}{l}\text { Estimated } \\
\text { Percent }\end{array}$ & $\begin{array}{l}\text { Average } \\
\text { Posterior } \\
\text { probability }\end{array}$ & $\begin{array}{l}\text { Odds of } \\
\text { correct } \\
\text { classification }\end{array}$ \\
\hline 1. Low-increasing & 143 & 9.1 & 9.7 & 0.91 & 94.3 \\
\hline 2. Low-medium, accelerating & 580 & 37 & 36.2 & 0.86 & 10.8 \\
\hline 3. Medium- high, increasing & 680 & 43.4 & 43.0 & 0.88 & 9.7 \\
\hline 4. High-stable & 163 & 10.4 & 11.1 & 0.90 & 72.0 \\
\hline
\end{tabular}




\subsection{Local social environmental factors are associated with household food insecurity in a longitudinal study of children - Manuscript 5}

Authors: Megan Ann Carter ${ }^{\mathrm{a}}$, Lise Dubois ${ }^{\mathrm{a}, \mathrm{b}}$, Mark S. Tremblay ${ }^{\mathrm{c}}$, Monica Taljaard ${ }^{\mathrm{b}, \mathrm{d}}$

1. Institute of Population Health, University of Ottawa

2. Department of Epidemiology and Community Medicine, University of Ottawa

3. Healthy Active Living and Obesity Research, Children's Hospital of Eastern Ontario Research Institute

4. Ottawa Hospital Research Institute, Clinical Epidemiology Program

This manuscript was written in accordance to the specifications for submission to the peer-reviewed, open access journal BMC Public Health. It has been accepted and appears here in its uncorrected format.

Suggested citation:

Carter MA, Dubois L, Tremblay MS, Taljaard M. Local social environmental factors are associated with household food insecurity in a longitudinal study of children. BMC

Public Health. 2012 


\section{Abstract}

Background: Food insecurity is a significant public health problem in North America and elsewhere. It is linked to country of residence as well as household socioeconomic status. The local environment may also play a role in food insecurity; specifically in increasing or decreasing the availability and/or accessibility of food. The purpose of this study was to determine if time-dependent measures of social cohesion, disorder, and living location were associated with changes in the odds of household food insecurity, while also adjusting for area material and social deprivation.

Methods: Data from the Québec Longitudinal Survey of Child Development, following same-aged children from 4-10 y of age, were used along with generalized estimating equations, to determine the longitudinal association between these place factors and food insecurity.

Results: Of the 2120 children originally included in the cohort, $1746(82 \%)$ were included in the present analysis. The prevalence of food insecurity was $9.2 \%$ when children were $4 \mathrm{y}$ of age $(95 \%$ CI: $7.8-10.6 \%)$ and decreased slightly over time. In the multivariable model, no variable was associated with a change in the odds of food insecurity over time. However, on average over the 6 y period, three adverse local factors were positively related to food insecurity: high social deprivation increased the odds of food insecurity by $62 \%(95 \% \mathrm{CI}$ : $1.16-2.26)$, low social cohesion increased the odds by $45 \%$ (95\%CI: $1.10-1.92)$, and high disorder increased the odds by $76 \%(95 \% \mathrm{CI}: 1.37-2.27)$. This was independent of other factors like household socioeconomic status.

Conclusion: These results highlight the potential role of the local social environment in preventing and ameliorating food insecurity. Stakeholders providing food security interventions at the community level should consider interactions with local social characteristics and perhaps changing the social environment itself. Rigorous evaluation with household food insecurity as the outcome should be a goal of future intervention research.

\section{Keywords}

Food insecurity, social capital, social cohesion, disorder, deprivation, neighbourhood, longitudinal study, environment, context 


\section{Background}

In high income, developed countries, health problems associated with positive caloric balance are common. What is less well known is that a portion of residents in these countries do not reap the benefits of prosperity; these people do not always get enough to eat because they cannot afford it. In 2007-2008, almost one million (7.7\%) Canadian households were food insecure [1]. This is in contrast to the US, where 14.5\% of American households in 2010 were food insecure [2].

Food insecurity exists when there is limited or uncertain access to nutritionally adequate and safe foods or limited or uncertain ability to acquire acceptable foods in socially acceptable ways [3]. It is linked to lack of financial resources and is composed of several dimensions, including the quality and quantity of foods, anxiety about having enough to eat, and negative impact on social interactions [4].

Aside from being ethically unacceptable, the occurrence of food insecurity in developed countries has been linked to a number of health conditions, such as developmental problems in children $[5,6]$, and depression among adults $[7,8]$. Other health correlates include obesity [9], cardiovascular disease risk factors [10], and delaying health care [11].

Food insecurity is strongly related to household income level [12-14], although not all households living in poverty are food insecure [14]. Children may be especially vulnerable as the prevalence of food insecurity tends to be higher in households with children compared to households without children [1,2]. Other individual-level characteristics found to relate to food insecurity after adjustment for income level include single-parent families headed by a female, minority-status [15], and smoking status of household members [16].

Individual-level attributes, however, do not tell the whole story. It is also wellknown that macro socio-political factors play a key role in the existence of food insecurity. For instance, at a global level, the degree of human development of countries is tightly linked to food insecurity, hunger, and undernourishment [17]. Active public policies to decrease poverty are seen as major ways to ensure food security for all $[13,15]$; thus, even among developed countries, the prevalence of food insecurity varies [18]. One study has 
even found that state-level characteristics in the US, such as low average wages, high rental housing costs, and residential instability, were significantly related to food insecurity [19].

Consistent with a social-ecological theory of health that considers multiple levels of influence, it is less clear whether more local levels of social organization could influence the food security status of local residents. Characteristics of the community food system such as food stores, food environments in schools and workplaces, and local policies, coupled with individual and collective social factors, may affect food availability and accessibility for households living in a particular area [20]. Understanding how these factors relate to food insecurity could inform approaches to sustainable food system reforms that could combat this public health concern.

Of interest in this study are the local residential factors: material disadvantage, social capital, disorder, and living location, which capture aspects of the physical and social environments of places. The following paragraphs describe how these may be relevant for promoting or preventing individual or household food insecurity.

Disadvantaged areas may have fewer healthy food services and resources, such as supermarkets or large grocery stores, compared to more affluent areas. The existence of these areas, often called food deserts, has been documented in the US, but is more controversial in other developed countries [21]. Even if disparities in food access do not exist, food stores available in disadvantaged areas may sell foods of lower quality [22], prices may be higher or lower depending on the type of food store and type of food, and discount shops or convenience stores selling unhealthy foods may be more accessible in more deprived areas $[23,24]$.

In place-based research, social capital is thought of as a group-level attribute, but does not have a consistent definition [25]. In broad terms it identifies the richness of social connections, trust, shared norms, and reciprocity among residents living within an area [26]. High social capital may allow residents to obtain food from neighbours or other institutions more easily in times of need, and mobilize for collective action to address food insecurity issues. Additionally, neighbourhood disorder, sometimes resulting from a break-down in the social structure of the area, may dissuade food service establishments, and other institutional 
supports from locating in particular areas, and fear may prevent residents from accessing nearby food resources [27]. High disorder may itself also negatively impact social capital.

The degree of development in an area, in terms of living location or urban/rural status, may also help to explain food insecurity. Fewer services and resources are available in rural areas $[23,28]$, and the quality of foods may vary depending on the location of stores [22]. Growth in supermarket size and food system innovations have enabled prices to decrease and quality to increase [29]. Because large tracts of land are needed, these stores are increasingly relocating from urban to suburban areas [29], which may impact negatively on food availability and access for disadvantaged urban dwellers.

The literature examining area disadvantage, measures of social capital, disorder or living location in relation to individual or household food insecurity is sparse and has been conducted, for the most part, in the US. In general, these studies have relied exclusively on cross-sectional data, with many concentrating on low income or ethnic subgroups, making it difficult to compare to the rest of the population. Among these studies, food insecurity has been variously measured. Examples include use of the 18-item USDA Food Security Survey Module (FSSM), the shorter 6-item FSSM version, different items from the Radimer/Cornell and Community Childhood Hunger Identification Project (CCHIP) instruments, and the US food insufficiency question.

Perhaps due to a focus on low income populations by many of these studies, few have examined material disadvantage specifically. None, to our knowledge, have examined neighbourhood disorder. Some studies examining measures of collective efficacy or other measures of neighbourhood social capital have found an inverse relationship between social capital and food insecurity [30-33], although, others have uncovered null results [34-37]. Associations for living location have been more consistent, with findings pointing towards a protective effect of rural living [19,36,38-42]. There have been, on the other hand, studies that have had opposite [31] or null findings [30,43,44].

More robust studies are needed that account for changes in variables over time, as are studies adjusting for potential confounding of area disadvantage. Associations may also be different in different country or community contexts (e.g. US versus other countries), and 
state/provincial/regional or nationally representative samples may reduce biases and increase power to detect significant differences compared to low-income, convenience samples drawn from particular counties or cities/towns.

The purpose of this study, therefore, was to analyze data from a representative longitudinal study of children living in the province of Québec (Canada), in order to determine if social cohesion, disorder, and living location were associated with changes in the likelihood of food insecurity over time, while accounting for material and social deprivation. Hypotheses were that low social cohesion, high disorder, and high material/social deprivation would each increase the likelihood of food insecurity, even after accounting for household socioeconomic status and other potentially important explanatory factors. Even though some previous studies have found rural living to be negatively associated with food insecurity, it was hypothesized that rural living would be positively associated, given than another study conducted in Québec uncovered disparities in food access by location of residence, with less access for residents in rural areas [23].

\section{Methods}

This study was a secondary data analysis based on the Québec Longitudinal Study of Child Development (QLCSD). The QLSCD is an ongoing cohort study conducted by the Provincial Government of Québec to determine important factors operating early in life that may influence the health and development of young children born and raised in Québec [45]. Cohort children have been participating since 1997-1998 when they were five months of age, and are representative of same aged children in the Québec population.

In the QLSCD, a stratified, three-stage random sampling strategy was used to select children for inclusion [45]. Strata were based on geography (regions and degree of remoteness) and on birthrate. The 1997-1998 Québec Birth Registry was used as the sampling frame. Sampling occurred throughout the year to minimize the effect of seasonality. Twins, children with major diseases at birth, and those living on remote Native lands and reserves were excluded [45].

The original sample at the first data collection cycle contained 2223 children, representing a response rate of $83 \% ; 2120$ children were retained for the longitudinal portion 
of the study [45]. Data were collected by trained interviewers every 12 months starting at approximately five months of age. By age four, timing of data collection changed to coincide with the school year and continued to occur once a year until age eight, after which it occurred every other year, in order to minimize respondent burden [46]. Data were largely collected through computer-assisted personal interviewing in the child's home, although some information, like food insecurity, was captured via mother self-completed questionnaire [45]. To date, 13 cycles of data are available (five months to $12 \mathrm{y}$ of age). The present study uses data primarily from four, eight, and $10 \mathrm{y}$ of age.

The QLSCD received ethics approval from an ethics board of the Québec Provincial Government [47]. Approval for the present data analysis was given by the University of Ottawa Research Ethics Board.

\section{Dependent variable - Food insecurity}

Food insecurity was measured three times, when children were approximately four, eight, and $10 \mathrm{y}$ of age. It was based on three questions, adapted from the Radimer/Cornell hunger and food insecurity measure, which the mother answered as part of a larger selfcompleted questionnaire [48]. This measure assesses economic food insecurity. It has been used in other province-wide surveys and has been validated as part of a previous study $[49,50]$.

The first two questions of the measure assess food insecurity at the household level and examine its qualitative and quantitative aspects ("We eat the same things several days in a row because we only have a few different kinds of food on hand, and don't have enough money to buy more," and "We eat less than we should because we don't have enough money for food"). The third question assesses the qualitative component of food insecurity at the child level ("We can't provide balanced meals for our children because we can't afford it financially"). Response options for all three questions include: "often true", "sometimes true," and "never true." Children were considered to be living in a food insecure household if the mother answered "sometimes" or "often true" to any of the three questions. Categorizing food insecurity based on any affirmative response (sometimes or often) is 
consistent with previous research [51]. Responses were considered missing at any one data collection cycle if the mother did not answer any of the three questions.

\section{Explanatory variables of interest - Place factors}

Five variables measured in the QLSCD captured aspects of place that may be related to food insecurity. These are the main independent variables of interest in this study and are discussed in more detail below. All original variables were previously derived by the Institut de la Statistique du Québec (ISQ). Raw area information, such as postal codes, was not available for analyses.

\section{Area-level deprivation}

Pampalon and colleagues developed an index to measure area-level deprivation, originally to aid in health and social services planning in Québec [52,53]. The index is largely based on the work of Peter Townsend. In the QLSCD, the ISQ collected postal codes from participating children at five months of age (first data collection cycle) and then linked these to 1996 census data describing enumeration areas. Using principal components analysis, six census indicators were found to contribute to two main dimensions: material and social deprivation. The following paragraph describes the indicators making up each dimension that was derived in the first data collection cycle.

Using principal components analysis, material deprivation factor scores were calculated from the proportion of persons $\geq 15 \mathrm{y}$ of age that had no high-school diploma, the employment/population ratio of people $\geq 15 \mathrm{y}$ of age, and average income of residents $\geq 15$ $y$ of age living in the enumeration area. This dimension assesses the ability of area residents to obtain the goods and services that are a part of everyday life. Social deprivation, on the other hand, assesses the strength of the family social structure within an area. Factor scores were calculated from the indicators: proportion of persons $\geq 15 \mathrm{y}$ of age that were separated, divorced or widowed, proportion of people $\geq 15 \mathrm{y}$ of age that lived alone, and proportion of single-parent families who were living in the enumeration area. All indicators used (except for single-parent family) were standardized for the age structure of the Québec population before being included in the principal components analysis [54]. 
Factor scores for each dimension were categorized into quintiles, where increasing quintiles indicate increasing deprivation. To facilitate interpretability in longitudinal analysis, both were dichotomized into low (quintiles 1-3) and high deprivation (quintiles 45) as has been done elsewhere [55].

These variables could change over time, but in this analysis they were entered into models as time-invariant as they were not available in other cycles. This is due mainly because the Canadian census is conducted once every five years. An update, based on the 2001 census, linked to postal codes was not available for this study, but descriptive data showed that these measures remained largely unchanged from 1996-2001, and in fact, were becoming more homogeneous in their deprivation status [56]. Children could also have moved to a different enumeration area, but the deprivation indices were not derived by the ISQ, each time a child moved.

\section{Neighborhood social cohesion and disorder}

Social cohesion and disorder were based on scales derived from the work of BarnesMcGuire, which have been previously validated and used in the Canadian National Longitudinal Survey of Children and Youth [47]. Both variables assess the mother's perceptions of her neighborhood and were collected every other data collection cycle, starting at five months of age (first data collection cycle). For the purposes of this analysis, only the responses at ages four, eight, and $10 \mathrm{y}$ were required; meaning both were analyzed as time-dependent variables.

Five items with a Likert-type response scale form the social cohesion measure, a general measure of trust and support of neighbors. The disorder scale assesses neighbourhood quality by asking about four types of problems, including drug use and drugdealing, presence of garbage and broken glass, public drinking, and groups of young people causing trouble. Response categories for this scale consist of: "a problem", "somewhat of a problem," and "not a problem." Scale scores for each were calculated by averaging the item scores. The social cohesion score ranges from 1 to 4 with higher scores indicating a less cohesive neighbourhood. Disorder ranges from 1 to 3 with lower scores indicating more problems. Both scales have demonstrated adequate internal consistency with each originally calculated to have a Cronbach's alpha of $\geq 0.75$ [57]. 
In order to increase interpretability, both scales were dichotomized. For social cohesion, this was based on the $50^{\text {th }}$ percentile, as has been done by other studies using similar scales [34]. Following the methods of Curtis et al (2004), disorder was dichotomized into: "any problems present" versus "no problems present"[58], as its distribution was highly skewed.

\section{Living location}

Postal codes were recorded in all data collection cycles and linked to Statistics Canada's census geographical areas by the ISQ. In this study, household locations were classified into one of three different types of areas: 1) Census Metropolitan Area (CMA) with $\geq 100,000$ inhabitants; 2) Census Agglomeration (CA) with 10,000 to $<100,000$ inhabitants; or 3) rural/small town with $<10,000$ inhabitants [59]. For methodological reasons, a living location variable was not derived when children were four y of age. In order to use this measure as a time-dependent variable, the value in the previous data collection cycle (at $3.5 \mathrm{y}$ ) was carried forward to four $\mathrm{y}$, and the values at eight and $10 \mathrm{y}$ were used in the analysis.

\section{Other explanatory variables}

In order to more clearly understand the relationship between place factors and food insecurity, a number of potential confounders and other pertinent explanatory variables were identified from the literature $[16,60]$ and were included in the multivariable model. Timedependent variables measured at age four, eight, and $10 \mathrm{y}$ included: socioeconomic status (SES - a composite measure of income, job status, and education of both parents that was derived by the ISQ); number of people living in the household; and single-parent family status. The theory and method behind derivation of the SES composite is described elsewhere [61]. Time-stable variables measured at baseline (four y) included: at least one person in the household smokes, immigrant status, and age of the mother. Sex of the respondent was not added as this was the mother in most cases (98\%).

\section{Statistical analysis}

SAS version 9.2 was used to conduct all analyses. Two-tailed significance tests with an alpha of 0.05 were used throughout. Initial exploratory analyses were carried out by 
graphically displaying the distributions of all considered variables, computing measures of central tendency and dispersion, and checking for outliers. Crude tests of association (chisquared, ANOVA) were conducted to examine unadjusted relationships between food insecurity and the explanatory variables at baseline, when children were four y of age.

Of the original sample $(n=2120)$, approximately $46 \%(n=978)$ had all three food insecurity measures, almost 18\% $(\mathrm{n}=377)$ had two, and 27\% $(\mathrm{n}=572)$ had one; $9 \%(\mathrm{n}=$ 193) did not have any and therefore could not be included in the analysis. A further 181 were excluded due to the cumulative effect of missing explanatory variables. There was no association between food insecurity at four, eight, and $10 \mathrm{y}$ and being excluded for having missing explanatory data $\left(\chi^{2}, P>0.05\right)$. Children with no food insecurity responses $(\mathrm{n}=193)$ were more likely to be disadvantaged (e.g. live in materially or socially deprived areas, have immigrant mothers, live in a household with a low SES, or a single parent) than those with at least one response $\left(\chi^{2}, P \leq 0.05\right)$.

To determine if changes in the place factors were associated with changes in food insecurity, a longitudinal logistic regression analysis was carried out using Generalized Estimating Equations (GEE), with robust standard errors calculated for the regression parameters. Time was modeled as a categorical predictor with age four y specified as the reference category. An unstructured working correlation matrix was initially specified to account for the correlations among repeated measures over time.

As a first step in model building, crude (unadjusted) associations between repeated measures of food insecurity and each considered explanatory variable were estimated using GEE models that included main effects for time, the explanatory variable (over time if timedependent), as well as an interaction term for the explanatory variable with time. This was done to determine the explanatory variables' unadjusted relationship with food insecurity over time.

A multivariable model was then estimated by including the main effects of time, and all considered explanatory variables together with their interactions with time. The model was reduced by removing insignificant time interaction terms via backwards elimination, with the level of significance set at 0.05 . For this model, four different correlation structures 
were compared using the quasilikelihood (QIC) statistic [62] (unstructured, AR(1), toeplitz, and exchangeable). Given that respondents could be included even if they were missing some time-dependent data, sample weights were not used.

\section{Results}

A total of $n=1746$ children were included in the analysis $(82 \%$ of the original sample). Of these children, the prevalence of food insecurity was $9.2 \%(n=158 / 1726$; 95\%CI: $7.8-10.6 \%)$ at four y of age. This decreased to $7.6 \%(\mathrm{n}=89 / 1169 ; 95 \% \mathrm{CI}: 6.2-$ $9.3 \%)$ at age eight, and to $7.1 \%(\mathrm{n}=72 / 1018 ; 95 \% \mathrm{CI}: 5.6-8.8 \%)$ at age $10^{9}$. Of food insecure families with at least two response points $(n=134 / 1355), 57 \%$ experienced food insecurity once, while $43 \%$ experienced food insecurity two or three times (from age four to $10 \mathrm{y}$ ). Table 1 details crude associations between food insecurity and the place factors, as well as with the other explanatory variables, when the child was four y of age. All variables except living location, number of people living in the household, and mother's age were significantly related to food insecurity at baseline. These were still included in the adjusted analysis as potential confounders.

In the multivariable model (Table 2), comparison of different correlation structures did not show any differences in the QIC. Given the large sample size and small number of repeated measures, the unstructured correlation matrix was preferred and all estimates reported are based on this correlation structure. The odds ratios for time suggested that as children aged, food insecurity became less likely in the household; however these associations were not statistically significant. There were no significant interactions between the explanatory variables and time in the crude or multivariable models. Therefore, odds ratios estimate the average association between the explanatory variable and food insecurity, while also controlling for time and correlations between the repeated measures of food insecurity. Among the place factors, social deprivation, low social cohesion, and high disorder significantly increased the odds of food insecurity, in the range of $45-76 \%$, and this was independent of other explanatory factors. Material deprivation became nonsignificant when other explanatory variables were added to the model. There continued to

\footnotetext{
${ }^{9}$ Denominators differ as not all children responded in each data collection cycle, but because of the longitudinal regression method used, these children are still included in the analysis
} 
be no significant association between living location and food insecurity in the multivariable model. Effect sizes for household-level factors such as SES and single-parent family status were much higher than the place factors. For instance, living in a low SES household was associated with an 8.5 fold increased odds of food insecurity (95\% CI: $5.05-14.1$ ) compared to living in a high SES household. One other explanatory variable was also significantly related to food insecurity: number of people in the household became significant in multivariable analysis, although with a relatively weak odds ratio (Table 2).

\section{Discussion}

The present study represents a step forward in this area of research in that it considers families with young children and was conducted using a more robust (longitudinal) design compared to previous studies. Household SES was by far the most important predictor of food insecurity in this sample of Québec families; however even after controlling for household SES and other important variables, social deprivation, low social cohesion, and high disorder were related to an increase in the odds of food insecurity.

In our study, living in socially deprived areas significantly increased the odds of being food insecure. This relationship has not been extensively studied in the literature, but past research in Québec has shown that the prevalence of food insecurity is higher when both forms of deprivation, material and social, are found together [63]. Higher social deprivation may indicate less intra-household social interaction occurring in particular areas. Fewer immediate kinship ties may reduce the interconnectedness of informal and formal social networks that could provide material resources, such as food, and non-material supports such as information on local food programs.

Low neighborhood social cohesion was found to relate to increased odds of food insecurity. Low cohesion may indicate less trust and reciprocity among neighbours within the neighbourhood, less interaction and support from neighbours, and a reduced capacity to mobilize for collective action to address food security-related issues. Brisson \& Altschul (2011) examined social cohesion in a low income population from 10 cities in the US, and found that it was inversely related to food insecurity, as measured by the question "In the last 12 months...was your family ever without enough money to buy food?"[33]. This same 
association held when individual responses were aggregated by neighbourhood. In contrast to the findings here, a study of elderly people living in New York City, did not find that neighbourhood social cohesion was significantly related to food insecurity[35]. This sample, however, was demographically much different from the one analyzed in this study.

Other studies have examined collective efficacy or neighbourhood social capital more generally; some with significant findings in the hypothesized direction [30-32], while others have had null results [34,36,37]. Overall, mixed results may have to do with different population demographics, varying definitions for predictor and outcome, or reliance on the cross-sectional study design.

Neighbourhood aesthetics or quality, as measured by disorder in this study, could lead residents to perceive the area as unsafe, and therefore avoid accessing services outside of the household. Perceptions by businesses and institutions that have the ability to invest in the area with respect to services and infrastructure relevant to food security may lead to decreased investment [27]. Thus, high disorder may also be a proxy for fewer services and/or weakened linkages to these services. No studies to our knowledge have examined the relationship between this specific construct and food insecurity.

Material deprivation was not associated with food insecurity in the multivariable analysis. This may be because the other place factors mediated the association between material deprivation and food insecurity. Although they did not analyze food insecurity as an outcome, Sampson and Raudenbush (1997) determined that collective efficacy, comprised of social cohesion and informal social control, mediated the effect of neighbourhood disadvantage on violence in their study of 343 Chicago neighbourhoods [64]. One study that used an adapted version of the 6-item USDA FSSM found that higher material deprivation was related to food insecurity in a clinic-based cohort of women with young children living in the UK [65]. Another study, conducted on a representative sample of Southern Australians, did not find that material deprivation was related to food insecurity as measured using the food depletion item of the Radimer/Cornell instrument [37]. Similar to our study, the Australian study included measures of neighbourhood social capital in the model, whereas, the UK study did not. 
Living location was not found to be important in this study. This is in contrast to the literature, which has shown a fairly consistent association between rurality and decreased odds of food insecurity [19,36,38-42]. These studies were based for the most part on US samples and used the 18- or 6-item versions of the USDA FSSM. Differences with the present study may also reflect different contexts. Many health and social programs and services are provided free to residents of Québec, which may prevent food insecurity irrespective of broad geographical location. A network of local community service centers (CLSCs) covering the entire province provides many of these services [66]. Each one is mandated to respond to the needs of the local area, and targets all social classes [66]. This, therefore, may help to reduce geographical inequalities in access to food. These findings demonstrate the limitations of generalizing some place-related factors between culturally, politically, or geographically distinct jurisdictions.

The results of the present study should be interpreted in light of some important limitations. First, sample weights were not used in this analysis, so the proportion of families estimated to be food insecure is not necessarily generalizable to the entire population of children born in Québec in 1997-1998. The definition of food insecurity was not based on the full USDA FSSM [67] and now used by Health Canada [68]. Therefore, it cannot estimate the prevalence of food insecurity comparable to the FSSM as it does not capture all dimensions, but it does provide an overview of important food insecurity components [50]. Additionally, the third question relating to providing balanced meals may be interpreted differently in non-English speaking populations [69]. However, this three question measure has been developed from a study of a Québec, French-speaking population using the entire 13-item measure, and is used in other large government surveys in Québec $[50]$.

Another limitation of this study is that the analysis did not control for car ownership or investigate effect modification of car ownership with the place factors considered. The significant relationships seen in the present study may exist only for those households that do not have a car; they may be less strong or non-existent for those that do have a car [70]. Car ownership, on the other hand, is related to income level, where lower income households would be less likely to own a car. Overall SES was controlled for in the present analysis. 
Although the longitudinal study design is methodologically more robust than crosssectional studies reported in the literature, the present study is limited by problems of attrition and non-response. Nonetheless, households excluded because they had no food insecurity responses were more likely to be disadvantaged, as measured by many different variables including SES, single-parent status, immigrant status, and area material and social deprivation. Because food insecurity is so tightly linked to disadvantage, one would expect that these non-responders would be more likely to be food insecure at some point than the average participating household in the cohort, which should then lead to similar or stronger relationships as those uncovered among included households.

Finally, data on neighborhood material and social deprivation were only available when children were five months of age. It is unknown if families moved to areas higher or lower in either of the two forms of deprivation. However, in general, families living in highly deprived areas tend to move laterally, to other deprived areas, rather than move to more affluent areas [71]. Canadian data indicate that new movers to deprived areas tend to stay on average for four years before moving out, and that the longer one stays in a deprived neighbourhood, the less likely they are to leave [72]. Additionally, American data show that it is common for families to return to high poverty areas after leaving for a period of time [73].

\section{Conclusion}

From this study it is likely that improving the household SES situation would lead to decreased food insecurity. But our results also suggest that addressing the immediate social environment in which people live may also improve their situation. More studies are needed to verify these results, and to delve more deeply into specific features of the physical and social characteristics of local environments. It is also pertinent to understand how these environmental factors might interact with household SES and other household factors that affect food utilization. Regardless, various stakeholders (e.g. urban planners, politicians, dietitians, social workers, health promoters) may want to consider local social environments when implementing any type of food security intervention in the community. Future research may show that the environment itself may be amenable to change by certain interventions, which could lead to improved food security and health-related outcomes. 
Consideration for interactions with the environment and changes to the environment itself may lead to sustainable food system reforms and thus improve overall community food security. Some examples include community capacity building and empowerment initiatives to build social capital, designing the built environment to encourage social interaction and prevent anti-social behaviour, and providing more targeted social support to isolated households. Planning and evaluating these interventions with individual food insecurity as the outcome should become a priority.

Disclaimer: This analysis was based on the ISQ QLSCD master files. All computations were prepared by MAC. The responsibility for the use and interpretation of these data is solely that of the authors. The opinions expressed in this paper are those of the authors and do not represent the views of the ISQ.

Competing interests: The authors declare that they have no competing interests

Author's contributions: MAC conceived of the study, conducted the analysis, and drafted and edited the manuscript; LD helped to conceive the study, provided content expertise, and critically edited the manuscript; MST provided content expertise and critically edited the manuscript; MT provided statistical expertise and critically edited the manuscript. All authors have given approval for the final version of this manuscript to be published.

Acknowledgements: The lead author was supported by the Banting \& Best Canada Graduate Scholarship from the Canadian Institutes for Health Research. The QLSCD is funded by the ministère de la Santé et des Services sociaux du Québec, ministère de la Famille et des Aînés, Lucie and André Chagnon Foundation, and the ISQ

\section{List of abbreviations used}

$\mathrm{CA}-$ Census agglomeration

CMA - Census metropolitan area

GEE - Generalized estimating equations

ISQ - Institut de la statistique de Québec

QLSCD - Québec Longitudinal Study of Child Development

SD - Standard deviation

SES - Socioeconomic status 


\section{Reference List}

1. Health Canada. Household Food Insecurity In Canada in 2007-2008: Key Statistics and Graphics. 2011. http://www.hc-sc.gc.ca/fn-an/surveill/nutrition/commun/insecurit/keystats-cles-2007-2008-eng.php

2. Coleman-Jensen, A., Nord, M., Andrews, M., and Carlson, S. Household Food Security in the United States in 2010. 2011. http://www.ers.usda.gov/Publications/ERR125/ERR125.pdf

3. Andersen SA: Life Sciences Research Office Report: Core Indicators of Nutritional State for Difficult-to-Sample Populations. Journal of Nutrition 1990, 120: 1555-1600.

4. Radimer KL, Olson CM, Campbell CC: Development of indicators to assess hunger. Journal of Nutrition 1990, 120: 1544-1548.

5. Slopen N, Fitzmaurice G, Williams DR, Gilman SE: Poverty, food insecurity, and the behavior for childhood internalizing and externalizing disorders. Journal of the American Academy of Child \& Adolescent Psychiatry 2010, 49: 444-452.

6. Alaimo K, Olson CM, Frongillo EA, Jr.: Food insufficiency and American school-aged children's cognitive, academic, and psychosocial development. Pediatrics 2001, 108: 4453.

7. Heflin $\mathrm{CM}$, Siefert K, Williams DR: Food insufficiency and women's mental health: findings from a 3-year panel of welfare recipients. Social Science \& Medicine 2005, 61: 1971-1982.

8. Zaslow M, Bronte-Tinkew J, Capps R, Horowitz A, Moore KA, Weinstein D: Food security during infancy: implications for attachment and mental proficiency in toddlerhood. Maternal \& Child Health Journal 2009, 13: 66-80.

9. Larson $\mathrm{NI}$, Story MT: Food insecurity and weight status among U.S. children and families: a review of the literature. American Journal of Preventive Medicine 2011, 40: 166-173.

10. Parker ED, Widome R, Nettleton JA, Pereira MA: Food security and metabolic syndrome in U.S. adults and adolescents: findings from the National Health and Nutrition Examination Survey, 1999-2006. Annals of Epidemiology 2010, 20: 364-370.

11. Kushel MB, Gupta R, Gee L, Haas JS: Housing instability and food insecurity as barriers to health care among low-income Americans. Journal of General Internal Medicine 2006, 21: 71-77.

12. Nord M, Parker L: How adequately are food needs of children in low-income households being met?Children and Youth Services Review 2010, 1175-1185.

13. Barrett CB: Measuring food insecurity. Science 2010, 327: 825-828.

14. Rose D: Economic determinants and dietary consequences of food insecurity in the United States. Journal of Nutrition 1999, 129: 517S-520S. 
15. Gundersen C, Kreider B, Pepper J: The Economics of Food Insecurity in the United States. Applied Economic Perspectives and Policy 2011, 33: 281-303.

16. Cutler-Triggs $\mathrm{C}$, Fryer GE, Miyoshi TJ, Weitzman M: Increased rates and severity of child and adult food insecurity in households with adult smokers. Archives of Pediatrics \& Adolescent Medicine 2008, 162: 1056-1062.

17. FAO. The State of Food Insecurity in the World (2009): Economic crises - impacts and lessons learned. 2009. ftp://ftp.fao.org/docrep/fao/012/i0876e/i0876e02.pdf

18. Nord M, Hooper MD, Hopwood H: Household-level income-related food insecurity is less prevalent in Canada than in the United States. Journal of Hunger and Environmental Nutrition 2008, 3: 17-35.

19. Bartfeld JS, Dunifon R: State-level predictors of food insecurity among households with children. Journal of Policy Analysis \& Management 2006, 25: 921-942.

20. Neff RA, Palmer AM, McKenzie SE, Lawrence RS: Food Systems and Public Health Disparities. Journal of Hunger and Environmental Nutrition 2009, 4: 282-314.

21. Beaulac J, Kristjansson E, Cummins S: A systematic review of food deserts, 1966-2007. Preventing Chronic Disease 2009, 6: A105.

22. Cummins S, Smith DM, Taylor M, Dawson J, Marshall D, Sparks L et al.: Variations in fresh fruit and vegetable quality by store type, urban-rural setting and neighbourhood deprivation in Scotland. Public health nutrition 2009, 12: 2044-2050.

23. Drouin $S$, Hamelin AM, Ouellet $D$ : Economic access to fruits and vegetables in the greater Quebec City: do disparities exist? Canadian Journal of Public Health Revue Canadienne de Sante Publique 2009, 100: 361-364.

24. Cummins S, Macintyre S: A Systematic Study of an Urban Foodscape: The Price and Availability of Food in Greater Glasgow. Urban Studies 2002, 39: 2115-2130.

25. Kawachi I, Kim D, Coutts A, Subramanian SV: Commentary: Reconciling the three accounts of social capital. Int J Epidemiol 2004, 33: 682-690.

26. Kawachi I., Subramanian SV., Kim D., editors. Social Capital \& Health. New York: Springer; 2008.

27. Macintyre S, Ellaway A, Cummins S: Place effects on health: How can we conceptualise, operationalise and measure them? Soc Sci Med 2002, 55: 125-139.

28. Pearce J, Witten $\mathrm{K}$, Hiscock R, Blakely $\mathrm{T}$ : Regional and urban-rural variations in the association of neighbourhood deprivation with community resource access: a national study. Environment and Planning A 2008, 40: 2469-2489. 
29. USDA. Access to Affordable and Nutritious Food: Measuring and Understanding Food Deserts and Their Consequences. 2009.

http://www.ers.usda.gov/publications/ap/ap036/ap036.pdf

30. Morton LW, Bitto EA, Oakland MJ, Sand M: Solving the problems of lowa food deserts: Food insecurity and civic structure. Rural Sociology 2005, 70: 94-112.

31. Dean WR, Sharkey JR: Food insecurity, social capital and perceived personal disparity in a predominantly rural region of Texas: an individual-level analysis. Social Science \& Medicine 2011, 72: 1454-1462.

32. Martin KS, Rogers BL, Cook JT, Joseph HM: Social capital is associated with decreased risk of hunger. Social Science \& Medicine 2004, 58: 2645-2654.

33. Brisson D, Altschul I: Collective Efficacy Predicting Experience of Material Hardship in LowIncome Neighborhoods. Urban Affairs Review 2011, 47: 541-563.

34. Kirkpatrick SI, Tarasuk V: Assessing the relevance of neighbourhood characteristics to the household food security of low-income Toronto families. Public health nutrition 2010, 13: $1139-1148$.

35. Chung WT, Gallo WT, Giunta N, Canavan ME, Parikh NS, Fahs MC: Linking neighborhood characteristics to food insecurity in older adults: The role of perceived safety, social cohesion, and walkability. Journal of Urban Health 2011, Early Online.

36. Bernell SL, Weber BA, Edwards ME: Restricted opportunities, personal choices, ineffective policies: What explains food insecurity in Oregon? Journal of Agricultural and Resource Economics 2006, 31: 193-211.

37. Foley W, Ward P, Carter P, Coveney J, Tsourtos G, Taylor A: An ecological analysis of factors associated with food insecurity in South Australia, 2002-7. Public health nutrition 2010, 13: 215-221.

38. Radimer KL, Allsopp R, Harvey PW, Firman DW, Watson EK: Food insufficiency in Queensland.[Erratum appears in Aust N Z J Public Health 1999 Feb;23(1):108]. Australian \& New Zealand Journal of Public Health 1997, 21: 303-310.

39. Garasky S, Morton LW, Greder KA: The effects of the local food environment and social support on rural food insecurity. Journal of Hunger \& Environmental Nutrition 2006, 1: 83103.

40. Bartfeld JS, Ryu JH, Wang L: Local Characteristics Are Linked to Food Insecurity Among Households With Elementary School Children. Journal of Hunger \& Environmental Nutrition 2010, 5: 471-483.

41. Mazur RE, Marquis GS, Jensen HH: Diet and food insufficiency among Hispanic youths: acculturation and socioeconomic factors in the third National Health and Nutrition Examination Survey. American Journal of Clinical Nutrition 2003, 78: 1120-1127. 
42. Bartfeld JS, Ahn HM: The School Breakfast Program strengthens household food security among low-income households with elementary school children. Journal of Nutrition 2011, 141: 470-475.

43. Quine S, Morrell S: Food insecurity in community-dwelling older Australians. Public Health Nutrition 2006, 9: 219-224.

44. Lee JS, Frongillo EA, Jr.: Factors associated with food insecurity among U.S. elderly persons: importance of functional impairments. Journals of Gerontology Series BPsychological Sciences \& Social Sciences 2001, 56: S94-S99.

45. Jetté M, Des Groseilliers L. Longitudinal Study of Child Development in Québec (ELDEQ 1998-2002) 5 month old infants: Survey Description and Methodology. 1[1]. 2000. Montreal, Institut de la statistique du Québec, Government du Québec. 11-3-2011.

46. Institut de la Statistique du Québec. ÉLDEQ 1998-2002 : retour sur l'étude - Description et méthodologie de la phase I de l'ÉLDEQ. 2004.

http://www.iamillbe.stat.gouv.qc.ca/pdf/doc tech/E4-E5Retour sur ELDEQ.pdf

47. Institut de la statistique du Québec. Concepts, Definitions and Operational Aspects: 5 month old enfants. Québec Longitudinal Study of Child Development (QLSCD 1998-2002). 2001. http://www.iamillbe.stat.gouv.qc.ca/bebe/bebe n12 pdf an.htm

48. Institut de la Statistique du Québec. Étude longitudinale du développement des enfants du Québec (ÉLDEQ 1998-2002): Sources, justifications et modifications entre les volets 2001 (E4) et 2002 (E5). 2004. http://www.iamillbe.stat.gouv.qc.ca/pdf/doc tech/SourcesE4 E5 11mai2005.pdf

49. Lavallée, C., Aubin, J., Audet, N., and Berthiaume, P. Enquête sociale et de santé auprès des enfants et des adolescents québécois: Cahier technique et méthodologique. 2003. http://www.stat.gouv.qc.ca/publications/sante/doc technique/enf ados cahier technVol 1.pdf

50. Daveluy C, Pica L, Audet N, Courtmanche R, Lapointe R, and et autres. Enquête sociale et de santé 1998, 2e édition. 2000.

http://www.stat.gouv.qc.ca/publications/sante/pdf/e soc98v2.pdf

51. Kendall A, Olson CM, Frongillo EA, Jr.: Validation of the Radimer/Cornell measures of hunger and food insecurity. Journal of Nutrition 1995, 125: 2793-2801.

52. Pampalon, R., Philibert, M., and Hamel, D. Développement d'un système d'évaluation de la défavorisation des communautés locales et des clientèles de CLSC. 2004. http://www.inspq.qc.ca/pdf/publications/279 DefavorisationClientelesCLSC.pdf

53. Pampalon R, Raymond G: A deprivation index for health and welfare planning in Quebec. Chronic Diseases in Canada 2000, 21: 104-113.

54. Gamache P, Pampalon R, Hamel D. Methodological guide "The material and social deprivation index: a summary". Institut national de santé publique Québec . 2010. 
55. Lebel A, Pampalon R, Hamel D, Theriault M: The geography of overweight in Quebec: a multilevel perspective. Canadian Journal of Public Health 2009, 100: 18-23.

56. Pampalon, R., Hamel, D., and Raymond, G. Indice de défavorisation pour l'étude de la santé et du bien-être au Québec - Mise à jour 2001. 2004.

http://www.inspq.qc.ca/pdf/publications/295-IndiceDefavorisation 2001.pdf

57. Desrosiers H. Family, Child Care and Neighbourhood Characteristic: Québec Longitudinal Study of Child Development (ÉLDEQ 1998-2002). 2000.

http://www.iamillbe.stat.gouv.qc.ca/bebe/pdf/baby no2-1.pdf

58. Curtis LJ, Dooley MD, Phipps SA: Child well-being and neighbourhood quality: evidence from the Canadian National Longitudinal Survey of Children and Youth. Social Science \& Medicine 2004, 58: 1917-1927.

59. Martinez, J., Pampalon, R., Hamel, D., and Raymond, G. Does living in rural communities rather than cities really make a difference in people's health and wellness? 2004.

http://www.inspq.qc.ca/pdf/publications/307-RuralHealthQuebec.pdf

60. Che J, Chen J: Food security in Canadian households. Health Reports 2001, 12: 11-22.

61. Institut de la statistique du Québec. Variables dérivées de l'ÉLDEQ 1998-2008: Partie A. 2009. http://www.jesuisjeserai.stat.gouv.qc.ca/pdf/doc tech/E1aE11Variables Derivees1101.pdf

62. Hardin JW, Hilbe JM: Generalized Estimating Equations. Boca Raton, Florida: Chapman \& Hall/CRC; 2003.

63. Dubois L: Food, Nutrition, and Population Health: From Scarcity to Social Inequalities. In Healthier Societies: From Analysis to Action. Edited by Heymann J, Hertzman C, Barer ML, Evans RG. New York: Oxford University Press; 2006:135.

64. Sampson RJ, Raudenbush SW, Earls F: Neighborhoods and violent crime: A multilevel study of collective efficacy. Science 1997, 277: 918-924.

65. Pilgrim A, Barker M, Jackson A, Ntani G, Crozier S, Inskip H et al.: Does living in a food insecure household impact on the diets and body composition of young children? Findings from the Southampton Women's Survey. Journal of Epidemiology \& Community Health 2011.

66. Bozzini L: Local Community Services Centers (CLSCs) in Quebec: Description, Evaluation, Perspectives. Journal of Public Health Policy 1988, 9: 346-375.

67. USDA. Food Security in the United States: Household Survey Tools. 2011. http://www.ers.usda.gov/briefing/foodsecurity/surveytools.htm\#six

68. Health Canada. Food and Nutrition: Determining Food Security Status. 2010. http://www.hc-sc.gc.ca/fn-an/surveill/nutrition/commun/insecurit/status-situationeng.php 
69. Harrison GG, Stormer A, Herman DR, Winham DM: Development of a spanish-language version of the U.S. household food security survey module. J Nutr 2003, 133: 1192-1197.

70. Bader MDM, Purciel M, Yousefzadeh P, Neckerman KM: Disparities in Neighborhood Food Environments: Implications of Measurement Strategies. Economic Geography 2010, 86: 409-430.

71. Fauth R: The Impacts of Neighborhood Poverty Deconcentration Efforts on Low-Income Children's and Adolescents' Well-Being. Children, Youth and Environments 2004, 14: 1-55.

72. Frenette, M., Picot, G., and Sceviour, R. How long do people live in low-income neighbourhoods? Evidence for Toronto, Montreal, and Vancouver. 2004. http://www.statcan.gc.ca/pub/11f0019m/11f0019m2004216-eng.pdf

73. Quillian L: How long are exposures to poor neighborhoods? The long-term dynamics of entry and exit from poor neighborhoods. Population Research and Policy Review 2003, 22: 221-249. 
Table 1: Characteristics of households with children participating in the QLSCD and included in the analysis at age $4 y$ (2002), by food insecurity status ${ }^{\text {ab }}$

\begin{tabular}{|c|c|c|c|c|}
\hline \multicolumn{5}{|c|}{ Food insecurity status at $4 \mathrm{y}$} \\
\hline Variables & $\begin{array}{c}\text { Food secure } \\
90.8 \%(n=1568)\end{array}$ & $\begin{array}{l}\text { Food insecure } \\
9.2 \%(n=158)\end{array}$ & Total \% (n) & Total $\mathbf{N}$ \\
\hline \multicolumn{5}{|l|}{ Place factors } \\
\hline Materially deprived & $36.3(569)$ & $53.2(84)$ & $37.8(653)$ & 1726 \\
\hline Socially deprived & $34.6(542)$ & $52.5(83)$ & $36.2(625)$ & 1726 \\
\hline Low social cohesion $^{c}$ & $50.5(771)$ & $69.1(105)$ & $52.2(876)$ & 1679 \\
\hline High social disorder ${ }^{c}$ & $23.9(374)$ & $45.5(71)$ & $25.9(445)$ & 1719 \\
\hline Living location $^{c}$ & & & & 1710 \\
\hline Rural/small town & $22.1(343)$ & $22.6(35)$ & $22.1(378)$ & \\
\hline CA (semi-urban) & $11.3(176)$ & $11.0(17)$ & $11.3(193)$ & \\
\hline CMA (urban) & $66.6(1036)$ & $66.5(103)$ & $66.6(1139)$ & \\
\hline \multicolumn{5}{|l|}{ Other explanatory } \\
\hline $\begin{array}{l}\text { Number of people in } \\
\text { household (mean, SD) }\end{array}$ & $4.1(0.96)$ & $4.3(1.2)$ & $4.1(1.0)$ & 1726 \\
\hline SES (tertiles) ${ }^{c}$ & & & & 1715 \\
\hline Low & $28.8(449)$ & $62.8(98)$ & $32.0(547)$ & \\
\hline Medium & $34.3(535)$ & $28.9(45)$ & $33.8(580$ & \\
\hline High & $36.9(575)$ & $8.3(13)$ & $34.3(588)$ & \\
\hline Single parent family ${ }^{c}$ & $11.0(173)$ & $26.0(41)$ & $12.4(214)$ & 1726 \\
\hline $\begin{array}{l}\text { At least one person in } \\
\text { household smokes }\end{array}$ & $28.9(453)$ & $42.4(67)$ & $30.1(520)$ & 1726 \\
\hline Mother is an immigrant & $8.1(127)$ & $17.7(28)$ & $9.0(155)$ & 1726 \\
\hline $\begin{array}{l}\text { Age of the mother (mean } y \text {, } \\
S D \text { ) }\end{array}$ & $33.3(5.0)$ & $32.5(6.3)$ & $33.2(5.2)$ & 1726 \\
\hline $\begin{array}{l}{ }^{a} \text { All variables except living location, } \\
\text { food insecurity at the } 5 \% \text { level } \\
{ }^{b} \text { All variables (except where indicat } \\
{ }^{c} \text { Measured at } 4 \text { y (2002) here but u } \\
\text { QLSCD - Québec Longitudinal Study } \\
\text { standard deviation; SES - socioecor }\end{array}$ & $\begin{array}{l}\text { mber of people in the } \\
\text { in italics) are percenta } \\
\text { as a time-dependent } \\
\text { Child Development; C } \\
\text { hic status }\end{array}$ & $\begin{array}{l}\text { hold, and age of th } \\
\text { le in multivariate a } \\
\text { nsus agglomeration }\end{array}$ & - census metro & $\begin{array}{l}\text { sociated wi } \\
\text { area; SD - }\end{array}$ \\
\hline
\end{tabular}


Table 2: GEE multivariable logistic regression model to measure the adjusted association between place and food insecurity among households with children participating in the QLSCD, $2002-2008$ ( $n=1746)$

\begin{tabular}{|c|c|c|}
\hline Variables included in the model & Adjusted Odds Ratio & 95\% Confidence Limits \\
\hline Time 1 (child 4 y, 2002) & Ref & Ref \\
\hline Time 2 (child 8 y, 2006) & 0.83 & $0.64-1.08$ \\
\hline Time 3 (child 10 y, 2008) & 0.77 & $0.58-1.02$ \\
\hline \multicolumn{3}{|l|}{ Place factors } \\
\hline Materially deprived & 1.12 & $0.81-1.54$ \\
\hline Socially deprived & 1.62 & $1.16-2.26 * *$ \\
\hline Low social cohesion & 1.45 & $1.10-1.92 * *$ \\
\hline High disorder & 1.76 & $1.37-2.27^{* * *}$ \\
\hline \multicolumn{3}{|l|}{ Living location } \\
\hline Rural/small town & 0.88 & $0.59-1.31$ \\
\hline CA (semi-urban) & 0.93 & $0.59-1.46$ \\
\hline CMA (urban) & Ref & Ref \\
\hline \multicolumn{3}{|l|}{ Other explanatory variables } \\
\hline Number of people in household & 1.26 & $1.07-1.48^{* *}$ \\
\hline \multicolumn{3}{|l|}{ SES (tertiles) } \\
\hline Low & 8.45 & $5.05-14.12^{* * *}$ \\
\hline Medium & 3.51 & $2.10-5.86^{* * *}$ \\
\hline High & Ref & Ref \\
\hline Single parent family & 2.49 & $1.69-3.67^{* * *}$ \\
\hline At least one person smokes in the household & 1.17 & $0.86-1.58$ \\
\hline Mother is an immigrant & 1.37 & $0.82-2.29$ \\
\hline Age of the mother & 1.00 & $0.97-1.03$ \\
\hline
\end{tabular}

$* P \leq 0.05, * * P \leq 0.01, P \leq 0.0001$

GEE - generalized estimating equations; QLSCD - Québec Longitudinal Study of Child Development; Ref - reference group; CA - census agglomeration; CMA - census metropolitan area; SES - socioeconomic status 


\section{Chapter 6 - Discussion}

\subsection{Summary of key findings}

The overall purpose of this thesis was to investigate the relationship between specific place characteristics (material and social deprivation, social cohesion, disorder, and living location) and childhood excess weight and family food insecurity. Chapter 5 presents the three analyses that address Objectives 1a, $1 \mathrm{~b}$, and 2 of this thesis. Study 1a examined the longitudinal relationship of the five place factors with child excess weight using a mixed models approach. Study $1 \mathrm{~b}$ used the same cohort, examined the same place factors and outcome, but used group-based trajectory modeling to model change over time. Results from both analyses did not indicate that these place factors were important influences on child weight status. The final analysis, in study 2, used the same cohort, examined the same place factors, but in relation to family food insecurity over time. The results from this analysis suggest that social deprivation, low social cohesion, and high disorder may increase the likelihood of experiencing food insecurity, irrespective of household SES and other confounders. Taken together, these specific place factors do not appear to play a role in child excess weight; however, some may be important for family food insecurity.

The results of this thesis are important because few studies have examined the relationship between place and child excess weight over time, and none as far as we are aware, have examined the relationship between place and family food insecurity over time, or tried to determine if the same place characteristics could explain child excess weight and food insecurity using the same cohort and the same time frame. This thesis adds to the knowledge base in general but also provides a Canadian context that is otherwise missing in the literature. 
A lack of a strong and consistent association between the place factors and child excess weight challenges the hypothesis that place matters for child weight status. Rather, the results here heavily support the influence of early life factors on child excess weight. Although not explored here, it is possible that these early life factors mediated, to a certain extent, the mother's exposure to certain environments while pregnant. This may be a fruitful area for future research.

The strong association of social deprivation, low social cohesion, and high disorder with family food insecurity strengthens the existing knowledgebase of cross-sectional studies that have uncovered similar associations. A lack of association between living location and family food insecurity also challenges previous findings that pointed to a potential protective influence of rural living.

In the following sections, the objectives are revisited, and the results are discussed in more detail. Strengths and limitations of the thesis are next presented, followed by future research directions.

\subsection{Objectives revisited}

\subsubsection{Place and weight gain - a comparison of two approaches}

Two different statistical methods were used to examine the relationship between place and child weight status in the QLSCD, according to Objective 1 of this thesis: "To determine the longitudinal association of local environmental factors (living location, social cohesion, disorder, and material and social deprivation) with child weight status, after consideration for important social and early life factors; achieved through comparison of results using two 
different statistical methods: a) mixed models regression and b) group-based trajectory modeling.."

These two methods offer two different, but complimentary ways of looking at the same question. This is especially helpful given the intricacies of the population health approach and the overall complexity of excess weight development. Important to note is that all statistical models are not perfect. They do however help to organize this complexity so that we can attempt to make sense of health phenomena. Using two different ways to examine the same problem can therefore, lend credibility to overall results.

In both the mixed and group-based models, social cohesion was not significantly related to weight status. These results do not support the hypothesis that high social cohesion prevents excess weight gain. For the mixed model, children who lived in a materially deprived area at an early age were estimated to have a different BMI Z-score trend than those who were not living in a deprived area. Children who were not deprived had a flatter ushaped quadratic curve (less change) versus those who lived in a deprived area (accelerating rate of BMI Z-score increase). The general positive association is in line with the original hypothesis, where it was thought that material deprivation would be related to increasing weight over time. However, even though the difference was significant, it was very small when graphically represented. In the group-based model, material deprivation did not predict group membership, which runs contrary to the original hypothesis that material deprivation would predict membership in a high -stable or normal-increasing-to- high weight group. 
Trends for having lived in a socially deprived area at a young age versus not, and for living in a disordered area versus not, were significantly different in the mixed model analysis. Children who had lived in a socially deprived area at a young age demonstrated slower growth in BMI Z-score versus those who had not, while children living in disordered areas were estimated to have quadratic trends with a flat $\mathrm{n}$-shape compared to the flat $\mathrm{u}$ shape of children not living in disordered areas. These differences, however, were very small and graphical representations suggested that they were not important. These findings were in contrast to the original hypotheses where it was thought that social deprivation and high disorder would be positively related to weight gain. Group-based trajectory modeling did not find that social deprivation was significantly related to weight status. Like material deprivation, it was originally thought that social deprivation would predict membership in a high- stable or normal-increasing-to- high weight group. The results do not support this hypothesis. High disorder was found to decrease BMI Z-score in the low group only, indicating that the small relationship uncovered in the mixed model was driven by and/or may only be important for children in the low end of the BMI Z-score distribution. Again, these results do not support the original hypothesis that high disorder would be related to weight gain.

Compared to urban living, semi-urban living was associated with a decrease in BMI Zscore over time in the mixed model. The group-based model uncovered this same association in the low and medium-high groups only, and also estimated a positive association for rural living in the high-stable group only. This general positive association of rural living was not captured in the mixed model. In both models, the magnitudes of these associations were small. It was originally hypothesized that semi-urban living would be 
positively related to weight status (in relation to urban living), yet the results from both models do not support this hypothesis. Results from the group-based model in the highstable group do support the hypothesis that rural living is positively related to weight. But it is unclear why this relationship was not uncovered in the other weight groups. One explanation is that children already at excess weight are more sensitive to changes in urban/rural lifestyle (1).

There are few studies that have assessed the relationship between social capital and child weight status. The one longitudinal study on social cohesion found that neighbourhood parent-perceived social cohesion was inversely related to children's BMI (2). This study was similar to the present study in that social cohesion was a perceived, not an objective measure, and the items included in the measure of social cohesion were closely related to those studied here. On the other hand, this study did not adjust for household or neighbourhood SES, or standardize BMI for age and sex. This could explain the discrepancy with the results seen here.

Based on the literature, both cross-sectional and longitudinal studies consistently find that material deprivation relates positively to child excess weight (3-5). The young age of cohort children analyzed in this thesis may explain differences with the literature as a whole, as the majority of previous studies have examined samples with ages that are older than 10 years, or those with wide age ranges (e.g. 5-18 years). Those studies specifically examining younger age groups (10 and younger) are less consistent in their results (6-8). Some studies that have examined a range of ages have found that effect sizes are smaller for younger children or inconsistent across the sexes $(9 ; 10)$. 
No other studies to our knowledge have assessed social deprivation in relation to child weight status. Another study that examined social deprivation in relation to overweight among adults living in Québec, did not uncover a significant association (11). Few studies have examined disorder in relation to child weight status. These studies have tended to find that high disorder is positively related to child weight status $(4 ; 5 ; 12)$; however definitions of disorder were slightly different than that used here, young children were not specifically examined, and two out of the three studies were cross-sectional.

Previous longitudinal studies examining living location in relation to child weight status have been mixed $(7 ; 13)$. Others that have used similar measures such as population size (4) or county sprawl (14) have uncovered null associations. Many cross-sectional studies have found that as the level of rurality increases, childhood weight significantly increases (15-18); although others have had inconsistent, null, or opposite results (19-22). The results here suggest that living location may matter for child weight status, but the influence is likely to be small and the nature of the relationship is currently unclear. Further work is needed, with more nuanced indicators of sprawl and population sparseness.

Both mixed and group-based models estimated a strong influence of early life factors on weight status, such as smoking during pregnancy, obesity status of the mother, high birthweight, overeating, and rapid infant weight gain. Less consistent between the two models were associations for sex and SES. Based on these two sets of analyses, it seems that early life factors play a relatively larger role in the development of excess weight than the place factors and even other individual or social factors such as SES and sex. 
In summary, at this stage in the life-course, place factors in general do not appear to be important, as differences were relatively small and inconsistent between modeling strategies. Results from both modeling strategies do suggest a potential role of living location, although it is unclear at this time the exact nature of the relationship. Even though early life factors were included to adjust for prior exposures, it is possible that they mediated, to a certain extent, the mother's exposure to certain environments while pregnant. This may be a fruitful area for future research.

\subsubsection{Place and family food insecurity}

The second objective of this thesis was: "To determine the longitudinal association of local environmental factors (living location, social cohesion, disorder, and material and social deprivation) with family food insecurity, after consideration for other important covariates related to SES.”

A longitudinal analysis was again conducted using the QLSCD and the same place factors as those examined in Objective 1 ( $a$ and $b$ ), in order to determine whether these place factors were also associated with change in family food insecurity status. This analysis used a population-averaged approach, and GEE specifically. Chapter 5 presents the manuscript that details this analysis.

After adjusting for other important explanatory variables, significant main effects of social deprivation, low social cohesion, and high disorder were uncovered, with the largest effect size seen for high disorder. These variables were positively related to family food insecurity on average when children were $4-10$ years of age. Time was not found to be significantly related with family food insecurity and no interactions with time were observed 
for any of the explanatory variables, including the place factors. These results support the hypotheses that social deprivation, low social cohesion, and high disorder increase the likelihood of experiencing family food insecurity.

Material deprivation and living location, on the other hand, were not significantly related to family food insecurity. This is in contrast to the original hypotheses where it was thought that material deprivation and rural living would be positively related to family food insecurity.

The results for social deprivation and social cohesion support the results of other crosssectional studies that have examined various measures of social capital and uncovered inverse associations with food insecurity (23-26). One study that specifically examined social cohesion found it to be inversely associated with food insecurity in a low income sample (23); although another study that examined seniors, uncovered null results (27). An elderly population is likely to be much different than a family with children and this may largely explain the discrepancy with the results of this thesis. No studies to our knowledge have examined social deprivation or disorder specifically.

Perhaps because of the nature of food insecurity, few studies have specifically examined material deprivation. One study that used a similar material deprivation index to that used in this study found that higher material deprivation was related to food insecurity in a UK sample of women with children (28). Conversely, a study conducted in Australia did not find that deprivation was related to food insecurity (29). Similar to our study, the Australian study included measures of neighbourhood social capital in the model, whereas, the UK 
study did not. Thus, it is possible that the effect of material deprivation is mediated by the other place factors. However, this was not explored here.

The results of this analysis challenge the results from mostly US studies that have found a protective effect of rural living on food insecurity (30-36). Differences in study design, and the social, economic, and political context between Québec and the US may explain why results are discrepant.

In summary, considering social deprivation, social cohesion and disorder, in addition to other important factors such as household SES, may provide a leverage point for the development of interventions to ameliorate family food insecurity. However, further observational and experimental research is warranted, in order to replicate and further clarify the results found here.

\subsubsection{The importance of place for different population health outcomes}

The third objective in this thesis was: "To compare and contrast the results from Objectives $1 a, 1 b$, and 2." In other words, to determine if the studied place factors material and social deprivation, social cohesion, disorder and living location matter for both child weight status and for family food insecurity. This section of the discussion addresses this objective, in light of theoretical considerations on the nature of both outcomes.

Social deprivation, social cohesion and disorder were strongly and positively associated with family food insecurity. These place factors, on the other hand, were not consistently associated with child weight status. Material deprivation was not important for both outcomes, except for a slight positive association in the single growth curve analysis of child weight status. Living location was not important in explaining family food insecurity; 
however, it may be important in explaining child weight status. Thus, the same place factors are not important for both child weight status and family food insecurity.

Food insecurity is an outcome that occurs without much time delay or lag. Thus, characteristics in the local environment such as disorder, in addition to other factors such as income, would not take a lot of time to exert their effect, and therefore we see those effects during the time frame of the study. Obesity on the other hand, does have a time lag. Simplistically, it is a developmental biological process where children need to be consistently exposed to a positive energy balance for a certain length of time before they first begin to gain weight, and then more time to gain enough weight to be considered at excess weight for their age and sex. Therefore, one explanation for differing results is that exposure time for children was not long enough for the environment to exert its obesogenic effects within the study timeframe. Adolescence and adulthood may be a different story, but we cannot extrapolate beyond the data at hand. The second explanation is that the place factors considered here are simply not all that important in explaining differences in weight status in early childhood (or at any stage of the life-course).

Certainly, more evidence, particularly intervention research, is needed to determine whether material and social deprivation, social cohesion, disorder and living location matter for child weight status and family food insecurity. The results of this thesis, nonetheless further our social-ecological understanding of these two related health problems.

\subsection{Strengths}

This research is timely due to the high prevalence of child excess weight and food insecurity among households with children in Canada. The literature examining the 
relationship between place and child weight status and between place and food insecurity generally lacks methodological rigour (e.g. use of a cross-sectional rather than the more robust longitudinal design, reliance on parent-reported height and weight), and a socialecological perspective. For the most part, the literature derives from US samples, with studies on Canadian populations being far less numerous.

This dissertation addresses these gaps by drawing heavily on a priori theory and comprehensive reviews of the literature. It was based on a large cohort of Québec children followed from early life to pre-adolescence, with fairly high response rates over time, and detailed data collected that described many different faucets of child development. This detail enabled consideration of variables acting at multiple levels of potential influence, and a more nuanced view of both public health problems. The longitudinal regression methods used allowed for changes over time among many explanatory variables to be taken into account, the removal of bias arising from correlations between repeated outcomes, reduction of selection bias as children with missing time-dependent data were retained in the analysis, and for children and families to act as their own controls. Finally, given that there are different approaches to assessing change in child weight status over time, the use of two different but common statistical methods allowed for the corroboration of overall results.

\subsection{Limitations}

This thesis has several important limitations that bear mentioning. Because this was an analysis of secondary data, analysis of place was limited to the indicators employed in the survey. Material and social deprivation were measured when children were five months of age only. Both may have changed over the study period. Particularly for social deprivation and family food insecurity, bias cannot be ruled out as a possible explanation for the 
significant relationship found. Families can move out of deprived areas, however, they generally move from deprived into less deprived areas, not directly into affluent areas (37). Thus categorizing deprivation based on the highest two population quintiles ( $40 \%$ of the population) may have accounted somewhat for this slight movement. Québec data also show that over time, areas have become more homogeneous in terms of material and social deprivation (38), which reinforces the likelihood that families make lateral or small moves across area social classes. Also, this thesis was unable to account for whether the family moved, in general, from one residential area to another. Adjusting for changes in the other place factors, social cohesion, disorder, and living location, may help to account for moving.

Social cohesion and disorder were based on the mother's perceptions of her neighbourhood, and may be different than children's perceptions. This may be problematic for the analyses of child weight status. On the other hand, when children are young, it is parents that mediate children's access to the broader environment, so parent's perceptions are likely to be the most influential. Living in less affluent conditions may also cloud judgments about the environment, which is a potential limitation for the family food insecurity analysis. For example, material hardship such as food insecurity may lead individuals to perceive that the environment is more adverse than it actually is) (39). Ecometric analysis, aggregating responses of individuals to the same scale that live in the same area, could help to assuage this bias (39). However, few families lived in the same area and residential addresses were not available. Brisson \& Altschul (2011) conducted an individual-level and ecometric analysis of the relationship between perceived social cohesion and informal social control with food insecurity and other indicators of material hardship (23). They found that results for food insecurity were the same regardless of whether social 
cohesion and informal social control were measured at the individual level, or aggregated across individuals within the same neighbourhood. Another study, conducted in the Netherlands, found that neighbourhood level variance in perceived neighbourhood unattractiveness and unsafety [sic] was explained, for the most part, by objective neighbourhood features (40). Finally, in this thesis, social deprivation, a related measure that was based on census data of administrative areas and not perceptions, was found to relate to food insecurity in the expected direction, similar to results found for the perceived measures of social cohesion and disorder. Taken together, this suggests that mothers were adequately able to characterize their environments.

Local area level variation in child weight status and family food insecurity could not be assessed in this thesis because residential addresses were not available for use in the dataset. Additionally, given the complexity of longitudinal data and modeling, an exploration of synergistic and antagonistic effects between place variables and between place and other early life and social factors was not conducted. Variables describing the physical infrastructure of local environments, such as availability of food stores and public transportation, was also lacking in this thesis. These may serve as mediators or moderators of the variables examined here. Thus, this thesis was unable to provide an overall picture of the social and physical environments of local residential areas in relation to child weight status and family food insecurity. Finally, this thesis was unable to explore social and physical environments in other settings. These other settings, such as school, daycare and the workplace, may contribute to the promotion or prevention of childhood obesity and family food insecurity. 


\subsection{Future Research Directions}

This thesis contributes to the established evidence-base and also provides a stepping stone for future research. The observational studies conducted as part of this thesis provided an exploratory means to examine two population health problems and have uncovered a number of recommendations and issues that will aid in future population health research on these topics. These recommendations are highlighted below:

1. Consideration for both observed and perceived place characteristics in analysis. Both may provide different, but important pieces of information.

2. Observed measures also need to carefully consider the boundary definition of place, as for example, a family living in a neighbourhood defined by administrative boundaries, may be exposed to some degree by the adjacent neighbourhood, since they live on the border. Thus, administrative boundaries may not be all that informative.

3. Use of directly measured heights and weights of children, as parent-reported measures have been shown to be inaccurate and potentially can lead to biased results.

4. In addition to child excess weight and family food insecurity, examine intermediate or related variables as outcomes, such as diet.

5. Consider adjustment for early life factors in determining future associations between place factors and weight status.

6. Explore the potential for early life factors to mediate a relationship between perinatal environmental exposures and later child excess weight.

7. More fully characterize the physical and social environments of local areas, including measures of physical infrastructure such as store or park availability, layout of neighbourhoods, parks, etc., and measures of safety and civic engagement. 
8. Research into how to incorporate potential influences from different settings (e.g. daycare, school), and synergies and antagonistic relationships between variables operating at the same level or between levels. Structural equation modeling may be ideally suited to untangling these intricacies.

9. Development of more fine-grained indicators of living location that can be used in large longitudinal surveys. Examples include indicators of urban sprawl.

10. Continued research using longitudinal data sets, and a heightened emphasis on conducting intervention studies (including natural experiments or quasi-experimental studies) embedded within a social-ecological framework. In randomized trials, intention-to-treat analysis should be used.

11. Analyses should also account for changes in all place factors and examine how moving out of an area may change results, in ways that are simple and easy to understand.

\subsection{Conclusion}

The results of this thesis largely challenge current thinking surrounding local environments and child excess weight, but support studies estimating a protective effect of social capital on food insecurity. The notion that early life is an important developmental window for childhood excess weight is strongly supported here. This thesis has also added new insights to the evidence base as, to our knowledge, this is the first time social deprivation and disorder have been studied in relation to food insecurity; thus the positive association uncovered here is of substantive interest. The theoretical and methodological rigour and Canadian context in this thesis strengthens the existing literature, although much research, particularly intervention research, is needed to further untangle the complexity. 


\subsection{References}

(1) Williams PT. Evidence that obesity risk factor potencies are weight dependent, a phenomenon that may explain accelerated weight gain in western societies. PLoS One 2011; 6(11):e27657.

(2) Veitch J, van Stralen MM, Chinapaw MJ, Te Velde SJ, Crawford D, Salmon J, et al. The neighborhood social environment and body mass index among youth: a mediation analysis. Int J Behav Nutr Phys Act 2012; 9:31.

(3) Carter MA, Dubois L. Neighbourhoods and child adiposity: a critical appraisal of the literature. Health Place 2010; 16(3):616-28.

(4) Burdette AM, Needham BL. Neighborhood environment and body mass index trajectories from adolescence to adulthood. J Adolesc Health 2012; 50(1):30-7.

(5) Slater SJ, Ewing R, Powell LM, Chaloupka FJ, Johnston LD, O'Malley PM. The association between community physical activity settings and youth physical activity, obesity, and body mass index. J Adolesc Health 2010; 47(5):496-503.

(6) Lovasi GS, Jacobson JS, Quinn JW, Neckerman KM, Ashby-Thompson MN, Rundle A. Is the environment near home and school associated with physical activity and adiposity of urban preschool children? J Urban Health 2011; 88(6):1143-57.

(7) Oliver LN, Hayes MV. Effects of neighbourhood income on reported body mass index: an eight year longitudinal study of Canadian children. BMC Public Health 2008; 8:16.

(8) Koller D, Mielck A. Regional and social differences concerning overweight, participation in health check-ups and vaccination. Analysis of data from a whole birth cohort of 6-year old children in a prosperous German city. BMC Public Health 2009; 9:43.

(9) Townsend N, Rutter H, Foster C. Age differences in the association of childhood obesity with area-level and school-level deprivation: cross-classified multilevel analysis of crosssectional data. Int J Obes 2012; 36(1):45-52.

(10) Kinra S, Nelder RP, Lewendon GJ. Deprivation and childhood obesity: a cross sectional study of 20,973 children in Plymouth, United Kingdom. J Epidemiol Community Health 2000; 54(6):456-60.

(11) Lebel A, Pampalon R, Hamel D, Theriault M. The geography of overweight in Quebec: a multilevel perspective. Can J Public Health 2009; 100(1):18-23.

(12) Grafova IB. Overweight children: assessing the contribution of the built environment. Prev Med 2008; 47(3):304-8.

(13) Nonnemaker JM, Morgan-Lopez AA, Pais JM, Finkelstein EA. Youth BMI trajectories: evidence from the NLSY97. Obesity 2009; 17(6):1274-80.

(14) Ewing R, Brownson RC, Berrigan D. Relationship between urban sprawl and weight of United States youth. Am J Prev Med 2006; 31(6):464-74. 
(15) Bruner MWL. Rural Canadian adolescents are more likely to be obese compared with urban adolescents. Int J Pediatr Obes 2008; 3(4):2008.

(16) Lutfiyya MN, Lipsky MS, Wisdom-Behounek J, Inpanbutr-Martinkus M. Is rural residency a risk factor for overweight and obesity for U.S. children? Obesity 2007; 15(9):2348-56.

(17) Lewis RD, Meyer MC, Lehman SC, Trowbridge FL, Bason JJ, Yurman KH, et al. Prevalence and degree of childhood and adolescent overweight in rural, urban, and suburban Georgia. J Sch Health 2006; 76(4):126-32.

(18) McMurray RG, Harrell JS, Bangdiwala SI, Deng S. Cardiovascular disease risk factors and obesity of rural and urban elementary school children. J Rural Health 1999; 15(4):365-74.

(19) Verger P, Saliba B, Guagliardo V, Bouhnik AD, Eichenbaum-Voline S. Individual social characteristics, municipal environment and the prevalence of weight problems in early childhood: a multilevel analysis. Rev Epidemiol Sante Publique 2007; 55(5):347-56.

(20) Sandercock GR, Ogunleye A, Voss C. Comparison of cardiorespiratory fitness and body mass index between rural and urban youth: findings from the East of England Healthy Hearts Study. Pediatr Int 2011; 53(5):718-24.

(21) Cleland V, Hume C, Crawford D, Timperio A, Hesketh K, Baur L, et al. Urban-rural comparison of weight status among women and children living in socioeconomically disadvantaged neighbourhoods. Med J Aust 2010; 192(3):137-40.

(22) Ismailov RM, Leatherdale ST. Rural-urban differences in overweight and obesity among a large sample of adolescents in Ontario. Int J Pediatr Obes 2010; 5(4):351-60.

(23) Brisson D, Altschul I. Collective Efficacy Predicting Experience of Material Hardship in Low-Income Neighborhoods. Urban Affairs Review 2011; 47(4):541-63.

(24) Martin KS, Rogers BL, Cook JT, Joseph HM. Social capital is associated with decreased risk of hunger. Soc Sci Med 2004; 58(12):2645-54.

(25) Dean WR, Sharkey JR. Food insecurity, social capital and perceived personal disparity in a predominantly rural region of Texas: an individual-level analysis. Soc Sci Med 2011; 72(9):1454-62.

(26) Morton LW, Bitto EA, Oakland MJ, Sand M. Solving the problems of Iowa food deserts: Food insecurity and civic structure. Rural Sociology 2005; 70(1):94-112.

(27) Chung WT, Gallo WT, Giunta N, Canavan ME, Parikh NS, Fahs MC. Linking neighborhood characteristics to food insecurity in older adults: The role of perceived safety, social cohesion, and walkability. J Urban Health 2011; Early Online.

(28) Pilgrim A, Barker M, Jackson A, Ntani G, Crozier S, Inskip H, et al. Does living in a food insecure household impact on the diets and body composition of young children? Findings from the Southampton Women's Survey. J Epidemiol Community Health 2011 Jun 7. 
(29) Foley W, Ward P, Carter P, Coveney J, Tsourtos G, Taylor A. An ecological analysis of factors associated with food insecurity in South Australia, 2002-7. Public Health Nutr 2010; 13(2):215-21.

(30) Radimer KL, Allsopp R, Harvey PW, Firman DW, Watson EK. Food insufficiency in Queensland. Aust NZ J Public Health 1997;21(3):303-10.

(31) Bartfeld JS, Dunifon R. State-level predictors of food insecurity among households with children. Journal of Policy Analysis \& Management 2006; 25(4):921-42.

(32) Bernell SL, Weber BA, Edwards ME. Restricted opportunities, personal choices, ineffective policies: What explains food insecurity in Oregon? Journal of Agricultural and Resource Economics 2006; 31(2):193-211.

(33) Garasky S, Morton LW, Greder KA. The effects of the local food environment and social support on rural food insecurity. Journal of Hunger \& Environmental Nutrition 2006; 1(1):83-103.

(34) Bartfeld JS, Ahn HM. The School Breakfast Program strengthens household food security among low-income households with elementary school children. J Nutr 2011; 141(3):470-5.

(35) Bartfeld JS, Ryu JH, Wang L. Local Characteristics Are Linked to Food Insecurity Among Households With Elementary School Children. Journal of Hunger \& Environmental Nutrition 2010; 5(4):471-83.

(36) Mazur RE, Marquis GS, Jensen HH. Diet and food insufficiency among Hispanic youths: acculturation and socioeconomic factors in the third National Health and Nutrition Examination Survey. Am J Clin Nutr 2003; 78(6):1120-7.

(37) Fauth R. The Impacts of Neighborhood Poverty Deconcentration Efforts on Low-Income Children's and Adolescents' Well-Being. Children, Youth and Environments 2004; 14(1):155.

(38) Pampalon R, Hamel D, Raymond G. Indice de défavorisation pour l'étude de la santé et du bien-être au Québec - Mise à jour 2001. Institut National de Santé Publique du Québec 2004 [cited 2012 Apr 12]; INSPQ-2004-035 Available from URL: http://www.inspq.qc.ca/pdf/publications/295-IndiceDefavorisation_2001.pdf

(39) Raudenbush SW. The Quantitative Assessment of Neighborhood Social Environments. In: Kawachi I., Berkman LF, editors. Neighbourhoods \& Health.New York, New York: Oxford University Press; 2003. p. 112-31.

(40) Kamphuis CB, Mackenbach JP, Giskes K, Huisman M, Brug J, van Lenthe FJ. Why do poor people perceive poor neighbourhoods? The role of objective neighbourhood features and psychosocial factors. Health Place 2010;16(4):744-54. 


\section{Appendix}

$\underline{\text { Ethics }}$

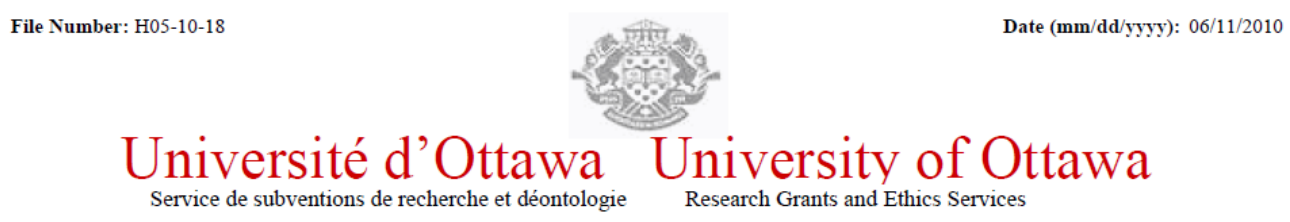

Ethics Approval Notice

Health Sciences and Science REB

Principal Investigator / Supervisor / Co-investigator(s) / Student(s)

$\begin{array}{llll}\text { First Name } & \text { Last Name } & \underline{\text { Affiliation }} & \underline{\text { Role }} \\ \text { Lise } & \text { Dubois } & \text { Medicine / Medicine } & \text { Supervisor } \\ \text { Megan A. } & \text { Carter } & \text { Health Sciences / Population Health } & \text { Student Researcher }\end{array}$

File Number: H05-10-18

Type of Project: Doctoral thesis - Secondary use of data

Title: Contextual Factors in the Development of Excess Weight During Chidlhood: A Longitudinal Study of Young Children Living in Québec

Approval Date (mm/dd/yyyy)

Expiry Date (mm/dd/yyyy) Approval Type

$06 / 11 / 2010$

$06 / 10 / 2011$

Ia

(Ia: Approval, Ib: Approval for initial stage only)

Special Conditions / Comments:

N/A 


\section{Université d'Ottawa University of Ottawa \\ Service de subventions de recherche et déontologie Research Grants and Ethics Services}

This is to confirm that the University of Ottawa Research Ethics Board identified above, which operates in accordance with the Tri-Council Policy Statement and other applicable laws and regulations in Ontario, has examined and approved the application for ethical approval for the above named research project as of the Ethics Approval Date indicated for the period above and subject to the conditions listed the section above entitled "Special Conditions / Comments".

During the course of the study the protocol may not be modified without prior written approval from the REB except when necessary to remove subjects from immediate endangerment or when the modification(s) pertain to only administrative or logistical components of the study (e.g. change of telephone number). Investigators must also promptly alert the REB of any changes which increase the risk to participant(s), any changes which considerably affect the conduct of the project, all unanticipated and harmful events that occur, and new information that may negatively affect the conduct of the project and safety of the participant(s). Modifications to the project, information/consent documentation, and/or recruitment documentation, should be submitted to this office for approval using the "Modification to research project" form available at

http://www.rges.uottawa.ca/ethics/application_dwn.asp

Please submit an annual status report to the Protocol Officer 4 weeks before the above-referenced expiry date to either close the file or request a renewal of ethics approval. This document can be found at:

http://www.rges.uottawa.ca/ethics/application_dwn.asp

If you have any questions, please do not hesitate to contact the Ethics Office

or by e-mail at:

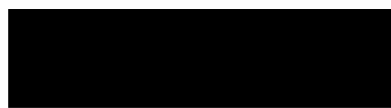

Germain Zongo

Assistant Director, Ethics (Interim)

For Dr. Daniel Lagarec, Chair of the Health Sciences and Sciences REB 


\section{Copyright Permissions}

Dear Ms Carter,

Thank you for your enquiry. On behalf of the World Health Organization, we are pleased to grant you permission to reproduce the following WHO item/s, as indicated in your message below:

From: A Powerful Equalizer Final Report for the World Health Organization's Commission on the Social Determinants of Health - Figure 1, page 17

Please note that this permission is granted under the following terms:

- $\quad$ This is a non-exclusive permission to reproduce the material detailed below.

- WHO material should not be reproduced for use in association with commercial nor promotional activities

- There should be no suggestion that WHO endorses any specific company nor products in the (article, book etc.) nor in the manner of distribution of the article, book etc.).

- The material will be reproduced as it was published by WHO and no changes should be made to the content or meaning. Publishers may reformat the material in the style of the publication.

- $\quad$ The WHO Logo/Emblem should not be reproduced, unless it appears on an original WHO publication or unless a specific permission is given by WHO for it's use.

- $\quad$ Please ensure that the original WHO source is appropriately acknowledged with either (i) the appropriate bibliographical reference (including publication title, author, publisher, volume/edition number, page numbers, copyright notice year) or (ii) in the case of materials published on the WHO web site, the URL reference and the date accessed.

- WHO will not charge any fee for the above permission, however we would like you to please provide me with 1 original hard copy or 2 of your final publication for our records, specifically showing where/how WHO material appears and how it is referenced on your product. Also indicate the attached Permission ID.... Number and please send directly to this address:

Ms Dolores Campanario

World Health Organization Press

WHP (Permissions Management and Reprint Rights)

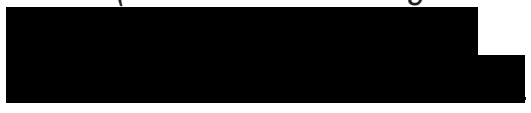

Please also send as well a copy by e-mail to If available on CD/DVD please send me copies or if web page (send the direct link to where WHO is indicated on your site as well). 
We thank you for your interest in WHO Information products. We wish you all the best with your project.

With kind regards.

Ms Dolores Campanario

WHO Press - (Permissions Management, Licensing and Reprint Rights)

Department of Knowledge Management and Sharing

Innovation, Information, Evidence and Research Cluster

World Health Organization Press

Tel:

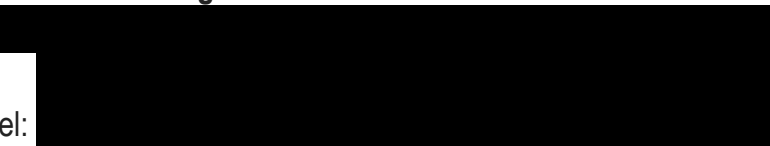

Office: 4 - E-mail:

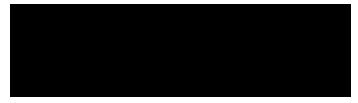

Direct Links:

To request for permission to reproduce parts or complete reprints of WHO copyrighted materials, complete this form http://www.who.int/about/licensing/copyright_form/en/index.html

Information on Permissions and Licensing - http://www.who.int/about/licensing/en/

To order WHO publications on sale - http://apps.who.int/bookorders/

"Please note that if the requested item was jointly produced with other organization/s outside WHO or if not originally produced by WHO source, then please, also make every effort to obtain permissions from the appropriate external sources as mentioned on the original product details." 


\section{RightsLink \\ Copyright \\ Clearance \\ Center}

\section{Thank You For Your Order!}

Dear Ms. Megan Carter,

Thank you for placing your order through Copyright Clearance Center's RightsLink service. Nature Publishing Group has partnered with RightsLink to license its content. This notice is a confirmation that your order was successful.

Your order details and publisher terms and conditions are available by clicking the link below

\section{Order Details}

Licensee: Megan Carter

License Date: Jul 3, 2012

License Number: 2941451484715

Publication: Obesity

Title: Implications of the Foresight Obesity System Map for Solutions to Childhood

Obesity

Type Of Use: reuse in a thesis/dissertation

Total: 0.00 USD

To access your account, please visit https://myaccount.copyright.com.

Please note: Online payments are charged immediately after order confirmation; invoices are issued daily and are payable immediately upon receipt.

To ensure we are continuously improving our services, please take a moment to complete our customer satisfaction survey.

B.1:v4.2 


\section{RightsLink 1 copyight $^{\text {Corr }}$ \\ Clearance \\ Center}

\section{Thank You For Your Order!}

Dear Ms. Megan Carter,

Thank you for placing your order through Copyright Clearance Center's RightsLink service. Elsevier has partnered with RightsLink to license its content. This notice is a confirmation that your order was successful.

Your order details and publisher terms and conditions are available by clicking the link below:

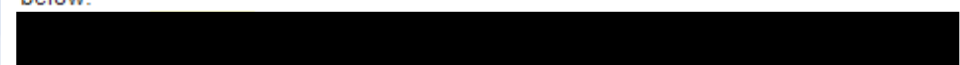

Order Details

Licensee: Megan Carter

License Date: Jun 27, 2012

License Number: 2937180799223

Publication: Social Science \& Medicine

Title: Health inequalities and pla A theoretical conception of neighbourhood

Type Of Use: reuse in a thesis/dissertation

Total: 0.00 USD

To access your account, please visit https://myaccount.copyright.com

Please note: Online payments are charged immediately after order confirmation; invoices are issued daily and are payable immediately upon receipt.

To ensure we are continuously improving our services, please take a moment to complete our customer satisfaction survey.

B.1:v4.2 
Taylor \& Francis

Tnyor ba trandis Croup

\section{Permissions}

T \& F Reference Number: P102412-06

$10 / 24 / 2012$

Megan A. Carter, MSc. PhD (Candidate)

Institute of Population Health.

University of Ottawa.

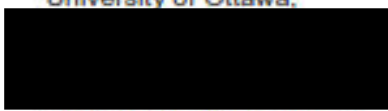

Dear Ms. Carter:

We are in receipt of your request to reprint FIGURE 1 Concept Model: Food Systems and Health Disparities from the article

"Food Systems and Public Health Disparities", Neff R.A., Palmer A.M., McKenzie S.E., Lawrence

R.S., 2009, Journal of Hunger and Environmental Nutrition, Vol. 4, Issue 3-4, pp. 282-314.

for your PhD dissertation .

We will be pleased to grant you permission free of charge on the condition that:

This permission is limited to non-exclusive English rights for this usage only.

This permission does not cover any third party copyrighted work which may appear in the material requested.

Full acknowledgement must be included showing article title, author, and full Journal title, reprinted by permission of Taylor \& Francis (http://www.tandfonline.com).

Thank you very much for your interest in Taylor \& Francis publications. Should you have any questions or require further assistance, please feel free to contact me directly.

Sincerely.

Mary Ann Muller

Permissions Coordinator

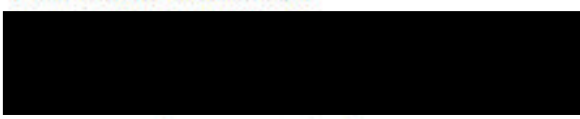

Web: whe fandfonene.com 
4th February 2013

Dear Megan Carter

Thank you for your recent emailed enquiry. Cambridge University Press has no objection to your article being published as part of your forthcoming thesis, for non-commercial publication in the archives of Theses Canada, in print and electronic format. Please accept this email as granting nonexclusive permission.

Please ensure full copyright acknowledgement to the forthcoming journal article, if you know which volume and issue the paper will appear in, please include that in your acknowledgement line, which should be in the following format:

Author, title of paper, name of journal, volume number, issue number, page references, year of publication () The Nutrition Society, published by Cambridge University Press, reproduced with permission.

Yours sincerely

Claire Taylor

Senior Publishing Assistant

Legal Services

Cambridge University Press

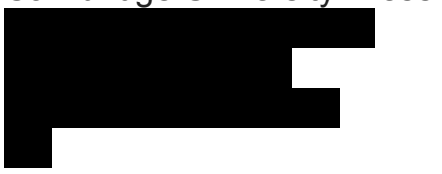

